RECEIVED

JAN 021997

LOC KME O STI

ENVIRONMENTAL

RESTORATION

PROGRAM

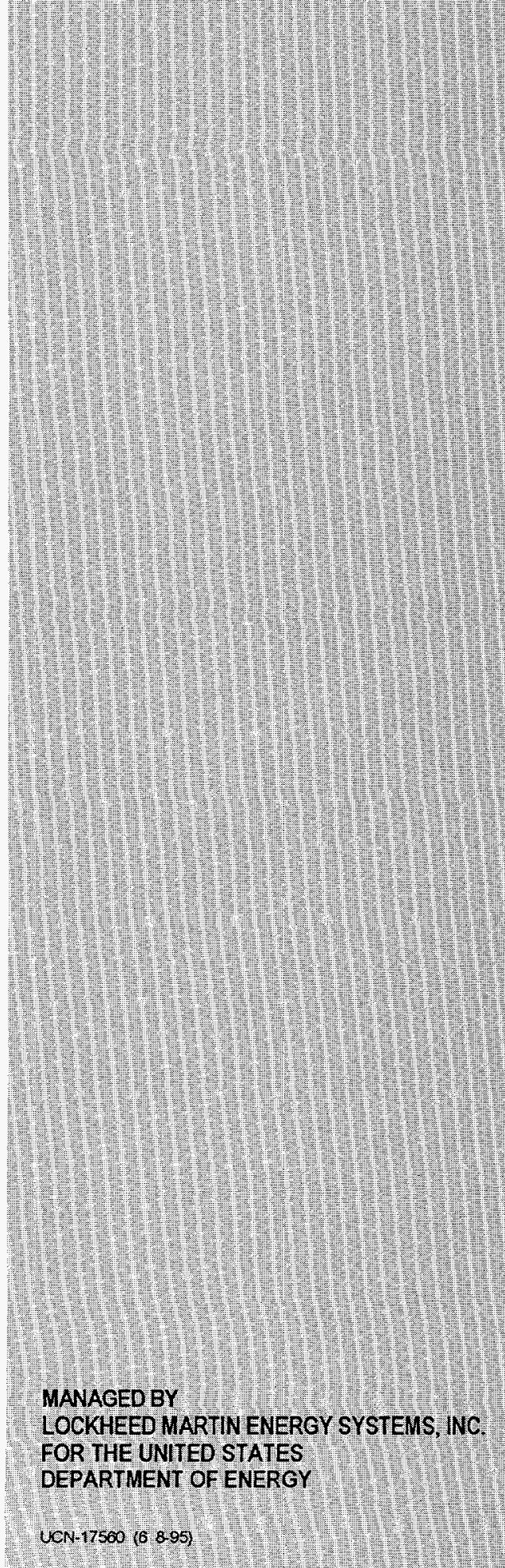

\title{
Engineering-Scale In Situ Vitrification Tests of Simulated Oak Ridge National Laboratories Buried Wastes
}

This document has been approved by the ORNL Technical Information Office for release to the public. Date: $10 / 28 / 96$

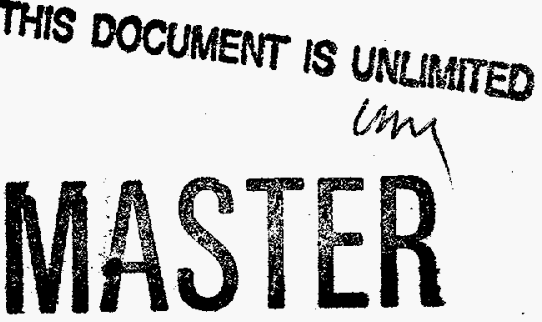




\section{Pacific Northwest National Laboratory}

contributed to the preparation of this document and should not be considered an eligible contractor for its review. 


\section{Energy Systems Environmental Restoration Program ORNL Environmental Restoration Program}

\section{Engineering-Scale In Situ Vitrification Tests of Simulated Oak Ridge National Laboratory Buried Wastes}

Date Issued-December 1996

Prepared by

Battelle Memorial Institute

Battelle Boulevard

P. O. Box 999

Richland, Washington 99352

Prepared for

U.S. Department of Energy

Office of Environmental Restoration and Waste Management

under budget and reporting code EW 20

Environmental Restoration Program

OAK RIDGE NATIONAL LABORATORY

Oak Ridge, Tennessee 37831-6285

managed by

LOCKHEED MARTIN ENERGY SYSTEMS, INC.

for the

U.S. DEPARTMENT OF ENERGY

under contract DE-AC05-84OR21400 


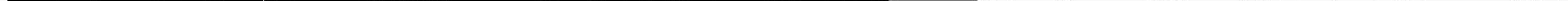

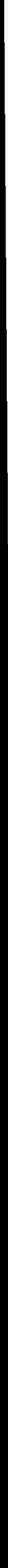




\section{DISCLAIMER}

Portions of this document may be illegible in electronic image products. Images are produced from the best available original document. 


\section{PREFACE}

As part of the Comprehensive Environmental Response, Compensation, and Liability Act process for remediation of Waste Area Grouping (WAG) 6 at Oak Ridge National Laboratory, a public meeting was held on the proposed plan. It was recognized that contaminant releases from WAG 6 posed minimal potential risk to the public and environment. The U.S. Department of Energy (DOE) in conjunction with the U.S. Environmental Protection Agency and the Tennessee Department of Environment and Conservation agreed to defer remedial action at WAG 6 until higher risk release sites were first remediated.

DOE and the regulators also recognized the need for technology development for final remediation of WAG 6 . Consequently, the record of agreement for the WAG 6 deferred action established the WAG 6 Remedial Technology Research, Development, and Demonstration Program for the Environmental Restoration (ER) Program to develop and demonstrate innovative technologies for the final remediation of WAG 6 and other ER contaminated sites.

This report presents the results of a series of in situ vitrification (ISV) tests designed to assess the potential of ISV for remediating buried waste trenches in WAG 6. The tests were conducted at the Pacific Northwest National Laboratory Engineering-Scale ISV Facility in Richland, Washington. A series of 10 tests were performed that included investigation of the merits of dynamic compaction prior to ISV. Dynamic compaction reduces the volume of waste and breaches any containers in the waste. Also, the use of the bottom-up approach to ISV was examined with some of the tests. This approach initiates the melt below the waste. Details on the series of tests are provided in this report. 



\section{EXECUTIVE SUMMARY}

A series of ten engineering-scale in situ vitrification (ISV) tests were performed in this work. These tests were designed to help assess the efficacy of ISV for remediating the buried waste trenches at the Oak Ridge National Laboratory's Solid Waste Storage Area 6 (ORNL SWSA-6) site.

The first of these tests involved processing a simulated buried waste trench loaded with 3.5 $\mathrm{wt} \%$ plastic materials, $0.3 \mathrm{wt} \%$ paper and cloth materials, and $0.4 \mathrm{wt} \%$ aluminum and steel. This test demonstrated that a site with relatively high waste loadings could be processed using ISV with little or no consequence to the ISV equipment, system, or their operation.

A number of follow-on engineering-scale tests were performed to determine the sealed canister configuration necessary to both be representative of the full-scale waste drums and provide significant, but tolerable, pressure and temperature excursions to the engineering-scale ISV off-gas plenum when these canisters failed catastrophically during processing with ISV. There were three engineering-scale ISV tests performed in this part of the work

Two tests were performed to assess the efficacy of pretreating the simulated waste canisters using dynamic compaction (DC) followed by final processing using ISV. These tests utilized the "standard" top-down approach to melting the target vitrification zone. They confirmed that pretreatment with DC can be an effective method for rendering the sealed canisters in a state which will not produce significant plenum pressure and temperature excursions in the ISV plenum during remediation. Moreover, the results of these tests indicated that a complete breach of the sealed canisters is a sufficient but not necessary condition for precluding their generating significant plenum pressure and temperature events during ISV processing. The canisters need only be significantly affected by the DC process, not ruptured.

A novel bottom-up approach was employed in the following two engineering-scale ISV tests to assess the merits of this approach to processing sites containing sealed containers. In this approach, the melt is initiated below the target vitrification zone. The materials are then "fed" into the melt pool by a combination of natural and operator-induced subsidence events. These tests indicated that processing the sealed containers without the benefit of pretreatment using DC did not reduce the severity of the pressure excursions experienced by the ISV plenum during the catastrophic failure of these canisters. The bottom-up approach did prevent the expulsion of molten glass during these pressure excursions. However, there was evidence that the partial contents of unprocessed canisters had been displaced to the soil surface during these pressure events. Finally, as may be expected, the bottom-up test involving pretreatment with DC was successful at 
processing the entire target vitrification zone without generating any plenum pressure and temperature excursions. Bottom-up processing does complicate the operation of the ISV process. Electrode sticking was a frequent problem during both of these tests. In addition, the uncertainty in determining the location of the top surface of the melt pool clouded the ability to accurately assess the extent to which the simulated wastes had been processed. Both these concerns were relatively minor annoyances, however. In the larger view, the bottom-up approach appears to offer some substantial benefits to the ISV remediation process.

The last two engineering-scale tests performed in this work involved the "standard" topdown processing of dynamically-compacted canisters staged together with simulants for the nonvolatile and semi-volatile radioactive wastes, as well as the volatile organic wastes typically found in the ORNL SWSA-6 site. The tests performed in this work involved no radioactive materials, however.

The first of these tests combined non-radioactive simulants for the cesium, strontium, europium, uranium, and plutonium materials found in the actual buried waste trenches. Cerium was used in this test to represent the behavior of the uranium and plutonium species. Cesium chloride, together with strontium and europium oxide materials were used to represent their radioactive counterparts. This test successfully processed all these materials without consequence. A significantly higher percentage $(4.3 \mathrm{wt} \%)$ of the cesium material was volatilized to the off-gas system than had been experienced in previous tests, however. For comparison, $2.4 \mathrm{wt} \%$ cesium was volatilized in a 1991 ORNL pilot-scale ISV test. The increase in volatilization is attributed to the fact that cesium chloride was staged in this test (rather than the cesium carbonate compound used in previous ISV tests). The presence of chlorides has been shown to have a dramatic effect on the volatility of cesium during ISV processing. The results obtained in this test confirmed this. In addition, the manner in which the materials were staged (e.g., loose vs. containerized), and the cesium-soil surface chemistry also are suggested to have affected the cesium volatility realized in this test.

The final test involved "standard" top-down processing of a simulated wastes zone composed of dynamically-compacted canisters and containerized volatile organic solvent materials. These organic materials were o-cresol, toluene, 1,1,2-trichloroethane, and xylene. Again, these materials were successfully processed without encountering significant plenum pressure and temperature events. The toluene, 1,1,2-trichloroethane, and xylene were very effectively remediated in this test. Approximately $60 \mathrm{wt} \%$ of the cresol was also destroyed in this test. The remaining $40 \mathrm{wt} \%$ was transported to the soil beneath the ISV melt and was not processed during the test. This transport was attributed to several factors. First, the cresol is partially water soluble 
( $2 \mathrm{~g} / 100 \mathrm{ml}$ water at STP). There was a large quantity of water that had migrated to the soil beneath the ISV melt during processing in this test. It is postulated that most (if not all) of the unprocessed cresol was solubilized and transported away from the melt with this water. In addition, the nature in which the cresol materials were staged in this test, together with the surface chemistry at the interface between the cresol and soil granules (i.e., the sorption coefficient) also are suggested to have affected the processability of cresol in this test. This later consideration is not well characterized at this point in time, however.

In summary, this array of engineering-scale tests demonstrated that pretreatment of buried sealed canisters with DC can be effective for precluding their catastrophic failure during follow-on remediation with ISV. In addition, the bottom-up approach to melting also offers some advantages for precluding these events. 



\section{ACKNOWLEDGEMENTS}

This work has been supported under subcontract 10X-GJK96V from the Environmental Restoration Program at Oak Ridge National Laboratory (ORNL) in Oak Ridge, Tennessee. ORNL is operated by Lockheed Martin Energy Systems Incorporated for the U.S. Department of Energy under Contract DE-AC05-84OR21400. The Pacific Northwest National Laboratory (PNNL) is operated by Battelle Memorial Institute for the U.S. Department of Energy under Contract DE AC06-76RLO 1830.

The two PNNL authors, Patrick S. Lowery and Douglas K. Seiler, gratefully acknowledge the support and guidance (both technical and administrative) provided by the ORNL Project Manager for this work, Dr. John R. Trabalka. The authors also wish to acknowledge the support provided by Messrs. C. K. Hyman, T. D. Powell, and W. A. Sliger of PNNL in the staging and performance of several of the ISV tests performed for this work. Their diligence made it possible to get these experiments off in a timely fashion. Moreover, their expertise with the engineeringscale ISV facility and its appurtenances helped ensure the successful performance of these tests.

The bottom-up tests were successful in large part due to the previous subsurface start-up experience provided by Mr. J. K. Luey. Therefore, the authors gratefully acknowledge his support on two of the tests in this effort.

Finally, the authors are particularly grateful for the diligent review and excellent comments offered by Messrs. Craig Timmerman of the Geosafe Corporation, and John Tixier of PNNL. Mr. Timmerman's extensive ISV experience and general knowledge of hazardous chemicals were particularly appreciated as they provided very valuable insights in the evaluation of the data obtained from the last two tests in this work. 



\section{CONTENTS}

PREFACE $\ldots \ldots \ldots \ldots \ldots \ldots \ldots \ldots \ldots \ldots \ldots \ldots \ldots \ldots \ldots \ldots \ldots \ldots$

EXECUTIVE SUMMARY $\ldots \ldots \ldots \ldots \ldots \ldots \ldots \ldots \ldots \ldots \ldots \ldots$

ACKNOWLEDGMENTS $\ldots \ldots \ldots \ldots \ldots \ldots \ldots \ldots \ldots \ldots \ldots \ldots \ldots \ldots$

1.0 INTRODUCTION $\ldots \ldots \ldots \ldots \ldots \ldots \ldots \ldots \ldots \ldots \ldots \ldots \ldots$

2.0 THE PNNL ENGINEERING-SCALE ISV FACILITY $\ldots \ldots \ldots \ldots \ldots \ldots \ldots$

3.0 ENGINEERING-SCALE ISV TESTS w/o SIMULANTS $\ldots \ldots \ldots \ldots \ldots$

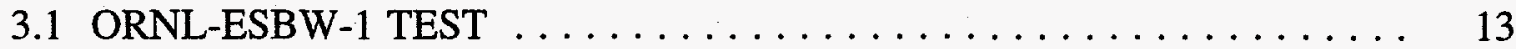

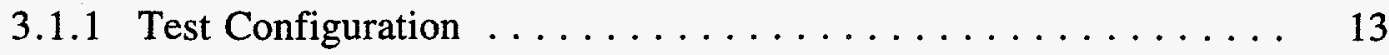

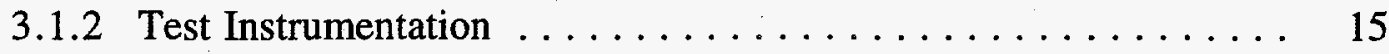

3.1 .3 Test Start-Up and Operation $\ldots \ldots \ldots \ldots \ldots$

3.1.4 Phase Voltage, Current, and Resistance Results ... . . . . . . . . 19

3.1.5 Electrode Depth and Soil Temperature Results ............ 21

3.1.6 Plenum Pressure and Temperature Results .............. 23

3.1 .7 ISV Hood Heat Flux and Temperature Results ........... 25

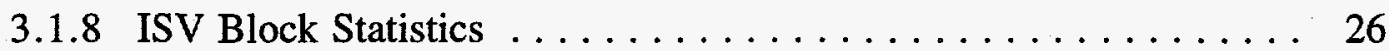

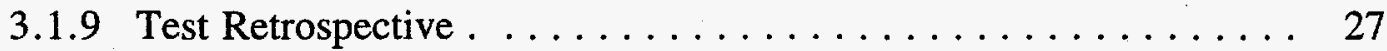

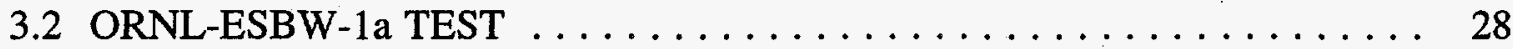

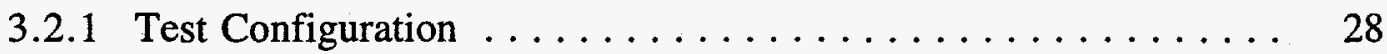

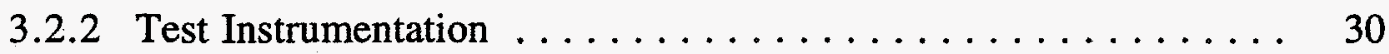

3.2 .3 Test Start-Up and Operation $\ldots \ldots \ldots \ldots \ldots \ldots \ldots \ldots \ldots \ldots$

3.2.4 Phase Voltage, Current, and Resistance Results . . . . . . . . . . 32

3.2.5 Electrode Depth and Soil Temperature Results ............ 33

3.2.6 Canister Pressure and Temperature Results .............. 34

3.2.7 Plenum Pressure and Temperature Results ............ 37

3.2 .8 ISV Block Statistics $\ldots \ldots \ldots \ldots \ldots \ldots \ldots \ldots \ldots \ldots \ldots$

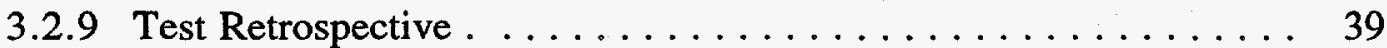

3.3 ORNL-ESBW-1b TEST $\ldots \ldots \ldots \ldots \ldots \ldots \ldots \ldots \ldots \ldots \ldots \ldots \ldots$

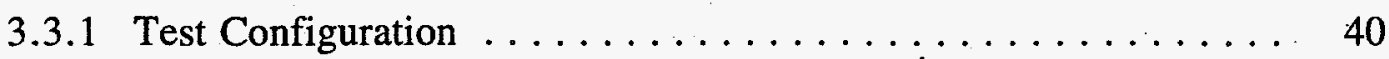

3.3 .2 Test Instrumentation $\ldots \ldots \ldots \ldots \ldots \ldots \ldots \ldots \ldots \ldots \ldots \ldots . \ldots \ldots$

3.3.3 Test Start-Up and Operation ................. 43

3.3.4 Phase Voltage, Current, and Resistance Results ... . . . . . . . . 44

3.3.5 Electrode Depth and Soil Temperature Results . . . . . . . . . . . 45 


\section{CONTENTS}

3.3.6 Canister Pressure and Temperature Results ............. 46

3.3.7 Plenum Pressure and Temperature Results . . . . . . . . . . . . . 49

3.3 .8 ISV Block Statistics $\ldots \ldots \ldots \ldots \ldots \ldots \ldots \ldots \ldots \ldots \ldots \ldots$

3.3 .9 Test Retrospective . . . . . . . . . . . . . . . 51

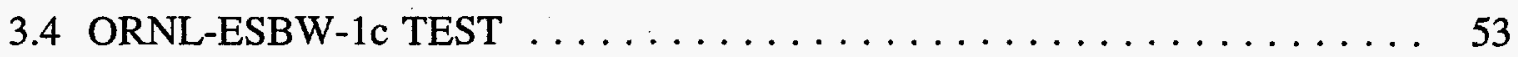

3.4 .1 Test Configuration $\ldots \ldots \ldots \ldots \ldots \ldots \ldots \ldots \ldots \ldots$

3.4 .2 Test Instrumentation $\ldots \ldots \ldots \ldots \ldots \ldots \ldots \ldots \ldots \ldots \ldots \ldots$

3.4 .3 Test Start-Up and Operation . . . . . . . . . . . . 55

3.4.4 Phase Voltage, Current, and Resistance Results . . . . . . . . . . 56

3.4.5. Electrode Depth and Soil Temperature Results . . . . . . . . . . . 57

3.4.6. Plenum Pressure and Temperature Results . . . . . . . . . 58

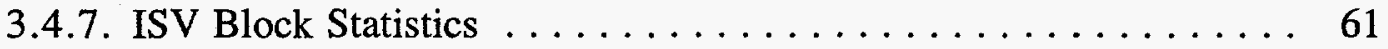

3.4 .8 Test Retrospective . . . . . . . . . . . . . . . 61

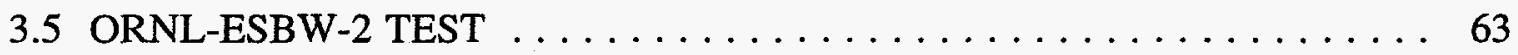

3.5 .1 Test Configuration $\ldots \ldots \ldots \ldots \ldots \ldots \ldots \ldots \ldots \ldots \ldots$

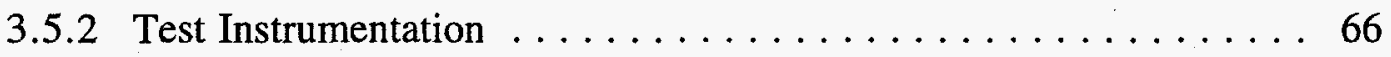

3.5 .3 Test Start-Up and Operation . . . . . . . . . . . . . 67

3.5.4 Phase Voltage, Current, and Resistance Results . . . . . . . . . . 67

3.5.5 Electrode Depth and Soil Temperature Results . . . . . . . . . . . 68

3.5.6 Plenum Pressure and Temperature Results . . . . . . . . . . . . 69

3.5.7 ISV Block Statistics $\ldots \ldots \ldots \ldots \ldots \ldots \ldots \ldots \ldots \ldots$

3.5 .8 Test Retrospective . . . . . . . . . . . . . . . . . . 69

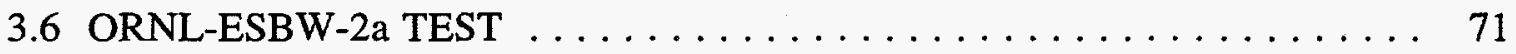

3.6 .1 Test Configuration $\ldots \ldots \ldots \ldots \ldots \ldots \ldots \ldots \ldots$

3.6 .2 Test Instrumentation . . . . . . . . . . . . . . 74

3.6 .3 Test Start-Up and Operation . . . . . . . . . . . . 74

3.6.4 Phase Voltage, Current, and Resistance Results . . . . . . . . . . 76

3.6.5 Electrode Depth and Soil Temperature Results . . . . . . . . . . . 78

3.6.6 Plenum Pressure and Temperature Results . . . . . . . . . . . 78

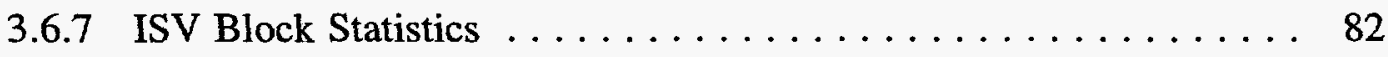

3.6 .8 Test Retrospective . . . . . . . . . . . . . . 82 


\section{CONTENTS}

3.7 ORNL-ESBW-3 TEST $\ldots \ldots \ldots \ldots \ldots \ldots \ldots \ldots \ldots \ldots \ldots \ldots$

3.7 .1 Test Configuration $\ldots \ldots \ldots \ldots \ldots \ldots \ldots \ldots \ldots \ldots \ldots$

3.7 .2 Test Instrumentation $\ldots \ldots \ldots \ldots \ldots \ldots \ldots \ldots \ldots \ldots$

3.7.3 Test Start-Up and Operation $\ldots \ldots \ldots \ldots \ldots \ldots \ldots \ldots \ldots .66$

3.7.4 Phase Voltage, Current, and Resistance Results ............ 86

3.7.5 Electrode Depth and Soil Temperature Results ............ 88

3.7.6 Plenum Pressure and Temperature Results ............ 90

3.7 .7 ISV Block Statistics $\ldots \ldots \ldots \ldots \ldots \ldots \ldots \ldots \ldots \ldots \ldots$

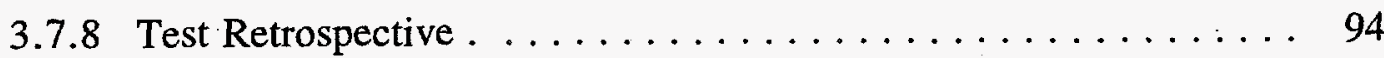

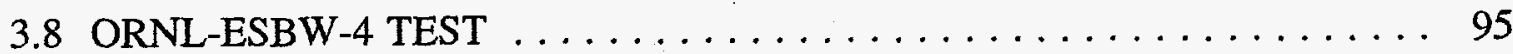

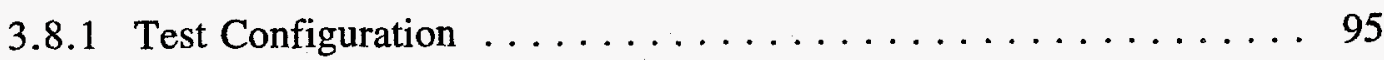

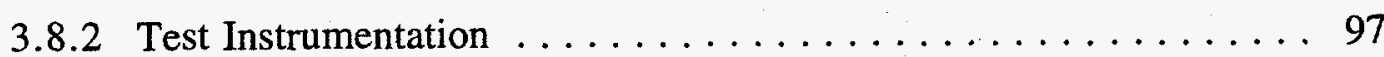

3.8.3 Test Start-Up and Operation ................... 97

3.8.4 Phase Voltage, Current, and Resistance Results . . . . . . . . 97

3.8.5 Electrode Depth and Soil Temperature Results ............ 99

3.8.6 Plenum Pressure and Temperature Results ............ 100

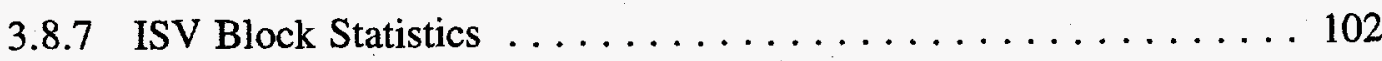

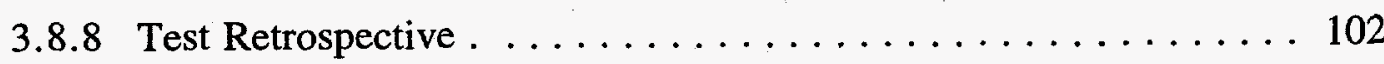

4.0 ENGINEERING-SCALE ISV TESTS INVOLVING SIMULATED WASTES $\ldots \ldots 103$

4.1 ORNL-ESBW-5 TEST $\ldots \ldots \ldots \ldots \ldots \ldots \ldots \ldots \ldots \ldots \ldots \ldots \ldots$

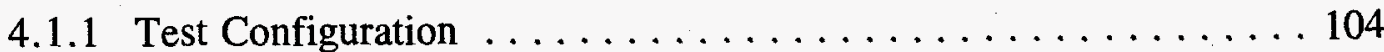

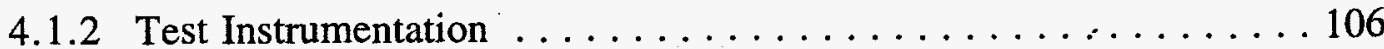

4.1 .3 Test Start-Up and Operation $\ldots \ldots \ldots \ldots \ldots \ldots \ldots \ldots \ldots \ldots$

4.1.4 Phase Voltage, Current, and Resistance Results . . . . . . . . . 107

4.1.5 Electrode Depth and Soil Temperature Results . . . . . . . . . 107

4.1.6 Plenum Pressure and Temperature Results . . . . . . . . . . . 109

4.1 .7 ISV Block Statistics . . . . . . . . . . . . . . . . . 109

4.1.8 Post-Test Chemical Sampling Analysis Plan \& Resulrs . . . . . . . 110

4.1 .9 Test Retrospective . . . . . . . . . . . . . . . 116 


\section{CONTENTS}

4.2 ORNL-ESBW-6 TEST $\ldots \ldots \ldots \ldots \ldots \ldots \ldots \ldots \ldots \ldots \ldots \ldots \ldots$

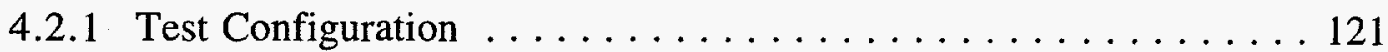

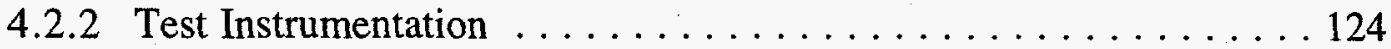

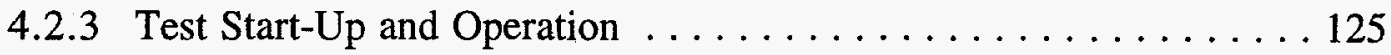

4.2.4 Phase Voltage, Current, and Resistance Results . . . . . . . . 125

4.2.5 Electrode Depth and Soil Temperature Results . . . . . . . . 127

4.2.6 Plenum Pressure and Temperature Results . . . . . . . . . 127

4.2.7 ISV Block Statistics . . . . . . . . . . . . . . . . . . 129

4.2.8 Post-Test Chemical Sampling Analysis Plan \& Resulrs . . . . . . . 129

4.2 .9 Test Retrospective . . . . . . . . . . . . . . . . 136

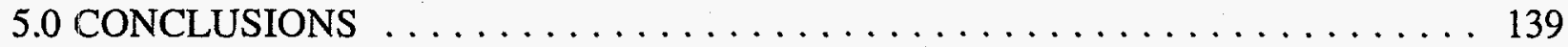

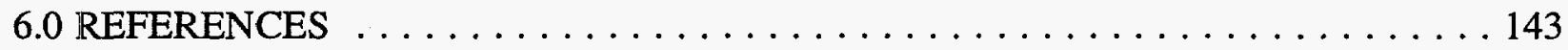




\section{FIGURES}

2.0.1 The PNNL Engineering-Scale ISV Facility $\ldots \ldots \ldots \ldots \ldots$

2.0.2 Box-X Starter Path Configuration $\ldots \ldots \ldots \ldots \ldots \ldots \ldots$

3.1.1 ORNL-ESBW-1 Test Configuration - Plan View of Staged

Engineering Scale ISV Test Setup . . . . . . . . . . . . . . 16

3.1.2 ORNL-ESBW-1 Test Configuration - Elevation View of Staged

Engineering Scale ISV Test Setup Along the $0^{\circ}-180^{\circ}$ Plane $\ldots \ldots \ldots \ldots \ldots 17$

3.1.3 ORNL-ESBW-1 Test Configuration - Elevation View of Staged

Engineering Scale ISV Test Setup Along the $90^{\circ}-270^{\circ}$ Plane $\ldots \ldots \ldots \ldots \ldots$

3.1.4 ORNL-ESBW-1 Phase Voltage, Current, and Resistance Transients . . . . . . 20

3.1.5 ORNL-ESBW-1 Phase Power, and Total Power \& Energy Transients ....... 20

3.1.6 ORNL-ESBW-1 Electrode Depth and Centerline Temperature Transients . . . . . 21

3.1.7 ORNL-ESBW-1 Thermocouple Transients at the $15 \mathrm{~cm}$ Depth . ........ 22

3.1 .8 ORNL-ESBW-1 Thermocouple Transients at the $37.5 \mathrm{~cm}$ Depth . . . . . . . 23

3.1.9 ORNL-ESBW-1 Plenum Pressure and Temperature Transients $\ldots \ldots \ldots \ldots \ldots$

3.1.10 ORNL-ESBW-1 Plenum Pressure and Temperature Transients During the "Event" . . 24

3.1.11 ORNL-ESBW-1 Plenum Pressure and Temperature Transients During the "Event" -

Detail Time Trace . . . . . . . . . . . . . . . . . . . . . 25

3.1.12 ORNL-ESBW-1 Off-Gas Hood Skin Temperatures and Heat Transfer . . . . . . 25

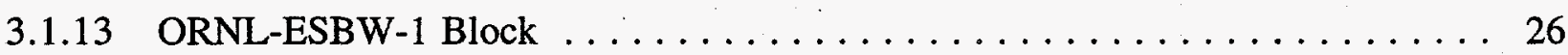

3.2.1 ORNL-ESBW-1a Test Configuration - Plan View of the Staged EngineeringScale ISV Test Setup . . . . . . . . . . . . . . . . . . . . . . 29

3.2.2 ORNL-ESBW-1a Test Configuration - Elevation View of Staged EngineeringScale ISV Test Setup . . . . . . . . . . . . . . . . . 30

3.2.3 ORNL-ESBW-1 a Test Canister Instrumentation Detail $\ldots \ldots \ldots \ldots \ldots$

3.2.4 ORNL-ESBW-1a Phase Voltage, Current, and Resistance Transients ... . . . 32

3.2.5 ORNL-ESBW-1a Phase Power, and Total Power \& Energy Transients . . . . . . 33

3.2.6 ORNL-ESBW-1a Electrode Depth and Centerline Temperature Transients . . . . . 34 


\section{FIGURES}

3.2.7 ORNL-ESBW-1a Canister Pressure Transients $\ldots \ldots \ldots \ldots \ldots \ldots \ldots \ldots$

3.2.8 ORNL-ESBW-1a Pressure/Temperature Transients on the Upper Canister Layer .. 35

3.2.9 ORNL-ESBW-1 a Pressure/Temperature Transients on the Middle Canister Layer . . . 36

3.2.10 ORNL-ESBW-1a Pressure/Temperature Transients on the Lower Canister Layer . . 36

3.2.11 ORNL-ESBW-1a Plenum Pressure/Temperature Transients $\ldots \ldots \ldots \ldots \ldots . .37$

3.2.12 ORNL-ESBW-1a Plenum Pressure/Temperature Transients Following Spray

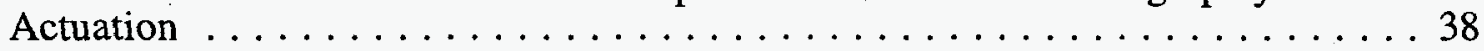

3.3.1 ORNL-ESBW-1b Test Configuration - Elevation View of Staged EngineeringScale ISV Test Setup $\ldots \ldots \ldots \ldots \ldots \ldots \ldots \ldots \ldots \ldots \ldots \ldots \ldots \ldots \ldots$

3.3.2 ORNL-ESBW-1b Test Canister Instrumentation $\ldots \ldots \ldots \ldots \ldots \ldots \ldots \ldots$

3.3.3 ORNL-ESBW-1b Test -- Soil Surface Following a GDE . ............ 44

3.3.4 ORNL-ESBW-1b Phase Voltage, Current, and Resistance Transients . . . . . . 45

3.3.5 ORNL-ESBW--1b Phase Power, and Total Power \& Energy Transients . . . . . 45

3.3.6 ORNL-ESBW-1b Electrode Depth and Centerline Temperature Transients ...... 46

3.3.7. ORNL-ESBW-1b Canister Pressure Transients $\ldots \ldots \ldots \ldots \ldots \ldots \ldots \ldots$

3.3.8 ORNL-ESBW-1b Pressure/Temperature Transients at the $-15 \mathrm{~cm}$ Level . . . . . . 47

3.3.9 ORNL-ESBW-1b Pressure/Temperature Transients at the $-30 \mathrm{~cm}$ Level . . . . . . . 48

3.3.10 ORNL-ESBW-1b Pressure/Temperature Transients at the $-45 \mathrm{~cm}$ Level . . . . . . . 48

3.3.11 ORNL-ESBW-1b Pressure/Temperature Transients at the $-60 \mathrm{~cm}$ Level ....... 49

3.3.12 ORNL-ESBW-1b Off-Gas Inlet and Plenum Temperature Transients $\ldots \ldots \ldots \ldots 50$

3.3.13 ORNL-ESBW-1b Plenum Pressure and Temperature Transients $\ldots \ldots \ldots \ldots \ldots 0$

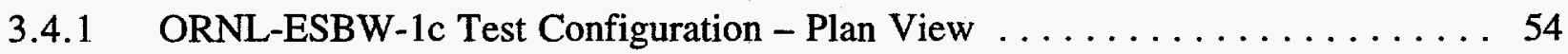

3.4.2 ORNL-ESBW-1c Test Configuration - Elevation View (Section C-C) $\ldots \ldots \ldots 54$

3.4.3 ORNL-ESBW-1c Seal Pot "Splash Pattern" Following the Second Event . . . . . . 55

3.4.4 ORNL-ESBW-1c -- Top Surface of the Melt $\ldots \ldots \ldots \ldots \ldots \ldots \ldots \ldots$ 


\section{FIGURES}

3.4.5 ORNL-ESBW-1c Phase Voltage, Current, and Resistance Transients . . . . . . 57

3.4.6 ORNL-ESBW-1c Phase Power, and Total Power \& Energy Transients . . . . . . 57

3.4.7 ORNL-ESBW-1c Electrode Depth and Centerline Temperature Transients . . . . . 58

3.4.8 ORNL-ESBW-1c Off-Gas Inlet and Plenum Temperature Transients ....... 59

3.4.9 ORNL-ESBW-1c Plenum Pressure and Temperature Transients While Processing the Top Layer of Cans . . . . . . . . . . . . . . . . . . 59

3.4.10 ORNL-ESBW-1c Plenum Pressure and Temperature Transients While Processing the Top Layer of Cans . . . . . . . . . . . . . . . . . . . 60

3.4.11 ORNL-ESBW-1c Plenum Pressure and Temperature Transients While Processing the Middle Layer of Cans . . . . . . . . . . . . . . 60

3.4.12 ORNL-ESBW-1c Plenum Pressure and Temperature Transients While Processing the Bottom Layer of Cans . . . . . . . . . . . . . . . 61

3.5.1 ORNL-ESBW-2 Test Configuration - Plan View . . . . . . . . . . 64

3.5.2 ORNL-ESBW-2 Test Configuration - Elevation View (Section C-C) . . . . . 64

3.5.3 ORNL-ESBW-2 Transfer Container - Pre-burial Stage . . . . . . . . . 65

3.5.4 ORNL-ESBW-2 Transfer Container - Post-burial Stage $\ldots \ldots \ldots \ldots$

3.5.5 ORNL-ESBW-2 Phase Voltage, Current, and Resistance Transients . . . . . . 67

3.5.6 ORNL-ESBW-2 Phase Power, and Total Power \& Energy Transients . . . . . 68

3.5.7 ORNL-ESBW-2 Electrode Depth Transient $\ldots \ldots \ldots \ldots \ldots$

3.5.8 ORNL-ESBW-2 Plenum Pressure and Temperature Transients . . . . . . . . 69

3.6.1 Cans Following Pretreatment with Dynamic Compaction $\ldots \ldots \ldots \ldots$

3.6.2 Detail View of Cans 1A and 2A Employed in the ORNL-ESBW-2a Test . . . . . 73

3.6.3 Detail View of Cans $1 \mathrm{~B}$ and 2B Employed in the ORNL-ESBW-2a Test $\ldots \ldots \ldots 73$

3.6.4 Detail View of Cans 3A and 3B Employed in the ORNL-ESBW-2a Test $\ldots \ldots \ldots 74$

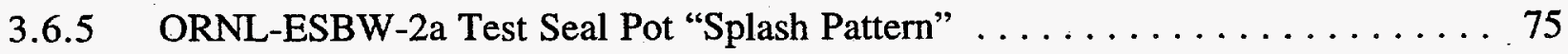

3.6.6 ORNL-ESBW-2a Test Glass Flow Pattern on the Soil Surface . . . . . . . . 76 


\section{FIGURES}

3.6.7 ORNL-ESBW-2a Phase Voltage, Current, and Resistance Transients . . . . . . 77

3.6.8 ORNL-ESBW-2a Phase Power, and Total Power \& Energy Transients . . . . . . 77

3.6.9. ORNL-ESBW-2a Electrode Depth and Centerline Temperature Transients . . . . 78

3.6.10 ORNL-ESBW-2a Plenum Pressure and Temperature Transients Produced While Processing the Top Layer of Cans . . . . . . . . . . . . . . . . . . . . 79

3.6.11 ORNL-ESBW-2a Plenum Pressure and Temperature Transients Produced While Processing the Bottom Layer of Cans . . . . . . . . . . . . . . . . . . 79

3.6.12 ORNL-ESBW-2a Off-Gas Hood Skin Temperatures and Heat Transfer . . . . . . 80

3.6.13 ORNL-ESBW-2a Plenum Pressure/Temperature Transients Following the First

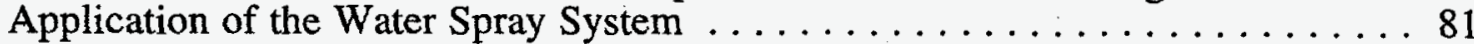

3.6.14 ORNL-ESBW-2a Plenum Pressure/Temperature Transients Following the Second Application of the Water Spray System . . . . . . . . . . . . . 81

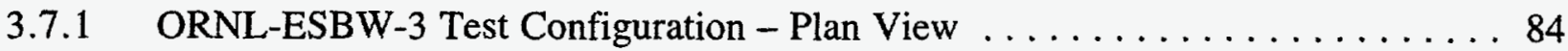

3.7.2 ORNL-ESBW-3 Test Configuration - Elevation View (Section C-C) . . . . . . 85

3.7.3 ORNL-ESBW-3 Phase Voltage, Current, and Resistance Transients . . . . . . 87

3.7.4 ORNL-ESBW-3 Phase Power, and Total Power \& Energy Transients . . . . . 88

3.7.5 ORNL-ESBW-3 Electrode Depth and Upper Centerline Temperature Transients ... 89

3.7.6 ORNL-ESBW-3 Electrode Depth and Lower Centerline Temperature Transients . . . 89

3.7.7 ORNL-ESBW-3 Plenum Pressure and Temperature Transients for Event \#1 . . . . 90

3.7.8 ORNL-ESBW-3 Plenum Pressure and Temperature Transients for Event \#2 . . . . 91

3.7.9 ORNL-ESBW-3 Plenum Pressure and Temperature Transients for Event \#3 . . . . 91

3.7.10 ORNL-ESBW-3 Plenum Pressure and Temperature Transients for Event \#4 . . . . 92

3.7.11 ORNL-ESBW-3 Plenum Pressure and Temperature Transients for Event \#5 . . . . 92

3.7.12 ORNL-ESBW-3 Off-Gas Hood Skin Temperatures and Heat Transfer . . . . . . . 93

3.8.1 ORNL-ESBW-4 Bottom Layer Can Condition \& Placement . . . . . . . . . . 95

3.8.2 ORNL-ESBW-4 Middle Layer Can Condition \& Placement . . . . . . . . . . 96 


\section{FIGURES}

3.8.3 ORNL-ESBW-4 Top Layer Can Condition \& Placement $\ldots \ldots \ldots \ldots \ldots$

3.8.4 ORNL-ESBW-4 Phase Voltage, Current, and Resistance Transients .......... 98

3.8.5 ORNL-ESBW-4 Phase Power, and Total Power \& Energy Transients . . . . . . . 98

3.8.6 ORNL-ESBW-4 Electrode Depth and Upper Centerline Temperature Transients ... 100

3.8.7 ORNL-ESBW-4 Electrode Depth and Lower Centerline Temperature Transients . . 100

3.8.8 ORNL-ESBW-4 Plenum Pressure and Temperature Transients . . . . . . . . 101

3.8.9 ORNL-ESBW-4 Plenum Pressure and Temperature Transients During a Major Subsidence Event . . . . . . . . . . . . . . . . . . . . . . . . . 101

4.1.1 ORNL-ESBW-5 Test Configuration - Elevation View . . . . . . . . . . . 105

4.1.2 ORNL-ESBW-5 Test Off-Gas Outlet Line and HEPA Filter Connections ....... 106

4.1.3 ORNL-ESBW-5 Phase Voltage, Current, and Resistance Transients . . . . . . . 108

4.1.4 ORNL-ESBW-5 Phase Power, and Total Power \& Energy Transients . . . . . . 108

4.1.5 ORNL-ESBW-5 Electrode Depth and Centerline Temperature Transients . . . . . . 109

4.1.6 ORNL-ESBW-5 Plenum Pressure and Temperature Transients $\ldots \ldots \ldots \ldots \ldots 110$

4.1.7 ORNL-ESBW-5 Soil and Glass Sample Locations $\ldots \ldots \ldots \ldots \ldots \ldots \ldots \ldots$

4.2.1 ORNL-ESBW-6 Test Configuration - Elevation View $\ldots \ldots \ldots \ldots \ldots \ldots 122$

4.2.2 ORNL-ESBW-6 Can \& Chemical Placement - Bottom Layer . . . . . . . . . 123

4.2.3 ORNL-ESBW-6 Can \& Chemical Placement - Middle Layer . .......... 123

4.2.4 ORNL-ESBW-6 Can \& Chemical Placement - Top Layer . . . . . . . . . . . 124

4.2.5 ORNL-ESBW-6 Phase Voltage, Current, and Resistance Transients . . . . . . 126

4.2.6 ORNL-ESBW-6 Phase Power, and Total Power \& Energy Transients . . . . . . . 126

4.2.7 ORNL-ESBW-6 Electrode Depth and Centerline Temperature Transients . . . . . 127

4.2.8 ORNL-ESBW-6 Plenum Pressure and Temperature Transients $\ldots \ldots \ldots \ldots 128$

4.2.9 ORNL-ESBW-6 Kaowool Heat Flux \& Temperature Transients . . . . . . . . . . 128

4.2.10 ORNL-ESBW-6 Soil Sample Locations $\ldots \ldots \ldots \ldots \ldots \ldots \ldots \ldots \ldots \ldots \ldots$ 


\section{FIGURES}

4.2.11 ORNL-ESBW-6 Lateral Soil Moisture Pattern . . . . . . . . . . . . . . . . . 134

4.2.12 ORNL-ESBW-6 Soil Moisture Pattern Beneath the ISV Block $\ldots \ldots \ldots \ldots \ldots$ 


\section{TABLES}

3.0.1 Summary of ORNL Buried Waste Test Parameters \& Key Results . . . . . . . 12

3.1.1 ORNL SWSA-6 Trench \& Waste Package Scaling Information $\ldots \ldots \ldots \ldots$

4.1.1 ORNL-ESBW-5 HEPA Filter Chemical Analysis Results . . . . . . . . . . 112

4.1.2 ORNL-ESBW-5 Soil/Block Sample Chemical Analysis Results . . . . . . . 113

4.1.3 ORNL-ESBW-5 Simulant Inventory \& Post-Test Distribution $\ldots \ldots \ldots \ldots$

4.1.4 ORNL-ESBW-5 TCLP Test Leachate Concentrations $\ldots \ldots \ldots \ldots \ldots \ldots \ldots$

4.2.1 ORNL-ESBW-6 Off-Gas Sample Chemical Analysis Results . . . . . . . . 130

4.2.2 ORNL-ESBW-6 Post-Test Dräger Tube Readings . . . . . . . . . . 131

4.2.3 ORNL-ESBW-6 Soil Sample Chemical Analysis Results . . . . . . . . . 133 



\subsection{INTRODUCTION}

Burial trenches have been commonly used to dispose of a wide range of hazardous wastes. At the Oak Ridge National Laboratory (ORNL) for example, hundreds of acres of waste have been buried in trenches over the past 45 years (Davis et al. 1986). At ORNL, six disposal sites have been designed for this purpose. Most recently, low-level radioactive wastes have been disposed-of in the Solid Waste Storage Area 6 (SWSA-6) trenches. The average depth of the burial trenches is approximately fifteen feet. Frequently, the wastes stored in these trenches are contained in barrels, crates, or other objects. The packing efficiency for these storage devices is less than optimal. Consequently, a significant fraction of the volume in the trenches is occupied by voids. The presence of voids causes a number of problems for the long-term storage and treatment of the wastes in the trenches. First, the voids can contribute to large, and sometimes rapid, subsidence events in the trenches. This has the undesirable effect of creating depressions in the soil surface of the trench. These depressions can trap surface water which can then percolate through the trench and come in contact with the buried waste. In addition, the depressions resulting from this subsidence represent a safety hazard to the operation and control of personnel and equipment at these sites.

Current options for remediation of buried radioactive and mixed waste sites are of limited long-term effectiveness. Perhaps the simplest and least expensive approach to "remediation" of buried waste sites might be to cap the area above the waste site. However, caps do not obviate continued infiltration or lateral migration of water over the long term. Moreover, they do not render the wastes themselves into a more stable form. Another approach involves the exhumation of buried wastes for subsequent treatment. This approach increases both the risk of exposure to operating personnel, as well as the potential for generating airborne contaminants, which can then spread during transfer. Reducing both the exposure and contamination risk adds greatly to the cost of remediation. Immobilizing the wastes in place is potentially achievable through injection of grout materials throughout the waste site. Concerns about the leaching characteristics of this waste form, as well as the cost and effectiveness of injection techniques, limit the application of this technology, however.

In situ vitrification (ISV) accomplishes a number of objectives simultaneously during processing of these buried waste sites. First, nonvolatile hazardous and radioactive contaminants are permanently incorporated in the glass produced during vitrification. Leach-rate tests performed on the ISV glass have shown that the waste form produced is effective at immobilizing the entombed wastes for geologic time frames (Buelt et al. 1987). Second, any organic wastes 
present in the target vitrification zone are destroyed during the process. Third, the waste volume is significantly reduced as a result of the natural densification that occurs during processing (viz. collapsing the soil's pore volume during melting). These "natural" volume reductions can be substantially accentuated when processing waste sites wherein a significant void volume exists due to the presence of inclusions and debris. Finally, the costs associated with the ISV process are comparable to, if not significantly less than, those of the competing technologies (e.g. - retrieve \& treat).

The ISV process was invented in the early 1980s by researchers at the Pacific Northwest National Laboratory (PNNL). The process has been patented by Battelle (Patent \#4,376,598 Brouns, et al. 1983). Its commercial application has been exclusively licensed to the Geosafe Corporation. ISV is a process in which electrical energy is supplied to the target vitrification zone by passing current through the soil/waste matrix. The resulting Joule heat dissipation raises the temperature of the matrix, producing a molten pool. Electrical power is supplied to the soil through graphite electrodes whose progress through the waste zone is controlled manually by the operators, or naturally by the action of gravity. The typical ISV melt is propagated through the waste zone from the top down. A solid, often monolithic, glass and crystalline block is produced upon termination of power and cool down of the melt. Typical large-scale melts draw approximately $3000 \mathrm{~kW}$ for a period of roughly 7 to 10 days to produce a block $5 \mathrm{~m}$ in depth and weighing 400 to 800 metric tons. Processing temperatures of $1600^{\circ} \mathrm{C}$ are routinely encountered with many sandy soils. Higher processing temperatures are required to treat soils that are rich in silica and aluminum oxide materials and depleted in alkali and alkaline-earth materials. In such soils, past ISV engineering-scale tests have produced melt temperatures approaching $2000^{\circ} \mathrm{C}$ without posing complications to the operation or design of the equipment. During processing, the entire surface of the target vitrification zone and a substantial buffer zone surrounding the melt is covered by an off-gas hood. The off-gas hood is maintained at a negative pressure to contain and collect for treatment any gases released to the off-gas plenum during processing.

ISV has been successfully applied to the remediation of a number of waste sites at both commercial- and government-owned facilities. These sites have contained radioactive wastes, as well as polychlorinated biphenyls (PCBs), dioxins, and other organic and inorganic contaminants (U.S. EPA 1995). Many applications have also resulted in the successful processing of substantial quantities of organic and inorganic debris. On occasion, application of ISV to sites containing sealed containers of waste has met with some difficulty, however (e.g. - Bergsman, et al. 1992; Geosafe Corporation 1993; Thompson et al. 1993). The heat required to vitrify the soil can produce excessive pressures in sealed containers that hold volatile materials even as benign as 
water. A sudden release of this pressure can produce melt overflow as the hot pool of molten soil is violently disturbed.

Several options have been proposed to preclude this occurrence. The first approach involves pretreatment of the waste site using dynamic compaction (DC). DC has been known to be an effective and inexpensive method for reducing the volume of wastes (e.g. - Spalding 1985; Phillips 1984) . In this process, a waste zone is repeatedly impacted by a very heavy object typically, on the order of 4 metric tons. The energy imparted to the waste zone collapses voids present in the zone and breaches any sealed containers present therein. By pretreating the waste site with DC, the potential for the follow-on ISV process to encounter sealed containers of volatile materials is greatly reduced, if not eliminated altogether. Alternatives to DC include the use of vibrating rods to puncture or otherwise compromise the integrity of any sealed containers present in the target vitrification zone. While this approach does not simultaneously reduce the volume of the waste site, it has been demonstrated to be effective at breaching sealed containers.

Since the DC process is intended to collapse subsurface voids and containers in place, it is difficult to assess the effectiveness of the pretreatment process after the fact without excavation. This is an undesirable requirement. However, as indicated previously, the presence of sealed canisters containing volatile materials as seemingly benign as water has proven troublesome for their safe processing with ISV. Indeed, this may be a problem for all remediation processes that employ extreme thermal environments to treat wastes buried in the soil. These sudden canister failures produce significant plenum pressure and temperature excursions in the off-gas plenum space of the ISV system. The ISV off-gas hood has not yet been designed to withstand such occurrences. Designing a hood to mitigate these excursions would likely prove to be a challenging engineering project. Therefore, a pretreatment process which can effectively compromise the integrity of any sealed containers buried in the waste zone and simultaneously require minimal exposure to the hazardous materials to be processed, is the preferred approach. DC appears to offer these advantages. The issues relating to the effectiveness of the $\mathrm{DC}$ process to compromise the integrity of buried sealed containers need to be addressed. These issues provide the purpose for a number of the tests performed in this effort. Specifically, most of the ISV tests discussed herein were designed to help determine the extent to which the integrity of sealed containers must be compromised in order to preclude a catastrophic rupture during follow-on processing with ISV.

Another potential approach for obviating pressure buildup in sealed containers involves ISV processing that is initiated from beneath the target waste zone. The waste is then processed by propagating the melt up through the waste zone and/or allowing the soil and waste materials to collapse down into the molten pool. This approach requires that the melt be initiated some distance 
below the waste zone. Techniques to facilitate laying the starter path are being investigated in other projects. Typically however, these techniques employ directional drilling and/or pneumatic fracturing to introduce a sufficient quantity of starter material (viz., graphite and glass frit) to initiate and sustain the melting process.

Conceptually, when the waste is introduced to the molten soil from above, it seems plausible that the pressure excursions resulting from any sudden rupture of a sealed container would be mitigated by the soil located above the canister. In effect then, only soil and possibly unprocessed wastes would be displaced as a consequence of the canister's sudden rupture. In concept, this appears preferable to the dispersal of molten soil that results when a canister suddenly bursts during top-down ISV processing. To investigate the merits of this approach, several of the tests performed for this work incorporated bottom-up processing to treat simulated wastes, both with and without the benefit of pretreatment by DC. Since each of these tests are configured to replicate the conditions of the other tests, a more direct comparison of the efficacy of this methodology is realized. 


\subsection{THE PNNL ENGINEERING-SCALE ISV FACILITY}

PNNL has pursued the development of ISV with a graduated-risk philosophy. New applications and extensions to the existing ISV technology are first tested at a reduced scale. Once proven at this scale, the concept or modification is transferred to progressively larger scales until a full-scale demonstration can be implemented. The smallest of these scales is the bench-scale apparatus. This system employs two 5-cm-diameter graphite electrodes spaced $11 \mathrm{~cm}$ apart. Single-phase power is applied to the system to generate power levels in the range of $10 \mathrm{~kW}$. Bench-scale melts range in size from 1 to $10 \mathrm{~kg}$.

The bench-scale system is used rather infrequently, however. Instead, most concepts are first tested at the engineering-scale. Here three, four, or six 5-cm-diameter graphite electrodes are used at a nominal separation of $30 \mathrm{~cm}$. Most applications use either the three electrode or four electrode systems. In the three- and six-electrode configurations, three-phase line sources are used to power the system. Voltage and current is controlled by a system of variacs. In the fourelectrode configuration, the electrodes are placed in a square pattern with the diagonally-opposed electrodes forming electrical pairs. Two-phase power is generated from the three-phase input by means of a transformer connected using the Scott-Tee configuration. One phase is then applied to each of the two electrode pairs. Power levels of $25 \mathrm{~kW}$ are typically employed at this scale. Engineering-scale melts range from 50 to $1000 \mathrm{~kg}$ and are on the order of 0.5 - to $1-\mathrm{m} \mathrm{deep.} \mathrm{A}$ photograph of the engineering-scale system used for these tests is presented in Figure 2.0.1

The next step up in the series of ISV systems is the pilot-scale system. This system is typically employed for the first field-scale demonstrations of the technology. In this system, 15-cm-diameter graphite electrodes are used with nominal separations of 1 to $1.5 \mathrm{~m}$. Only the twophase Scott Tee power supply system has been employed at this scale (though there is the capability to utilize a three-phase, three-electrode system). Power levels of $250 \mathrm{~kW}$ are commonly employed to produce melts ranging from 10 to 50 metric tons and 2 to $3 \mathrm{~m}$ in height.

Finally, the large-scale ISV system employs four 30-cm-diameter graphite electrodes placed in a square pattern with 3.5 to $5.5 \mathrm{~m}$ nominal spacing between neighboring electrodes. As with the four-electrode engineering- and pilot-scale configurations, a Scott-Tee connected transformer configuration is used to supply power to the melt zone. Typically, 2000 to $3500 \mathrm{~kW}$ are dissipated for 7 to 10 days to produce melts ranging from 400 to 800 metric tons and nominally $5 \mathrm{~m}$ in height. 
In each of these systems, the electrodes are fed by gravity into the melt. The electrodes can be raised and lowered by means of a pneumatically-controlled electrode feeder system located on the ISV off-gas hood. The engineering-scale electrode feeder system can be seen in Figure 2.0.1.

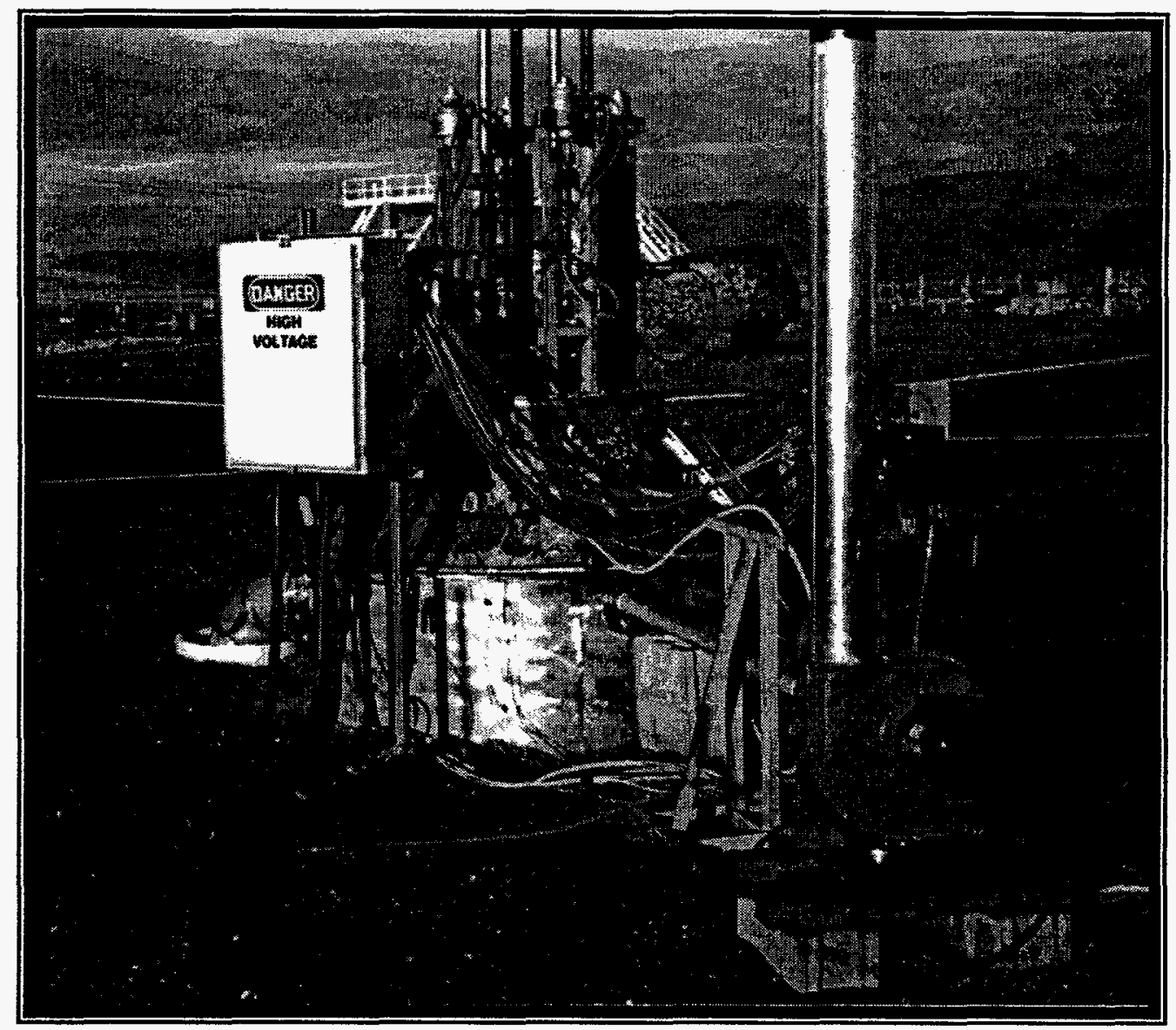

FIGURE 2.0.1. The PNNL Engineering-Scale ISV Facility.

Soil is naturally a very poor conductor of both thermal energy and electricity. Therefore, to initiate the melting process, the path between the electrodes must be supplemented with a starter path material. Typically, this material is composed of a mixture of graphite flakes and glass frit. The graphite provides the conductive medium and the glass frit provides the seed material to establish the initial melt. For these tests, the starter tube configuration developed by Sliger (1994) was employed. This technique involves the placement of starter material inside consumable tubing prior to final placement on the target vitrification zone. This arrangement greatly facilitates the 
starter path staging process. For these four-electrode, two-phase tests, the standard box-X starter path pattern was placed between the electrodes. Figure 2.0 .2 provides a photograph of this starter path arrangement.

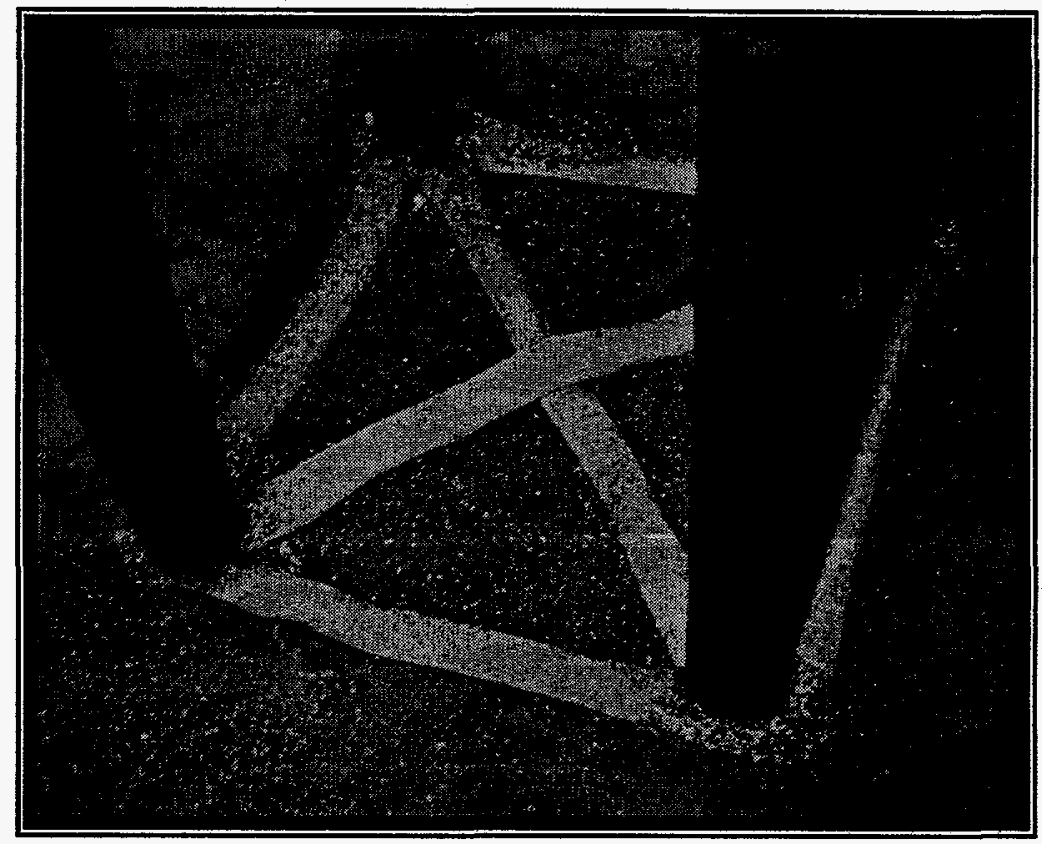

Figure 2.0.2. Box-X Starter Path Configuration.

As mentioned previously, the target melt zone and a surrounding buffer zone are covered with an off-gas hood. The engineering-scale ISV off-gas hood is presented in Figure 2.0.1. The off-gas hood is sealed to the ground and maintained at a partial vacuum so that the gases generated by the vitrification process are confined for subsequent processing by the off-gas treatment system. This system consists of a blower together with a series of scrubbers, separators, and highefficiency particulate air (HEPA) filters that serve to remove any particulate and other contaminants from the off-gas flow stream. When the melt zone does not involve contaminants however, the off-gas can be exhausted directly to atmosphere. This configuration is depicted in Figure 2.0.1. The blower driving off-gas flow for this system is located at the bottom right portion of this figure.

Previous experience with processing sites containing sealed drums have produced significant plenum pressure and temperature transients in the off-gas hood of the ISV system (Bergsman et al. 1992; Geosafe 1993; Thompson et al. 1993). In these instances, the plenum transients were of greater consequence than anticipated. Because plenum pressure excursions were anticipated in 
these tests, the engineering-scale ISV apparatus was modified to include a seal-pot pressure relief system to help mitigate their impact on the facility.

A 30-cm-I.D. vent pipe was connected to a flange on the side wall of the off-gas hood. This vent pipe ran directly to the seal pot reservoir. The water level in this reservoir was monitored and adjusted to provide the desired set-point for the pressure relief system. For these tests, the water level was maintained to provide a $+25 \mathrm{mbar}\left(+10\right.$ in. $\left.\mathrm{H}_{2} \mathrm{O}\right)$ set point for vent flow. In the event of a pressure rise in the off-gas hood, the pressure in the off-gas plenum would push down on the water surface in the seal pot reservoir. If the pressure rises sufficiently, the water level drops below the lip of the vent pipe thereby allowing gases to flow from the off-gas plenum region to the outside air space. This flow would then relieve the pressure build-up in the plenum region, helping to mitigate the event.

In addition to the seal pot pressure relief system, a water spray system was incorporated into the PNNL engineering-scale ISV facility for these tests. The introduction of a fine mist of relatively cool water droplets was intended to reduce the temperature and pressure of the off-gas plenum region, thereby further helping to mitigate the consequences of a plenum pressure/temperature event. This approach has been successfully employed in previous engineering-scale tests (Luey et al. 1992). Its employment in these tests provides an additional margin of safety for moderating any pressure/temperature transients generated.

This system was configured to automatically actuate water spray when either the plenum pressure exceeded $+25 \mathrm{mbar}$ and/or the plenum temperature reached $300^{\circ} \mathrm{C}$ for a period of 5 seconds or longer. Water spray remains active until the plenum pressure and temperature return to normal operating conditions - viz., $-7.5 \mathrm{mbar}$ and $200^{\circ} \mathrm{C}$. Actuation (both initiation and termination) of the water spray system could be invoked by the operator as well. The spray nozzle for this system was located in the ISV hood, centered between the electrode penetrations. The nozzle orifice diameter was 0.060 inches. This nozzle supplies 7.1 gph when supplied with water at 80 psig. At this pressure, the cone angle for the spray is $155^{\circ}$. For this application, a reservoir of water was maintained at 80 psig throughout the tests.

The ISV Data Acquisition System (DAS) is comprised of a series of Apple Macintosh IIci and IIfx computers configured with Labview ${ }^{\circledR}$ software. For these tests, the DAS was configured to record the temperature response of the thermocouples once every 30 seconds. Power data was displayed with Fluke multimeters and digitally recorded by a Macintosh IIci computer at a frequency of once every 15 seconds. The computer display screen was updated at this same 15 second interval to facilitate responsive operator control. In addition to computer recorded data, 
these data were also recorded manually once every hour on data sheets, and at shorter intervals as events warranted.

The plenum pressure and temperature data were also monitored and recorded for the record and as input to the plenum water spray system. These data were fed to a Macintosh IIfx computer equipped with Labview ${ }^{\circledR}$ software. The data recording frequency was set by the operator. Typically, these data were sampled and recorded at 2 second intervals. However, the sampling rate could be reset by the shift personnel as conditions warranted during the tests. In addition to the plenum pressure and temperature, the status of the water spray system (i.e. - on/off) and the system setpoints were also electronically recorded at these frequencies. This provided a tremendous volume of data with which to track the response of the ISV system during an event.

Electrode depth measurements were taken at hourly intervals (or more frequently as conditions warranted) throughout the test. These data were manually recorded on data sheets.

Each thermocouple staged to measure the soil temperature was tagged to facilitate interpretation of its response during and after the tests. The tag provided information indicating its depth, lateral, and azimuthal placement in the soil. All coordinates were with respect to an origin located along the vertical centerline of the ISV off-gas hood, the soil surface, and due North at the ISV site. The thermocouples were tagged using a zzz-rrr- $\theta \theta \theta$ nomenclature. zzz indicated the thermocouple depth in millimeters relative to grade. Similarly, the radial (lateral) position of the thermocouple was indicated (in $\mathrm{mm}$ ) by the rrr designation. Finally, the azimuthal position of the thermocouple was denoted (in degrees) by the value associated with the $\theta \theta \theta$ portion of the tag. Both Type " $\mathrm{C}$ " and Type " $\mathrm{K}$ " thermocouples were employed in these tests. This distinction is indicated in the figures presented in this report by the use of boldface type for Type " $C$ ": thermocouple tags, and standard type for Type " $\mathrm{K}$ " thermocouple tags.

The plenum region of the off-gas hood was videotaped for the duration of each test. Date and time stamps were also recorded on the video images. This record provided a means to correlate a visual reading of the plenum transients with the pressure and temperature data. This was especially helpful in interpreting the severity of any glass displacement events with the associated plenum pressure and temperature excursions. 


\subsection{ENGINEERING-SCALE ISV TESTS}

A series of ten engineering-scale ISV tests were performed for this project. Most of these tests were designed to investigate the merits of pretreating the simulated buried wastes with dynamic compaction (DC) prior to final processing using ISV. As such, many of these tests were performed in pairs -- one invoking the "standard" approach to ISV (i.e., without pretreatment), and one in which the waste zone was pretreated with DC prior to final processing with ISV. To facilitate comparison of the results, the configuration and operation of a test was designed to replicate those of its dual.

In addition to investigating the merits of pretreatment using DC, the efficacy of bottom-up ISV processing was investigated as part of this effort. Typically, ISV melts have employed the top-down approach to processing the target vitrification zone. With this approach, the melt is initiated at or near the surface. The melt is then propagated down through the waste zone as the electrodes gravity-feed through the melt. In the bottom-up approach, the melt is initiated below the waste zone. The wastes are then processed by either propagating the melt up through the target vitrification zone and/or allowing the unprocessed soil and waste to collapse into the molten pool below.

The identifier and a brief synopsis of the conditions for each of the series of ten tests are as follows:

- ORNL-ESBW-1 -- Top-down processing of metallic, cellulose, plastic, and canistered materials. The waste volume and canister sizes were scaled to replicate the loadings and canister sizes present in a typical ORNL buried waste trench. No DC pretreatment was employed. (Section 3.1)

- ORNL-ESBW-1a -- Top-down processing of canisters containing soil and water. The steel canisters were instrumented to record their pressure and temperature transients during processing. No DC pretreatment was employed. (Section 3.2)

- ORNL-ESBW-1b -- Repeat of the ORNL-ESBW-1a test with more steel canisters, different canister loadings, and fewer canisters instrumented. No DC pretreatment was employed. (Section 3.3) 
- ORNL-ESBW-1c -- Top-down processing of factory-sealed, steel canisters of hydrous, organic material. No DC pretreatment was employed. This test became the reference or baseline top-down test. (Section 3.4)

- ORNL-ESBW-2 -- Replicate of ORNL-ESBW-1c test conditions and operation with waste zone pretreated using DC. (Section 3.5)

- ORNL-ESBW-2a -- Replicate of ORNL-ESBW-2 test. Canisters recovered from waste zone following pretreatment with DC. The condition of each canister was recorded to facilitate correlation of any pressure/temperature events with the canisters being processed. Each canister was re-staged in the target vitrification zone before final processing with ISV. (Section 3.6)

- ORNL-ESBW-3 -- Bottom-up processing of factory-sealed, steel canisters of hydrous, organic material. No DC pretreatment was employed. This test became the reference or baseline bottom-up test. (Section 3.7)

- ORNL-ESBW-4 -- Replicate of ORNL-ESBW-3 test conditions but with canisters pretreated with DC. As with the ORNL-ESBW-2a test, each canister was recovered and its condition recorded following the DC pretreatment process. The canisters we then restaged for final processing with ISV. (Section 3.8)

- ORNL-ESBW-5 -- Replicate of ORNL-ESBW-2a test with non-radioactive simulants representing the non-volatile and semi-volatile radioactive waste present in the typical ORNL buried waste trench staged. (Section 4.1)

- ORNL-ESBW-6 - Replicate of ORNL-ESBW-2a test with non-radioactive simulants representing the volatile and semi-volatile chemical wastes present in the typical ORNL buried waste trench staged. (Section 4.2)

A summary of the key parameters and results obtained from each of these tests is provided in Table 3.0.1.

Tests ORNL-ESBW-1 through 4 are discussed in this section. The follow-on ORNLESBW-5 and ORNL-ESBW-6 tests involved the use of simulants to represent behavior of the 
spectrum of the buried wastes anticipated in the ORNL-SWSA-6 trenches. These last two tests will be discussed in section 4.0 of this report.

Table 3.0.1. Summary of ORNL Buried Waste Test Parameters \& Key Results.

\begin{tabular}{||c|c|c|c|c|c|c|c||}
\hline Test Name & $\begin{array}{c}\text { Test } \\
\text { Specifics }\end{array}$ & Date & $\begin{array}{c}\text { Event } \\
\text { Summary }\end{array}$ & $\begin{array}{c}\text { Run } \\
\text { Duration } \\
\text { (hrs) }\end{array}$ & $\begin{array}{c}\text { Block } \\
\text { Mass } \\
\text { (kg) }\end{array}$ & $\begin{array}{c}\text { Energy } \\
\text { Consumption } \\
\text { (kWh) }\end{array}$ & $\begin{array}{c}\text { Specific } \\
\text { Energy } \\
\text { Consumption } \\
\text { (kWh/kg) }\end{array}$ \\
\hline \hline ORNL-ESBW-1 & $\begin{array}{c}\text { Top-down } \\
\text { Uncompacted }\end{array}$ & $2 / 3 / 95$ & $\begin{array}{c}\text { Pressure1 } \\
\text { Temperature1 }\end{array}$ & 11.25 & 270 & 261 & 0.97 \\
\hline ORNL-ESBW-1a & $\begin{array}{c}\text { Top-down } \\
\text { Uncompacted }\end{array}$ & $3 / 7 / 95$ & None & 9.75 & 205 & 210 & 1.02 \\
\hline $\begin{array}{c}\text { Top-down } \\
\text { Uncompacted }\end{array}$ & $3 / 10 / 95$ & $\begin{array}{c}\text { Pressure } \\
\text { Temperature }\end{array}$ & 14.5 & 318 & 335 & 1.05 \\
\hline ORNL-ESBW-1b & $\begin{array}{c}\text { Top-down } \\
\text { Uncompacted }\end{array}$ & $3 / 31 / 95$ & $\begin{array}{c}\text { Pressure } \\
\text { Temperature }\end{array}$ & 8.1 & 208 & 178 & 0.86 \\
\hline ORNL-ESBW-1c & $\begin{array}{c}\text { Top-down } \\
\text { Compacted }\end{array}$ & $4 / 7 / 95$ & None & 8.17 & 209 & 178 & 0.85 \\
\hline ORNL-ESBW-2a & $\begin{array}{c}\text { Top-down } \\
\text { Compacted }\end{array}$ & $4 / 19 / 95$ & $\begin{array}{c}\text { Pressure } \\
\text { Temperature3 }\end{array}$ & 8.17 & 209 & 178 & 0.85 \\
\hline ORNL-ESBW-3 & $\begin{array}{c}\text { Bottom-up } \\
\text { Uncompacted }\end{array}$ & $6 / 28 / 95$ & $\begin{array}{c}\text { Pressure } \\
\text { Temperature }\end{array}$ & 12.25 & 370 & 274 & 0.74 \\
\hline ORNL-ESBW-4 & $\begin{array}{c}\text { Bottom-up } \\
\text { Compacted }\end{array}$ & $8 / 10 / 95$ & None & 13.25 & 356 & 300 & 0.84 \\
\hline ORNL-ESBW-5 & $\begin{array}{c}\text { Top-down } \\
\text { Compacted } \\
\text { Inorganics }\end{array}$ & $9 / 29 / 95$ & None & 9 & 270 & 198 & 0.73 \\
\hline ORNL-ESBW-6 & $\begin{array}{c}\text { Top-down } \\
\text { Organics }\end{array}$ & $11 / 8 / 95$ & None & 14 & 430 & 347 & 0.81 \\
\hline
\end{tabular}

1 Event caused when melt approached factory sealed 6 oz. hydrous, organic material cans placed below the simulated waste zone.

2 The initial integrity of the sealed containers is questionable because they were manually sealed and/or instrumented.

3 This test contained cans which were only slightly compacted, as well as, some uncompacted cans. 


\subsection{ORNL-ESBW-1 TEST}

Test ORNL-ESBW-1 involved the top-down processing of simulated wastes in a mock-up of an actual ORNL SWSA-6 buried waste trench. The test configuration is discussed in Section 3.1.1. This is followed by sections describing the instrumentation (Section 3.1.2), start-up and operation (Section 3.1.3), and results (Sections 3.1.4 through 3.1.8).

\subsubsection{Test Configuration}

In this ORNL-ESBW-1 test, an engineering-scale ISV melt was generated using the "standard" top-down approach. Simulated volatile and combustible wastes were emplaced in a mock-up of an actual ORNL SWSA- 6 buried waste trench. Both the trench and the waste dimensions (e.g., crates and containers) were scaled-down from the actual configuration for these engineering-scale tests. These were scaled on the electrode separation employed in the engineering-scale ISV system (viz., $30 \mathrm{~cm}$ ) relative to that employed at the large-scale (viz., 4.5 $\mathrm{m})$. This results in a scale-down ratio of 15:1 for each lineal dimension. A typical SWSA-6 400 series trench measures $3 \mathrm{~m} \times 15 \mathrm{~m} \times 4.3 \mathrm{~m}(\mathrm{~W} \times \mathrm{L} \times \mathrm{D})$. Thus, for this engineering-scale test, the scaled-down trench measured $20 \mathrm{~cm} \times 100 \mathrm{~cm} \times 30 \mathrm{~cm}$.

Photographic surveys of a number of the SWSA-6 trenches (Davis et al. 1986) indicate that they are filled with a combination of crates, barrels, boxes, pallets, and loosely packaged debris associated with low-level waste processing. In addition, sealed containers of solvents, scintillation cocktails, and other fluids have been placed in these trenches (Bechtel National Inc. 1988). Scale models of these items were therefore included in this test using the lineal scaling approach outlined above. Table 3.1.1 presents a list of the geometries associated with the trenches and waste packages/items for both the full-scale and engineering-scale configurations. An assortment of these items was included in the trench for this test. This assortment included: 0.3 $\mathrm{ml}, 1 \mathrm{ml}$, and $11.1 \mathrm{ml}$ glass and plastic vials containing a mixture of soil and water and, in the case of the $11.1 \mathrm{ml}$ vials, some paper and cloth materials; a number of simulated pallets; a number of simulated wooden containers containing steel and aluminum objects, as well as cloth and paper materials.

The volatile liquid waste simulants staged in this test contained only water and soil mixtures. This "sludge" was placed in sealed glass and plastic vials and positioned in the trench to approximate a typical arrangement depicted in the 400-series trenches at the ORNL SWSA-6 site (Davis et al. 1986). Similarly, crated wastes contained metal, cloth, and paper wastes, and were 
staged in the trench to approximate the configuration found in a typical SWSA-6 400 series waste trench. There were also loose combustible wastes (e.g., cloth, paper, and wood) placed in the trench for processing. The total waste loading of plastic, paper \& cloth, and aluminum \& steel was $3465 \mathrm{~g}, 270 \mathrm{~g}$, and $400 \mathrm{~g}$, respectively. Assuming a soil density of $1.65 \mathrm{~g} / \mathrm{cm}^{3}$, the mass of the trench when loaded completely with soil was approximately $99 \mathrm{~kg}$. Using this as the reference mass, the plastic, paper \& cloth, and aluminum \& steel loadings translate to $3.5 \mathrm{wt} \%, 0.3 \mathrm{wt} \%$, and $0.4 \mathrm{wt} \%$, respectively.

Table 3.1.1. ORNL SWSA-6 Trench \& Waste Package Scaling Information.

\begin{tabular}{|c||c|c|}
\hline Item & Full Scale & Engineering Scale \\
\hline Electrode Separation & $4.5 \mathrm{~m}$ & $30 \mathrm{~cm}$ \\
\hline Lineal Scale Factor & 1 & $1 / 15$ \\
\hline Trench $(\mathrm{W} \times \mathrm{L} \times \mathrm{D})$ & $3 \mathrm{~m} \times 15 \mathrm{~m} \times 4.3 \mathrm{~m}$ & $20 \mathrm{~cm} \times 1 \mathrm{~m} \times 30 \mathrm{~cm}$ \\
\hline Trench Volume & $193.5 \mathrm{~m}^{3}$ & $60000 \mathrm{~cm}^{3}$ \\
\hline \hline Lumber & $1^{\prime \prime} \times 4^{\prime \prime}\left(0.75^{\prime \prime} \times 3.5^{\prime \prime}\right)$ & $1 / 16^{\prime \prime} \times 1 / 4^{\prime \prime}$ \\
\hline & $2^{\prime \prime} \times 4^{\prime \prime}\left(1.5^{\prime \prime} \times 3.5^{\prime \prime}\right)$ & $1 / 8^{\prime \prime} \times 1 / 4^{\prime \prime}$ \\
\hline & $3 / 4^{\prime \prime} \mathrm{plywood}$ & $1 / 16^{\prime \prime}$ \\
\hline \hline Containers & 1 liter & $0.25 \mathrm{ml}$ \\
\hline & 5 gal $(3.785$ liter $)$ & $1 \mathrm{ml}$ \\
\hline & 55 gal $(41.635$ liter $)$ & $11 \mathrm{ml}$ \\
\hline Pallet Void Volume & $4^{\prime} \times 4^{\prime} \times 4^{\prime \prime}=0.15 \mathrm{~m}^{3}$ & $3.25^{\prime \prime} \times 3.25^{\prime \prime} \times 1 / 4^{\prime \prime}=4.5 \mathrm{~cm}^{3}$ \\
\hline
\end{tabular}

This basic test configuration was staged outdoors at the PNNL ISV Site using the engineering-scale ISV system hood, electrode feeders, and various other appurtenances. Plan and elevation views of the test configuration are illustrated in Figures 3.1.1, 3.1.2, and 3.1.3. As indicated in these figures, the soil and simulated buried waste was placed in a trench arrangement. 
A four-electrode arrangement using a Scott-Tee transformer connection was employed in this test. For engineering-scale, the graphite electrodes were arranged in a square pattern with a $30 \mathrm{~cm}$ separation between neighboring electrodes. The two diagonally-opposed electrode pairs were therefore approximately $42.5 \mathrm{~cm}$ apart. The electrodes were centered on the trench for this test.

The trench was staged with its bottom surface located $30 \mathrm{~cm}$ below grade, bringing the top surface of the trench even with the grade elevation of the system. The starter path and bottom of the electrodes were set at grade elevation. Once staged, the starter path was covered with $7.5 \mathrm{~cm}$ of soil overburden. The overburden layer was then covered with two layers of Kaowool insulation. Each layer was approximately $61 \mathrm{~cm}$ square and $3 \mathrm{~cm}$ thick. $5 \mathrm{~cm}$ diameter cutouts were provided in these insulative layers to allow passage of the electrodes through the Kaowool.

There was some question during the planing stages of this test whether or not the volume and configuration of the containerized sludge "wastes" would be sufficient to generate a glass displacement event (GDE) representative of those experienced during large-scale ISV tests involving sealed containers. As a consequence, a $6 \mathrm{oz}$ factory-sealed can of hydrous, organic material (i.e., tomato paste) was staged below the simulated trench for this test, at a depth of 52.5 $\mathrm{cm}$ below grade. If no GDEs were experienced during processing of the trench, the test was to be continued until this canister was effected by the ISV meit.

\subsubsection{Test Instrumentation}

Type " $\mathrm{C}$ " and " $\mathrm{K}$ " thermocouples were used to monitor the downward and outward growth of the melt front. Plan and elevation views indicating the placement of these thermocouples are provided in Figures 3.1.1, 3.1.2, and 3.1.3. This arrangement provides an extensive map of the

thermal progression and shape of the melt. A total of 27 thermocouples were placed in and around the target vitrification zone. Fourteen of these thermocouples were type " $C$ " and therefore provided readings well into the body of the melt. The remaining 13 thermocouples were type " $\mathrm{K}$ ".

In addition to the soil/melt temperature measurements, thermocouples were placed at several locations on the hood and ring foundation. These hood and ring foundation surface temperature measurements, when combined with heat flux measurements at coincident locations, provide data on the thermal transients experienced by these members. Temperature and pressure measurements were taken of the air inlet and off-gas outlet streams to monitor the thermal performance of this system. 


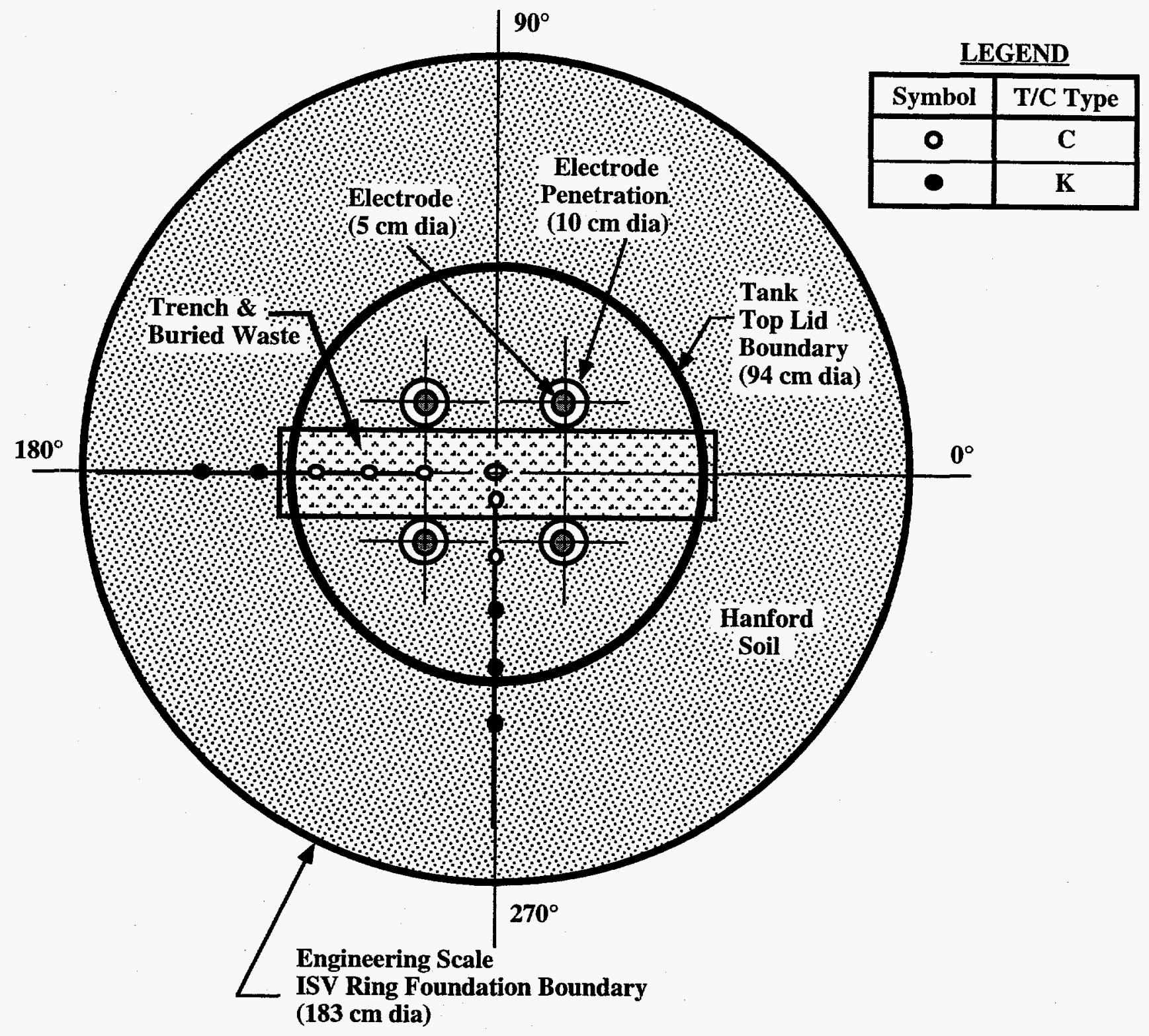

Figure 3.1.1. ORNL-ESBW-1 Test Configuration - Plan View of Staged Engineering-Scale ISV Test Setup. 


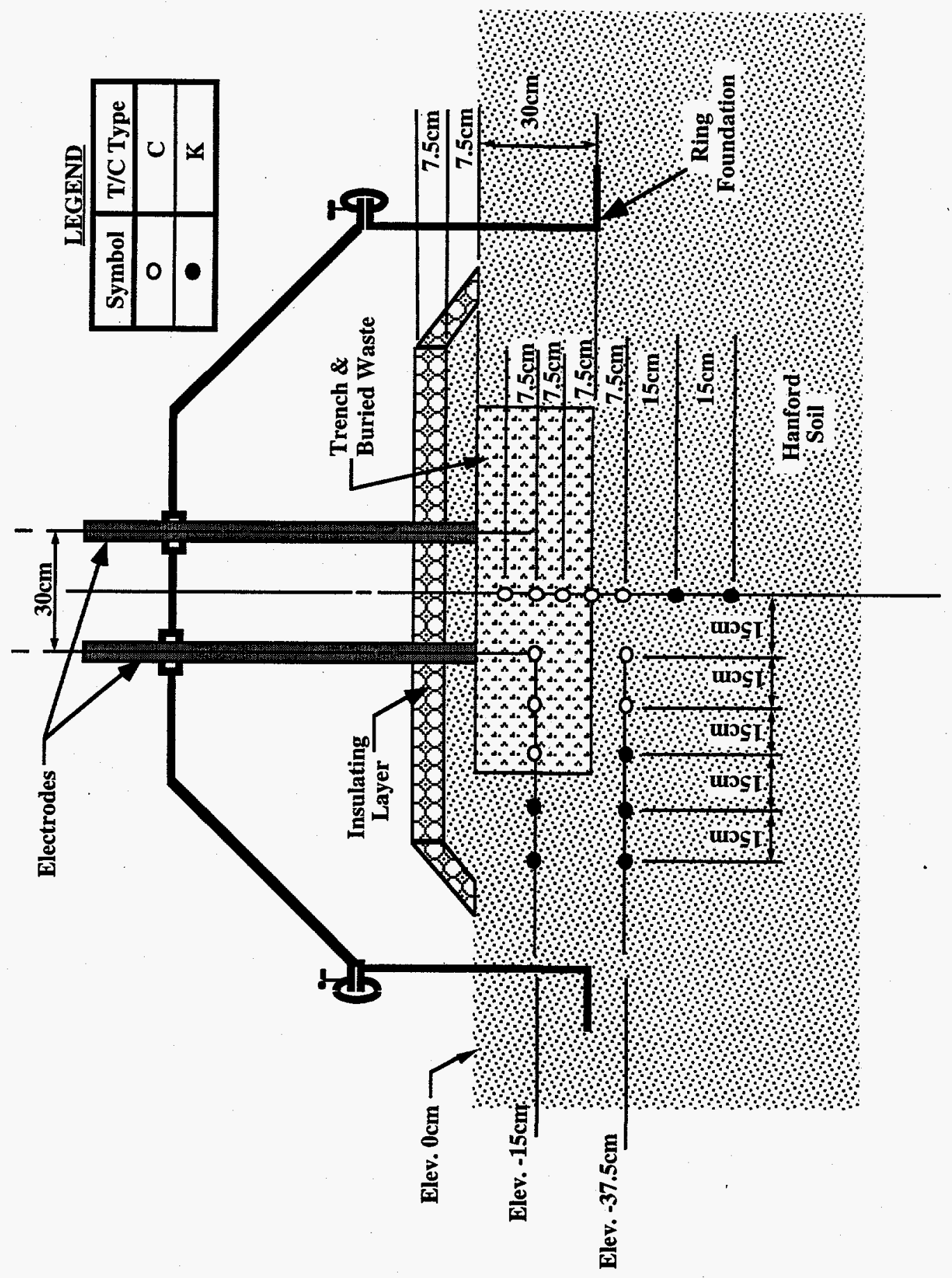

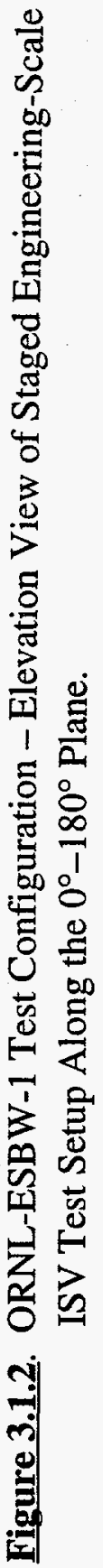




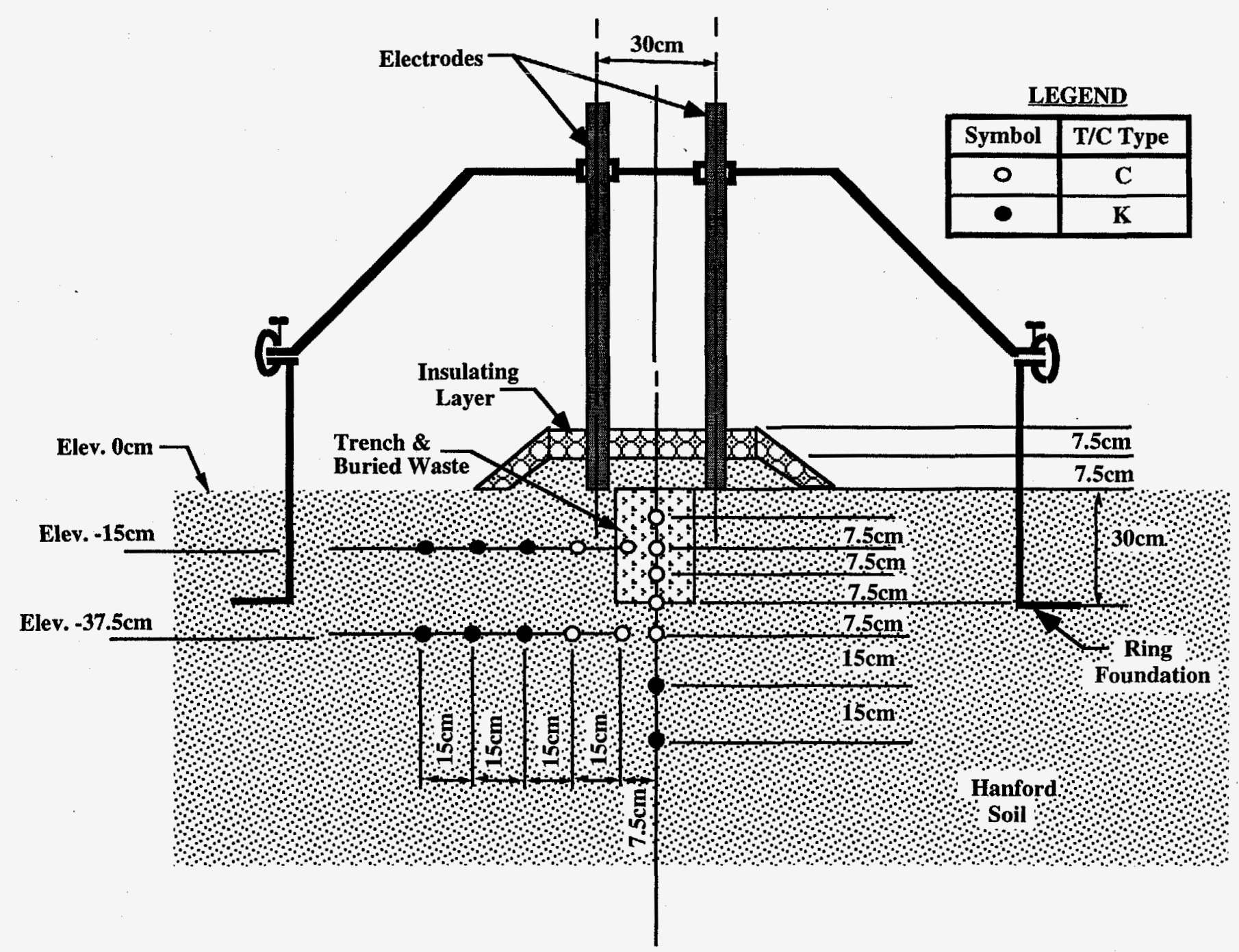

Figure 3.1.3. ORNL-ESBW-1 Test Configuration - Elevation View of Staged Engineering-Scale ISVTest Setup Along the $90^{\circ}-270^{\circ}$ Plane. 


\subsubsection{Test Start-Up and Operation}

The target steady-state power level for this test was $25 \mathrm{~kW}$ ( $12.5 \mathrm{~kW}$ per phase). This level was obtained by following a linear ramp-up in power for the first two hours of operation. Thus, the power was increased by $1 \mathrm{~kW}$ every 5 minutes for the first two hours of the test. Once the 25 $\mathrm{kW}$ level was reached, the power was maintained at this level for the duration of the test.

The test was initiated at 10:17:40 PST on February 3, 1995. The full $30 \mathrm{~cm}$ depth of the trench was processed in just over six hours of operation. There were no significant plenum pressure and temperature events experienced during this period. Apparently, the amount of volatile material staged, and the composition of the containers into which this material was placed were insufficient to generate a sudden rupture and consequent plenum pressure/temperature excursion. The seals on the vials must have provided a leak-before-rupture chain of events. While this was somewhat anticlimactic, the lack of any events also indicated that the entire volume of paper, cloth, metals, and plastics were processed without incident.

The test was continued beyond this point to involve the canister placed at the $52.5 \mathrm{~cm}$ depth. At approximately $21: 15$ that evening $(\Delta t \approx 11 \mathrm{~h}$ ), this canister failed catastrophically producing a significant GDE and the associated plenum pressure/temperature transients. A sizable volume of black smoke issued from the melt zone indicating the sudden processing of plastic material that must have been introduced to the melt as the steam bubble rose through the melt and upset the melt's configuration.

The test was concluded after approximately 11.25 hours of operation, at 21:36 PST on February 3, 1995.

\subsubsection{Phase Voltage, Current, and Resistance Results}

Graphs illustrating the electrical response of the ISV system for this test are presented in Figures 3.1.4 and 3.1.5. Figure 3.1.4 illustrates the phase voltage, current and resistance transients. As indicated here, the voltage and current transients exhibit the usual start-up behavior as the melt is being established. Thereafter, as the melt volume increases and the resistance to current flow decreases, the voltage drops to approximately $140 \mathrm{~V}$. The phase current exhibits the reverse trend, remaining low during the early phases of the test and climbing to about $100 \mathrm{~A}$ at the conclusion of the test. The phase resistance (computed as the ratio of phase voltage to current) is rather high early in the test and falls to about $1.5 \Omega$ at the end of the test. The good balance 
between phases achieved during this test is evident in Figure 3.1.4 by the overlap between the traces for $A \varnothing$ and $B \varnothing$ response.

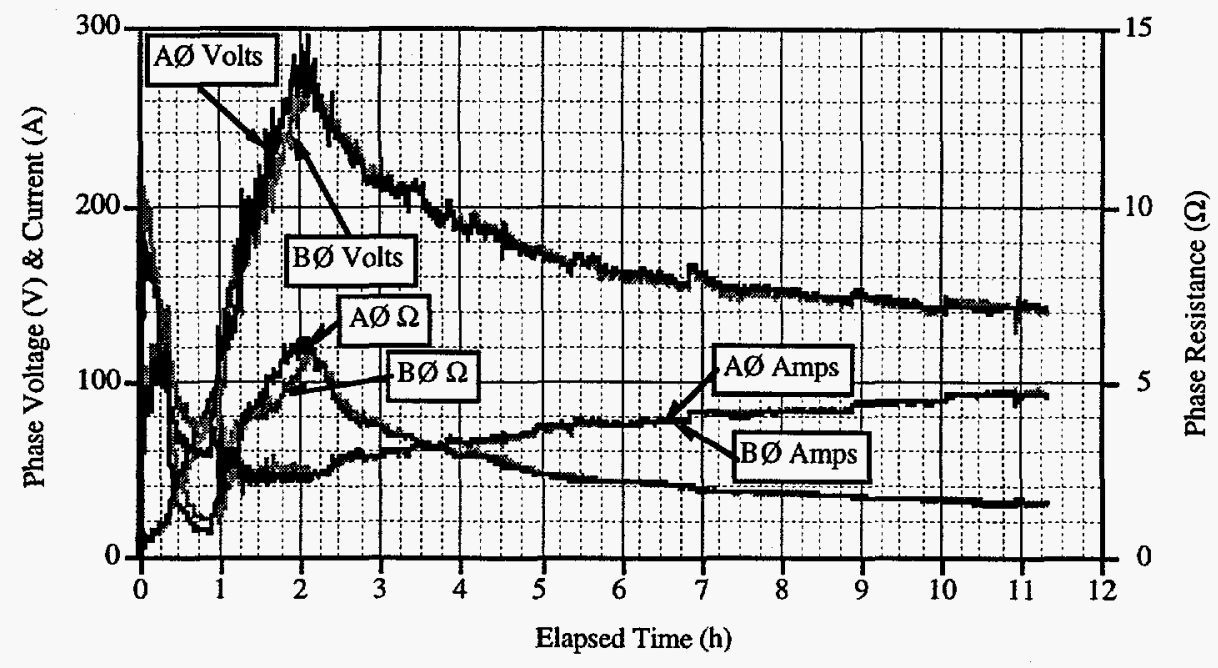

Figure 3.1.4. ORNL-ESBW-1 Phase Voltage, Current, and Resistance Transients.

Figure 3.1.5 illustrates the phase and total power transients experienced during this test, as well as the total electrical energy delivered to the system. The good balance between phases is also demonstrated by the results presented in this figure. The $A \varnothing$ and $B \varnothing$ power curves are virtually coincident. Also note that the $25 \mathrm{~kW}$ steady-state power level was effectively maintained throughout the test. As indicated in this figure, the total electrical energy delivered to the system during this test was approximately $261 \mathrm{kWh}$.

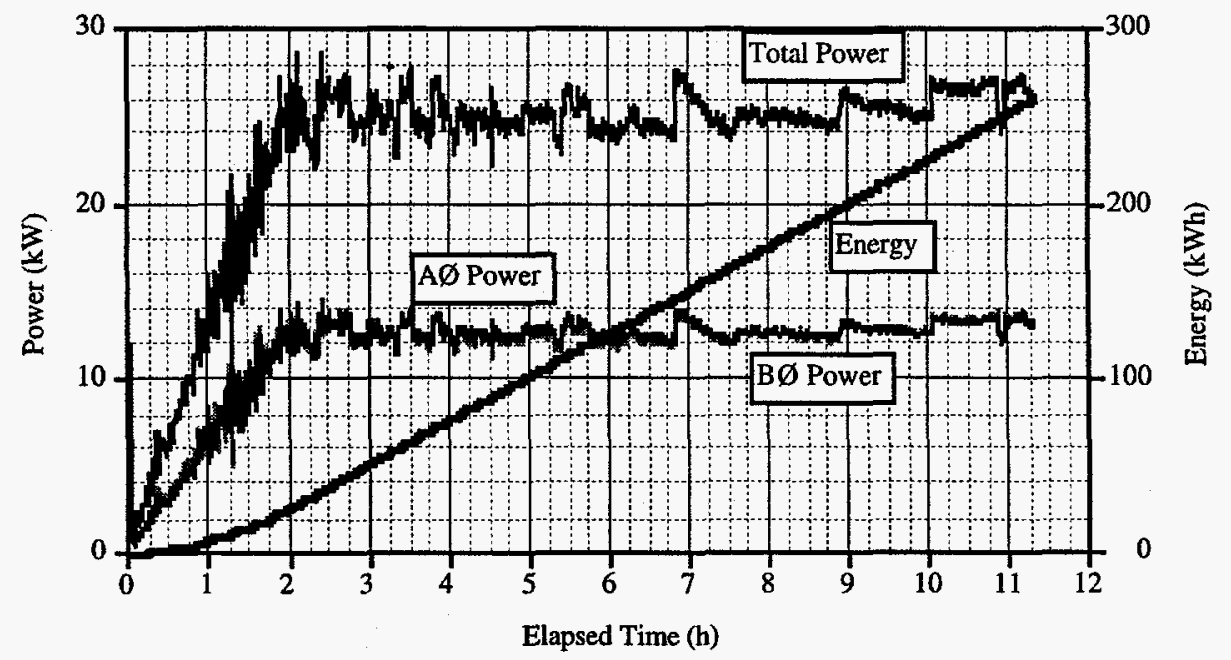

Figure 3.1.5. ORNL-ESBW-1 Phase Power, and Total Power \& Energy Transients. 
The "event" experienced at the end of this test is manifest in these figures as a slight glitch in the data just before $t=11$ hours. As will be discussed in a later section, this "event" produced a significant pressure and temperature excursion to the off-gas plenum. However, as these electrical data indicate, the electrical system was not adversely affected by the event.

\subsubsection{Electrode Depth and Soil Temperature Results}

The average electrode depth and centerline temperature transients are presented in Figure 3.1.6. The average electrode depth is obtained by averaging the four electrode depths.

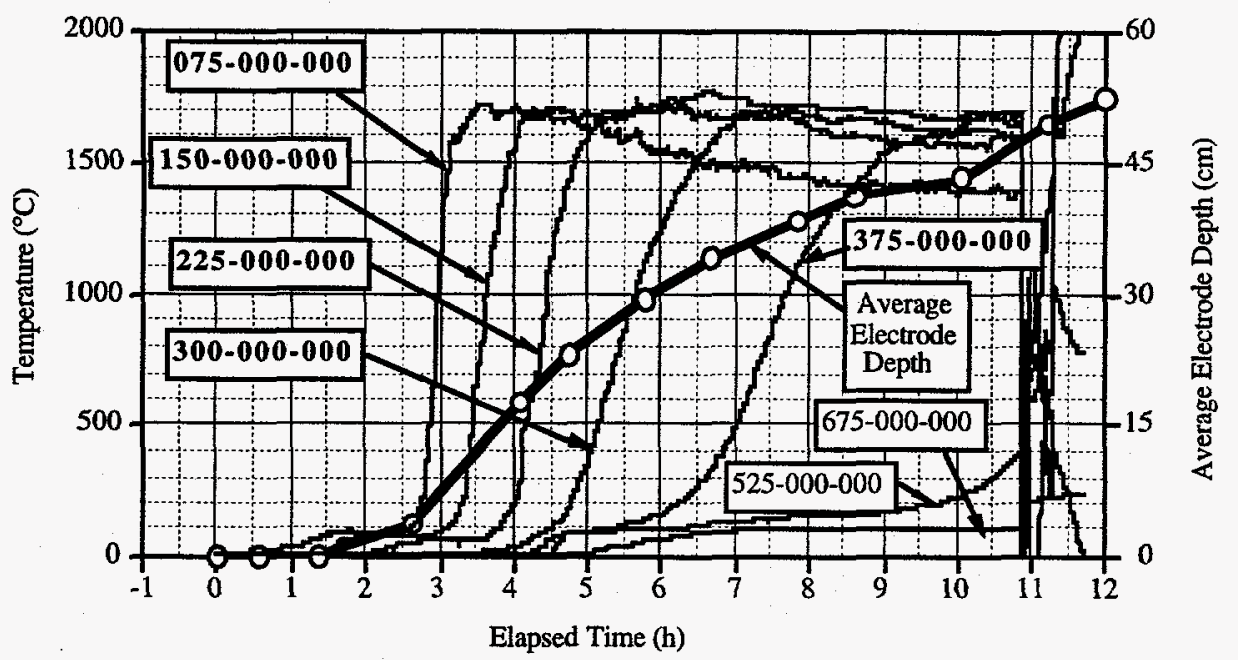

Figure 3.1.6. ORNL-ESBW-1 Electrode Depth and Centerline Temperature Transients.

As the data presented in Figure 3.1 .6 indicate, the full $30 \mathrm{~cm}$ depth of the trench was processed in just over 6 hours of operation. The centerline thermocouple data indicates that the bulk melt temperature hovered in the $1700^{\circ} \mathrm{C}$ range. Note that the centerline thermocouple at the $7.5 \mathrm{~cm}$ depth indicates a gradual decline in temperature after about five hours of the test. This is a manifestation of subsidence. At this point in the transient, this thermocouple protruded through the body of the melt and was measuring the temperature of the gas void located above the melt and below the Kaowool.

The erratic response of the centerline thermocouples indicated in Figure 3.1.6 at around 11 hours into the test is a manifestation of the "event" generated by the catastrophic failure of the can. The canister rupture and subsequent disruption of the melt essentially destroyed these thermocouples. Figures 3.1.7 and 3.1.8 present the thermocouple transients recorded by the 
lateral thermocouple bundles staged in this test. Figure 3.1.7 illustrates the thermocouple response at the $15 \mathrm{~cm}$ depth. Figure 3.1 .8 illustrates the thermocouple response at the $37.5 \mathrm{~cm}$ depth. Note that the thermocouples located along the $180^{\circ}$ axis coincide with the long axis (or length) of the trench, while those located along the $270^{\circ}$ axis coincide with the short axis (or width) of the trench. These results are consistent with those expected indicating a relatively uniform lateral growth pattern for the melt. The response of the 150-525-270 thermocouple would imply a slight preference for melt growth along the $270^{\circ}$ axis at this depth. This mild asymmetry leveled out by the time the melt advanced to the $37.5 \mathrm{~cm}$ depth, however, as the results of Figure 3.1 .8 indicate. The discrepancy in response between the two type "C" thermocouples 375-150-180 and 375075-270 would indicate a slight preference for the melt to grow along the $180^{\circ}$ axis. This difference is probably insignificant however, and is likely within the limits of accuracy and responsiveness of these thermocouples.

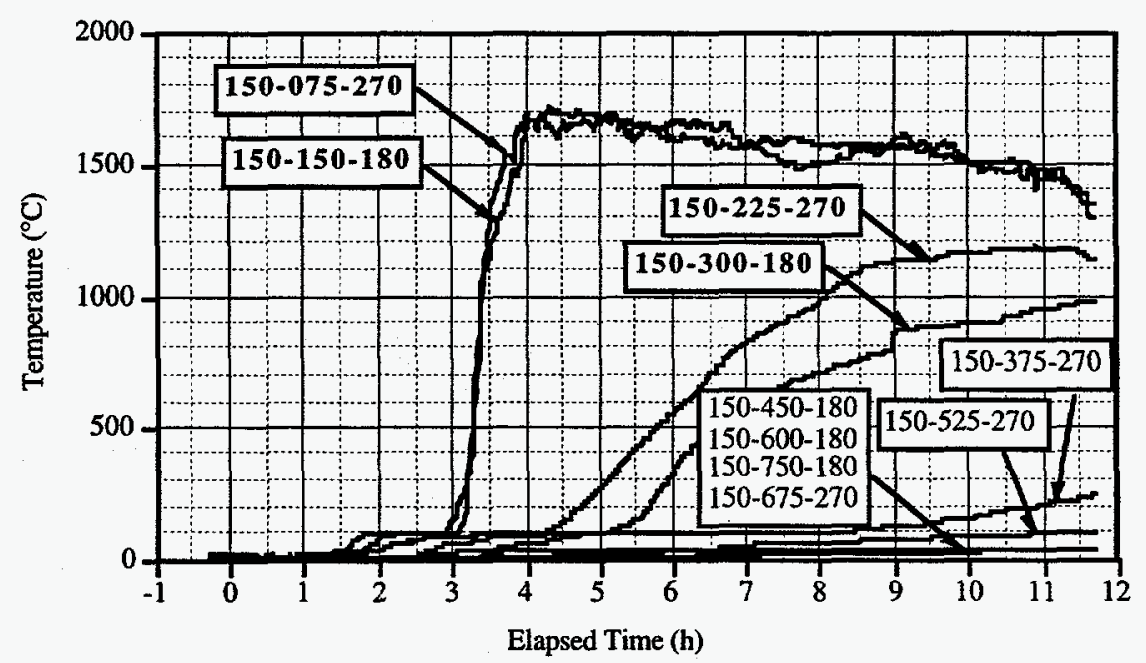

Figure 3.1.7. ORNL-ESBW-1 Thermocouple Transients at the $15 \mathrm{~cm}$ Depth. 


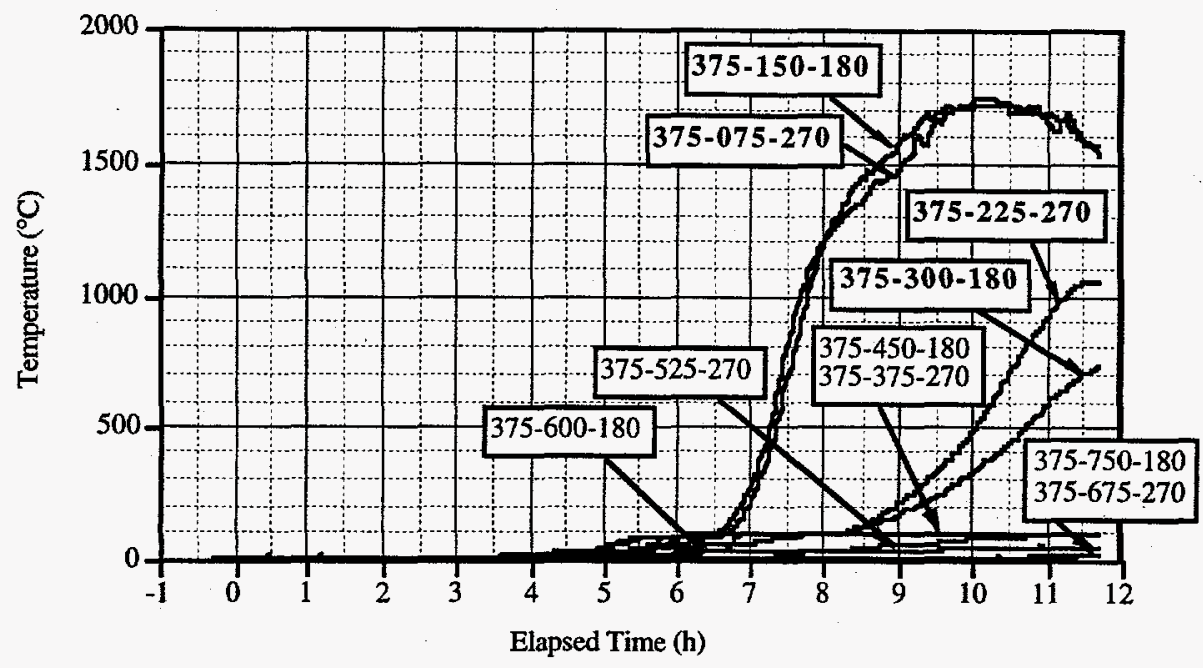

Figure 3.1.8. ORNL-ESBW-1 Thermocouple Transients at the $37.5 \mathrm{~cm}$ Depth.

\subsubsection{Plenum Pressure and Temperature Results}

The data obtained for the plenum pressure and temperature transients realized during this test are presented in Figure 3.1.9. The sharp drop in pressure indicated at approximately 6.5 hours into the test is a reflection of the operator closing-down the off-gas inlet valve to reduce the off-gas flow rate. This was done in an attempt to increase the sensitivity of the system to any subtle pressurization events that might be occurring due to rupture of the vials, but was masked by the flow through the system. As these data indicate however, if there were any pressure pulses produced as a result of vial rupture, they were still within the noise level. Note though, that the plenum temperature exhibited a rapid increase of approximately $15^{\circ} \mathrm{C}$ as a consequence of the reduced off-gas flow through the hood.

This figure clearly shows the pressure and temperature response to the "event" that occurred at the end of this test. The plenum pressure spiked from a nominal value of -2.50 inches water to -0.50 inches, a 2.0 inch rise. Similarly, the plenum temperature rose roughly $65^{\circ} \mathrm{C}$ to about $180^{\circ} \mathrm{C}$. These results are indicated more clearly in Figure 3.1.10 and 3.1.11 where the range of the time trace has been reduced to accentuate the temporal nature of the event. The sampling rate used during this transient was 2 seconds. As these figures indicate, the pressure response of the system was considerably faster than this. The pressurization aspects of this event were over in a few seconds. Therefore, unless the peak happened to occur at a sampling time, it was likely lost. The temperature transient was considerably slower, however. 


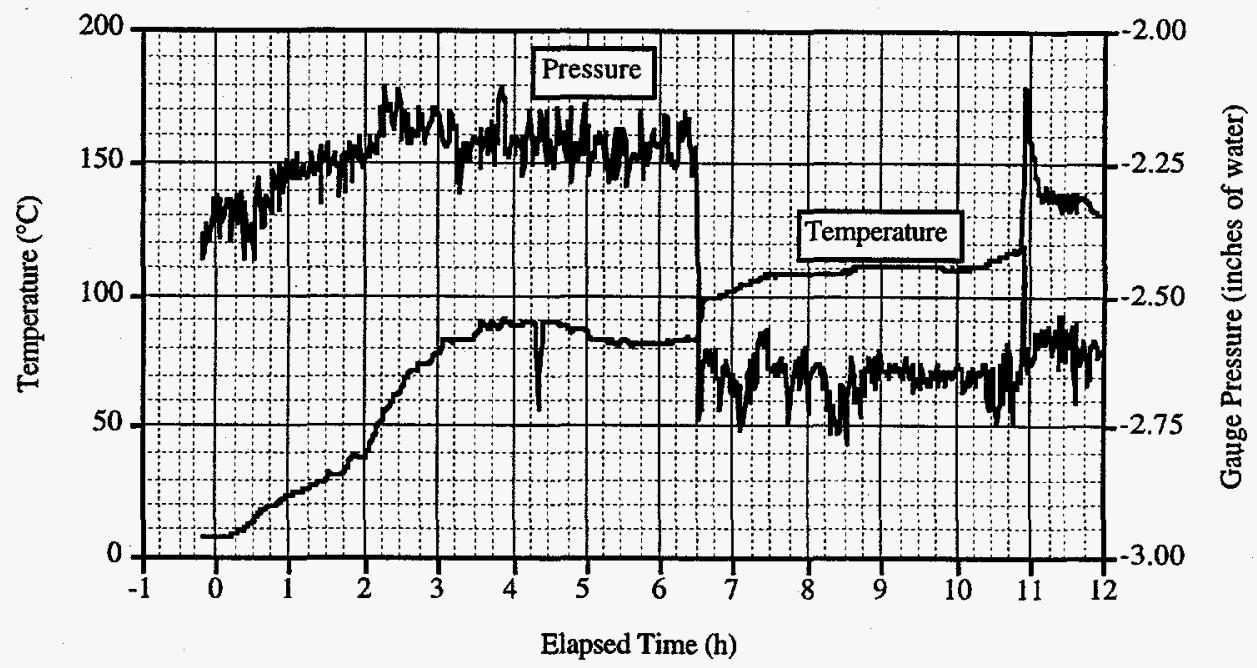

Figure 3.1.9. ORNL-ESBW-1 Plenum Pressure and Temperature Transients.

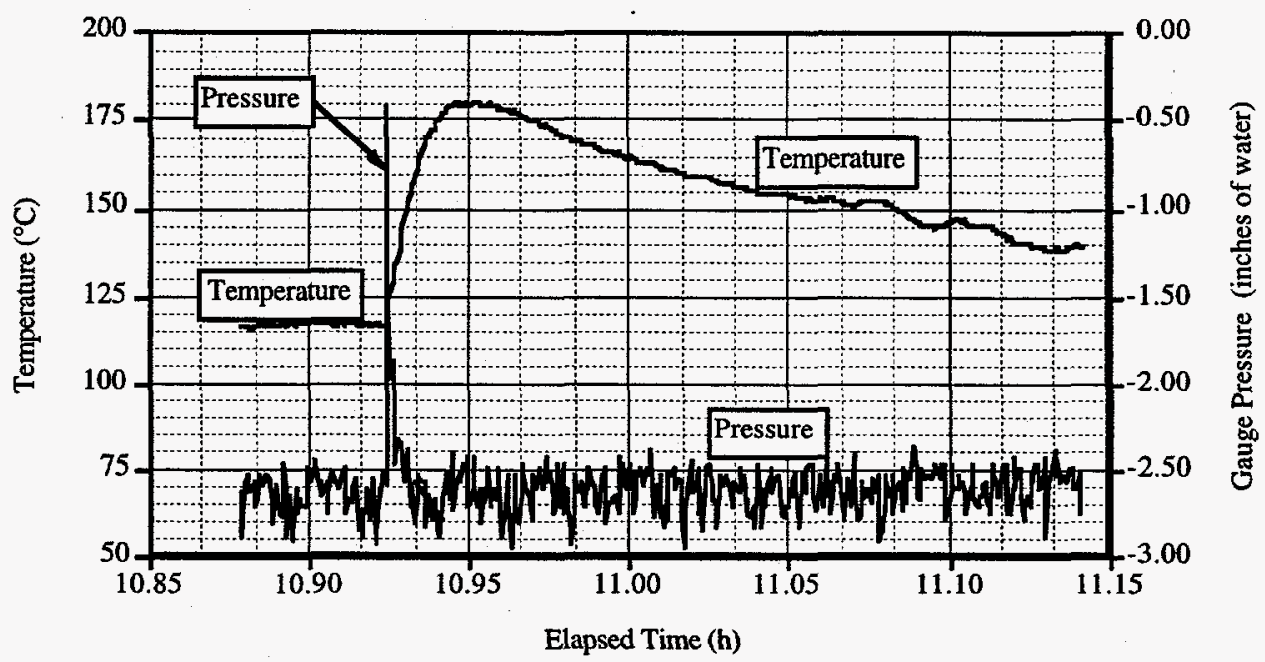

Figure 3.1.10. ORNL-ESBW-1 Plenum Pressure and Temperature Transients During the "Event". 


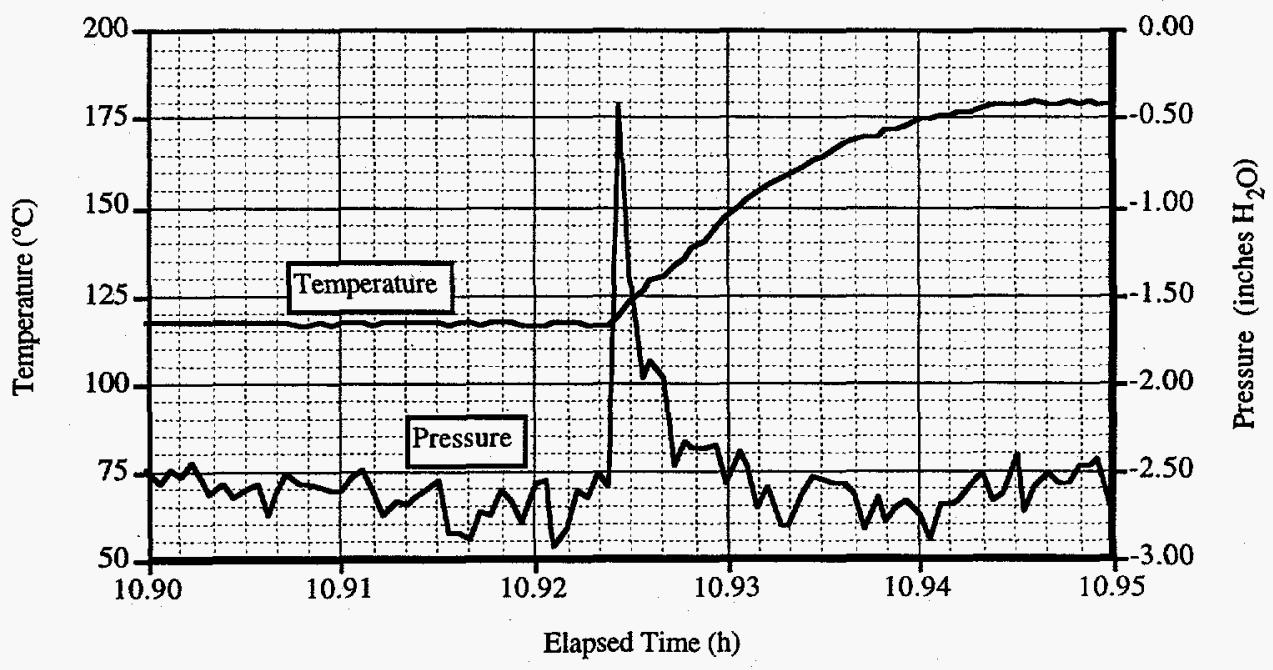

Figure 3.1.11. ORNL-ESBW-1 Plenum Pressure and Temperature Transients During the "Event" - Detail Time Trace

\subsubsection{ISV Hood Heat Flux and Temperature Results}

Figure 3.1.12 illustrates the off-gas hood and ring foundation temperature and heat flux transients realized during this test. In addition, the plenum and ambient temperatures are also plotted in this figure. As might be expected, the off-gas hood surface temperature was greater than that of the ring foundation. The heat flux data indicates just the opposite, however -- the heat flux out the ring exceeded that out the hood. This is a consequence of the orientation of the ring relative

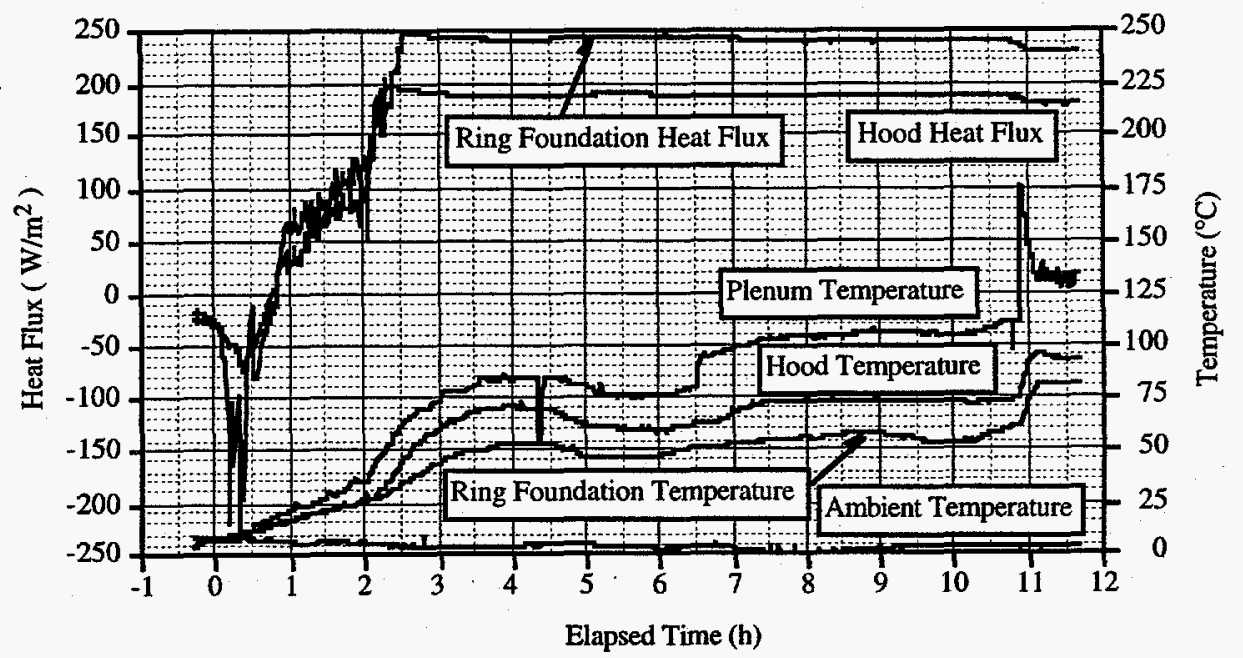

Figure 3.1.12. ORNL-ESBW-1 Off-Gas Hood Skin Temperatures and Heat Transfer. 
to that of the hood. The vertical surface of the ring presents a more optimal orientation for heat transfer. As these data indicate, the heat flux off the ring was approximately $240 \mathrm{~W} / \mathrm{m}^{2}$ while that off the hood was approximately $190 \mathrm{~W} / \mathrm{m}^{2}$. Multiplying these fluxes by their respective surface areas indicates that approximately $1.5 \mathrm{~kW}$ was lost as heat through these surfaces. This is $6 \%$ of the total energy budget for the system.

\subsubsection{ISV Block Statistics}

Figure 3.1.13 was obtained from a photograph of the block produced in this test. Overall, this block is rather typical of those produced at the engineering scale. The protrusion evident extending out the right side of the block in this figure is the remnant of the trench material that has not been completely incorporated into the melt.

A $270 \mathrm{~kg}$ block was produced in this test. As indicated previously, $261 \mathrm{kWh}$ were consumed to produce this block. Therefore, the specific energy consumption for this test was 0.97 $\mathrm{kWh} / \mathrm{kg}$. ISV melts performed at the engineering-scale typically consume $1 \mathrm{kWh} / \mathrm{kg}$.

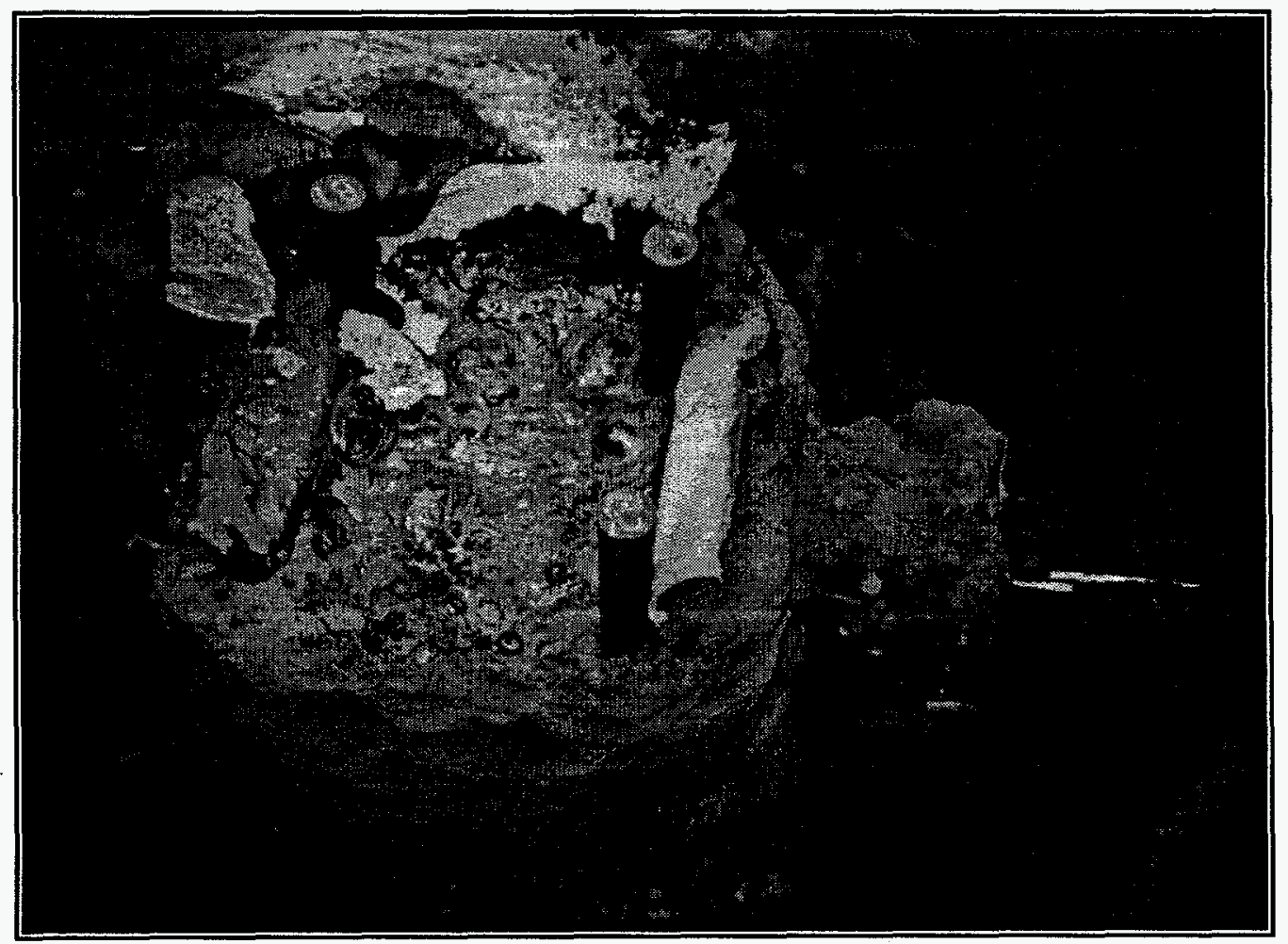

Figure 3.1.13. ORNL-ESBW-1 Block 


\subsubsection{Test Retrospective}

In this ORNL-ESBW-1 test, a scaled-down version of an ORNL SWSA-6 buried waste trench was processed using ISV. Scaling was based on the ratio of electrode separations between the large-scale and engineering-scale ISV systems. This resulted in a 15:1 scale factor for each lineal dimension. The simulated trench was loaded with an assortment of sealed glass and plastic vials and sample bottles. These bottles were filled with varying amounts of soil and water, in order to introduce the potential for rapid pressurization and failure of the sealed containers and subsequently, to a scaled-down version of a glass displacement event. In addition, a significant quantity of wood, paper, and metal scrap was staged to represent typical loadings of these materials in the actual buried waste trenches.

The full depth of the target vitrification zone was processed without incident in this test. The sealed containers were apparently unable to maintain their integrity to a high enough pressure and temperature to finally fail catastrophically when in close proximity to the advancing melt front. Instead, the containers apparently leaked far enough in advance of the melt front to allow their contents to be volatilized and vented-off in a non-catastrophic manner.

The combustibles staged in the simulated buried waste trench in this test did confirm that a relatively high loading of paper, plastic, wood, and metal can be accommodated without consequence to the ISV system.

In anticipation of this result, a factory-sealed $6 \mathrm{oz}$ steel canister of hydrous, organic matter was staged well below the bottom surface of the simulated buried waste trench. Melting was continued beyond the staged trench to process the canister. This canister did fail catastrophically, producing a significant pressure and temperature excursion in the ISV off-gas hood. While significant, the pressure and temperature was easily accommodated by the hood and its associated pressure-relief systems. This experience prompted the follow-on tests, in which the loading and instrumentation characteristics of these canisters were explored further. 


\subsection{ORNL-ESBW-1a TEST}

Processing the simulated buried waste trench in the ORNL-ESBW-1 test produced no discernable pressure and/or temperature transients. The entire target vitrification zone was processed in a rather uneventful manner. The melt proceeded to the $30 \mathrm{~cm}$ trench depth in just under 6 hours of operation. While this bodes well for the ability to process a relatively large volume-fraction of combustible wastes, the ORNL-ESBW-1 test did not produce the desired number of pressure and temperature events in the off-gas plenum.

At the outset, it was thought that the sealed glass vials would survive until they were sufficiently close to the melt as to produce "interesting" results. This, combined with their availability in a wide range of sizes and volumes, made them the containers of choice for the ORNL-ESBW-1 test. They did not perform as expected, however. The 6 oz canister staged at $52.5 \mathrm{~cm}$ did produce a measurable plenum pressure/temperature transient, however.

To assess whether this approach will prove efficacious, a series of "mini-melt" tests were conducted. In each of these "mini-melt" tests, an array of sealed metal cans were processed using ISV. The resultant pressure and temperature transients experienced by both the cans and the offgas plenum region were monitored during the course of the test. Test ORNL-ESBW-1a test represents the first in this series of "mini-melts." In this test, $4 \mathrm{oz}$ (nominal) sealed metal cans were used to contain the simulated wastes in an attempt to produce a GDE.

\subsubsection{Test Configuration}

The same hybrid engineering/pilot-scale system used in ORNL-ESBW-1 was employed for this test. An array of nine sealed metal cans were staged in the target vitrification zone. Plan and elevation views illustrating the canister placement are provided in Figures 3.2.1 and 3.2.2. As indicated in this figure, the cans were staged in three layers with the 3 cans on each layer centered on the vertical centerline of the setup. In addition, the cans were placed in different orientations with respect to the vertical centerline of the configuration. Two cans were placed with their long axis parallel to the vertical centerline of the arrangement. The remaining can was staged with its long axis parallel to the horizon. The top layer of cans were set with their uppermost extent located $15 \mathrm{~cm}$ below grade. The middle layers were staged at the $-30 \mathrm{~cm}$ depth. The bottom layer of cans were staged with their uppermost extent at the $-45 \mathrm{~cm}$ elevation.

Each can was filled with a specified quantity of soil. The remaining volume in the can was filled with water and/or air. The cans measured approximately $5.2 \mathrm{~cm}$ in diameter and $6.75 \mathrm{~cm}$ in 
height. Therefore, the can volume was approximately $143 \mathrm{~cm}^{3}$. Actual volumes were slightly different as the dish in the can lids was not accounted-for in these measurements. The can wall thickness was $0.3 \mathrm{~mm}$. These were to represent the contents of a $55 \mathrm{gal}$ drum at full scale. Therefore, they were filled with $117 \mathrm{~cm}^{3}$ of soil, leaving a $62 \mathrm{~cm}^{3}$ void volume in the can (assuming $30 \mathrm{vol} \%$ porosity for the soil). This left a head space in the can equivalent to that of a $55 \mathrm{gal}$ drum at full scale ( $55 \mathrm{gal} / 15^{3}=62 \mathrm{ml}$ for the $15: 1$ full-to-engineering scaling ratio). To assess the sensitivity of plenum pressure and temperature response to the catastrophic release of steam, the cans were loaded with different quantities of water prior to staging in the target vitrification zone. In addition, to assess the sensitivity of the can's response to the quantity of volatile material contained, each layer of cans was filled with a different quantity of water. Each can on the $15 \mathrm{~cm}$ depth layer contained $72 \mathrm{ml}$ of water. The cans placed with the can at the $30 \mathrm{~cm}$ depth contained $62 \mathrm{ml}$ water. Finally, the bottom layer of cans (staged at the $45 \mathrm{~cm} \mathrm{depth),}$ contained $52 \mathrm{ml}$ of water.

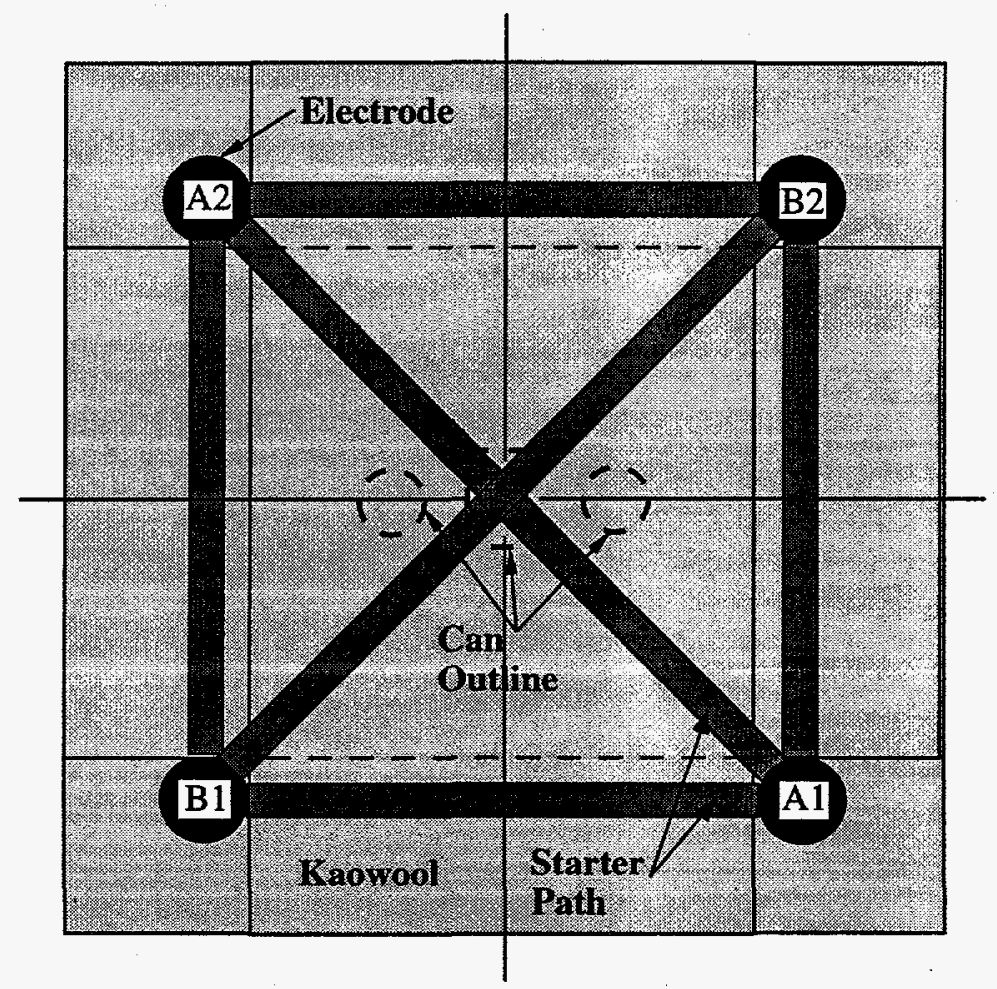

Figure 3.2.1. ORNL-ESBW-1a Test Configuration - Plan View of the Staged EngineeringScale ISV Test Setup. 


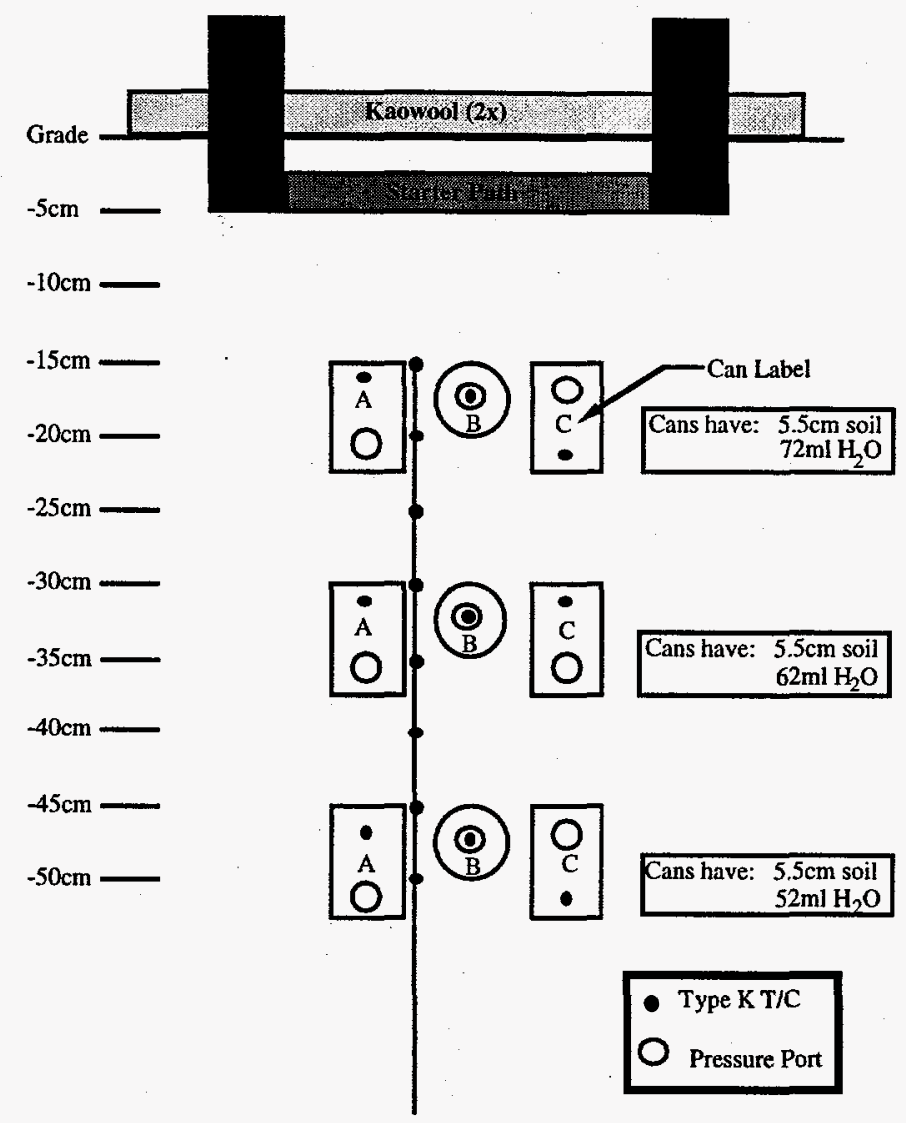

Figure 3.2.2. ORNL-ESBW-1 a Test Configuration - Elevation View of Staged Engineering-Scale ISV Test Setup.

\subsubsection{Test Instrumentation}

As indicated in Figure 3.2.2, an array of Type " $K$ " thermocouples was places along the vertical axis of the setup to provide a means to monitor the melt's progression. In addition, each can was instrumented to measure its internal pressure and temperature. The temperature measurement was obtained with a Type " $\mathrm{K}$ " thermocouple inserted into the can through a swagelok fitting welded to the can's sidewall. The pressure measurement was obtained by connecting tubing to a swagelok port welded to the can's sidewall. This arrangement is illustrated in Figure 3.2.3. A 3 foot length of $1 / 4^{\prime \prime}$ O.D. stainless steel tubing was connected directly to the pressure fitting on the can. This length of tubing was then connected with high pressure Teflon tubing to a pressure transducer located just outside the ring foundation of the ISV off-gas hood system. The electrical signal generated by the transducer was fed to the DAS for monitoring and storage. 
In addition to the canister instrumentation and centerline thermocouple array, the usual plenum pressure, temperature, and heat flux measurements were monitored and recorded for this test. These have been described previously in Section 3.1.2 for test ORNL-ESBW-1. The seal pot and containment spray pressure mitigation systems were also configured as per the ORNLESBW-1 test.

Can pressure, can, soil and off-gas temperatures, and heat flux data were sampled and recorded at 30 second intervals throughout the test. Plenum pressure and temperature was sampled and recorded at 2 second intervals. Sampling at higher frequencies was precluded due to software limitations.

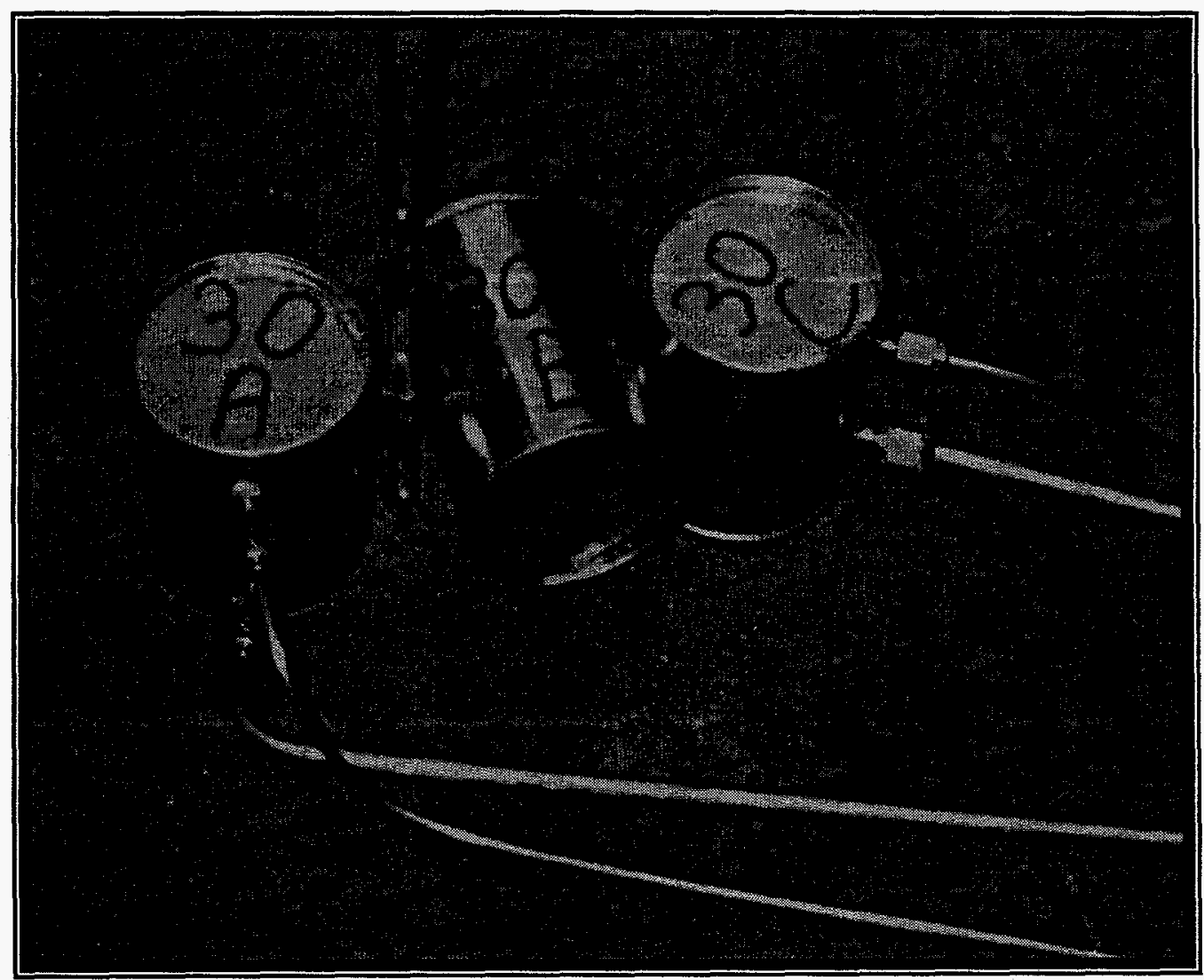

Figure 3.2.3. ORNL-ESBW-1a Test Canister Instrumentation Detail . 


\subsubsection{Test Start-Up and Operation}

The ORNL-ESBW-1 start-up transient and steady-state power level was targeted for this test. Thus, a linear power ramp of $1 \mathrm{~kW}$ increase every 5 minutes was followed for the first two hours of the test until the $25 \mathrm{~kW}$ total power level was attained. This $25 \mathrm{~kW}$ power level was maintained throughout the remainder of the test.

The test was initiated at 15:52 PST on March 7, 1995. Power was disrupted for approximately $1 / 2$ hour at $17: 36(\Delta t \approx 2.75 \mathrm{~h})$ due to an equipment malfunction in the silicon controlled rectifier (SCR) module of the electrical system. The faulty module was replaced and power resumed at 18:04 PST $(\Delta t \approx 3.1 \mathrm{~h})$.

As the can pressure transient data will indicate (Section 3.2.6.), all cans were processed in just under 9 hours of operation. During this time, there were no significant plenum pressure/temperature events realized. The test was continued beyond this point to exercise the water spray system and study its effect on plenum pressure and temperature. At 01:40 PST on March 8, $1995(\Delta t \approx 9.8 \mathrm{~h})$, power to the ISV system was terminated and the test concluded.

\subsubsection{Phase Voltage, Current, and Resistance Results}

Figure 3.2.4 presents the $A \emptyset$ and $B \emptyset$ voltage, current, and resistance transients experienced during this test. The power outage described associated with the SCR circuitry is clearly evident in this figure. At approximately 1.75 hours into the test, the power abruptly fell to zero as the SCR

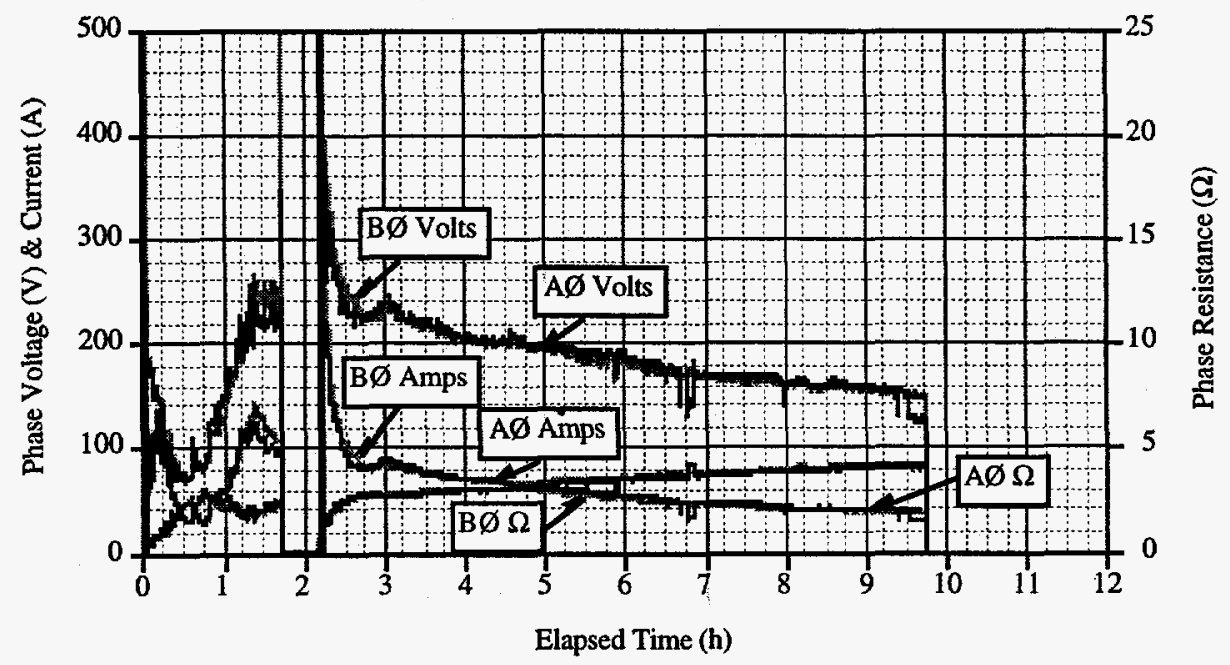

Figure 3.2.4. ORNL-ESBW-1a Phase Voltage, Current, and Resistance Transients. 
board malfunctioned. Operation was resumed approximately $1 / 2$ hour later after the necessary circuit boards were replaced. Thereafter, the electrical portion of this test continued without further complications. As the results in this figure indicate, the balance between phases was quite good throughout this test.

The phase power, and total power and electrical energy consumption transients are presented in Figure 3.2.5. Again, the results provided in this figure clearly indicate the good balance attained between the $\mathrm{A}$ and $\mathrm{B}$ phases of the system. Also, following the start-up transient and the equipment malfunction, the target $25 \mathrm{~kW}$ power level was also maintained throughout remainder of the test. As this figure indicates, a total of $210 \mathrm{kWh}$ was consumed during this test.

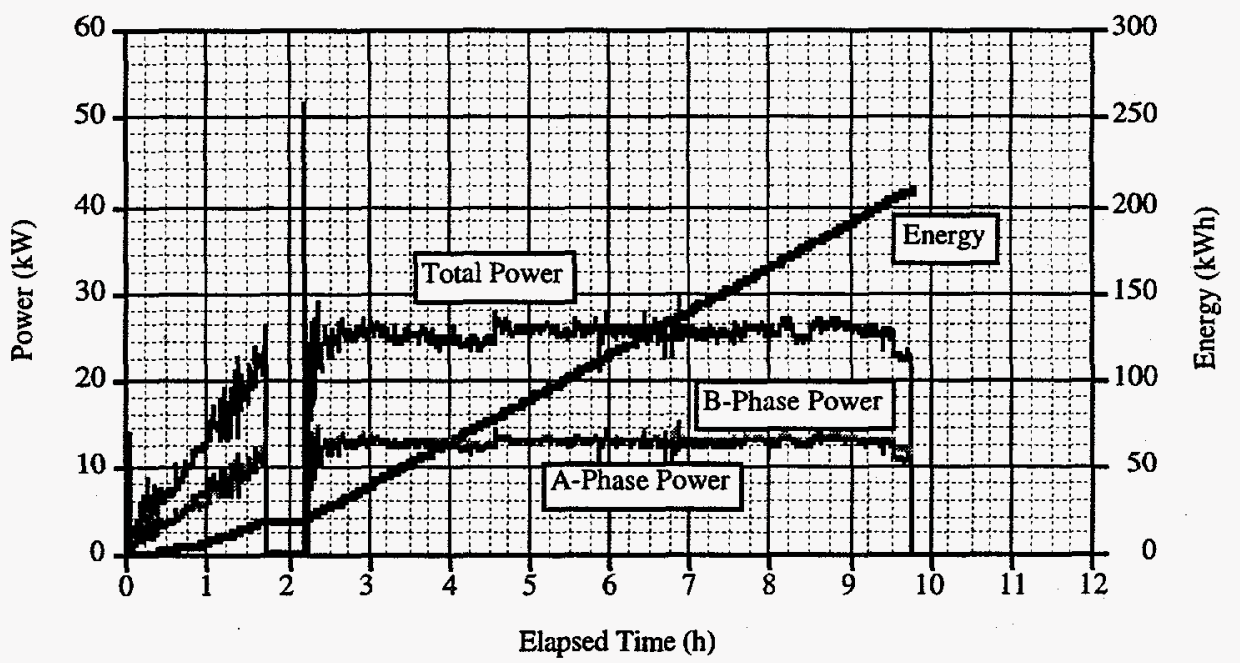

Figure 3.2.5. ORNL-ESBW-1a Phase Power, and Total Power \& Energy Transients.

\subsubsection{Electrode Depth and Soil Temperature Results}

Figure 3.2.6 illustrates the average electrode depth and centerline soil temperature transients realized during this test. Thermocouple 035-000-000 appeared to have malfunctioned during the test. Other than this though, these data are quite typical of those encountered during engineeringscale ISV melts. 


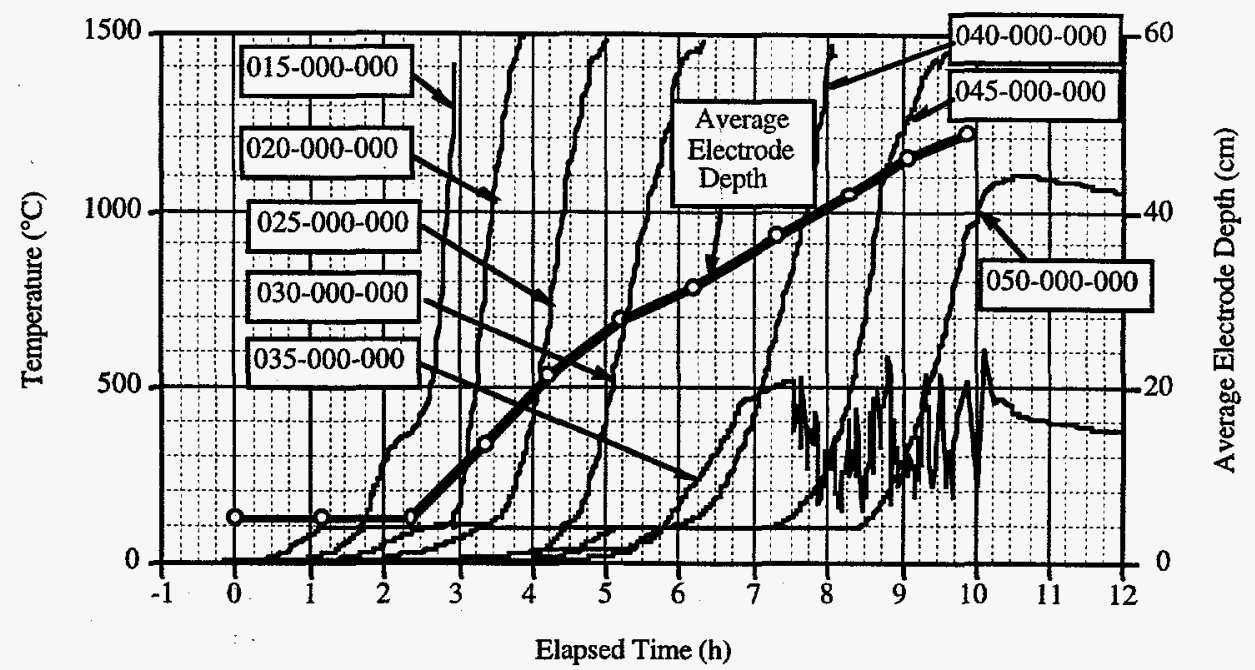

Figure 3.2.6. ORNL-ESBW-1a Electrode Depth and Centerline Temperature Transients.

\subsubsection{Canister Pressure and Temperature Results}

Figure 3.2.7 presents the pressure transients experienced by each of the nine cans staged in this test. As these results indicate, each of the cans built-up a significant pressure before their ultimate depressurization. Peak pressure in the range of 25 to $30 \mathrm{psig}$ were indicated. The buildup was rather gradual, however. 25 to $30 \mathrm{psig}$ pressure is more than enough to overcome the static head posed by the melt $(\approx 3$ psid for a $1 \mathrm{~m}$ deep melt). Consequently, the cans were apparently able to expel their steam in a controlled manner, giving it adequate time to vent around the melt.

Figures 3.2.8 through 3.2.10 provide a detail plot of the can pressure and temperature transients experienced at each of the three levels staged, as well as the appropriate centerline soil temperatures for that layer. Note that the can temperature response is between that of the two bounding centerline thermocouples for that layer. The can pressure rises in advance of significant temperature rise. In all cases however, the cans have essentially depressurized by the time the melt has progressed to the level of the cans. Apparently then, the seal provided by the lids and/or fittings on these cans is inadequate to withstand the melt's environment sufficiently to produce a catastrophic failure. 


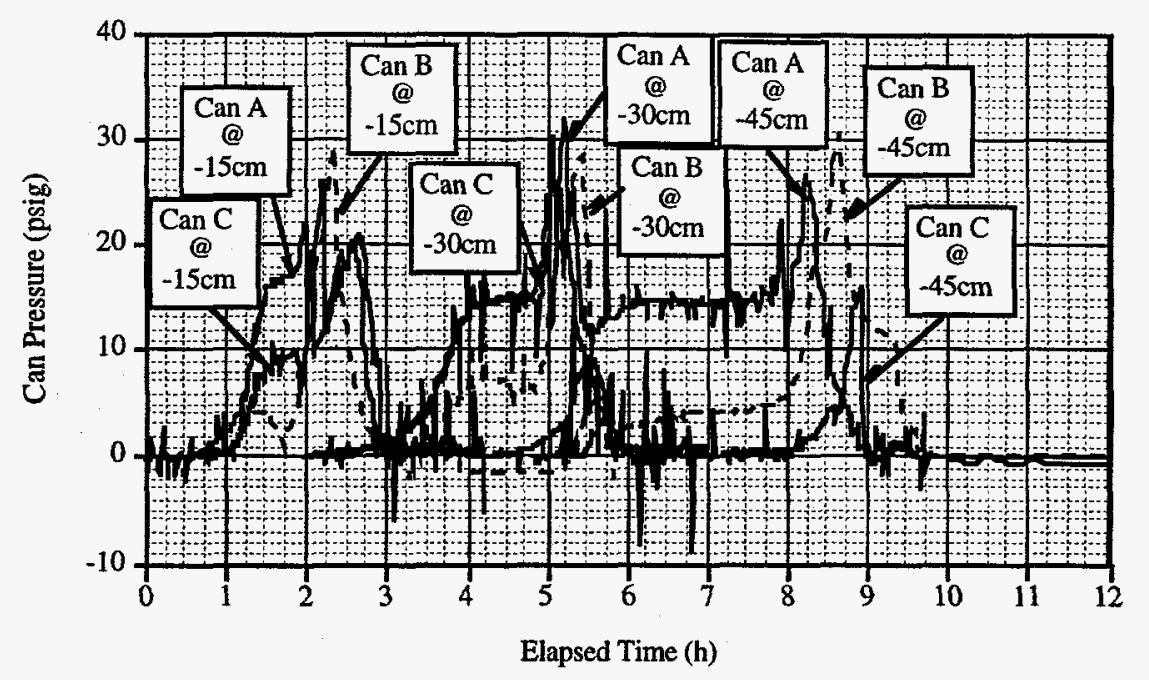

Figure 3.2.7. ORNL-ESBW-1a Canister Pressure Transients.

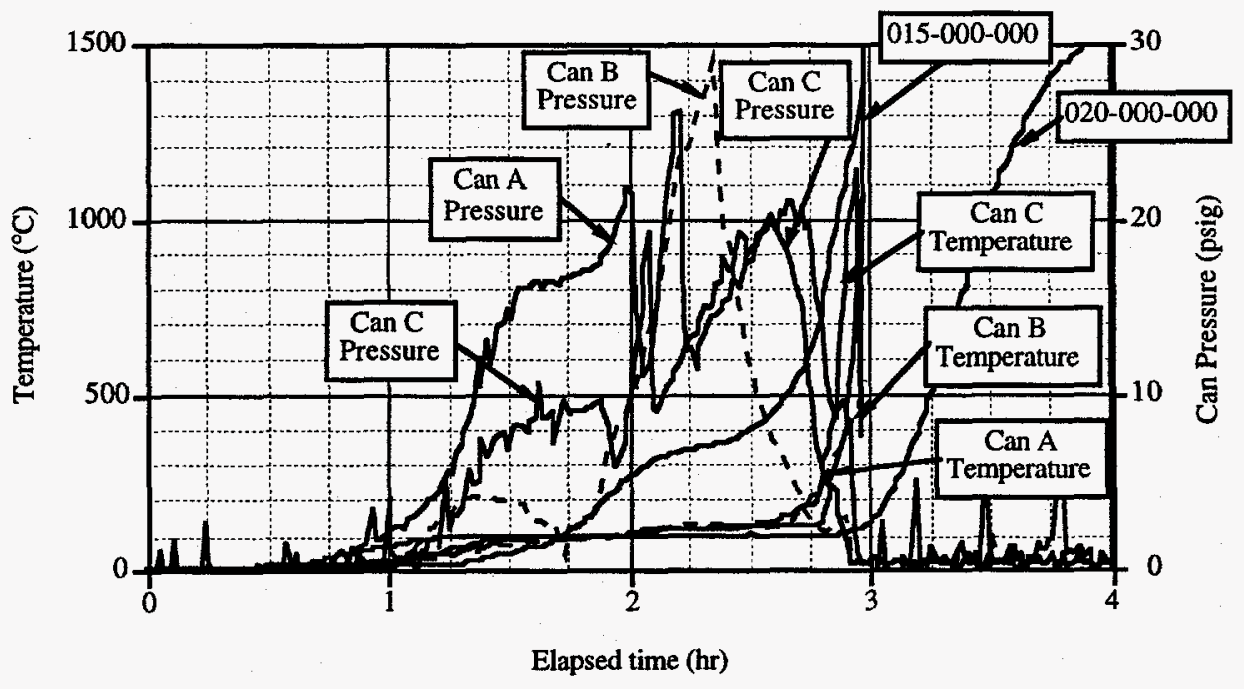

Figure 3.2.8. ORNL-ESBW-1a Pressure/Temperature Transients on the Upper Canister Layer. 


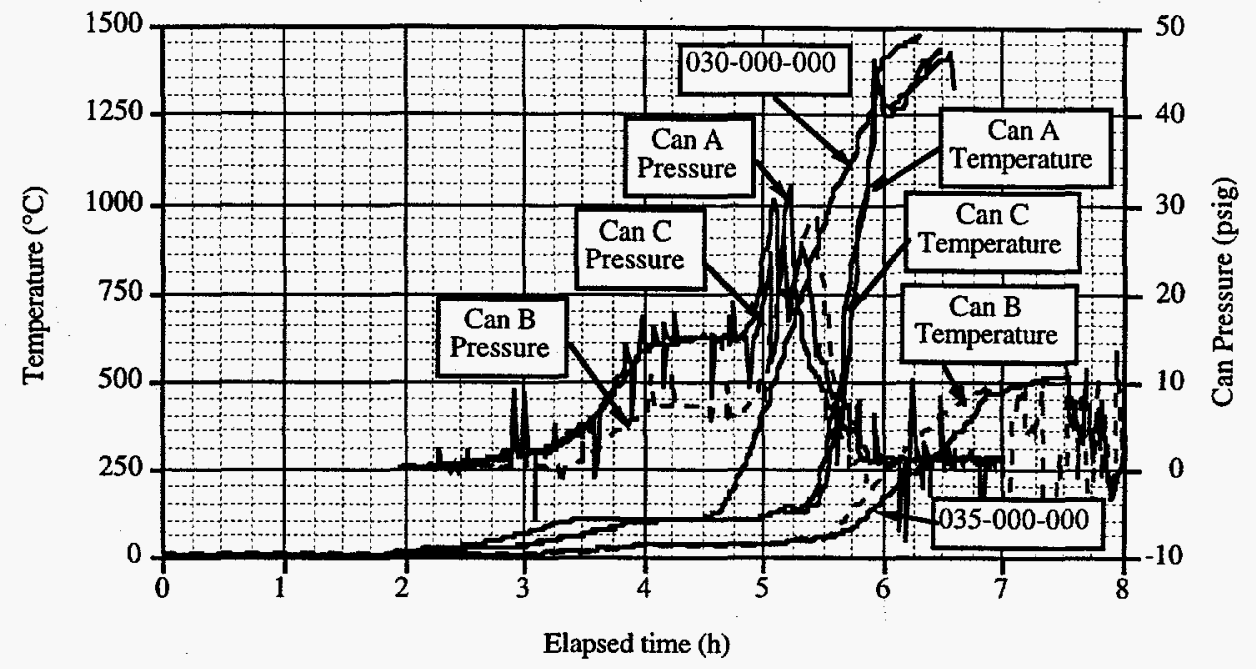

Figure 3.2.9. ORNL-ESBW-1a Pressure/Temperature Transients on the Middle Canister Layer.

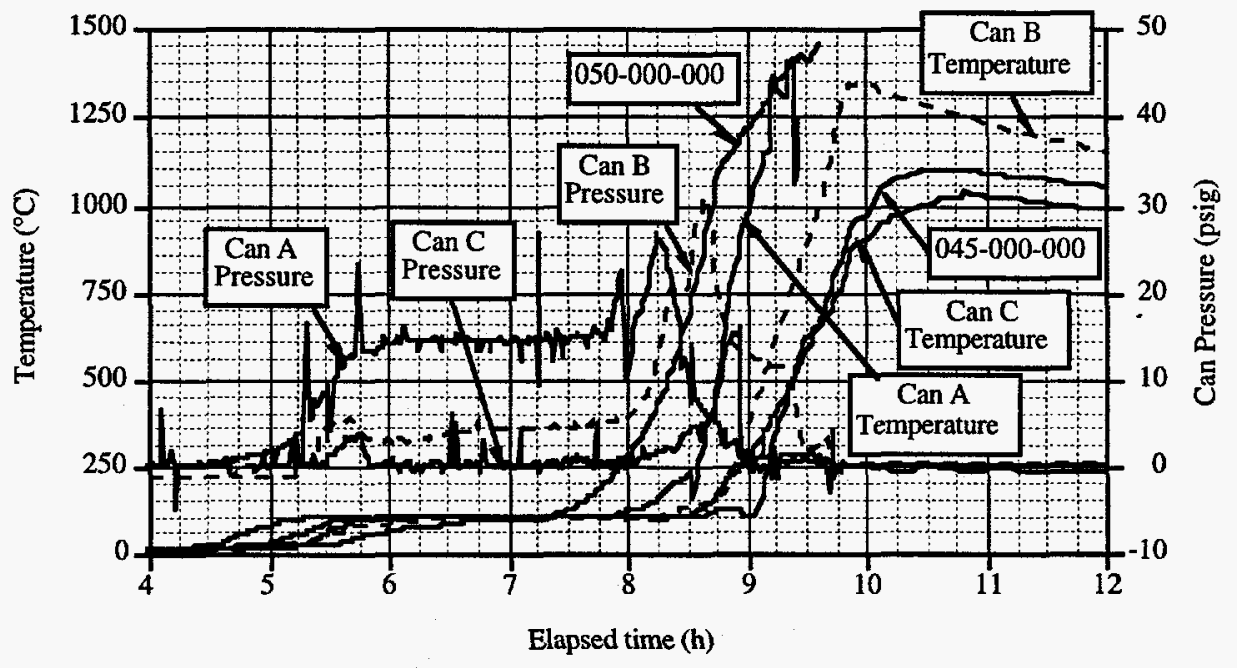

Figure 3.2.10. ORNL-ESBW-1a Pressure/Temperature Transients on the Lower Canister Layer. 


\subsubsection{Plenum Pressure and Temperature Results}

The plenum temperature transients experienced during this test are presented in Figure 3.2.11. As previously mentioned, there were no significant plenum pressure/temperature excursions realized during this test. At the conclusion of the test however, the plenum water spray system was purposely actuated to study the effect that this system's response had on the plenum pressure and temperature. The spray system was invoked in three passes. In the first application, the spray was introduced for 57.5 seconds. In the second and third applications, the spray system was actuated for 54 and 43 seconds, respectively. Figure 3.2.12 presents the results of this exercise. As these results indicate, the introduction of relatively cool spray water had a dramatic effect on the plenum temperature. Shortly after initiation of the spray, the plenum temperature fell roughly $20^{\circ} \mathrm{C}$. The plenum pressure also experienced a rapid drop immediately after spray actuation. However, this short term drop was followed by a rise in plenum pressure to levels above those that existed prior to actuation of the spray. This rise is attributed to a compression effect caused by the rapid conversion of water to steam. The rate of volatilization of this water and the volume that this steam occupies is greater than the rate of air/steam removal afforded by the offgas flow system. Consequently, the plenum pressure rises for a period while the off-gas flow

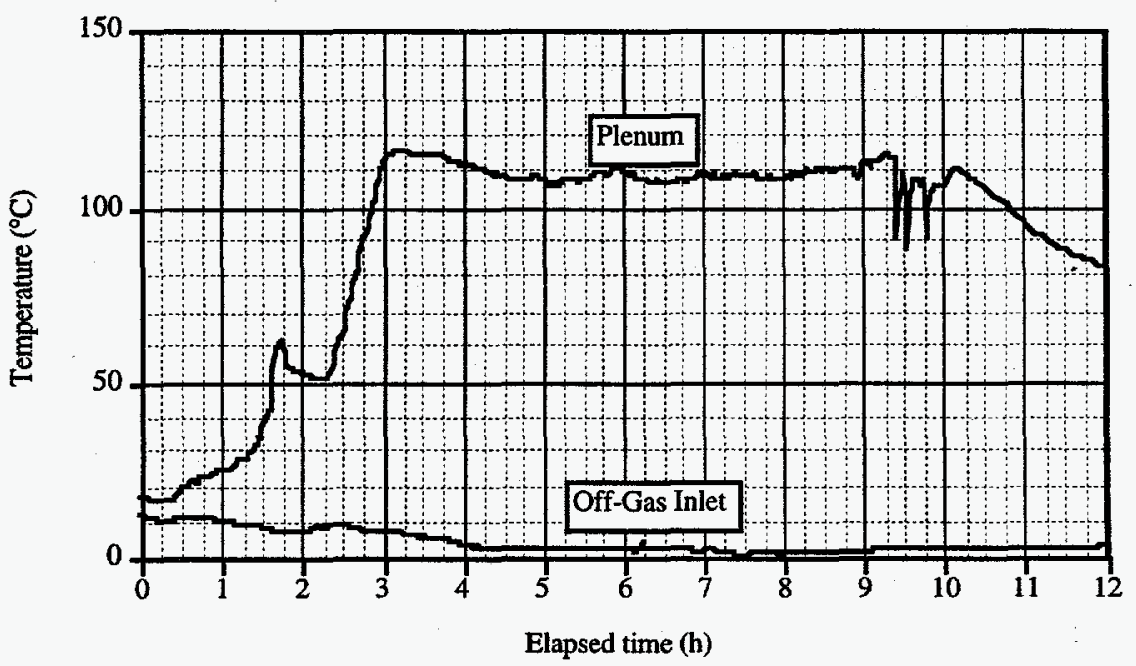

Figure 3.2.11. ORNL-ESBW-1a Plenum Pressure/Temperature Transients. 
works to catch-up to the transient. Once this is accomplished however, the plenum pressure falls back close to its original level. This response is likely sensitive to a number of factors. For example, the initial plenum pressure, temperature, and the water spray flow rate are all factors that will influence the plenum pressure/temperature dynamics. These factors must be kept in mind when considering the value of a containment spray system for mitigating transients of a different nature.

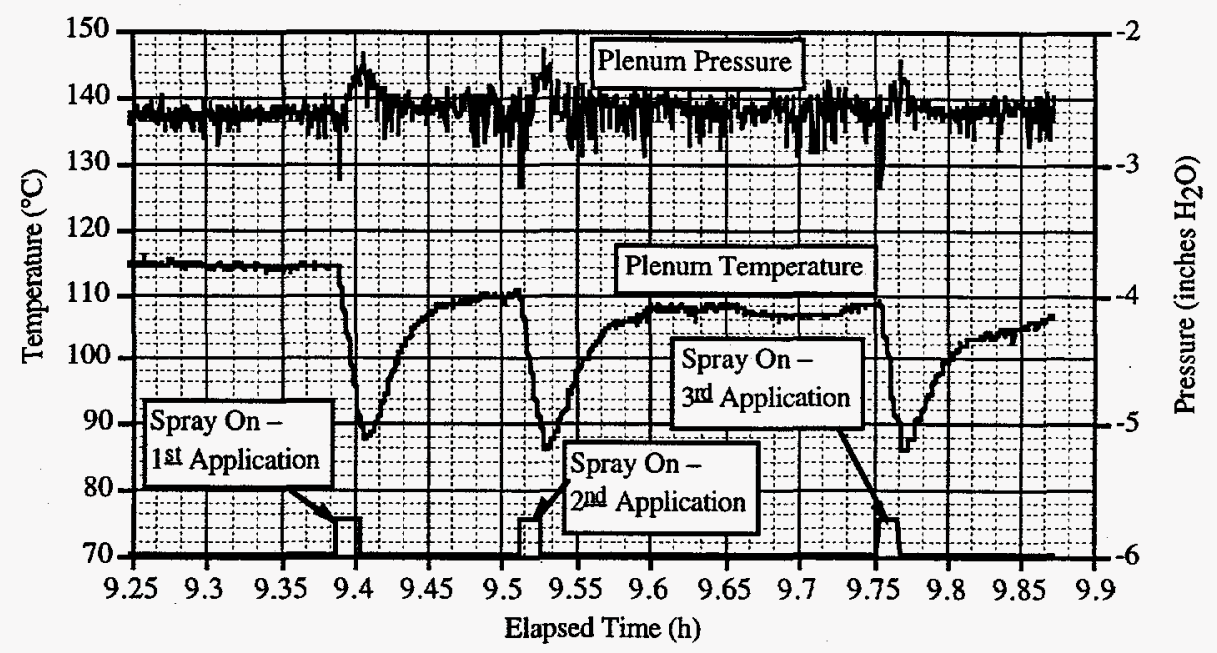

Figure 3.2.12. ORNL-ESBW-1a Plenum Pressure/Temperature Transients Following Spray Actuation.

\subsubsection{ISV Block Statistics}

A $205 \mathrm{~kg}$ block was produced in this test. As mentioned previously, this test consumed approximately $210 \mathrm{kWh}$ of electrical energy. Therefore, the specific energy consumption realized in producing this block was $1.02 \mathrm{kWh} / \mathrm{kg}$. This is slightly higher than that required to generate the ORNL-ESBW-1 block, but is comparable to nominal $1 \mathrm{kWh} / \mathrm{kg}$ associated with typical engineering-scale ISV blocks. 


\subsubsection{Test Retrospective}

This test involved the processing of an array of nine sealed steel canisters. Each canister was instrumented to measure and record its pressure and temperature transients during processing. The instrumentation was inserted into each can by means of swagelok fittings welded to the can's sidewall. Separate penetrations were provided for the thermocouple and pressure taps in each canister. The cans were loaded with varying quantities of soil and water to test the sensitivity of pressurization to loading level. Each can was sealed at the ISV site using a manually operated mechanical can sealer. This device produced a rolled and crimped seal around the lip of the can's circumference.

All cans were processed without incident in this test. Apparently, either the rim seal on the cans was insufficiently tight, or the welded instrumentation ports softened the sidewall of the cans enough to allow the cans to release their contents in a controlled manner, well ahead of their contact with the advancing melt front.

The cans did appear to pressurize to about 25 to $30 \mathrm{psig}$ before failing. As a point of reference, fire tests performed on actual sealed 55 gal metal waste drums containing flammable materials indicated that these drums burst at pressures in range of 8 to 15 psig (Hasegawa 1993). 


\subsection{ORNL-ESBW-1b TEST}

The preceding ORNL-ESBW-1a test was ineffective at producing the series of plenum transients sought-for in order to mimic the potential effects of a GDE. That test involved a series of cans which had welded penetrations on their sidewalls to allow their instrumentation, and which were manually sealed after loading with the desired quantities of soil and water. Apparently the cans were incapable of maintaining their seal until the melt was sufficiently close to result in their sudden catastrophic failure. Instead, each of the cans was able to leak-off a portion of its contents prior to its complete depressurization.

To assess whether this leak-before-break response was caused by softening of the can's sidewall when the fittings were welded-on, or whether the seal on the lid itself was inadequate to withstand the ISV environment, this follow-on test was performed -- ORNL-ESBW-1b. In this test, fewer of the cans were instrumented. In addition, an extra layer of cans was included to investigate the sensitivity of can pressure transient to the quantity of water placed in the can.

\subsubsection{Test Configuration}

For the most part, the conditions staged for the preceding test (ORNL-ESBW-1a) were reproduced for this test. A schematic illustrating an elevation view of this setup is provided in Figure 3.3.1. As this figure indicates, three cans were staged at each of four elevations in the soil. The upper three levels coincide with those staged in the ORNL-ESBW-1a test. The soil, water, and air contents of these cans are also the same as were staged in the ORNL-ESBW-1a test. Each can had $117 \mathrm{~cm}^{3}$ of soil. In addition to this soil, the top layer of cans were loaded with $72 \mathrm{ml}$ of water. Similarly the layer of cans staged at the $-30 \mathrm{~cm}$ and $-45 \mathrm{~cm}$ depths contained $62 \mathrm{ml}$ and 52 $\mathrm{ml}$ of water, respectively. An additional fourth layer of cans was staged for this test. These cans were loaded entirely with water, no soil. As Figure 3.3.1 indicates, the uppermost surfaces of these cans were placed at the $60 \mathrm{~cm}$ depth.

All three cans at each level were placed in a vertical orientation for this test. In addition, only one can on each level was instrumented to record its pressure and temperature. These cans were placed between the two neighboring cans on a level. Unlike what was done for the ORNL-ESBWla test however, the penetrations providing access for this instrumentation was not a fitting welded to the can. Instead, a mechanical seal was provided with a bulkhead swagelok fitting and washer arrangement. The dual pressure temperature measurement taken through this one penetration was 
then effected by means of a swagelok " $T$ " fitting located just outside the can sidewall. This arrangement is illustrated in Figure 3.3.2.

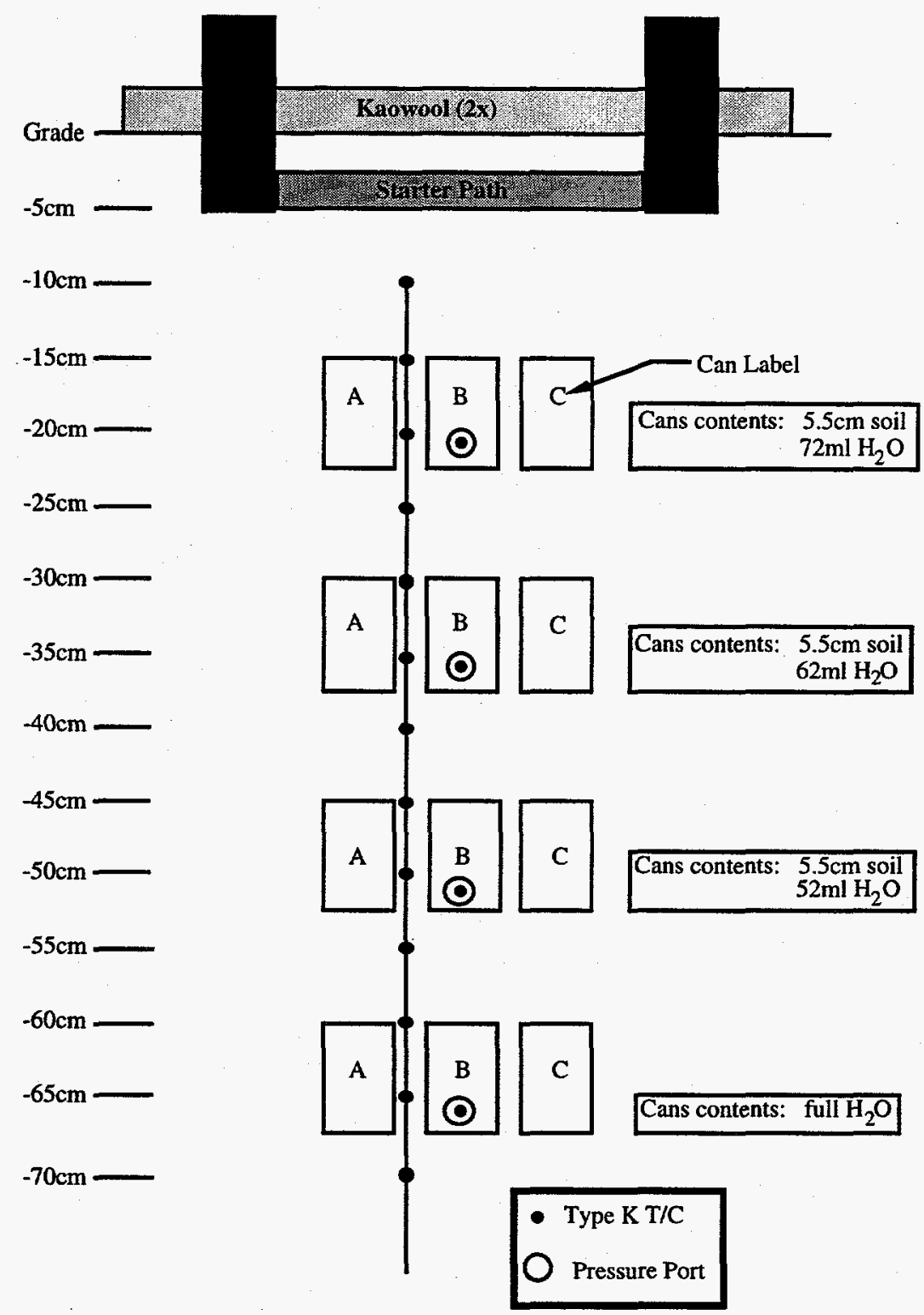

Figure 3.3.1. ORNL-ESBW-1b Test Configuration - Elevation View of Staged Engineering-Scale ISV Test Setup. 


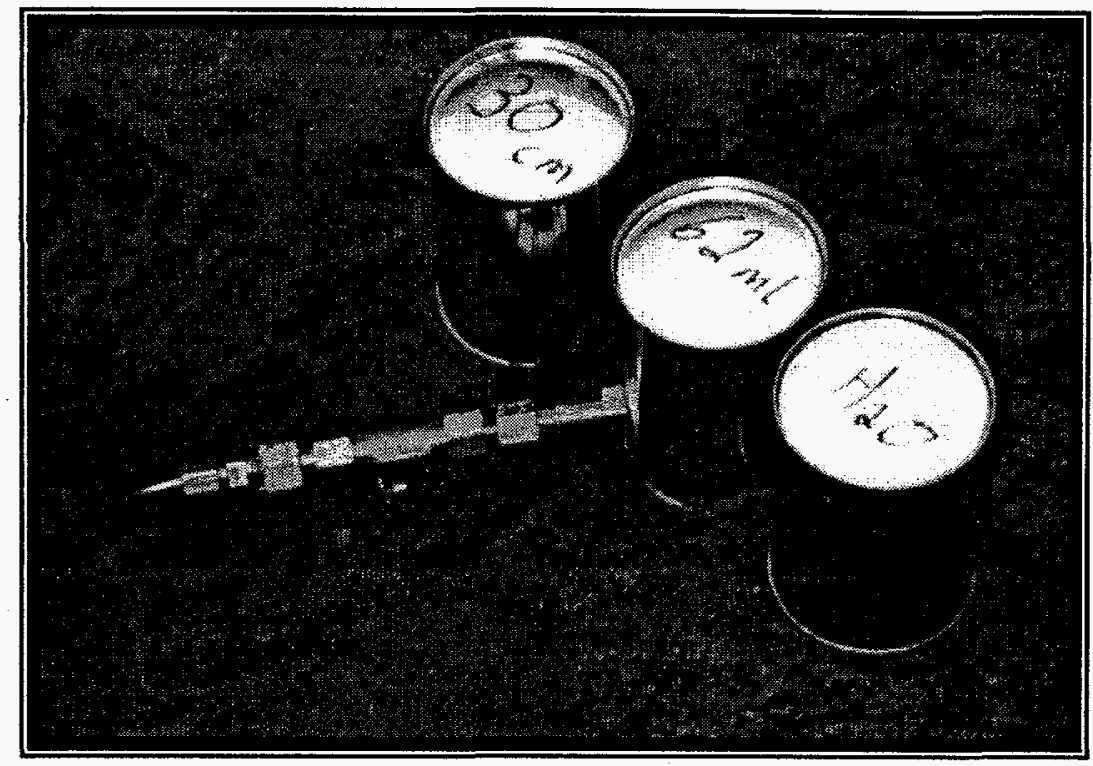

Figure 3.3.2. ORNL-ESBW-1b Test Canister Instrumentation.

\subsubsection{Test Instrumentation}

This test was instrumented in a manner similar to the ORNL-ESBW-1a test. The soil temperature and melt progression were monitored with an array of Type " $\mathrm{K}$ " thermocouples. These thermocouples were placed along the vertical centerline of the setup. The four instrumented cans were configured to record the internal pressure and temperature as per the ORNL-ESBW-1a test. Again, a type " $K$ " thermocouple was inserted into each of these four cans. The pressure was measured by plumbing each of these cans with a 1/4" O.D. stainless steel tube. This tube extended from the can out away from the melt to a region where the temperatures were expected to be sufficiently low to allow continuation of this tubing with Teflon instead of stainless steel. This Teflon tube was carried out to a pressure transducer located outside the ISV hood. The electrical signal generated by these transducers was sent to the DAS for monitoring and recording during the test. The remaining test instrumentation (e.g., plenum pressure, temperature, and electrical) was the same as was employed in the preceding tests. 


\subsubsection{Test Start-Up and Operation}

As was done in the preceding tests, a linear ramp-up in power from $0 \mathrm{~kW}$ to $25 \mathrm{~kW}$ in the first two hours of operation was targeted for this test. Following this, the $25 \mathrm{~kW}$ total power level was maintained for the duration of the test.

The power ramp was initiated at 15:32:27 PST on March 10, 1995. At approximately 17:50 PST $(\Delta t \approx 2.3 \mathrm{~h}$ ), the top layer of cans failed catastrophically. A significant mass of glass was expelled from the melt. An image of the melt flow is provided in Figure 3.3.3. As this figure indicates, the flow pattern is quite reminiscent of what has been produced by GDEs during largescale ISV tests -- though not to the same level of severity, however. This event significantly damaged the Kaowool insulation placed over the melt. This blanket serves two purposes in these tests: (1) to reduce heat loss from the melt to the plenum region, and (2) to dampen the effects of displaced glass during an event. With the Kaowool compromised by the first event, it was deemed necessary to temporarily shutdown the process and place an additional layer of Kaowool over the exposed melt. At 18:30 PST ( $\Delta \mathrm{t} \approx 3 \mathrm{~h}$ ), the system was powered-down to perform this operation. The system was re-energized 5 minutes later, at 18:35 PST. The photo presented in Figure 3.3.3 was taken during this operation.

At 20:19 PST $(\Delta t \approx 4.75 \mathrm{~h}$ ), a second event was experienced. The glass displaced by this event also damaged the Kaowool layer. Therefore, at 20:38 PST ( $\Delta \mathrm{t} \approx 5.1 \mathrm{~h}$ ), the system was powered-down to allow placement of an additional layer of Kaowool insulation over the melt zone. The system was re-energized at 20:43 PST $(\Delta t \approx 5.2 \mathrm{~h})$ and the test continued.

The test proceeded without further incident. After it was determined that all four layers of cans had been processed, the system was de-energized and the test concluded at 06:05 PST on March $11,1995(\Delta t \approx 14.5 h)$. 


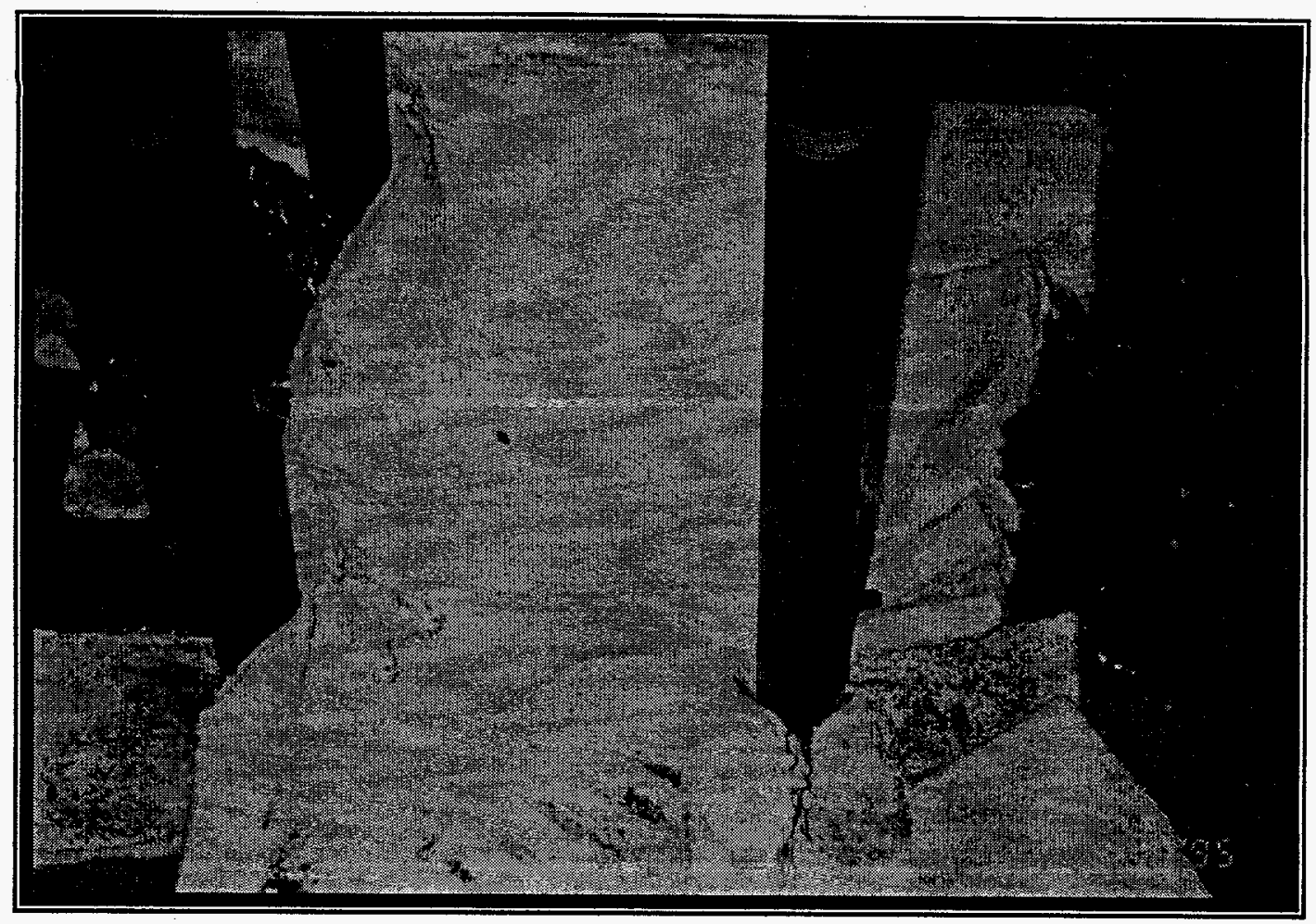

Figure 3.3.3. ORNL-ESBW-1b Test -- Soil Surface Following a GDE.

\subsubsection{Phase Voltage, Current, and Resistance Results}

Figure 3.3.4 illustrates the phase voltage, current, and resistance transients produced during this test. As with the preceding tests, the balance between phases is quite evident. Figure 3.3.5 presents the phase power and total power and electrical energy consumption realized in this test. Again, the balance between phases is evident. As this figure indicates, a total of $335 \mathrm{kWh}$ was consumed during this test. 


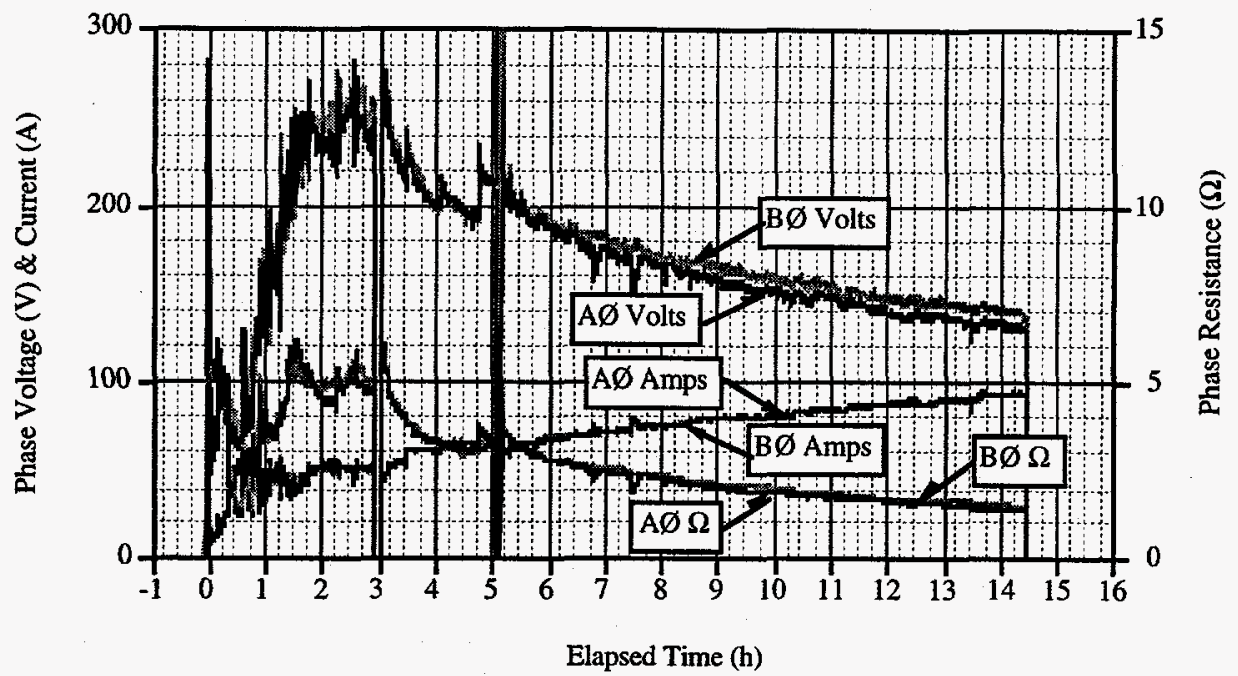

Figure 3.3.4. ORNL-ESBW-1b Phase Voltage, Current, and Resistance Transients.

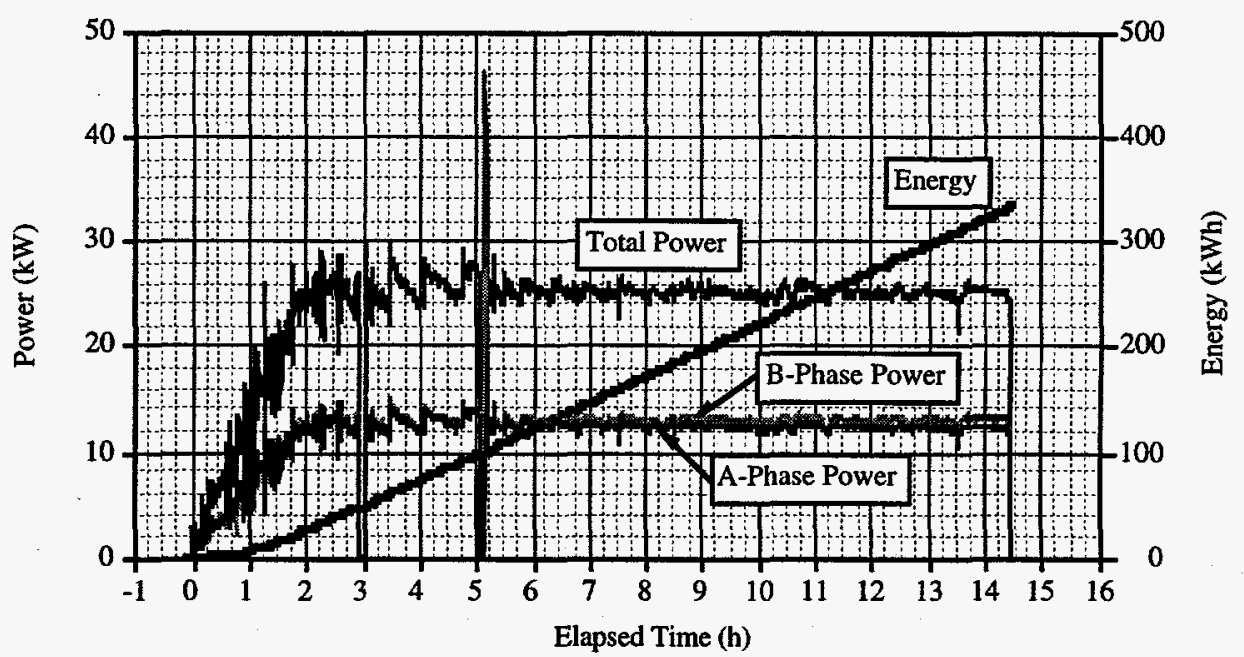

Figure 3.3.5. ORNL-ESBW--1b Phase Power, and Total Power \& Energy Transients.

\subsubsection{Electrode Depth and Soil Temperature Results}

Figure 3.3.6 illustrates the average electrode depth and centerline temperature transients produced during this test. Note that the temperature traces for the 015-000-000 and 030-000-000 exhibit several instances during which the temperature suddenly falls, followed by a rapid recovery. For the 015-000-000 thermocouple, these occur at approximately 2.25 hours into the 
test -- about the time of the first event. A similar response is indicated for the thermocouple 045000-000 at approximately 5 hours into the test -- about the time of the second event. These fluctuations are attributed to gas venting generated by the sudden rupture of a canister. The relatively cool gas released would result in a sudden drop in the temperature measured by the thermocouple. After it passed though, the displaced glass will relax to its original position causing a rapid rise in the indicated temperature back to its original value. Interestingly, the 045-000-000 thermocouple also indicates this response at approximately 8 hours into the test. There was no significant plenum event recorded at this time, however.

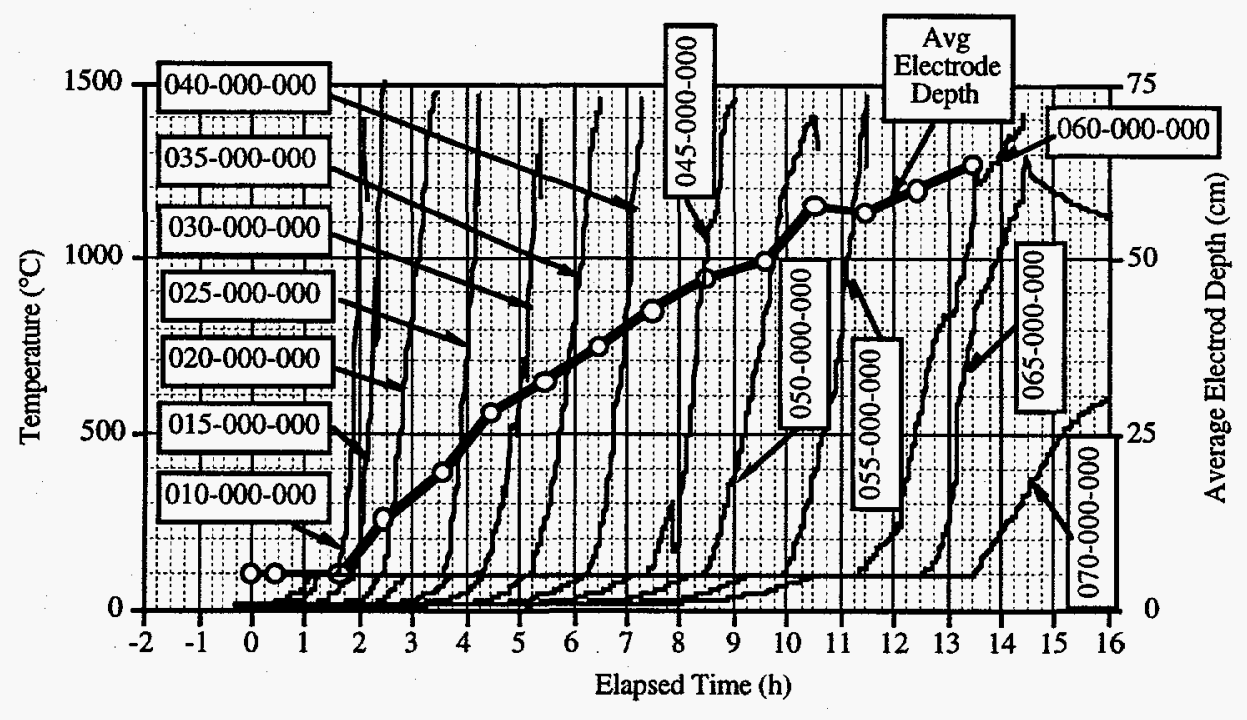

Figure 3.3.6. ORNL-ESBW-1b Electrode Depth and Centerline Temperature Transients.

\subsubsection{Canister Pressure and Temperature Results}

Figure 3.3.7 illustrates the canister pressures measured during this test. As mentioned previously, the cans at the $-15 \mathrm{~cm}$ and $-30 \mathrm{~cm}$ depths produced significant plenum pressure/temperature excursions and GDEs. Note that the rate of pressurization and depressurization indicated for the cans at these levels is considerably greater than for the cans at the $-45 \mathrm{~cm}$ and $-60 \mathrm{~cm}$ level. At the early stages of melt growth, the melt depth increases at a faster rate than it does later in the process. Therefore, the time over which a can is exposed to elevated temperatures prior to coming into close contact with the melt (or "soak" time) is greater for the cans staged at the greater depths. This may be the cause of the suspected leak-before-rupture phenomena. 


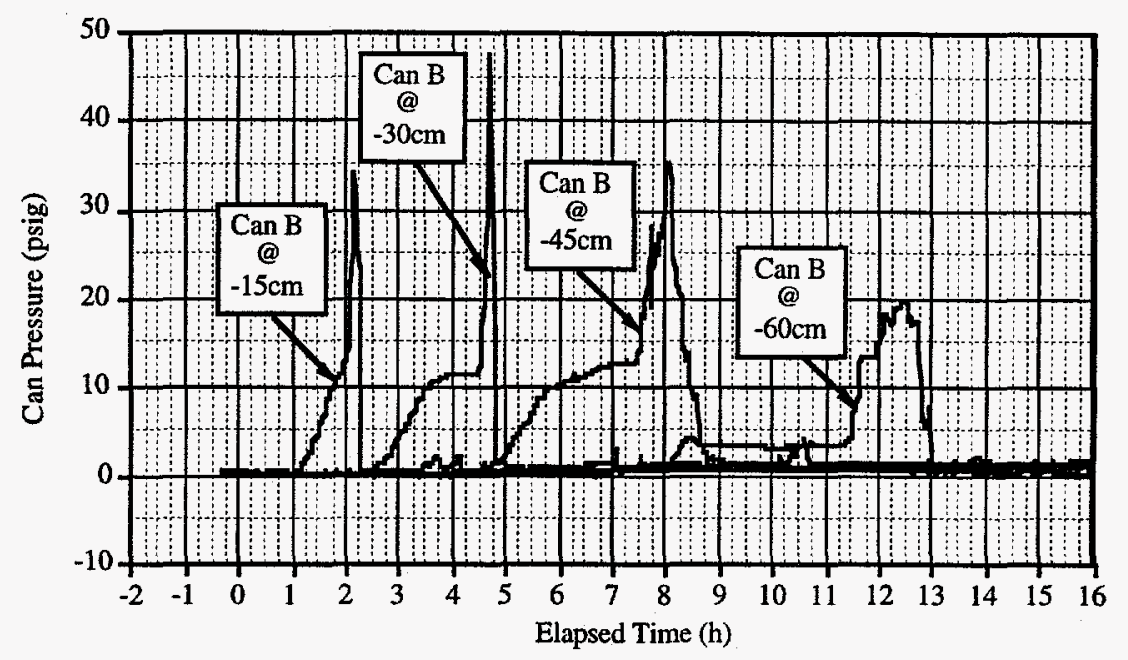

Figure 3.3.7. ORNL-ESBW-1b Canister Pressure Transients.

Figures 3.3.8 through 3.3.11 illustrate the can pressure and temperature transients at each of the four levels staged in this test, together with the centerline soil temperatures recorded in regions surrounding the cans. Again, the differing time scales associated with the cans at the four levels is apparent.

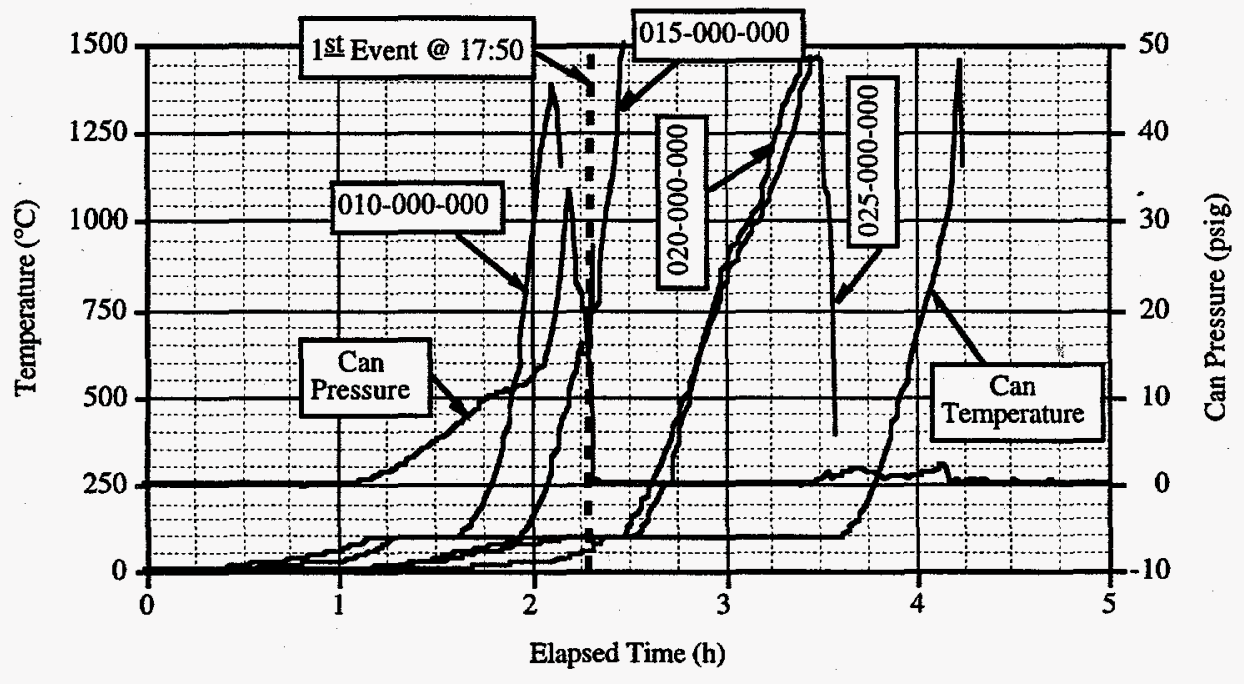

Figure 3.3.8. ORNL-ESBW-1b Pressure/Temperature Transients at the $-15 \mathrm{~cm} \mathrm{Level.}$ 


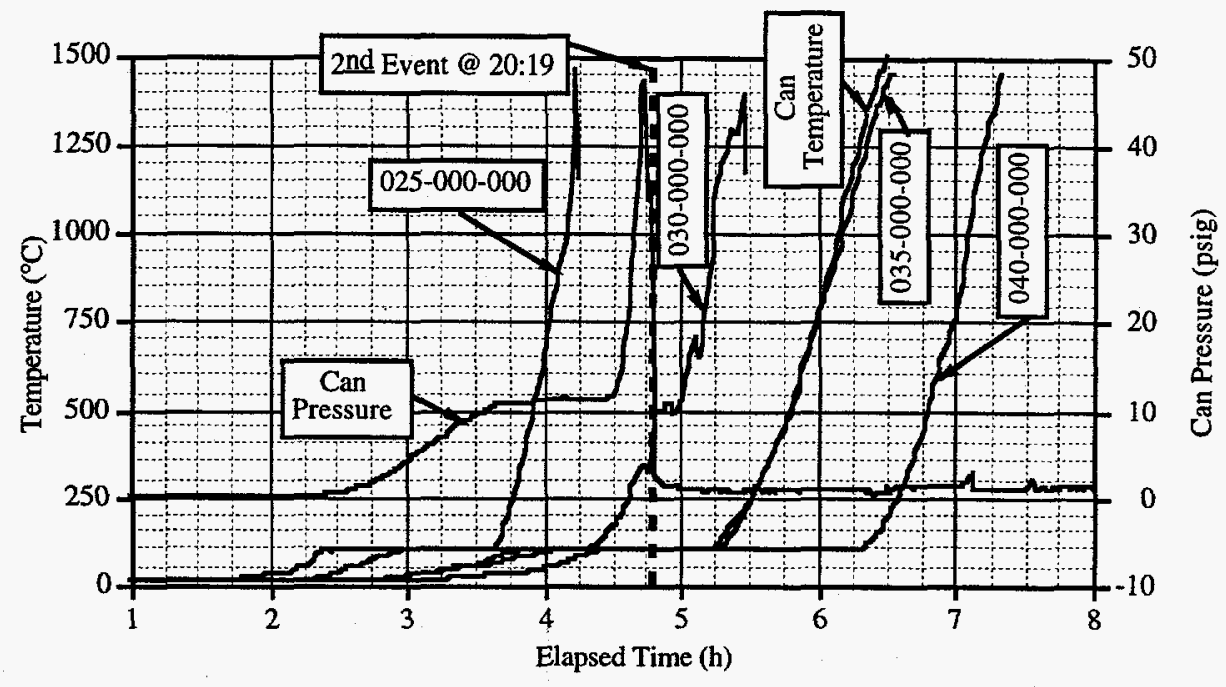

Figure 3.3.9. ORNL-ESBW-1b Pressure/Temperature Transients at the $-30 \mathrm{~cm}$ Level.

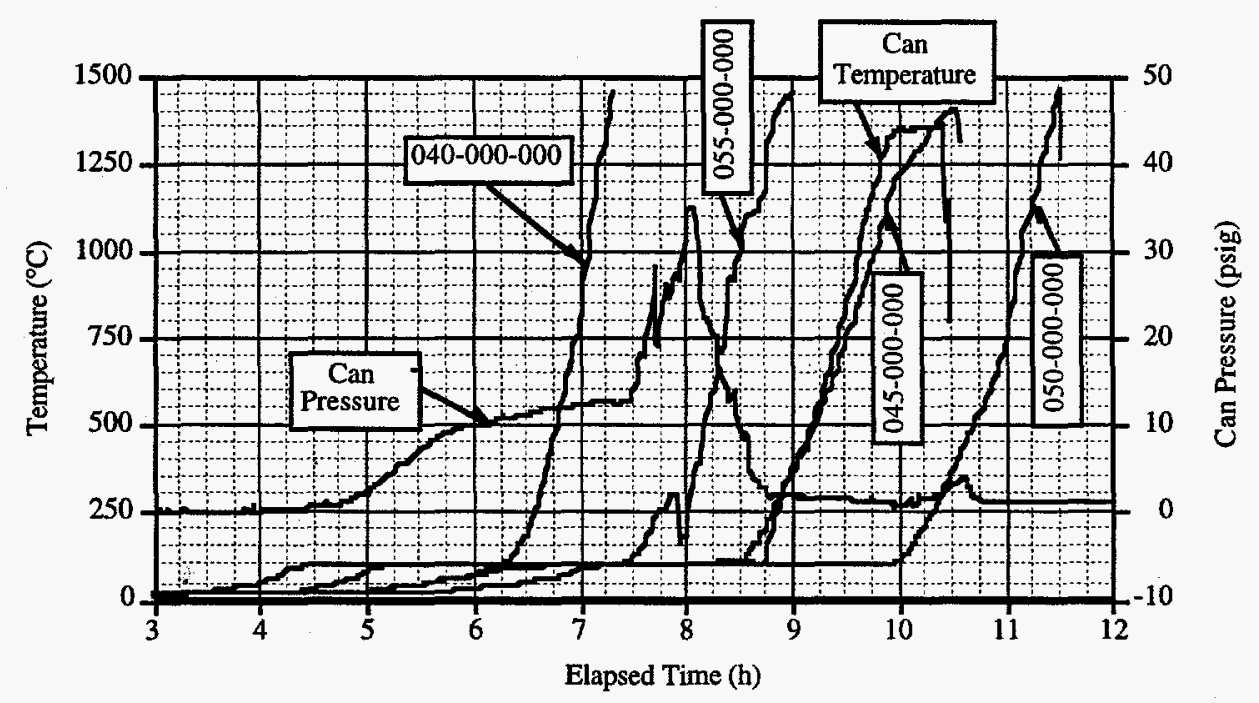

[Figure 3.3.10. ORNL-ESBW-1b Pressure/Temperature Transients at the $-45 \mathrm{~cm}$ Level. 


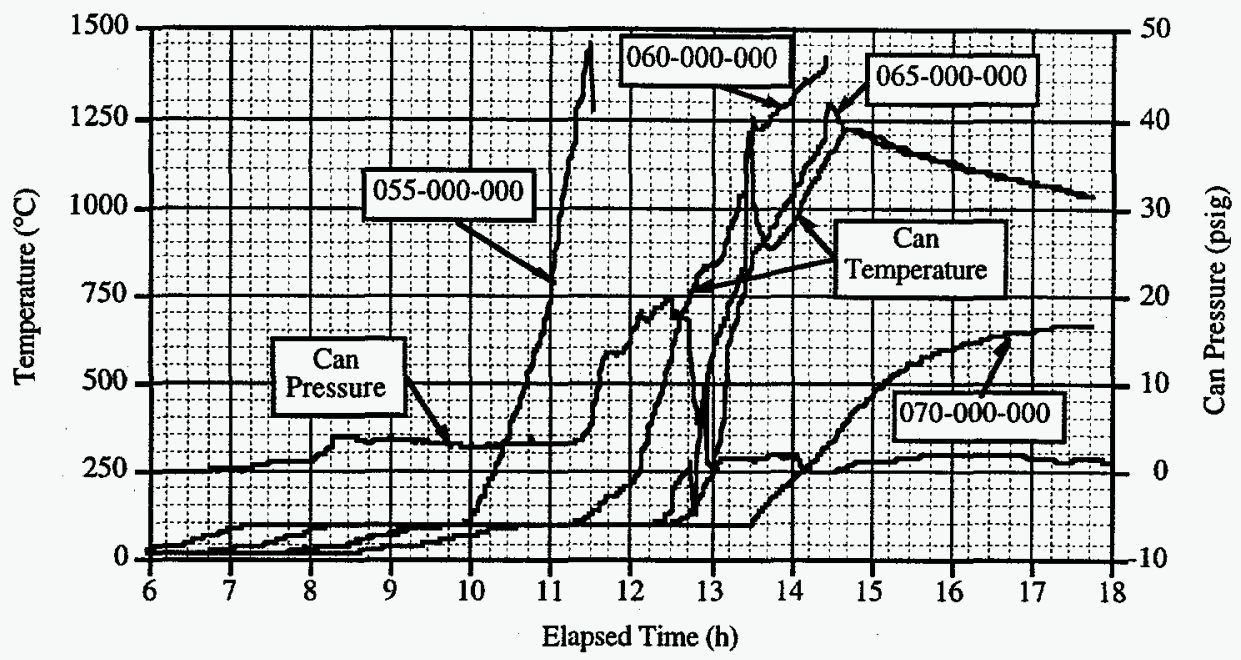

Figure 3.3.11. ORNL-ESBW-1b Pressure/Temperature Transients at the $-60 \mathrm{~cm}$ Level.

It is somewhat disconcerting that the cans behave in a rather unpredictable fashion. That is, one would expect that, if the likelihood for catastrophic failure was solely a consequence of the amount of volatile material present in the can, then the cans placed at the $-60 \mathrm{~cm}$ elevation should have produced an event more significant than that which was produced while processing the two uppermost layers. In addition, one would expect that the consequences of a can rupture would be more dramatic when the failure occurs beneath a more established melt. The pressures built-up in the cans were certainly greater than that required to overcome the static head of the melt. Moreover, with a more mature melt, the gases released would have had to traverse around and/or through greater distances to escape to the off-gas hood. In addition, for those gases traveling through the melt, there would have been be more glass to displace. This erratic response has been experienced in previous engineering-scale ISV tests, however (Bergsman et al. 1992).

\subsubsection{Plenum Pressure and Temperature Results}

The off-gas inlet and plenum temperatures transients realized in this test are plotted in Figure 3.3.12. The rapid temperature excursions experienced by the plenum are quite evident in this figure. The second event appears to be significantly more severe than the first, however. Following the second event, the plenum temperature rose sharply approximately $80^{\circ} \mathrm{C}$ to over $190^{\circ} \mathrm{C}$. The plenum pressure and temperature are plotted in Figure 3.3.13 for the period around the first and second events. Again, the greater severity of the second event is evident in this figure. 
There are also a number of lesser pressure spikes indicated in this figure. These are likely also manifestations of canister failures, though they did not produce plenum transients comparable to those of the second event.

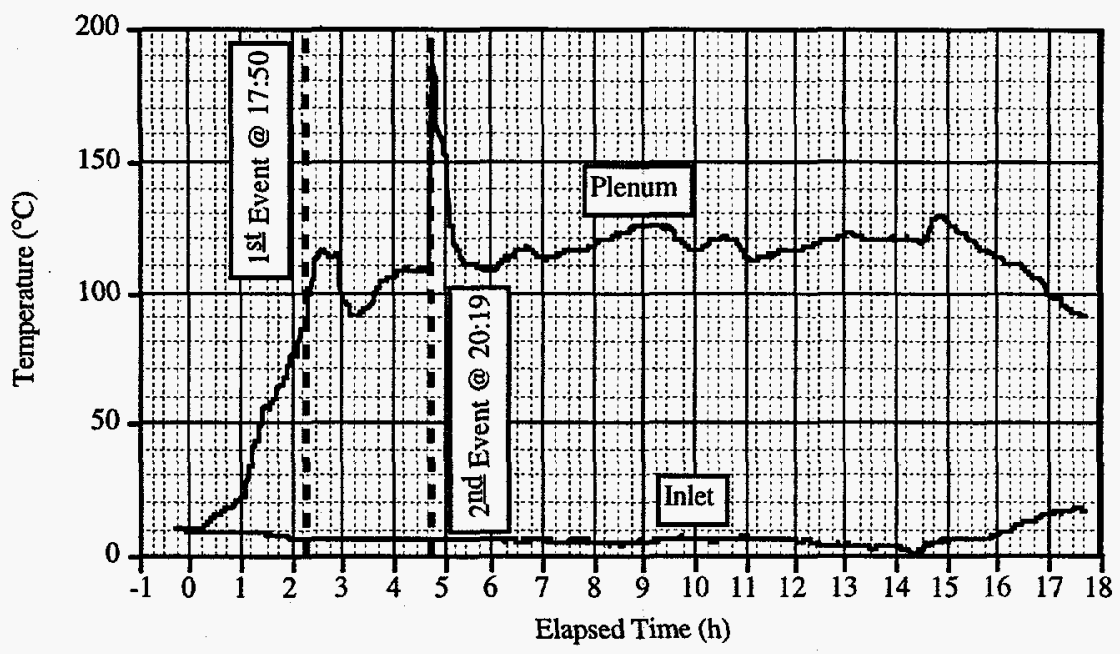

Figure 3.3.12. ORNL-ESBW-1b Off-Gas Inlet and Plenum Temperature Transients.

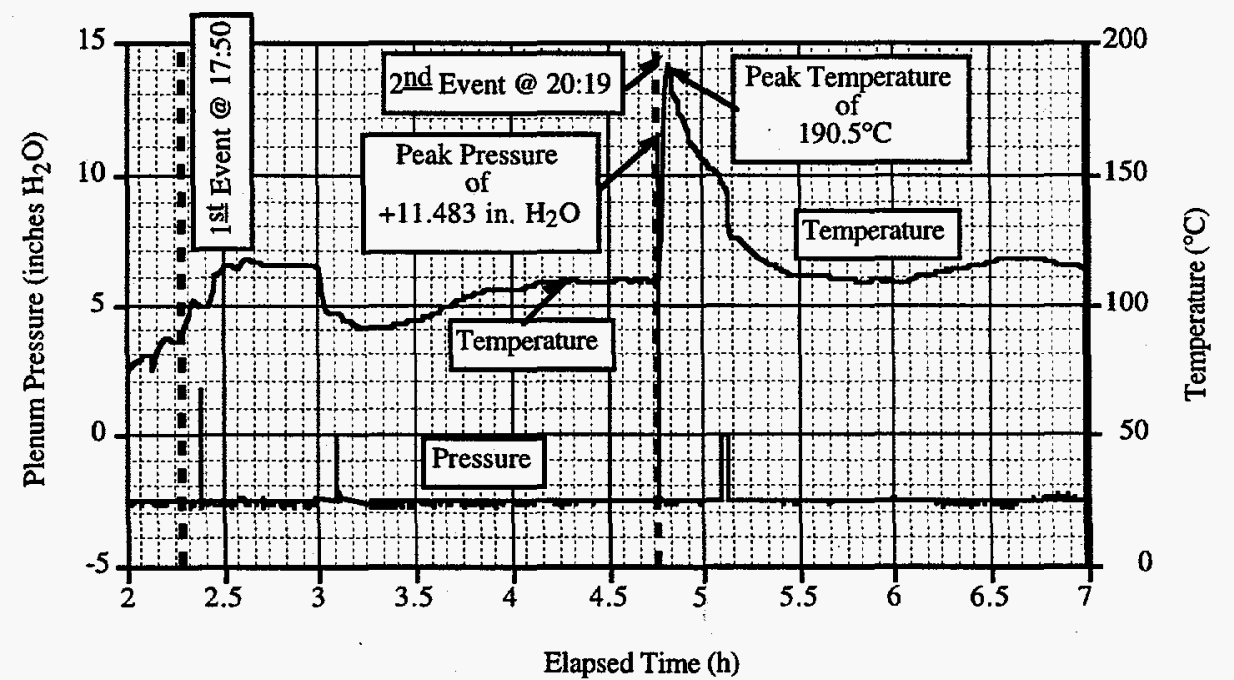

Figure 3.3.13. ORNL-ESBW-1b Plenum Pressure and Temperature Transients. 


\subsubsection{ISV Block Statistics}

A $318 \mathrm{~kg}$ block was produced in this test. Approximately $335 \mathrm{kWh}$ were consumed in the process. Therefore, the specific energy consumption realized for this test was $1.05 \mathrm{kWh} / \mathrm{kg}--$ consistent with the $1 \mathrm{kWh} / \mathrm{kg}$ typically required for ISV melts produced at the engineering-scale. A total of $6.3 \mathrm{~kg}$ of glass was expelled from the melt during the two events realized in this test.

\subsubsection{Test Retrospective}

Test ORNL-ESBW-1b involved the processing of an array of twelve sealed canisters. The canisters were staged at four elevations in the target vitrification zone, three cans at each elevation. Each can on a level was loaded with a specific quantity of soil and water to test the sensitivity of can pressurization to the amount of volatile material contained. Two of the three cans at each level were uninstrumented. The third can was instrumented to measure and record the can's pressure and temperature transient during processing.

Two plenum pressure/temperature events were experienced during this test -- one corresponding to processing the top layer of cans (at the $-15 \mathrm{~cm}$ depth), and another corresponding to the time at which the second layer of cans (at the $-30 \mathrm{~cm}$ depth) were being processed. The canister pressure and temperature data indicated that each instrumented can pressurized significantly during the process. The peak canister pressures were well above the static head of the melt in each case. However, only two plenum pressure events were experienced during this test. The inability of these cans to produce plenum pressure/temperature events consistently was disconcerting. This inconsistency had been experienced in previous engineeringscale ISV tests involving similarly configured canisters, however (Bergsman et al. 1992).

The canisters staged in both tests ORNL-ESBW-1a and ORNL-ESBW-1b were unable to produce plenum pressure and temperature excursions in a consistent manner. In test ORNLESBW-1a, all cans were instrumented and mechanically sealed by the ISV staff. In test ORNLESBW-1b, all cans were sealed using the same technique as was employed in the preceding ORNL-ESBW-1a test. Only one-third of the cans were instrumented in this ORNL-ESBW-1b test, however. The cans in both tests ORNL-ESBW-1a and ORNL-ESBW-1b produced inconsistent failure responses. In contrast, the one factory-sealed canister staged in the ORNLESBW-1 test did produce a significant plenum excursion. Therefore, the on-site sealing mechanism employed in the $1 \mathrm{a}$ and $1 \mathrm{~b}$ tests was suspected as not providing a sufficient seal to preclude premature rupture of the canister during processing. This is further corroborated by the 
results of previous engineering-scale ISV test which employed the same canister sealing apparatus (Bergsman et al. 1992). Subsequent tests will, therefore, employ only factor-sealed canisters. 


\subsection{ORNL-ESBW-1c TEST}

Tests ORNL-ESBW-1a and ORNL-ESBW-1b were intended to investigate the possibility of using cans which could be loaded with simulants and sealed at the ISV site. It was hoped that the sealing could be done tightly enough to insure that the cans could maintain their integrity until the melt's high temperatures produced a catastrophic failure and consequent GDE. The ability to seal the cans on site would allow placement of materials more representative of those found in the actual ORNL buried waste trenches for follow-on tests. Unfortunately, the manual canning device could not produce a tight enough seal to consistently effect the desired result. The commercially-sealed can staged in the ORNL-ESBW-1 test did produce this result, however. Therefore, this test was designed to include only these commercially-sealed cans in the target vitrification zone. If successful (i.e., if rupture of these cans produces GDEs), they will then be incorporated into the test matrix for the follow-on tests.

\subsubsection{Test Configuration}

For this test, three levels of cans were staged in the target vitrification zone. Each of these factory-sealed, steel cans contained $6 \mathrm{oz}$ of hydrous, organic material. The cans were staged as indicated in the plan and elevation schematic presented in Figures 3.4.1 and 3.4.2. This configuration was comparable to that employed in the ORNL-ESBW-1a test, except that the cans staged on the middle layer were placed on their sides. Also, since the GDEs generated in the preceding ORNL-ESBW-1b test effectively destroyed the two layers of Kaowool blanket placed over the melt zone, four layers were placed over this region for this test.

\subsubsection{Test Instrumentation}

This test was instrumented in much the same manner as for the previous tests. However, since the integrity of the cans was not to be compromised prior to the test, no canister pressure and temperature data could be obtained. Instead, the assessment relied on the response of the centerline thermocouple bundle, the plenum pressure and temperature measurements, and the video images obtained from the video cassette recorder (VCR). The centerline thermocouple bundle consisted of 8 type " $\mathrm{K}$ " thermocouples placed along the vertical centerline of the configuration (c.f. - Figure 3.4.2). The remaining suite of pressure, temperature, heat flux, and electrical measurement devices was the same as was employed in the preceding tests. 


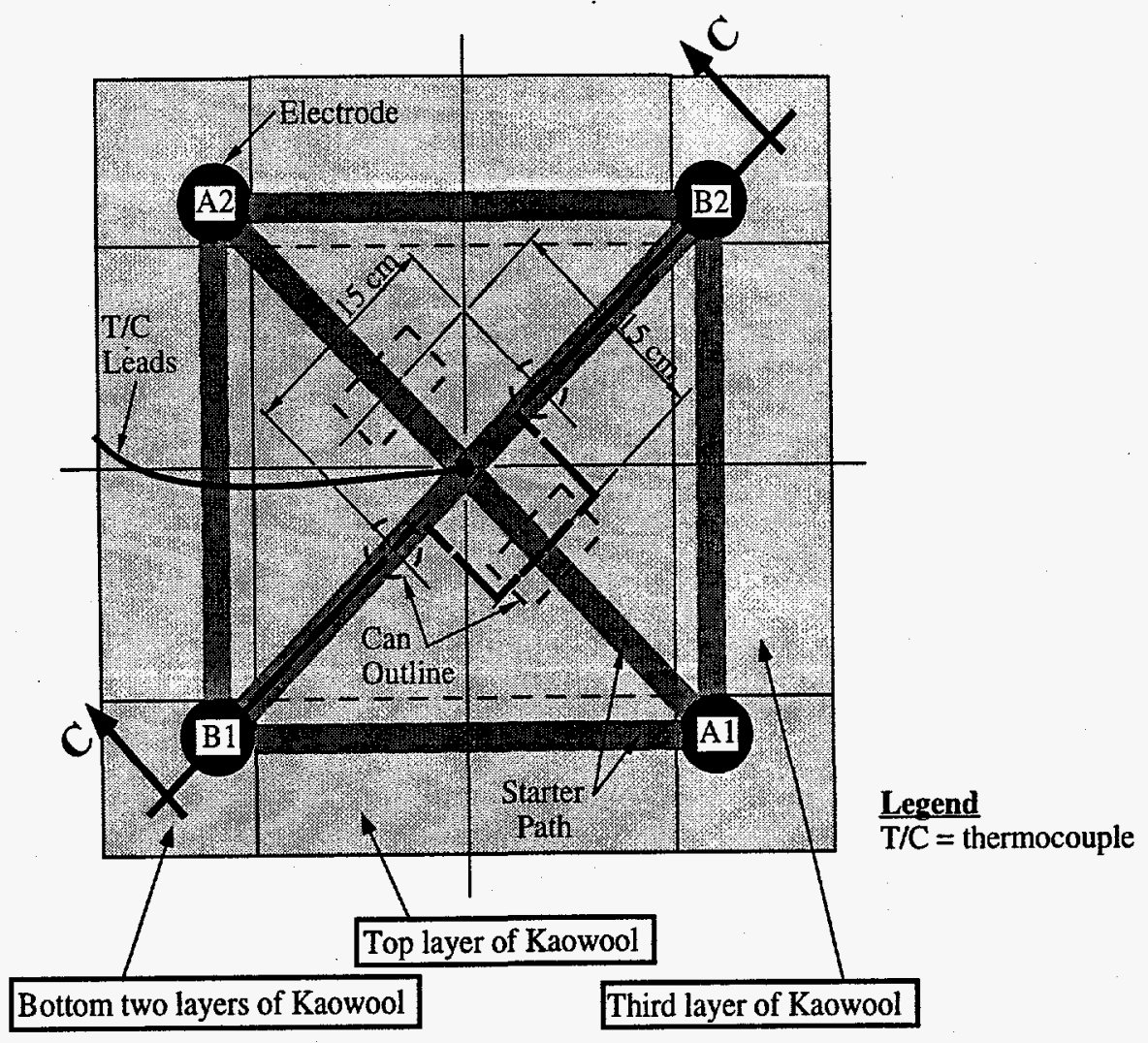

Figure 3.4.1. ORNL-ESBW-1c Test Configuration - Plan View.

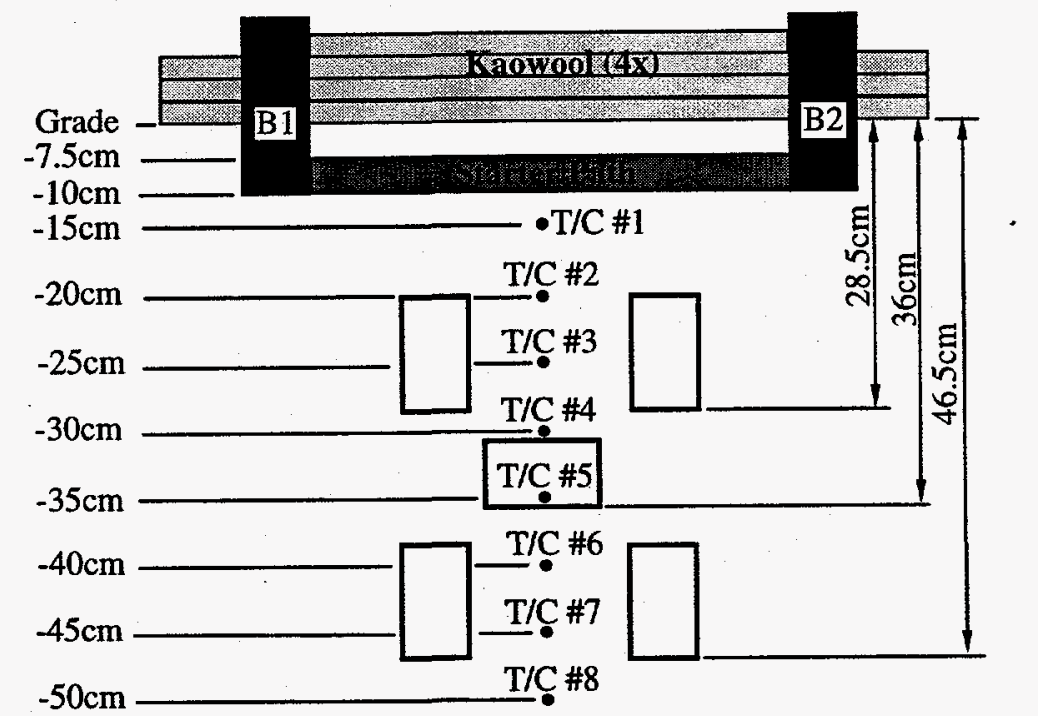

Figure 3.4.2. ORNL-ESBW-1c Test Configuration - Elevation View (Section C-C). 


\subsubsection{Test Start-Up and Operation}

As was done in the preceding tests, a linear ramp-up in power from $0 \mathrm{~kW}$ to $25 \mathrm{~kW}$ during the first two hours of operation was targeted for this test. Following this start-up phase, the 25 $\mathrm{kW}$ total power level was maintained for the duration of the test.

The system was energized at 10:15:00 PST on March 31, 1995. A linear power ramp was followed until full power was achieved at approximately 12:15 PST $(\Delta t \approx 2 \mathrm{~h})$. Shortly thereafter, at approximately $12: 31(\Delta \mathrm{t} \approx 2.25 \mathrm{~h})$, the first event was experienced -- corresponding to processing the top layer of cans. The plenum pressure rose to +1 inches w.c. during this occurrence. At $14: 27$ PST ( $\Delta \mathrm{t} \approx 4.25 \mathrm{~h}$ ), a second event occurred. This event displaced a significant quantity of water from the seal pot -- indicating a plenum pressure in excess of +10 inches w.c.. The "splash pattern" produced around the seal pot reservoir during this event is presented in the image provided in Figure 3.4.3. This event coincided with the processing of the middle layer of cans. Finally, at $15: 52 \operatorname{PST}(\Delta \mathrm{t} \approx 5.6 \mathrm{~h})$, a third and final event was generated. This event was considerably less severe than the second, however. The plenum pressure rose approximately 6 inches of water, to a level of +2 inches w.c..

From this point on, the test proceeded without incident. The test was concluded at 18:21:10 PST on March $31,1995(\Delta t \approx 8.1 \mathrm{~h}$ ). Approximately $178 \mathrm{kWh}$ were consumed during this test. A significant quantity of glass was displaced during this test. This is clearly evident in the photo of the top surface of the melt (following cooldown) presented in Figure 3.4.4.

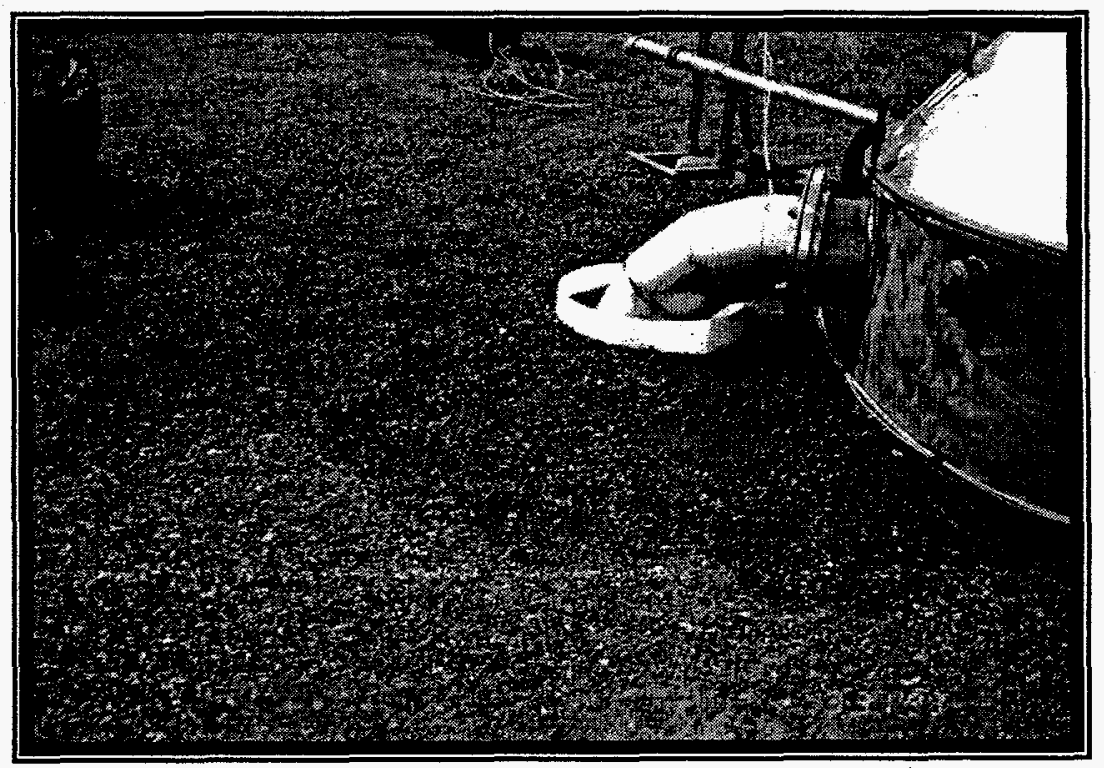

Figure 3.4.3. ORNL-ESBW-1c Seal Pot "Splash Pattern" Following the Second Event. 


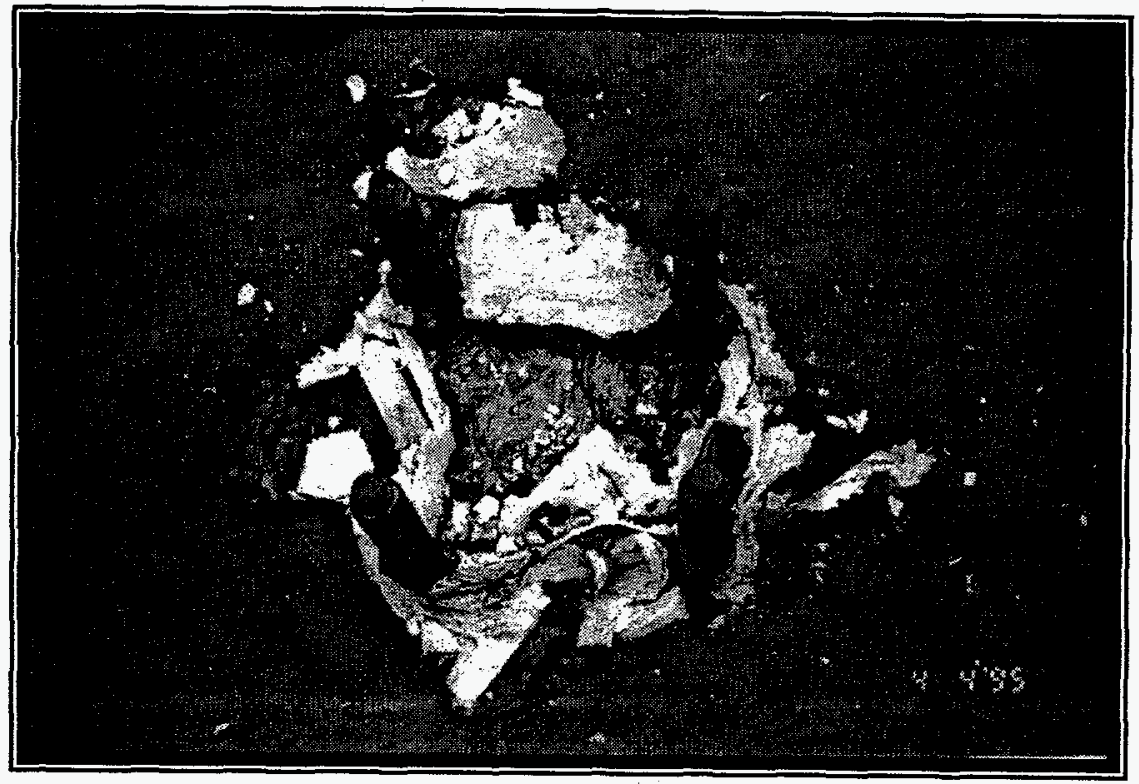

Figure 3.4.4. ORNL-ESBW-1c -- Top Surface of the Melt.

\subsubsection{Phase Voltage. Current, and Resistance Results}

Figure 3.4.5 illustrates the phase voltage, current and resistance transients realized during this test. As with the preceding tests, the good balance between phases is evident in these data. Note that the event associated with processing the middle layer of cans (at $\approx 14: 30, \Delta \mathrm{t} \approx 4.25 \mathrm{~h}$ ) produced a significant perturbation to the electrical system. Figure 3.4.6 illustrates the phase power and total power and energy consumption transients produced during this test. As these data also indicate, a good balance between phases was obtained. Moreover, the $25 \mathrm{~kW}$ total power level was also well maintained following the start-up phase of this test. The energy data plotted in this figure indicate that $178 \mathrm{kWh}$ were consumed during this test. 


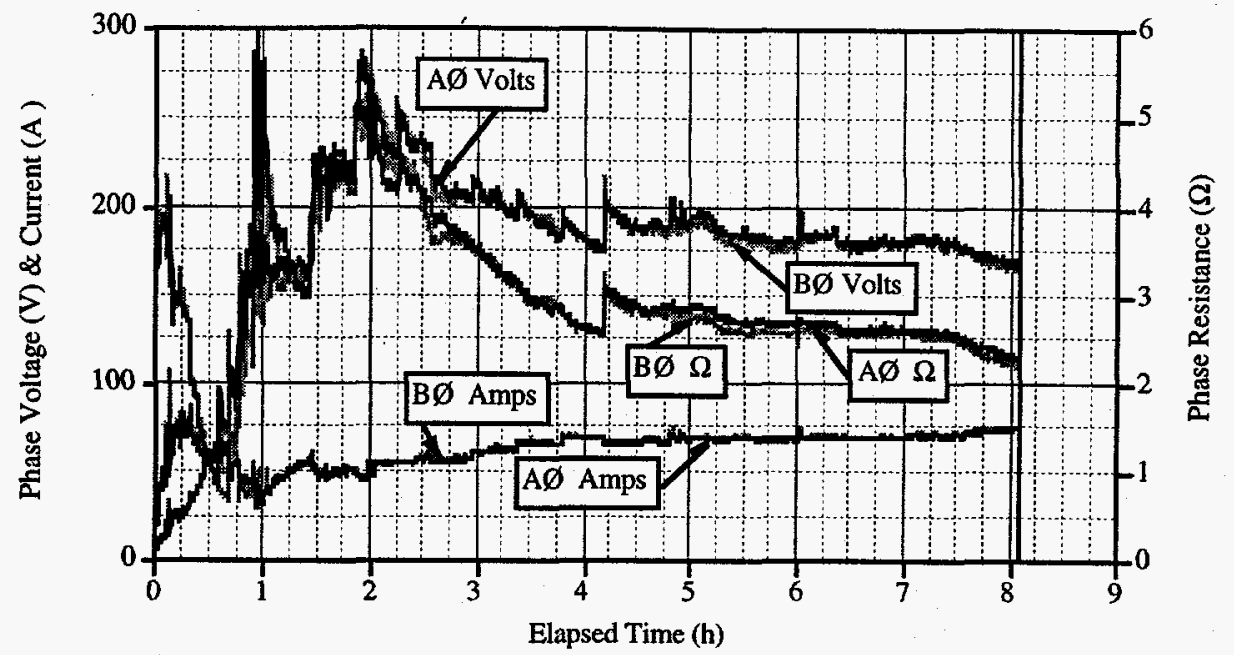

Figure 3.4.5. ORNL-ESBW-1c Phase Voltage, Current, and Resistance Transients.

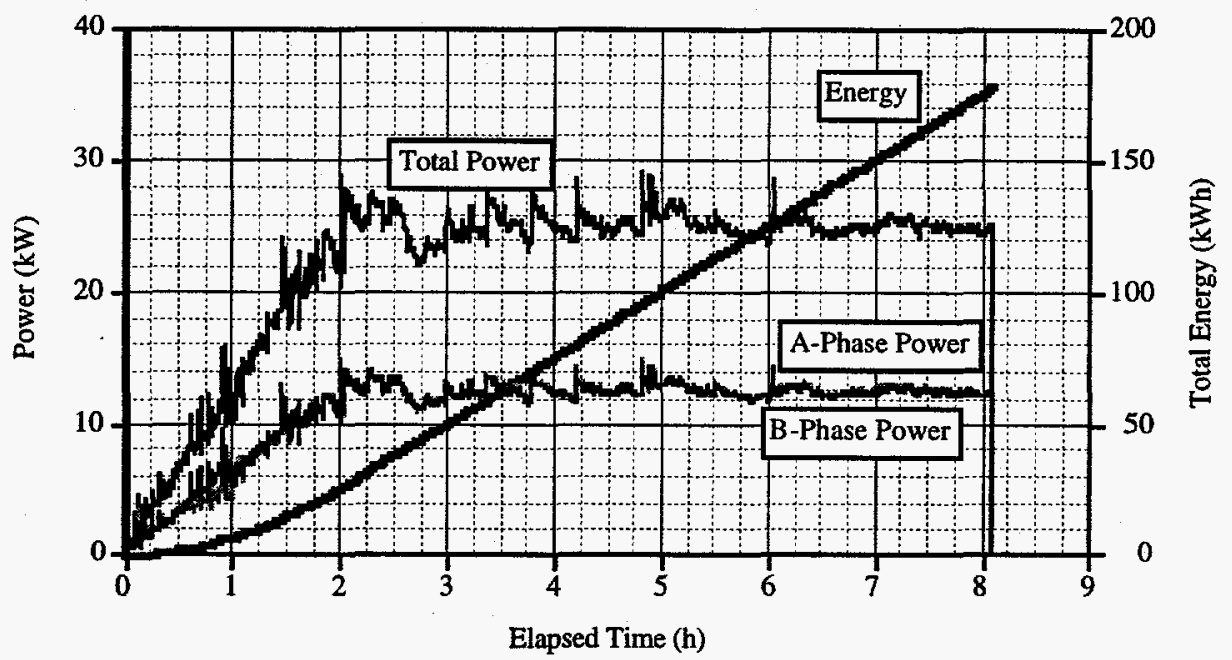

Figure 3.4.6. ORNL-ESBW-1c Phase Power, and Total Power \& Energy Transients.

\subsubsection{Electrode Depth and Soil Temperature Results}

Figure 3.4.7 illustrates the average electrode depth and soil centerline temperature transients produced by this process. Note the sawtooth response indicated at $t \approx 2.25 \mathrm{~h}$ for thermocouple $020-000-000$, at $\mathrm{t} \approx 4.25 \mathrm{~h}$ for thermocouple $030-000-000$, and at $\mathrm{t} \approx 5.6 \mathrm{~h}$ for thermocouple 035000-000. As was discussed previously fore test ORNL-ESBW-1b in Section 3.3.5, these transients are likely the result of the passage of relatively cool steam released by the rupturing cans. Hence, they serve to mark the passage of an event. 


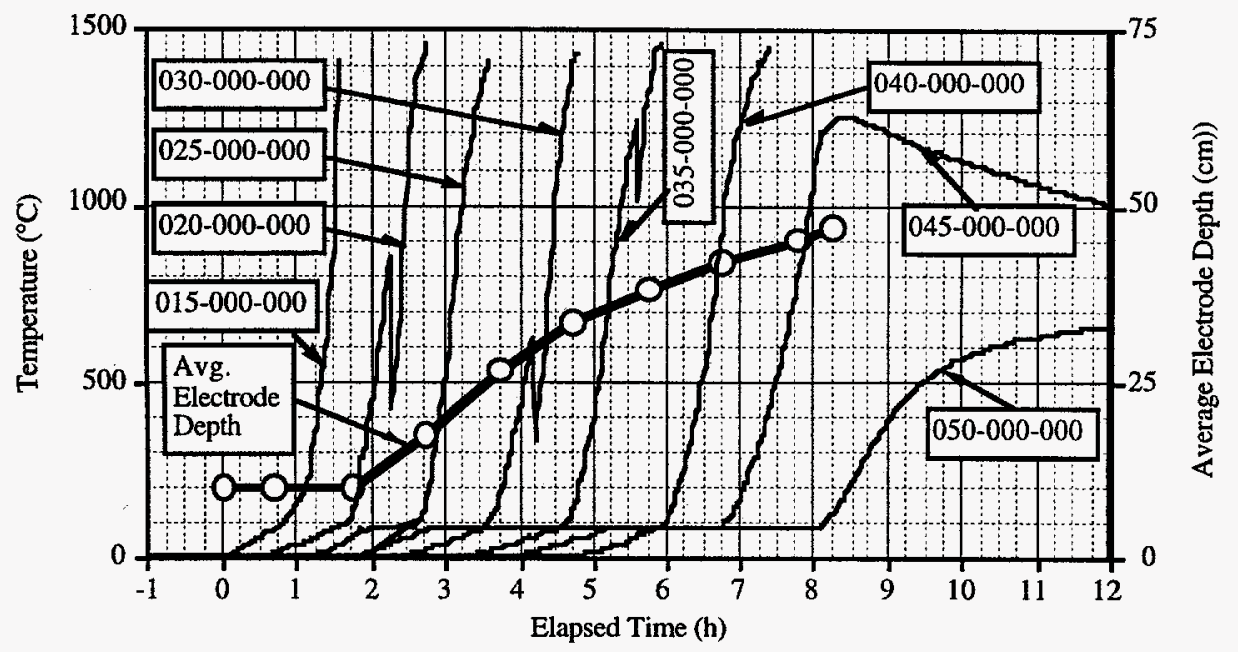

Figure 3.4.7. ORNL-ESBW-1c Electrode Depth and Centerline Temperature Transients.

\subsubsection{Plenum Pressure and Temperature Results}

The inlet and plenum temperature transients realized during this test are presented in Figure 3.4.8. As these data indicate, there were actually two distinct events associated with the processing of the top layer of cans. These events produced a $20^{\circ} \mathrm{C}$ temperature rise in the off-gas plenum. The most significant event occurred while processing the middle layer of cans, however. The GDE associated with this event produced a sharp $55^{\circ} \mathrm{C}$ temperature rise in the off-gas plenum. The final event associated with processing the bottom layer of cans was considerably less severe -producing a modest $15^{\circ} \mathrm{C}$ rise in the plenum temperature.

The plenum pressure and temperature transients produced during each of these four these events is presented in Figures 3.4.9 through 3.4.12. As these data indicate, the plenum 


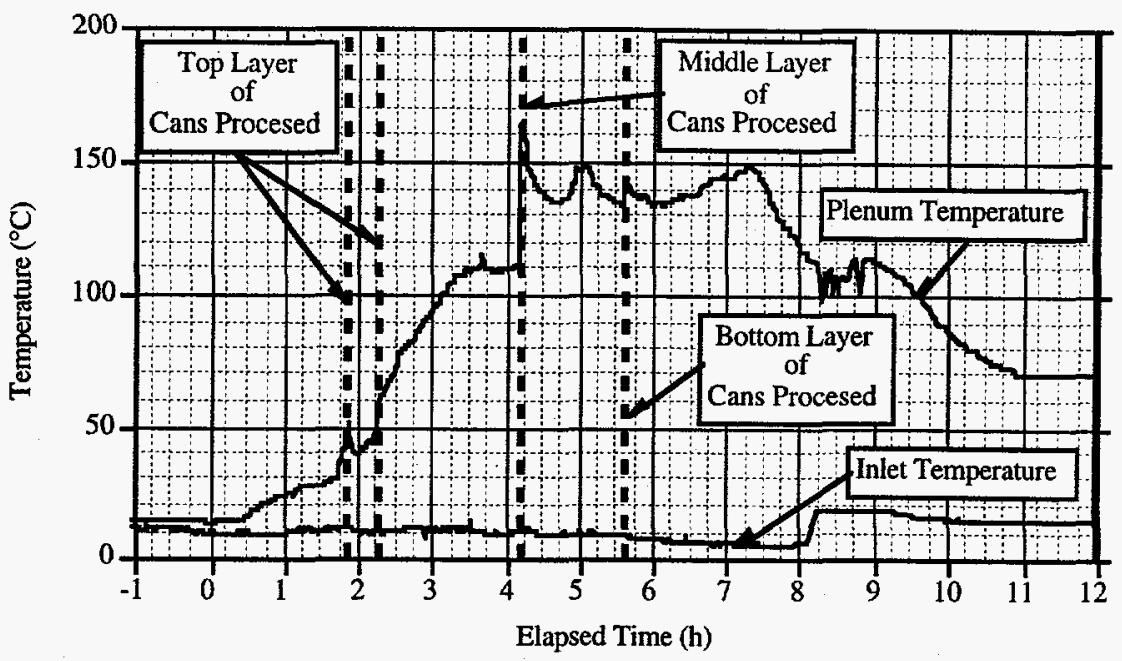

Figure 3.4.8. ORNL-ESBW-1c Off-Gas Inlet and Plenum Temperature Transients.

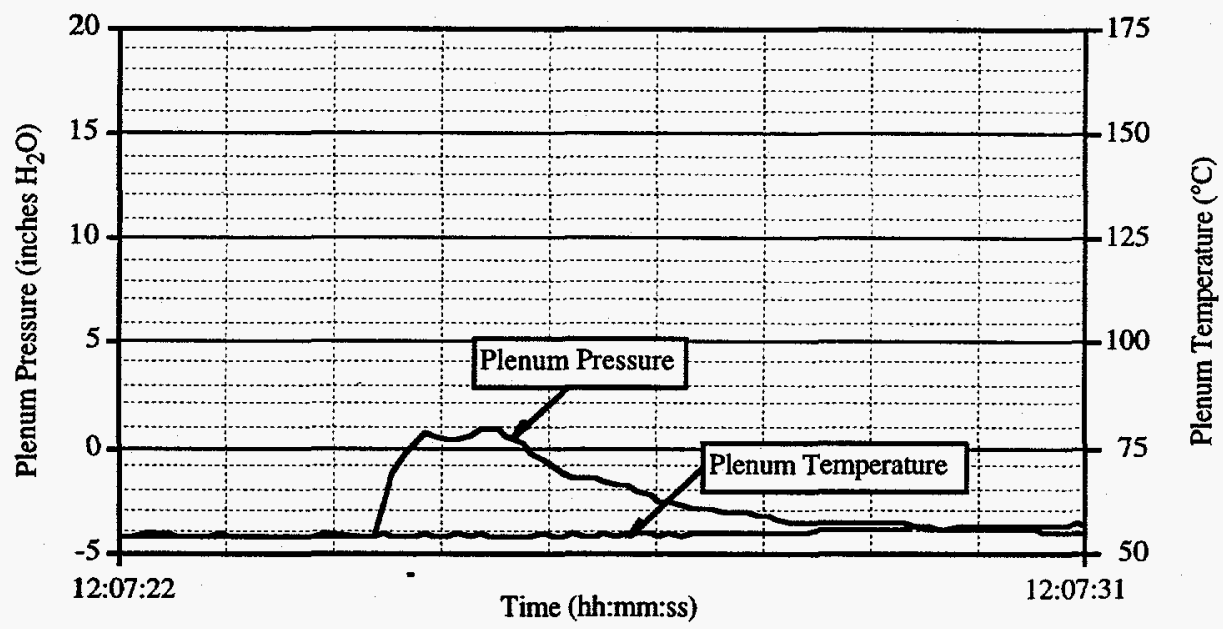

Figure 3.4.9. ORNL-ESBW-1c Plenum Pressure and Temperature Transients While Processing the Top Layer of Cans.

transients associated with processing the top layer of cans brought the plenum pressure up approximately 5 inches water, from -4 inches water gauge to about +1 inch water gauge. The transient associated with the second event (Figure 3.4.11) indicates a much more significant rise in plenum pressure -- from -4 inches water gauge to +14 inches water gauge, about 18 inches water. The plenum pressure and temperature response generated by the final event is presented in Figure 3.4.12. As this figure indicates, the pressure rise was comparable to (though slightly 
higher than) that realized while processing the top layer of cans. In each of these figures, the disparity in the time scale for response between the pressure and temperature transients is clearly evident. The pressure spikes last only a matter of seconds (with the peaks occurring very rapidly after initiation of the event), while the temperature transients are much more long lived. With this in mind, it seems likely that a water spray system will be relatively ineffective at mitigating the pressure consequences of a GDE. Water spray will be more effective at reducing the severity of the slower temperature transients, however.

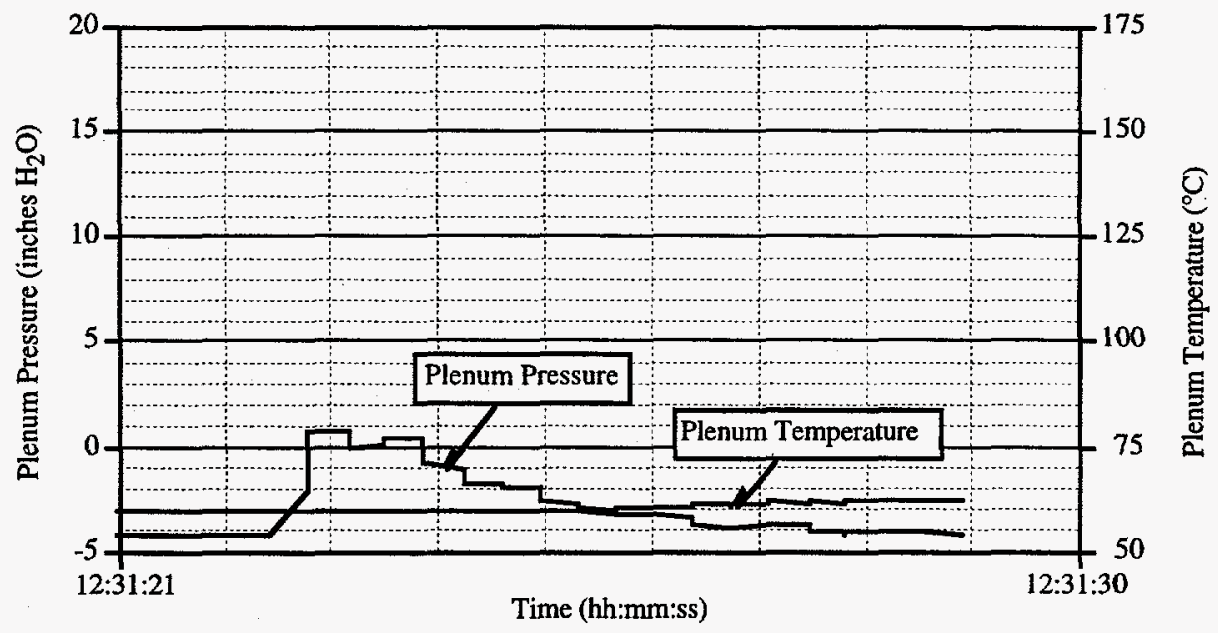

Figure 3.4.10. ORNL-ESBW-1c Plenum Pressure and Temperature Transients While Processing the Top Layer of Cans.

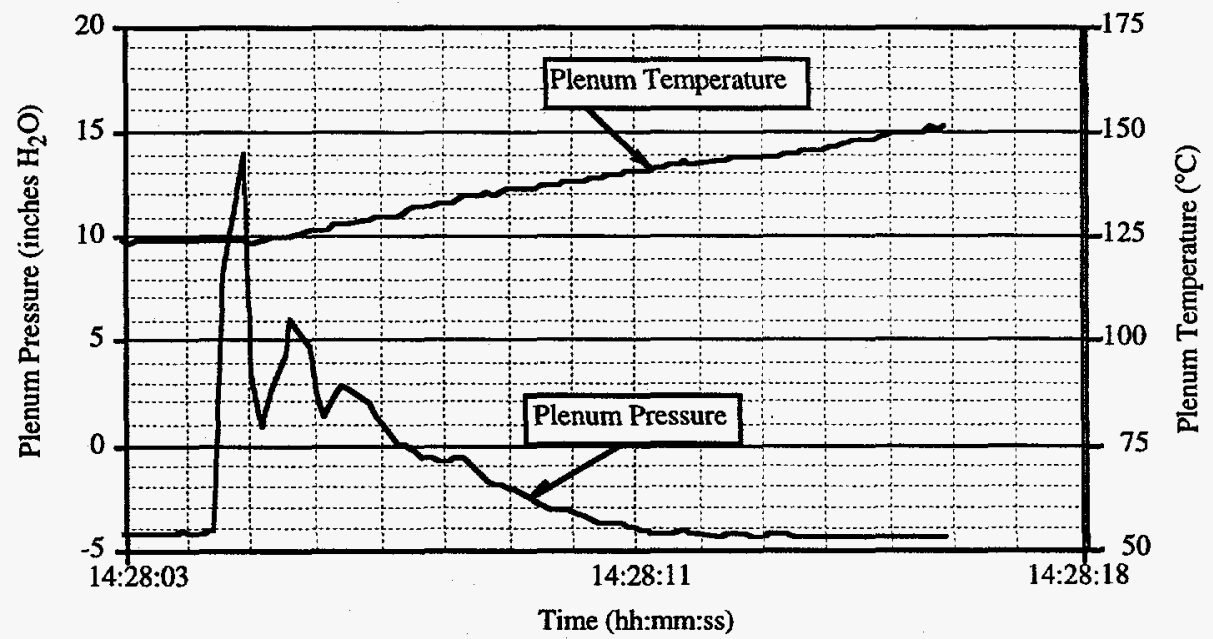

Figure 3.4.11. ORNL-ESBW-1c Plenum Pressure and Temperature Transients While Processing the Middle Layer of Cans. 


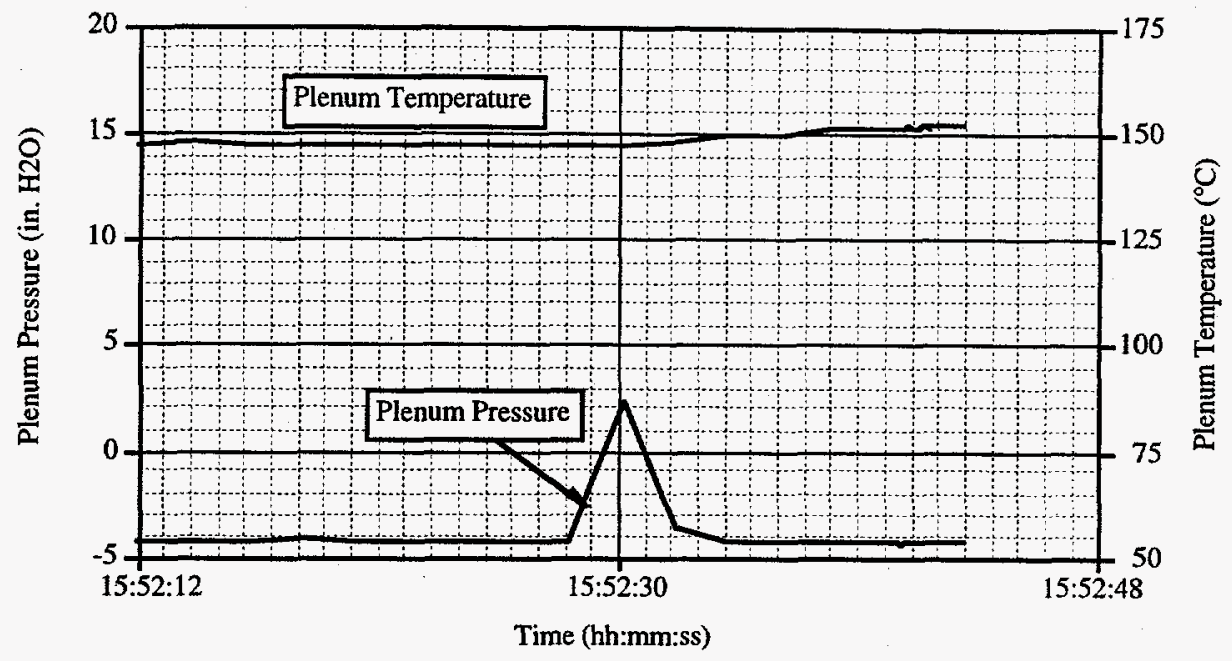

Figure 3.4.12. ORNL-ESBW-1c Plenum Pressure and Temperature Transients While Processing the Bottom Layer of Cans.

\subsubsection{ISV Block Statistics}

A $208 \mathrm{~kg}$ block was produced in this test. As indicated above, $178 \mathrm{kWh}$ were consumed in this process. Therefore, the specific energy consumption for this test was $0.86 \mathrm{kWh} / \mathrm{kg}$. This is an increase in efficiency over that realized in the preceding tests. Typically, the melt grows more rapidly during the early phases of the process. Since this melt was smaller than the others, and the test was completed in less time, the reduced specific energy consumption results.

A total of $5.2 \mathrm{~kg}$ of glass was expelled from the melt during the three pressurization events realized in this test.

\subsubsection{Test Retrospective}

This test involved the processing of six factory-sealed steel canisters. Each canister contained $6 \mathrm{oz}$ of hydrous, organic matter. The cans were staged two to a layer at three elevations in the target vitrification zone.

Three distinct, significant plenum pressure/temperature excursions were produced during this test. The events corresponded to the times during which each layer of cans was being processed. While the plenum transients were significant, they were readily accomodated by the design of the ISV off-gas hood and its associated pressure-reilef systems. Therefore, the composition and 
staging of the cans used in this test, together with the response generated during the processing of these cans, can serve as a baseline for the follow-on top-down melts produced in this effort. 


\subsection{ORNL-ESBW-2 TEST}

The results of the ORNL-ESBW-1c test provided an acceptable baseline against which to compare the results of ISV processing simulated waste containers with and without pre-processing by dynamic compaction. The ORNL-ESBW-1c test involved six $6 \mathrm{oz}$ commercially-sealed steel cans of hydrous, organic material strategically placed in the target vitrification zone. This test reproduced the ORNL-ESBW-1c arrangement of simulated waste canisters, pre-process them with dynamic compaction, and then treat the trench using ISV.

\subsubsection{Test Configuration}

This test reproduced the ORNL-ESBW-1c arrangement of simulated waste canisters, preprocessed them with dynamic compaction, and then treated the trench using ISV. Since this test involved pretreatment with dynamic compaction (DC) however, a modification to the staging procedure was required. The arrangement of cans staged in the target vitrification zone was the same as was used in the ORNL-ESBW-1c test. This configuration is depicted in plan and elevation schematics presented in Figures 3.5.1 and 3.5.2.

The cans were staged in a transfer container to facilitate pretreatment with DC, instrumentation, and subsequent placement in the ISV container. The centerline thermocouple lance could not be placed in the target vitrification zone before pretreatment with DC as the process would, at the very least, alter the position and configuration of the thermocouple bundle. Therefore, a plywood container was constructed such that the cans and soil could be arranged as depicted in Figures 3.5.1 and 3.5.2. This container was designed to allow insertion of the thermocouple bundle up through the bottom of the transfer container following pretreatment with DC, but prior to final placement in the ISV vessel. In addition, the transfer container walls were arranged so that the container could be disassembled once it had been placed in the ISV vessel. A picture of this container as it existed following pretreatment with $\mathrm{DC}$, but just prior to final burial and disassembly in the ISV vessel is provided in Figure 3.5.3. The contents following the burial process is presented in Figure 3.5.4. 


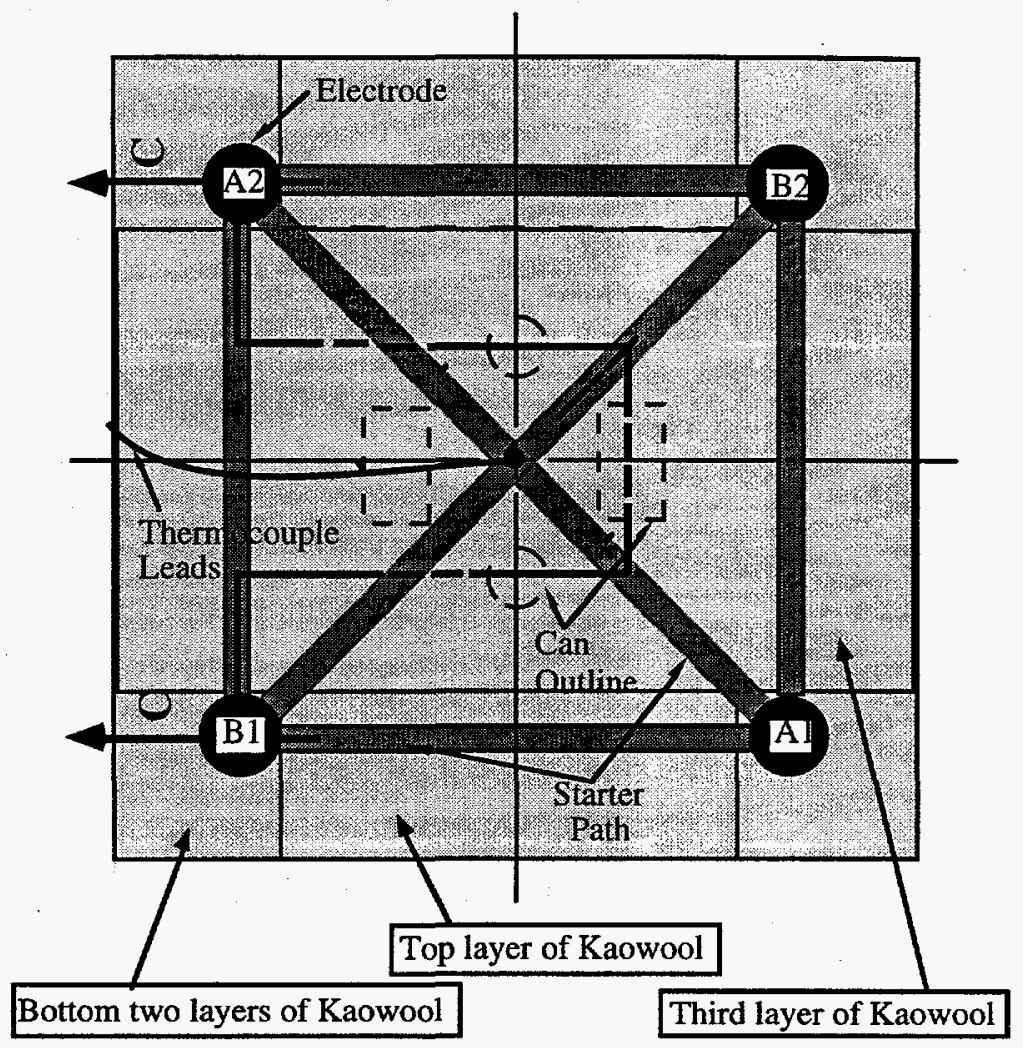

Figure 3.5.1. ORNL-ESBW-2 Test Configuration - Plan View.

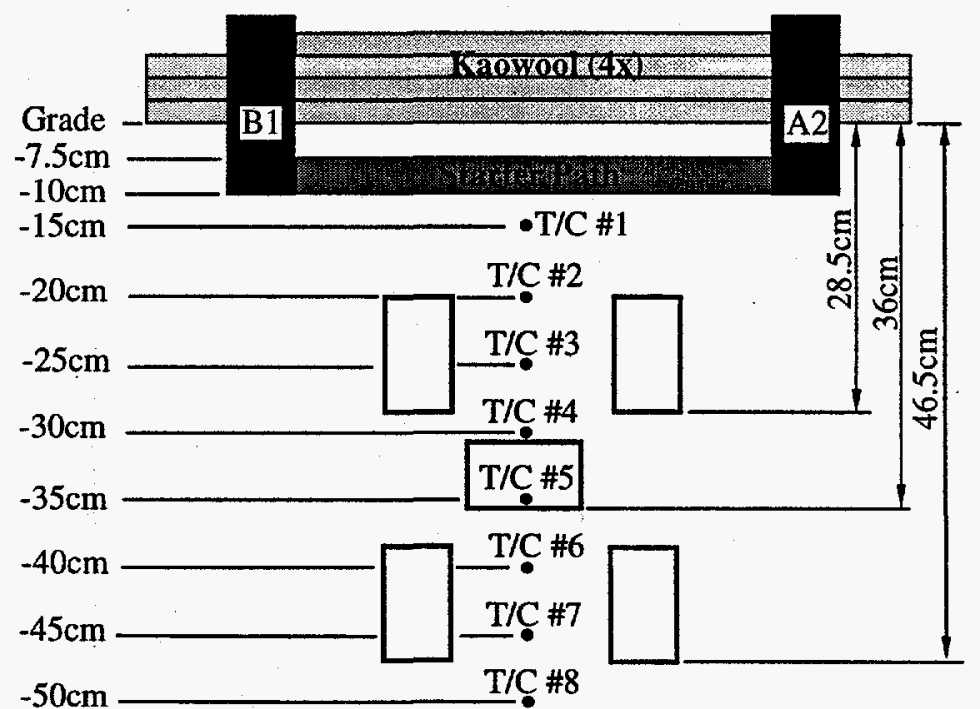

Figure 3.5.2. ORNL-ESBW-2 Test Configuration - Elevation View (Section C-C). 


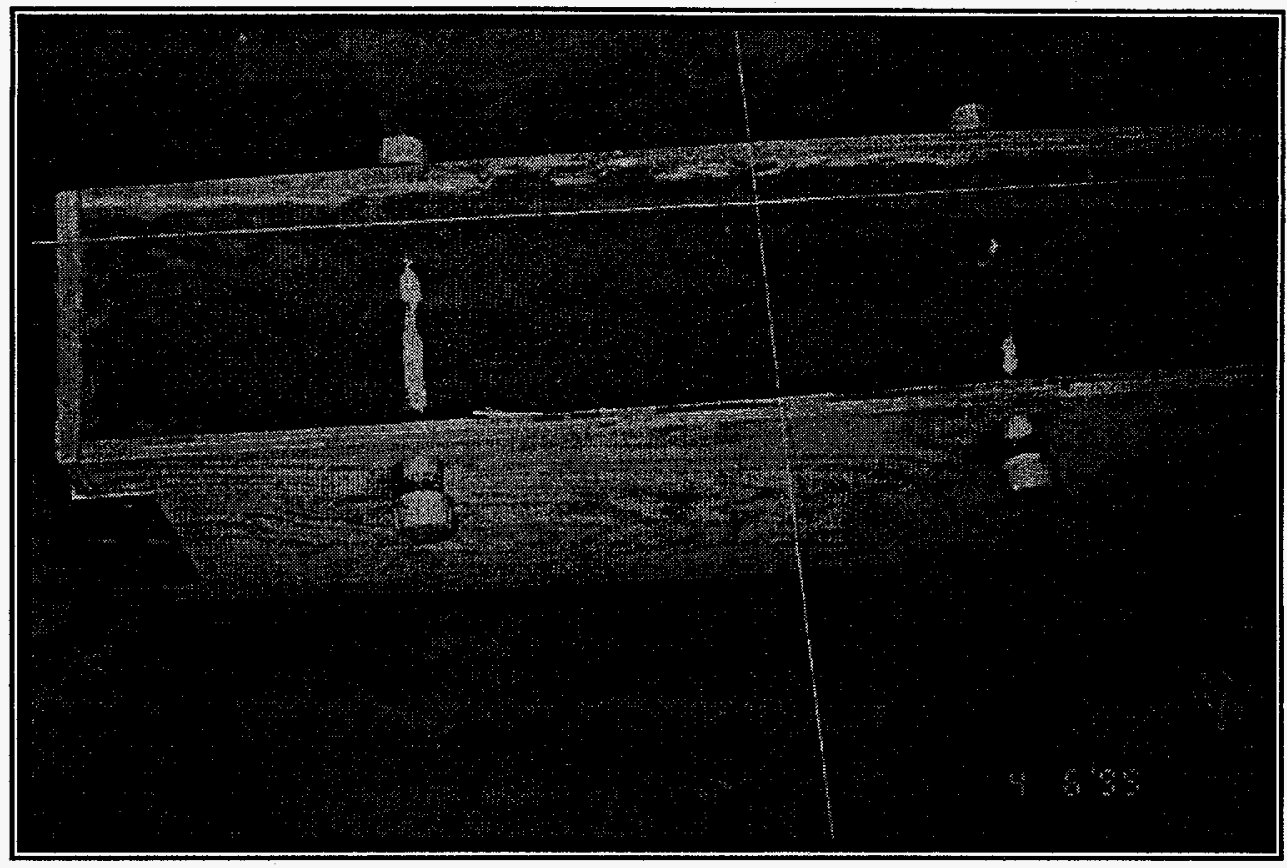

Figure 3.5.3. ORNL-ESBW-2 Transfer Container - Pre-burial Stage.

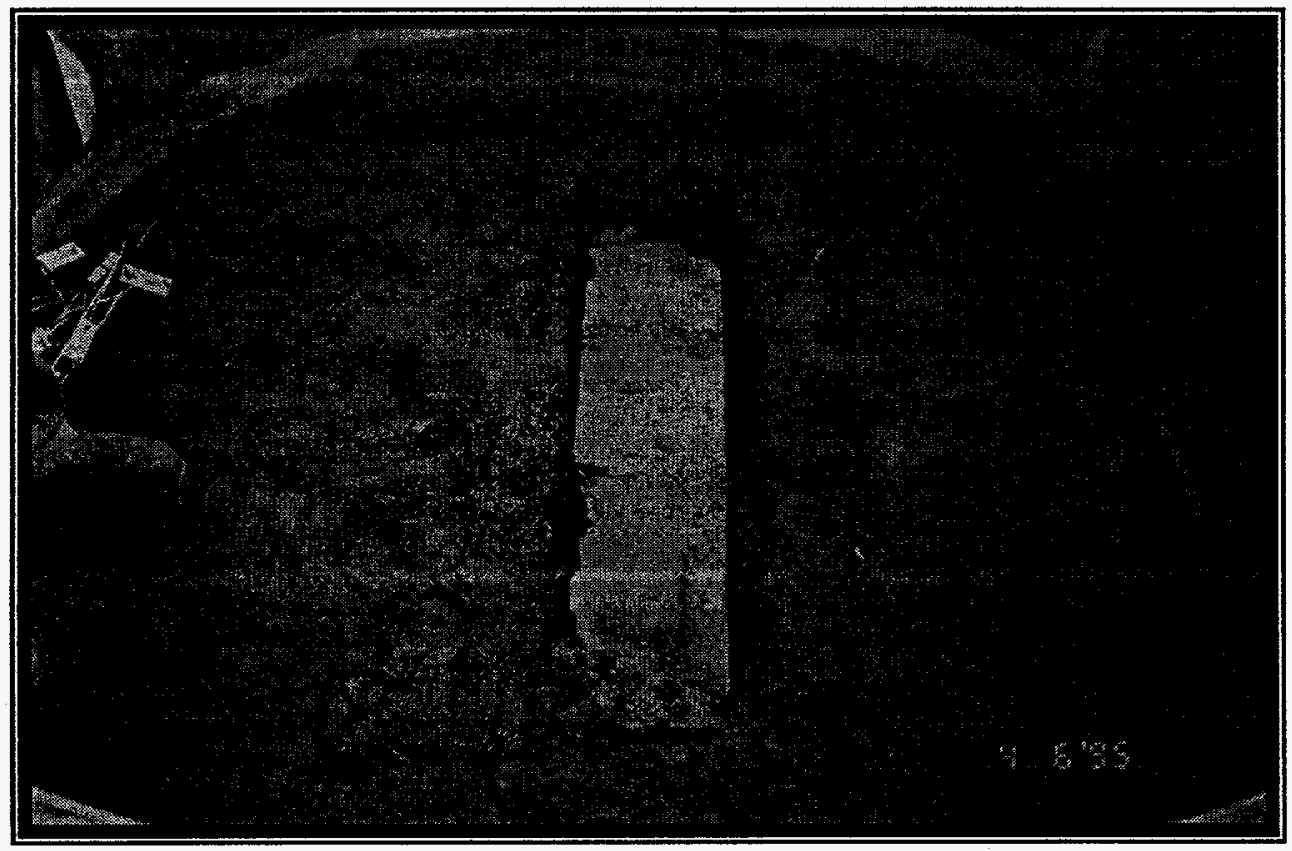

Figure 3.5.4. ORNL-ESBW-2 Transfer Container - Post-burial Stage. 
The DC process was effected by repeatedly dropping a heavy object onto the soil surface of the target vitrification zone. A regular drop pattern was utilized to "cover" this region. The drop weight, fall height, and number of drops were scaled-down from that employed in the series of tests performed on an ORNL Buried Waste trench (Spalding 1985). Scaling information provided in Mayne et al. (1984) was also utilized to size the components of the engineering-scale DC system.

The ORNL DC tests were performed on an actual buried waste trench at the ORNL site. In this large-scale application, a $4000 \mathrm{~kg}$ weight was dropped 1000 to 1500 times on the surface of the trench. Drop heights ranged from $4 \mathrm{~m}$ to $8 \mathrm{~m}$. For this engineering-scale test, the ORNL conditions were scaled-down to match the energy density applied to the trench volume and the impact "pressure" of the drop weight. As a consequence of this scaling, an $18 \mathrm{~kg}$ mass would need to be dropped 90 times from a height of $4.5 \mathrm{~m}$ above the engineering-scale replica of the trench to achieve the target energy density over the entire surface of the trench. Moreover, the drop pattern must uniformly cover the surface of the trench. The $18 \mathrm{~kg}$ slug had a diameter of approximately $9 \mathrm{~cm}$. Thus, it required 22 drop sites (in a $2 \times 11$ pattern) to cover the surface of the trench. This means 4 drops per setting were required to approximate the target energy density for the compaction process. Since the six cans were staged in a restricted region of the trench however, rather than drop the mass this many times over just soil, the number of drops were reduced to 24, and were concentrated over the central region of the trench where the cans had been staged. Four drops per setting were made in a $2 \times 3$ pattern centered over the target vitrification zone.

\subsubsection{Test Instrumentation}

As mentioned above, the target vitrification zone was instrumented with an array of 8 type " $\mathrm{K}$ " thermocouples placed along the vertical centerline of the setup. The positioning of these thermocouples is indicated in Figure 3.5.2. This arrangement is consistent with the soil temperature measurements taken in the baseline test for this sequence, ORNL-ESBW-1c. The remaining suite of pressure, temperature, heat flux, and electrical measurements were also configured as per the ORNL-ESBW-1c test. 


\subsubsection{Test Start-Up and Operation}

As was done for the preceding tests, a linear power ramp from $0 \mathrm{~kW}$ to $25 \mathrm{~kW}$ in the first two hours of operation of this test was targeted. The system was maintained at this $25 \mathrm{~kW}$ power level for the duration of the test.

The system was energized at 10:30 PDT on April 7, 1995. A linear ramp-up in power was performed until the target steady-state power level of $25 \mathrm{~kW}$ was attained at $12: 30(\Delta \mathrm{t} \approx 2 \mathrm{~h})$. Thereafter the power was maintained at this $25 \mathrm{~kW}$ level.

The test proceeded without incident. All three levels of cans were processed with no discernable plenum pressure and/or temperature excursions. There was one interruption to the electrical system, however. Apparently a line surge (not related to the ISV test) caused the electrical system DAS to shutdown. This occurred at 15:50 PDT $(\Delta \mathrm{t} \approx 5.3 \mathrm{~h})$. The system was restarted without consequence to the ISV melt and the test proceeded.

The test was completed at $18: 40$ that evening $(\Delta t \approx 8.2 \mathrm{~h})$. A total of $178 \mathrm{kWh}$ were consumed in this test.

\subsubsection{Phase Voltage, Current, and Resistance Results}

Figure 3.5.5 illustrates the voltage, current, and resistance transients experienced by each phase of the power supply system. The temporary shutdown mentioned above is evident in this figure. As with all the preceding tests, this test also exhibited very good electrical balance between phases.

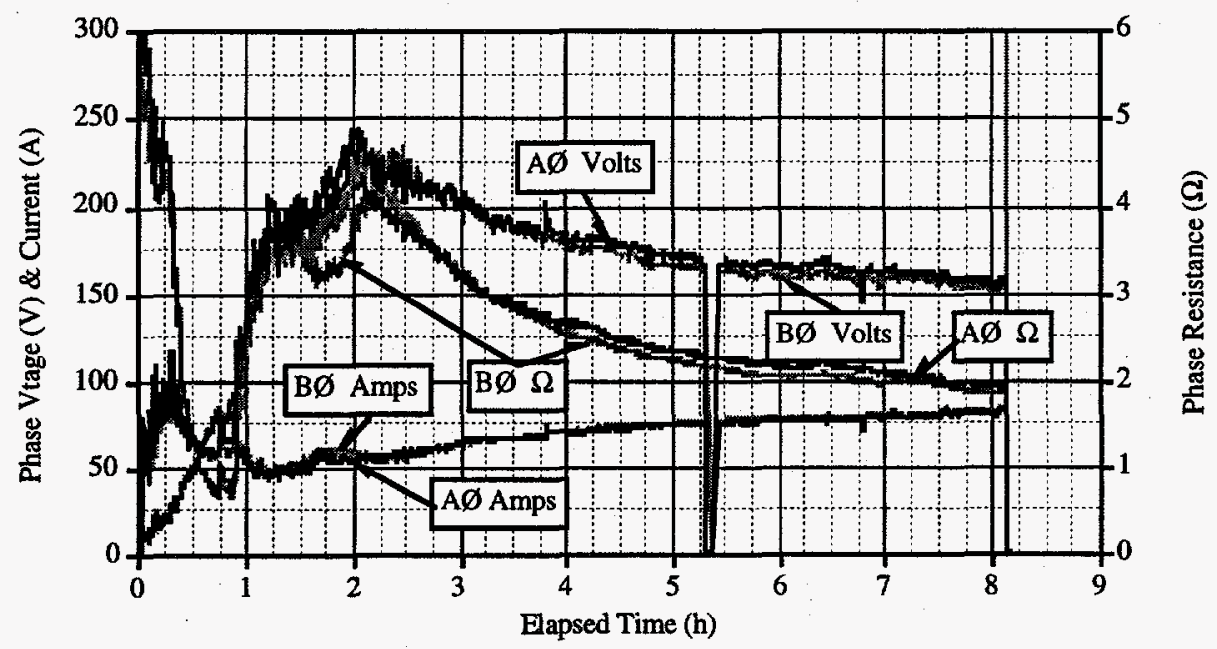

Figure 3.5.5. ORNL-ESBW-2 Phase Voltage, Current, and Resistance Transients. 
Figure 3.5.6 presents the corresponding phase power, total power, and energy consumption transients realized in this test. Again, the balance between phases is evident, as is the uniformity of the $25 \mathrm{~kW}$ steady-state power level. As this figure indicates, approximately $178 \mathrm{kWh}$ were consumed to produce this melt.

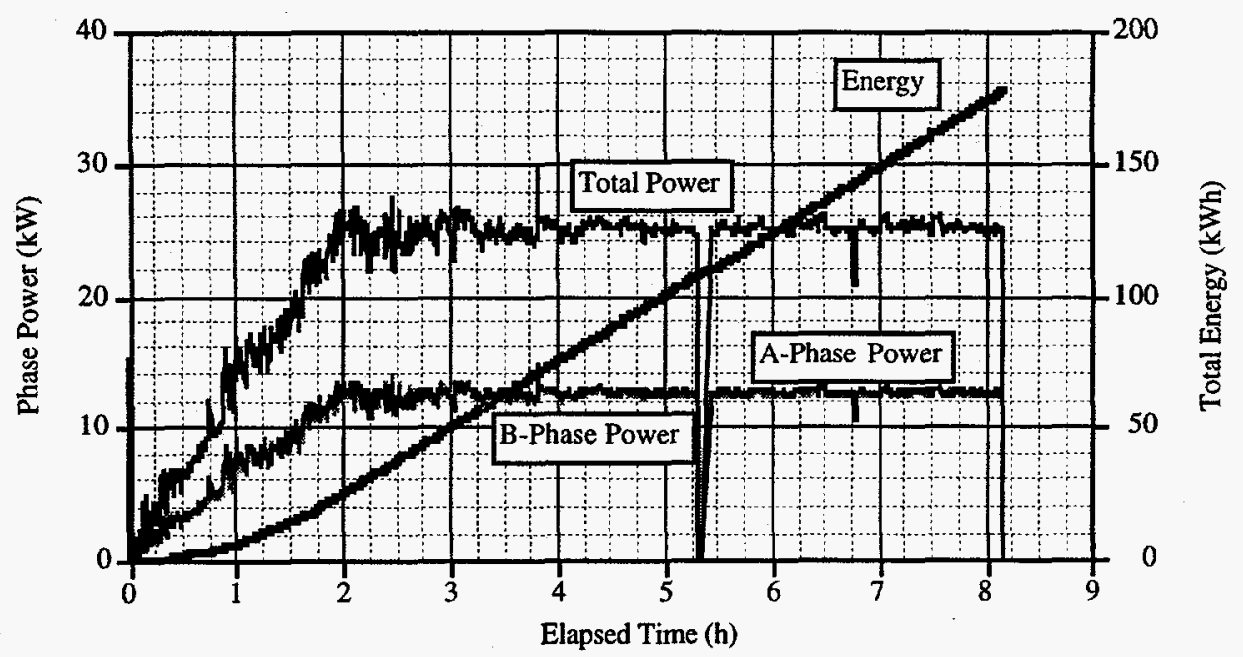

Figure 3.5.6. ORNL-ESBW-2 Phase Power, and Total Power \& Energy Transients.

\subsubsection{Electrode Depth and Soil Temperature Results}

Due to a file conversion error during downloading of the centerline thermocouple data following the test, all this data was lost. The average electrode data was recorded manually and was therefore still available. These data are presented in Figure 3.5.7. The data are consistent with those obtained in all the previous tests.

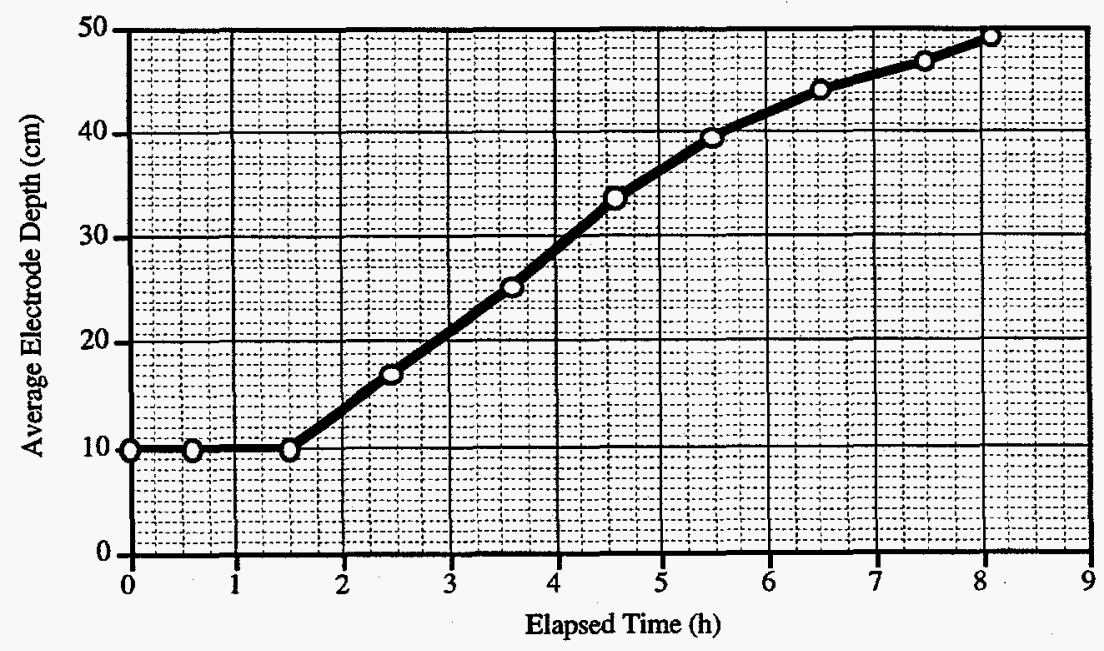

Figure 3.5.7. ORNL-ESBW-2 Electrode Depth Transient. 


\subsubsection{Plenum Pressure and Temperature Results}

The plenum pressure and temperature transients experienced during this test are plotted in Figure 3.5.8. As indicated, both the plenum pressure and temperature responses were wellbehaved throughout the course of the test.

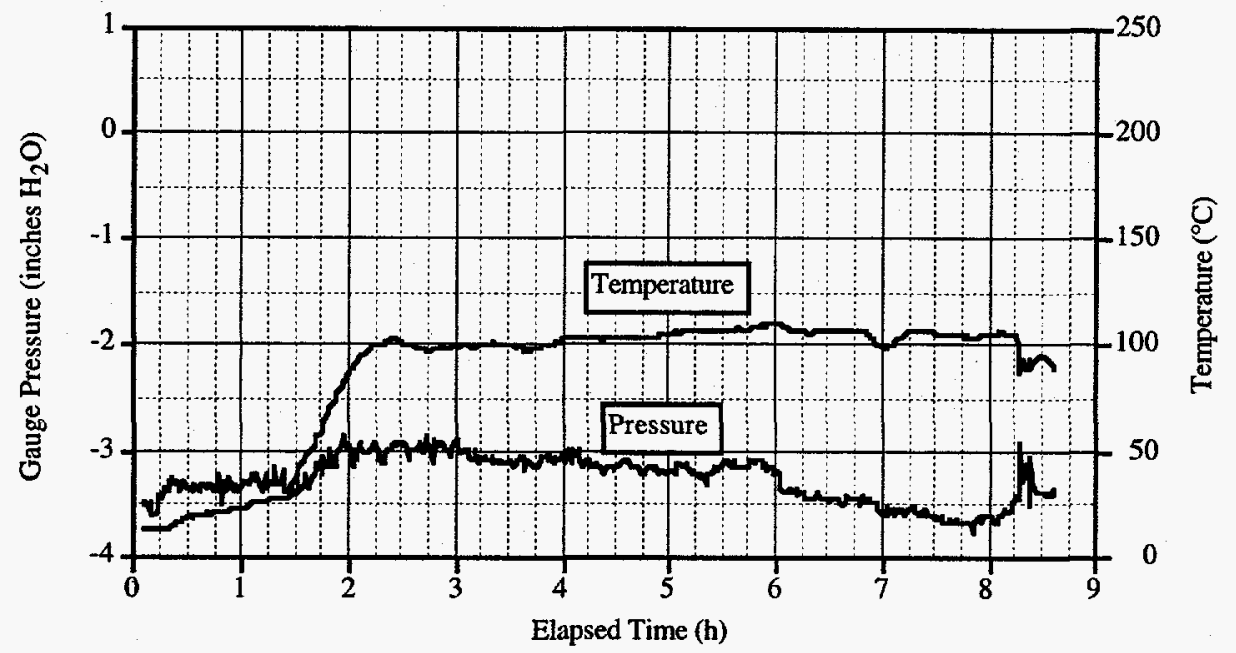

Figure 3.5.8. ORNL-ESBW-2 Plenum Pressure and Temperature Transients.

\subsubsection{ISV Block Statistics}

A $209 \mathrm{~kg}$ block was produced in this test. This, together with the $178 \mathrm{kWh}$ required to produce this mass, indicates that the specific energy consumption was $0.85 \mathrm{kWh} / \mathrm{kg}$. This block was a virtual carbon copy of that generated in the previous ORNL-ESBW-1c test -- despite the numerous GDEs experienced in that test.

\subsubsection{Test Retrospective}

This test involved a repeat of the preceding ORNL-ESBW-1c test, but with the target vitrification zone pretreated with DC prior to processing with ISV. The DC process employed in this test was a scaled-down version of that performed on an actual ORNL buried waste trench. The energy density and impact "pressure" employed in that full-scale application was duplicated in this scaled-down version. 
The DC pretreatment process was effective at sufficiently compromising the array of canisters staged in this test so as to preclude the generation of plenum pressure and temperature excursions during processing with ISV. 


\subsection{ORNL-ESBW-2a TEST}

In the preceding ORNL-ESBW-2 test, there were no significant pressure events registered in the off-gas plenum when any of the three layers of cans were processed. However, in each of tests ORNL-ESBW-1a, 1b, and 1c, the pressure spikes produced when processing the bottom layer of cans were significantly less than those generated when the top two layers of cans were processed -- despite the comparable configuration and staging of the cans at this bottom layer. Therefore, there remained some question whether the lack of a pressure excursion when processing cans at the bottom layer of the ORNL-ESBW-2 test was a consequence of the state of the cans at this level, or was due to something related more to the state of the melt and/or its development at this depth. Consequently, this ORNL-ESBW-2a test was devised to further investigate the extent to which the integrity of the cans must be compromised to preclude pressurization events in the off-gas plenum region.

\subsubsection{Test Configuration}

The number and arrangement of cans staged in this test was intended to duplicate the arrangement invoked in the ORNL-ESBW-1c and ORNL-ESBW-2 tests. However, for the initial setup phase of this test (prior to pretreatment with DC), all six cans were staged only at the bottom layer of the transfer container (i.e. -- placed $46.5 \mathrm{~cm}$ below grade) for pretreatment using DC. The DC process described previously in Section 3.5.1 (test ORNL-ESBW-2) was again employed to the cans used in this test. After application of the DC process, each can was recovered from the drop zone and its condition recorded.

Two of the six cans pretreated with DC were completely breached by the process. The remaining four cans were significantly deformed, but their integrity was still intact. Figure 3.6.1 provides a photographic image of the cans after pretreatment with $\mathrm{DC}$, but prior to final staging in the target vitrification zone. The two breached cans in the uppermost row of cans in this picture would clearly not generate an event during the ISV processing phase. In the interest of obtaining additional data and experience with GDEs produced by the catastrophic failure of cans during the later stages of the melt process, these two breached can were replaced with new cans. The two new cans were staged at the bottom layer of the arrangement. The remaining four deformed (but not breached) cans were staged on the middle and upper layers of the setup. The can arrangement and thermocouple instrumentation employed in this test was essentially identical to that used in the 


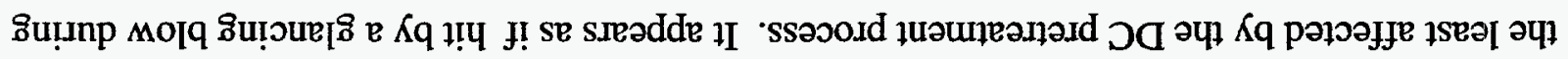

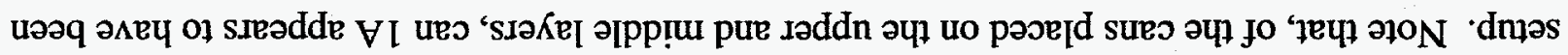

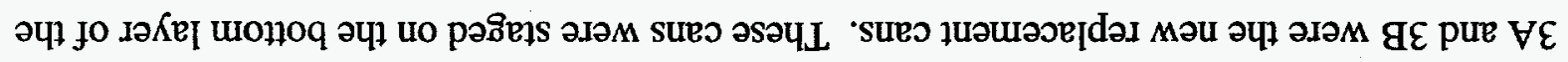

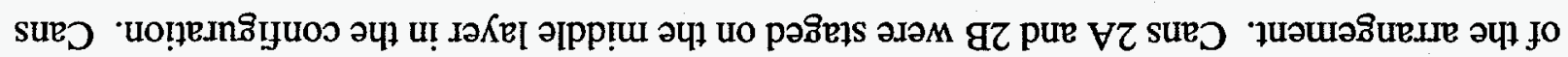

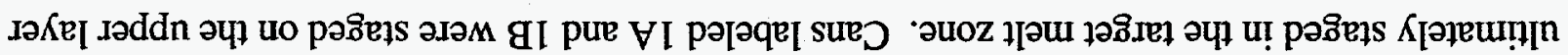

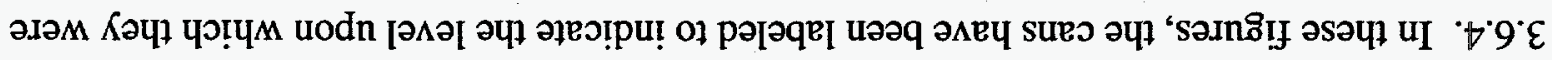

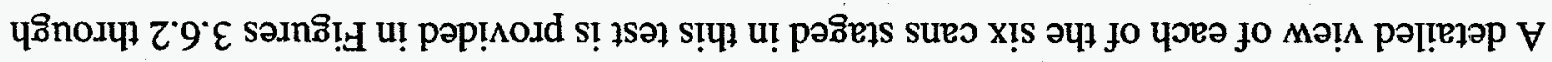

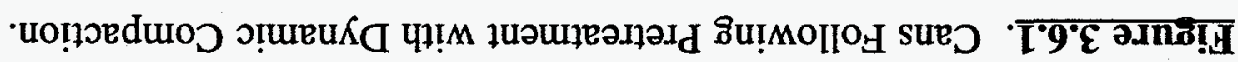

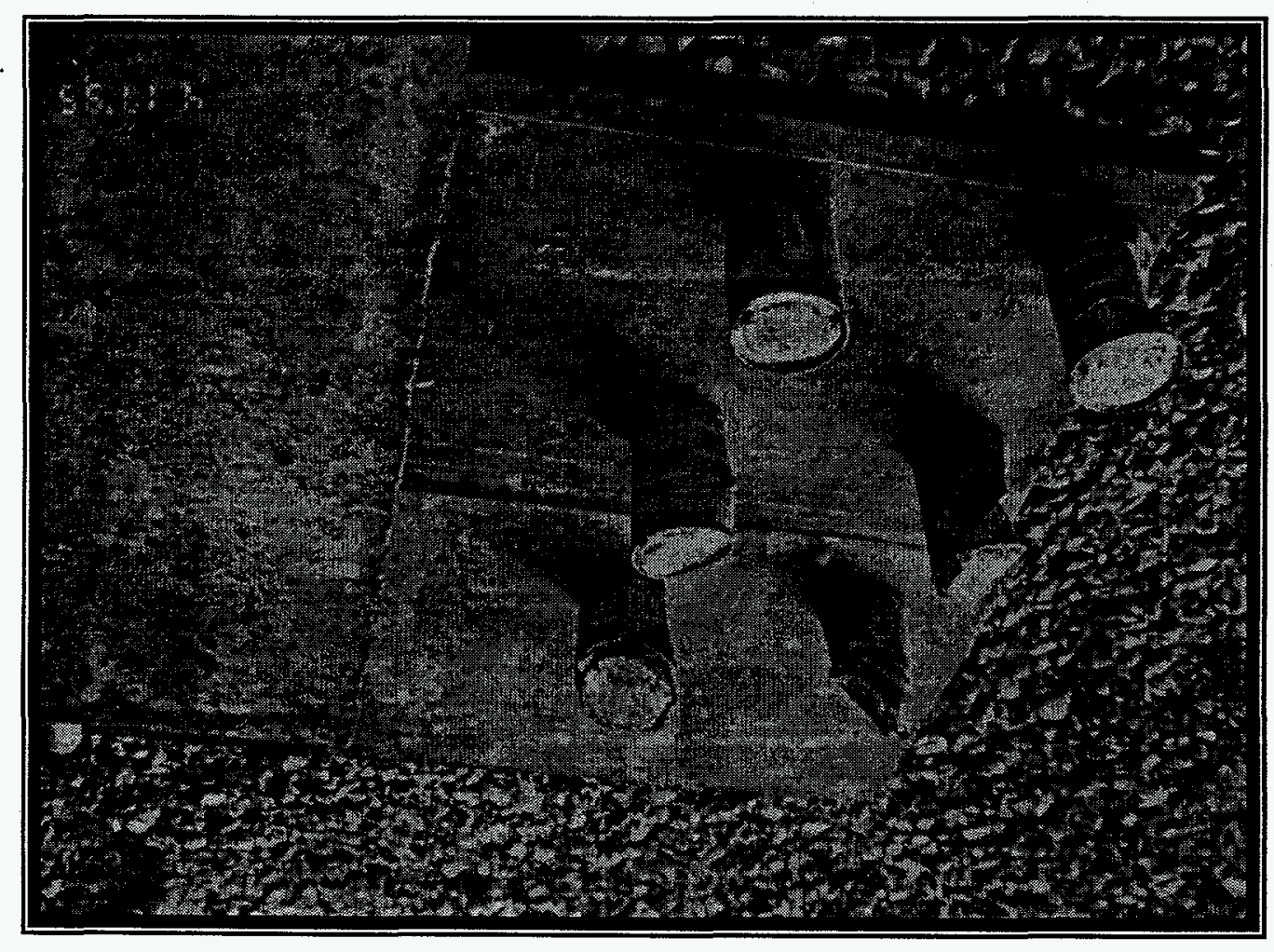

'でち•

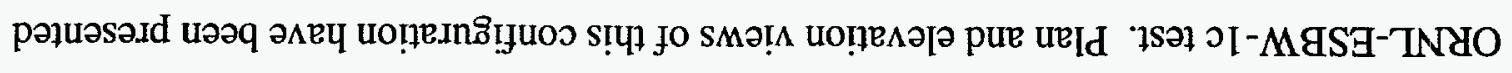




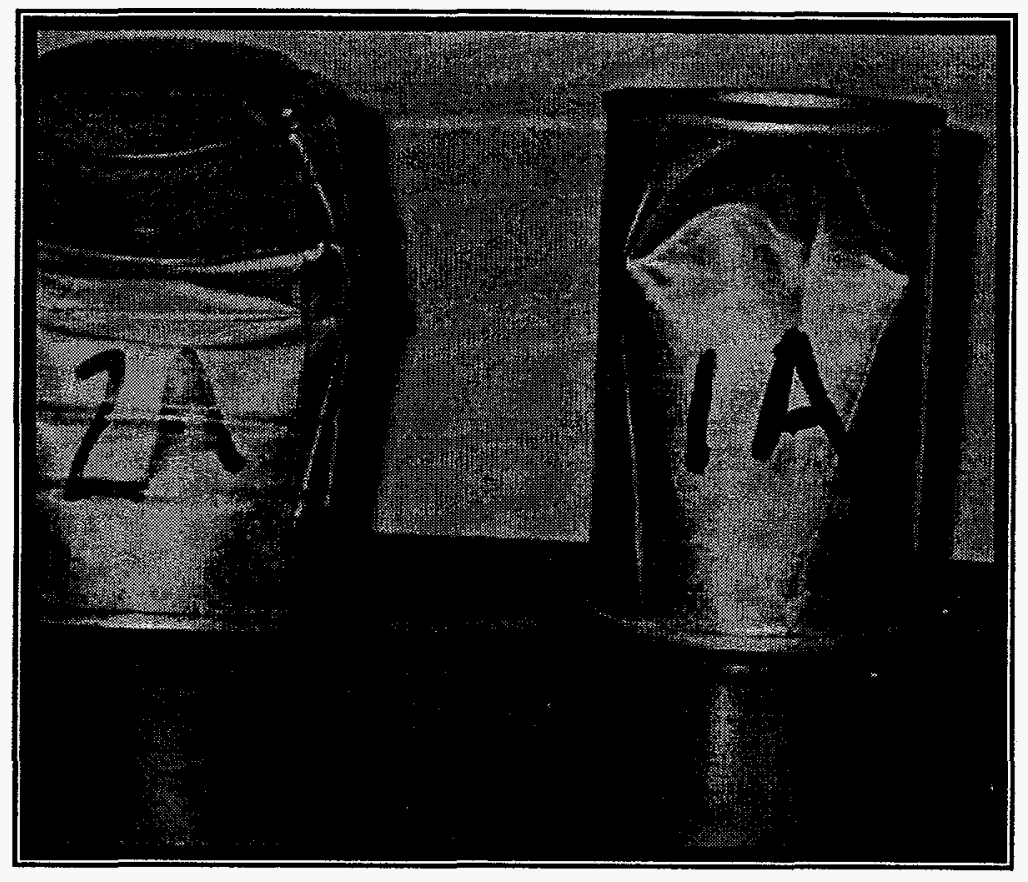

Figure 3.6.2. Detail View of Cans 1A and 2A Employed in the ORNL-ESBW-2a Test.

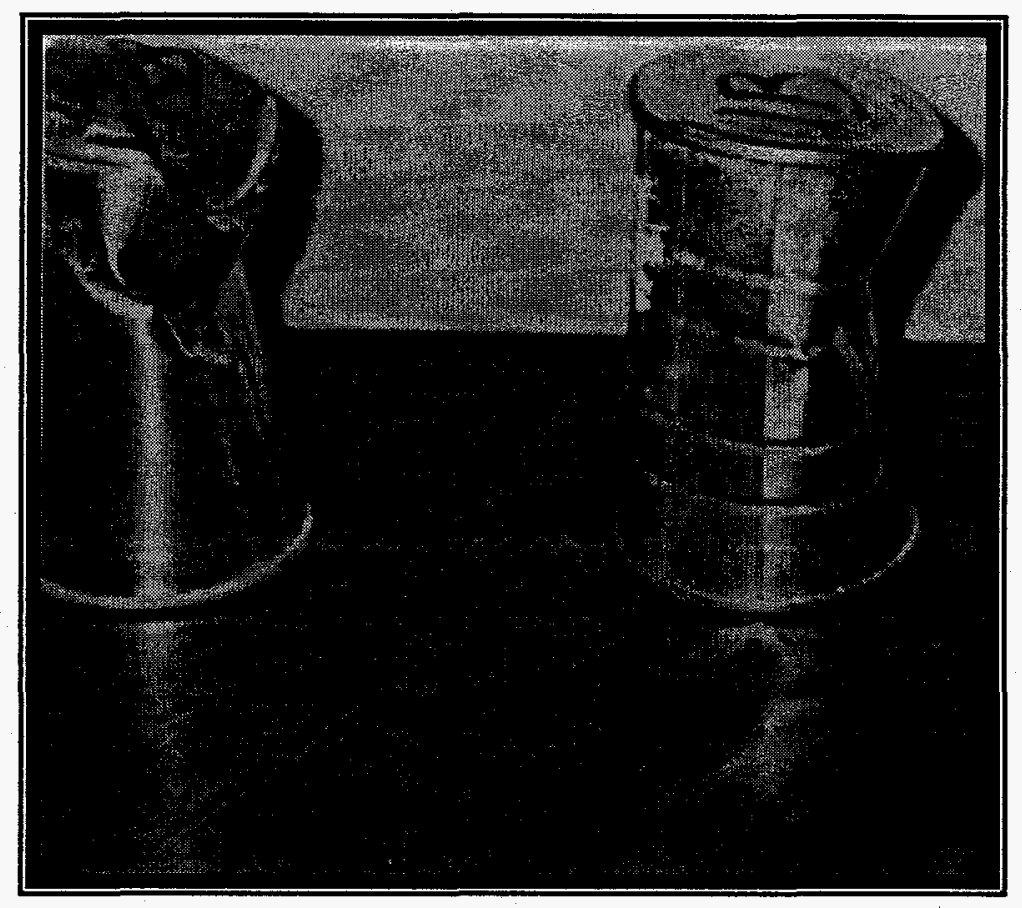

Figure 3.6.3. Detail View of Cans 1B and 2B Employed in the ORNL-ESBW-2a Test. 


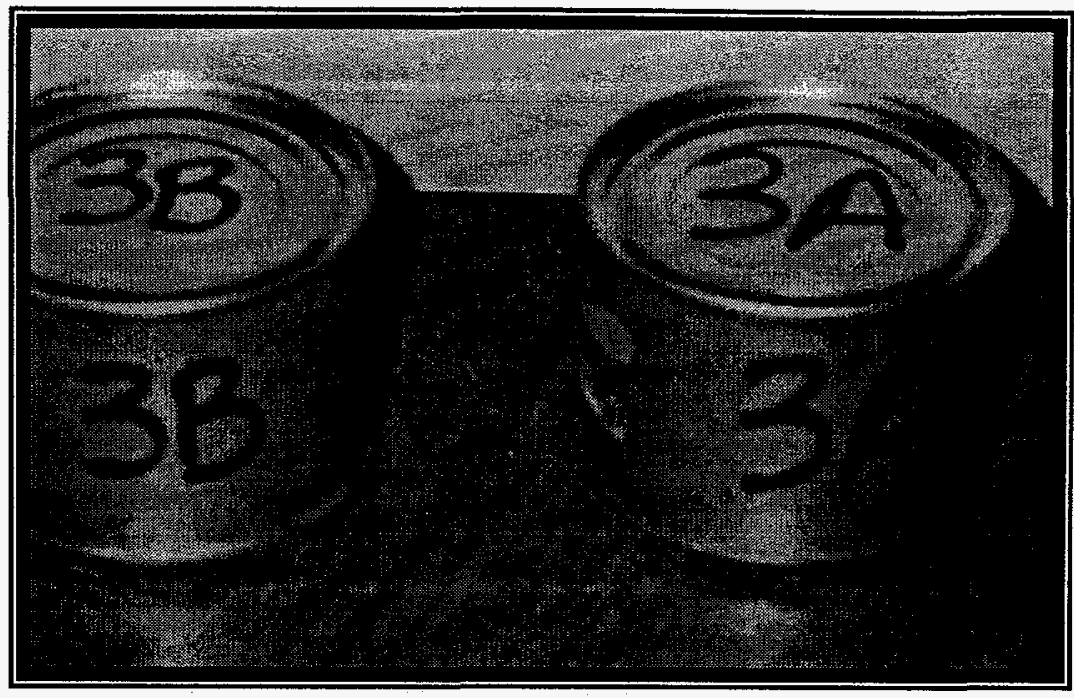

Figure 3.6.4. Detail View of Cans 3A and 3B Employed in the ORNL-ESBW-2a Test.

\subsubsection{Test Instrumentation}

The soil, plenum, and electrical systems were instrumented in the same fashion as for the previous tests. Eight type " $K$ " thermocouples were placed along the vertical centerline of the target vitrification zone as depicted in Figure 3.4.2. The plenum pressure and temperature were measured and recorded as before, as were the electrical aspects of the system.

\subsubsection{Test Start-Up and Operation}

The electrical system was energized at 08:31:30 PDT on April 19, 1995. A linear ramp-up in power was followed until the target $25 \mathrm{~kW}$ steady-state power level was attained. This occurred at approximately 10:30 $(\Delta \mathrm{t} \approx 2 \mathrm{~h})$. This $25 \mathrm{~kW}$ power level was maintained thereafter for the duration of the test.

At 11:15 ( $\Delta \mathrm{t} \approx 2.75 \mathrm{~h}$ ), while processing the top layer of cans, a plenum pressure and temperature event was experienced. This event was not of sufficient magnitude to disrupt the Kaowool, but as the plenum pressure and temperature results will indicate, it did produce a significant pulse to the off-gas plenum air space. There was also some minor expulsion of water from the seal pot reservoir in response to this event. This event was likely caused by the catastrophic rupture of can $1 \mathrm{~A}$. 
Following this first event, the test proceeded through the middle layer of cans without incident. As anticipated however, processing the bottom layer of cans did produce a significant GDE. At 16:17 ( $\Delta \mathrm{t} \approx 7.75 \mathrm{~h}$ ), a major GDE event was experienced. In fact, the video produced during this test indicates that there were two clearly distinct pulses generated during this event -one for each can placed at this layer. A considerable quantity of water was expelled from the seal pot reservoir. The "splash pattern" associated with this event is illustrated in Figure 3.6.5. A significant quantity of glass was expelled from the melt during this last event. Figure 3.6.6 was obtained from a photograph of the soil surface inside the ISV container after the test. The large glass bubble in the foreground is reminiscent of those produced during the GDEs experienced during the Geosafe OAT \#2 Test (Geosafe 1993) and the PNL UTV Test (Thompson et al. 1993).

The test was concluded at 16:38 on April $19,1995(\Delta t \approx 8.1 \mathrm{~h}$ ). As with the ORNL-ESBW$1 \mathrm{c}$ and ORNL-ESBW-2 tests, $178 \mathrm{kWh}$ were consumed in the production of this block.

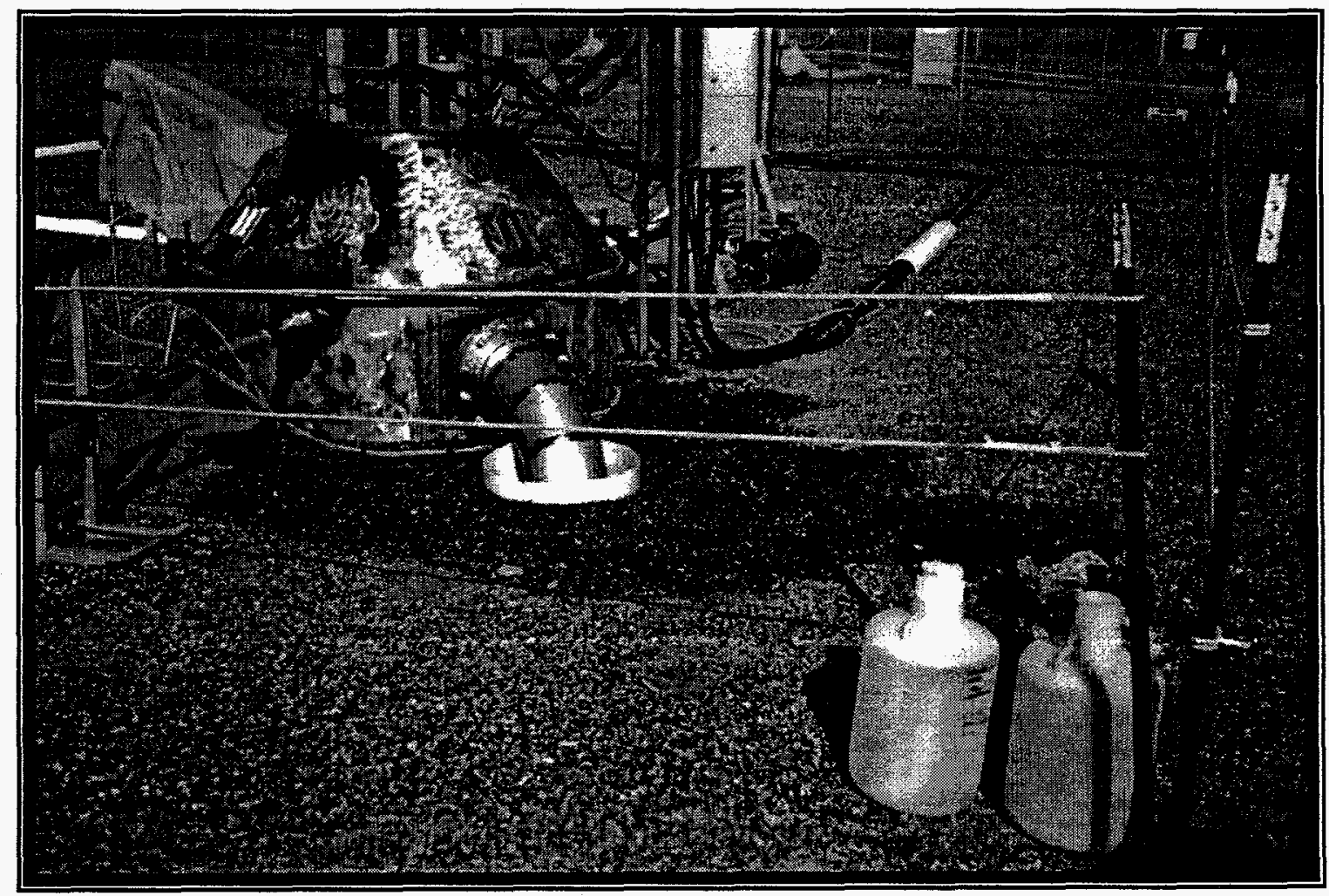

Figure 3.6.5. ORNL-ESBW-2a Test Seal Pot "Splash Pattern". 


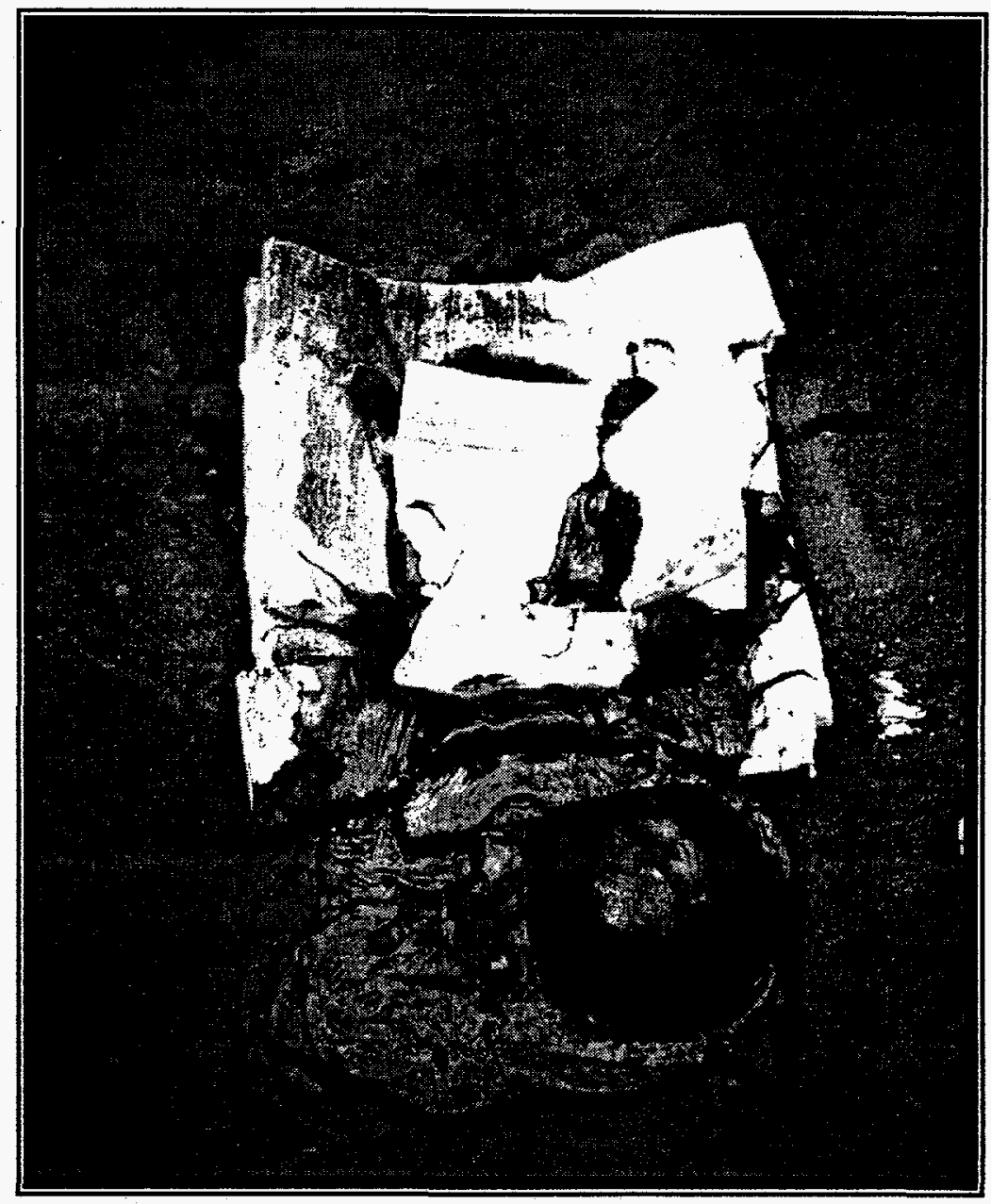

Figure 3.6.6. ORNL-ESBW-2a Test Glass Flow Pattern on the Soil Surface.

\subsubsection{Phase Voltage, Current, and Resistance Results}

Figure 3.6.7 represents a plot of the phase voltage, current, and resistance transients experienced during this test. The sharp jumps in the voltage and resistance traces at 11:15 $(\Delta t \approx 2.75 \mathrm{~h})$ and $16: 15(\Delta \mathrm{t} \approx 7.75 \mathrm{~h})$ are manifestations of the two pressurization events realized in this test. Other than these two anomalies however, these data once again exhibit the good balance obtained in the electrical system during this test. 


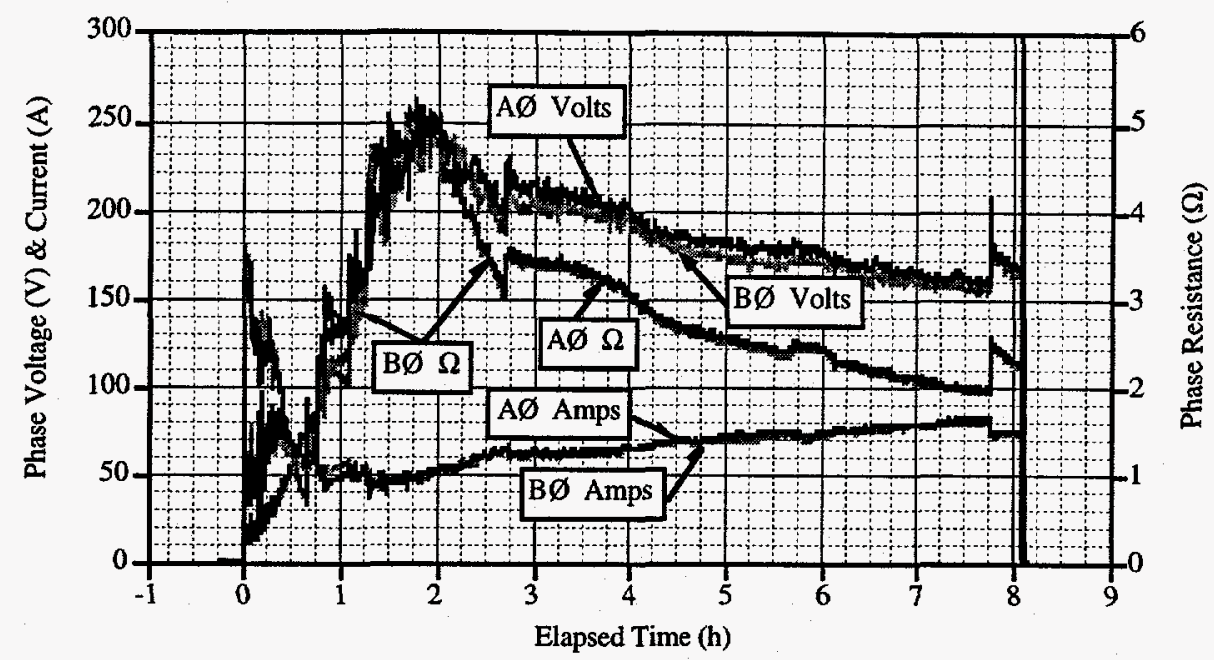

Figure 3.6.7. ORNL-ESBW-2a Phase Voltage, Current, and Resistance Transients.

The phase power, total power, and energy consumption transients experienced during this test are presented in Figure 3.6.8. As in the phase voltage and resistance traces provided in Figure 3.6.6, the sharp spikes at 11:15 $(\Delta t \approx 2.75 \mathrm{~h})$ and $16: 15(\Delta t \approx 7.75 \mathrm{~h})$ in the power curves plotted in this figure also indicate the influence of the pressurization events on the electrical system. This figure also indicates that $178 \mathrm{kWh}$ were consumed during this test.

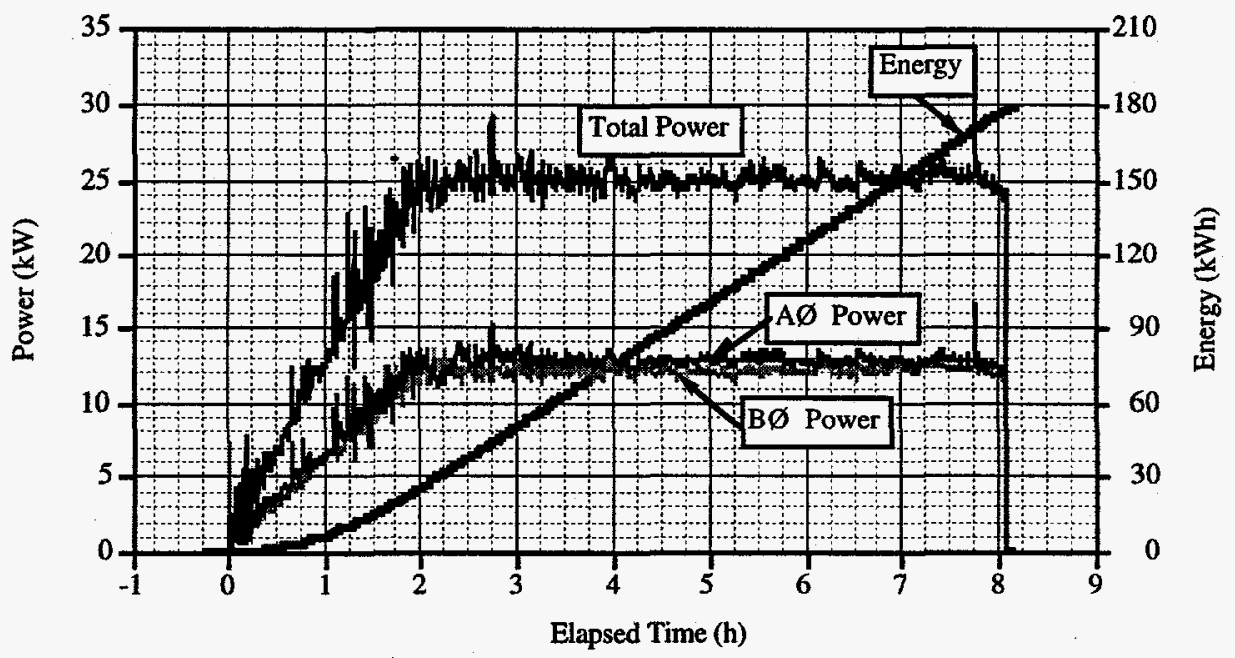

Figure 3.6.8. ORNL-ESBW-2a Phase Power, and Total Power \& Energy Transients. 


\subsubsection{Electrode Depth and Soil Temperature Results}

Figure 3.6.9 presents the average electrode depth and centerline temperature transients realized in this test. The sawtooth behavior exhibited in the trace of the 020-000-000 thermocouple's response at $11: 15(\Delta t \approx 2.75 \mathrm{~h})$ again indicates the passage of relatively cool steam that was released from a ruptured canister during an event.

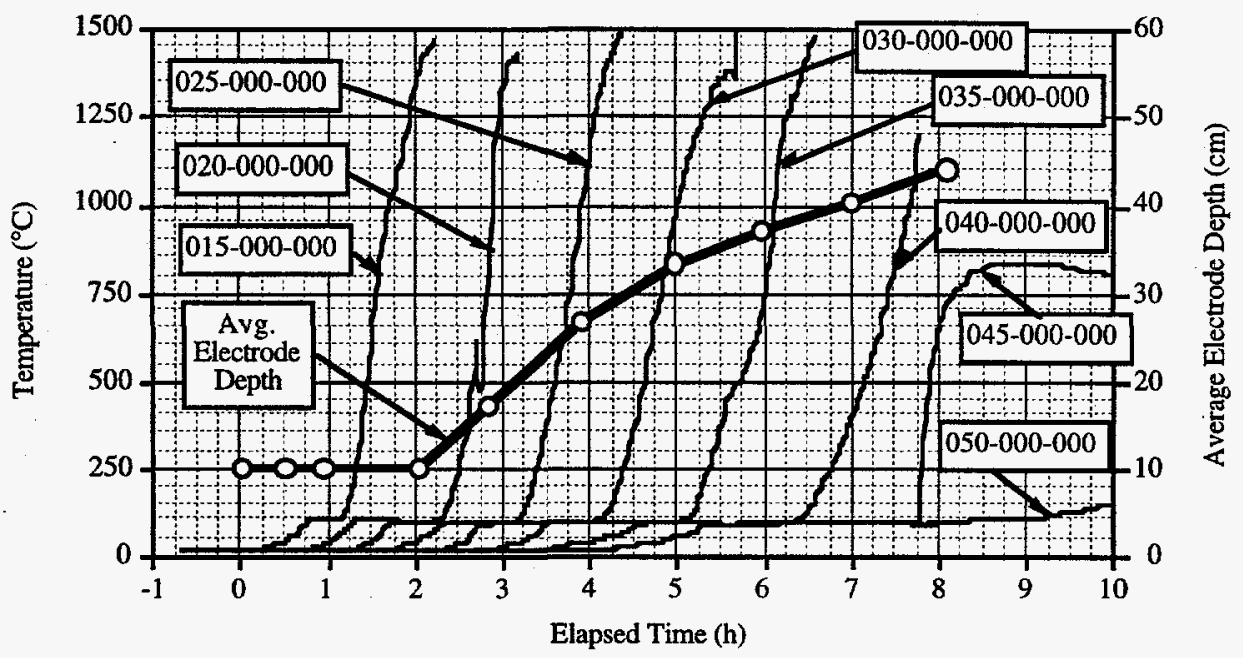

Figure 3.6.9 ORNL-ESBW-2a Electrode Depth and Centerline Temperature Transients.

\subsubsection{Plenum Pressure and Temperature Results}

The plenum pressure and temperature transients experienced around the time of the first event are presented in Figure 3.6.10. As indicated in this figure, the plenum pressure rose 9 inches w.c., from -3 inches w.c. to +6 inches w.c.. The pressurization aspects of this event lasted only a few seconds. The temperature response was considerably longer lived, however. 


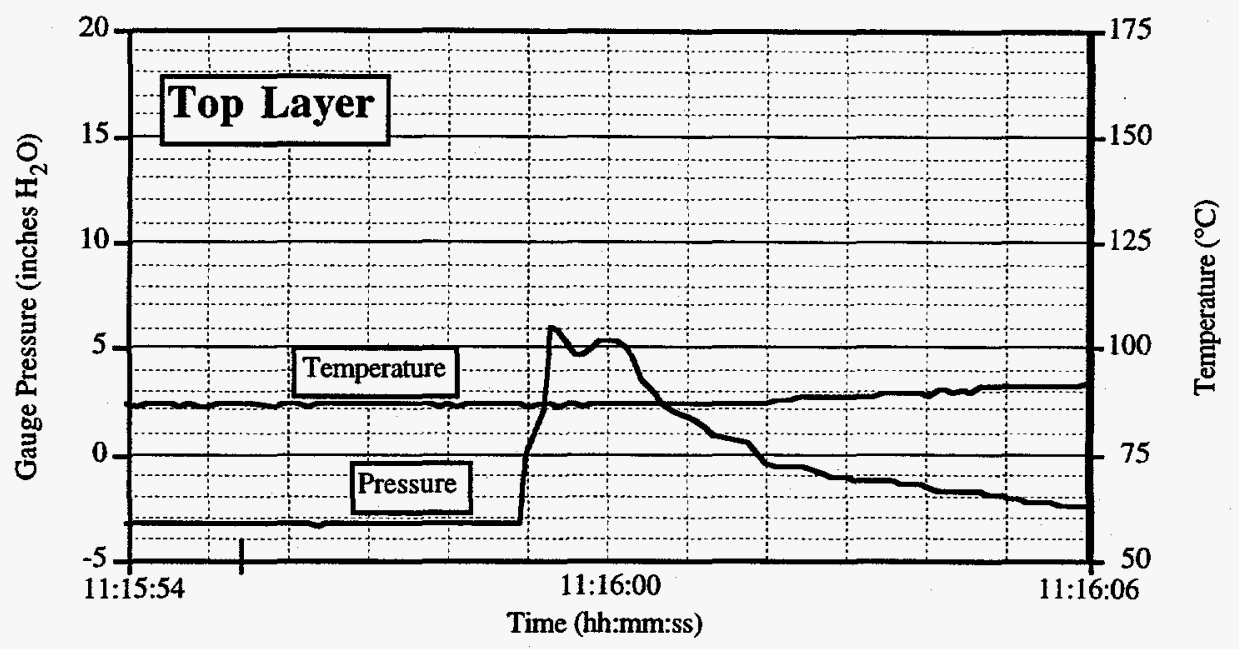

Figure 3.6.10. ORNL-ESBW-2a Plenum Pressure and Temperature Transients Produced While Processing the Top Layer of Cans.

Figure 3.6.11 presents a detailed view of the plenum pressure and temperature response during the second event realized in this test. The pressure rise experienced during this event was significantly greater than that realized while processing the top layer of cans in this test. The pressure rise was in excess of 18 inches of water. The double pulse nature of this transient is also evident in this figure.

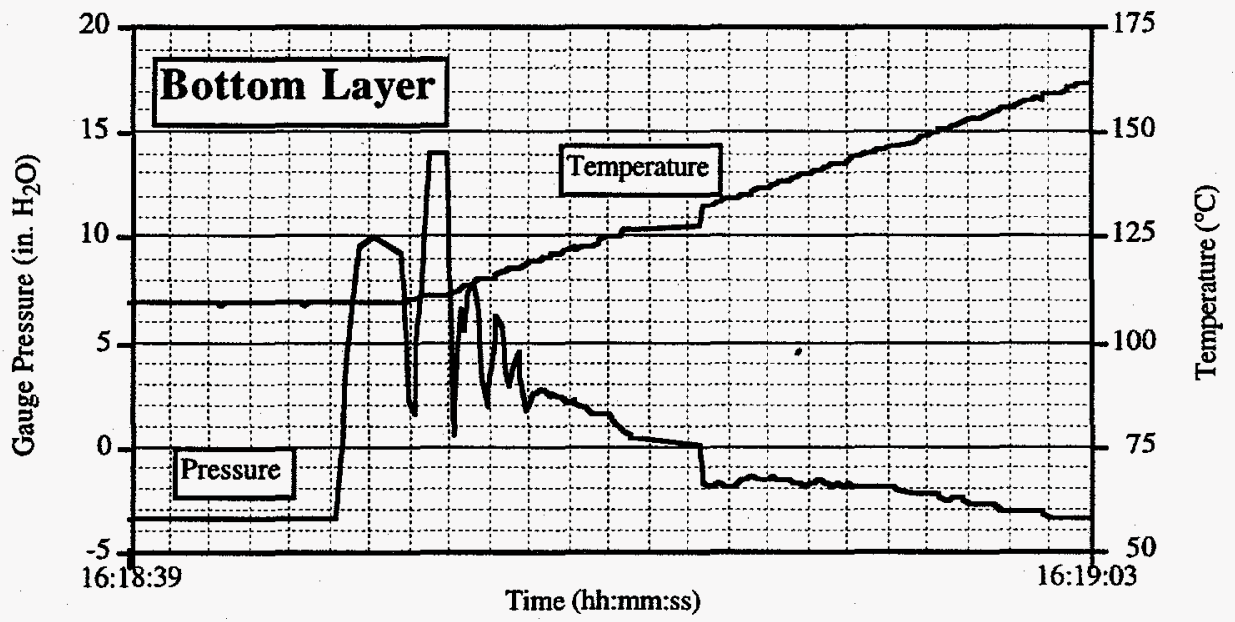

Figure 3.6.11. ORNL-ESBW-2a Plenum Pressure and Temperature Transients Produced While Processing the Bottom Layer of Cans. 
Figure 3.6.12 provides traces of the overall plenum temperature response realized during this test. The off-gas inlet temperature is also plotted in this figure. As these data indicate, the first event (at $11: 15, \Delta \mathrm{t} \approx 2.75 \mathrm{~h}$ ) produced a plenum temperature jump of approximately $20^{\circ} \mathrm{C}$. The second event (at $16: 15, \Delta t \approx 7.75 \mathrm{~h}$ ) produced a considerably greater increase in the plenum temperature - an increase of approximately $95^{\circ} \mathrm{C}$. The ISV hood and ring foundation skin temperatures and heat fluxes are also presented in this figure. As was discussed in Section 3.1.7 (ORNL-ESBW-1, Figure 3.1.12), the skin temperature of the ISV hood is higher than that of the ring foundation on which it rests. The heat flux out the ring foundation is, however, greater than that out the inclined surfaces of the ISV hood. Again, this is a consequence of the enhanced convective currents on a vertical surface (viz., the ring foundation wall) vis-à-vis those on the inclined surface of the ISV hood. The heat fluxes off both surfaces are comparable to those realized in the ORNL-ESBW-1 test - approximately $250 \mathrm{~W} / \mathrm{m}^{2}$ on the ISV ring foundation, and approximately $200 \mathrm{~W} / \mathrm{m}^{2}$ on the inclined surface of the ISV hood.

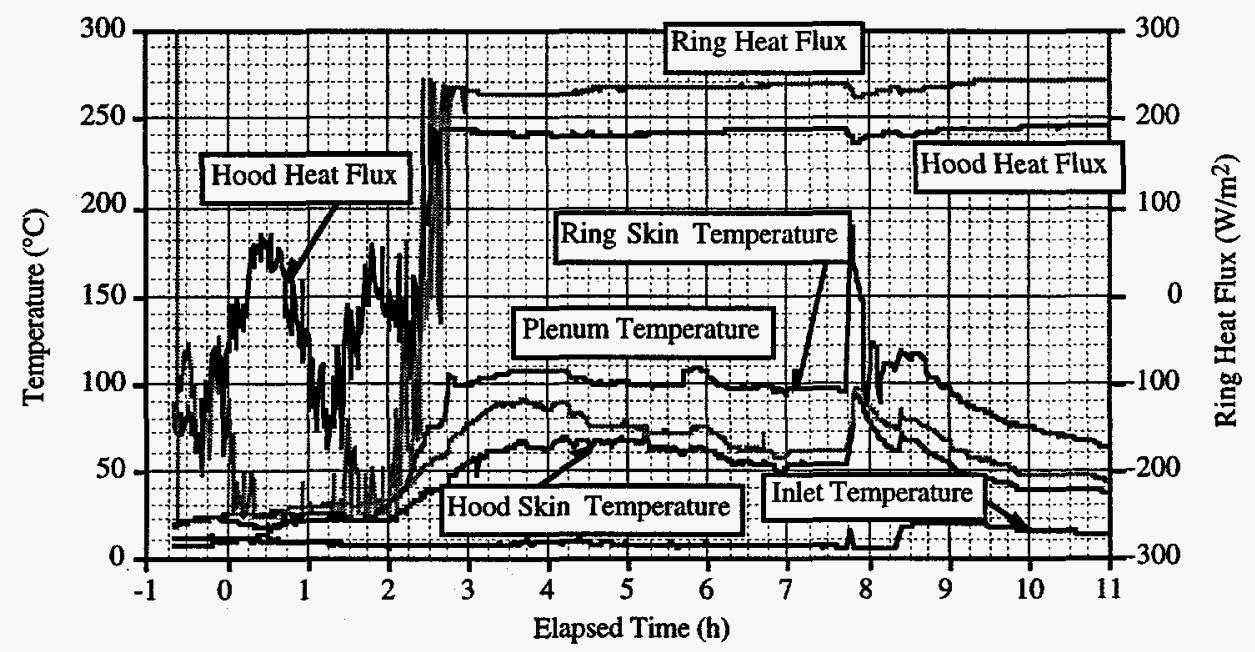

Figure 3.6.12. ORNL-ESBW-2a Off-Gas Hood Skin Temperatures and Heat Transfer.

The effectiveness of the water spray system was again exercised at the conclusion of this tests. Figures 3.6.13 and 3.6.14 illustrate the response of the plenum pressure and temperature before, during, and after actuation of the spray system. As was noted previously (Section 3.2.7, ORNL-ESBW-1a), the effect appears to be more pronounced for the plenum temperature than for the plenum pressure. In fact, the pressure rebound effect is again evidenced in these results. The effect on plenum pressure is a bit more pronounced in this application than was realized in the previous results. Also, there appears to be a secondary spike in plenum pressure above that 
realized in the initial rebound. This second peak occurs just as the water spray is terminated. This may be a consequence of the slightly lower plenum pressure and/or increased plenum temperatures that existed during this exercise relative to those in existence during the corresponding exercise performed at the conclusion of the ORNL-ESBW-1a test. The spray flow rate, pattern, and temperature were the same for both tests, however.

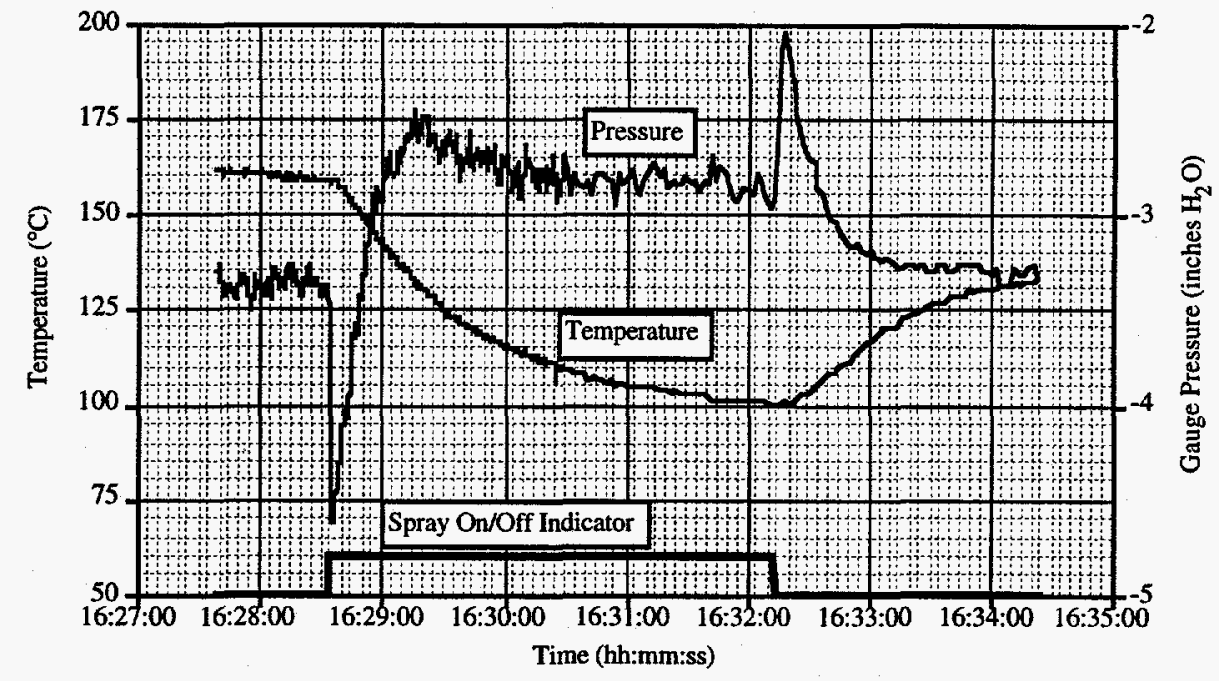

Figure 3.6.13. ORNL-ESBW-2a Plenum Pressure/Temperature Transients Following the First Application of the Water Spray System.

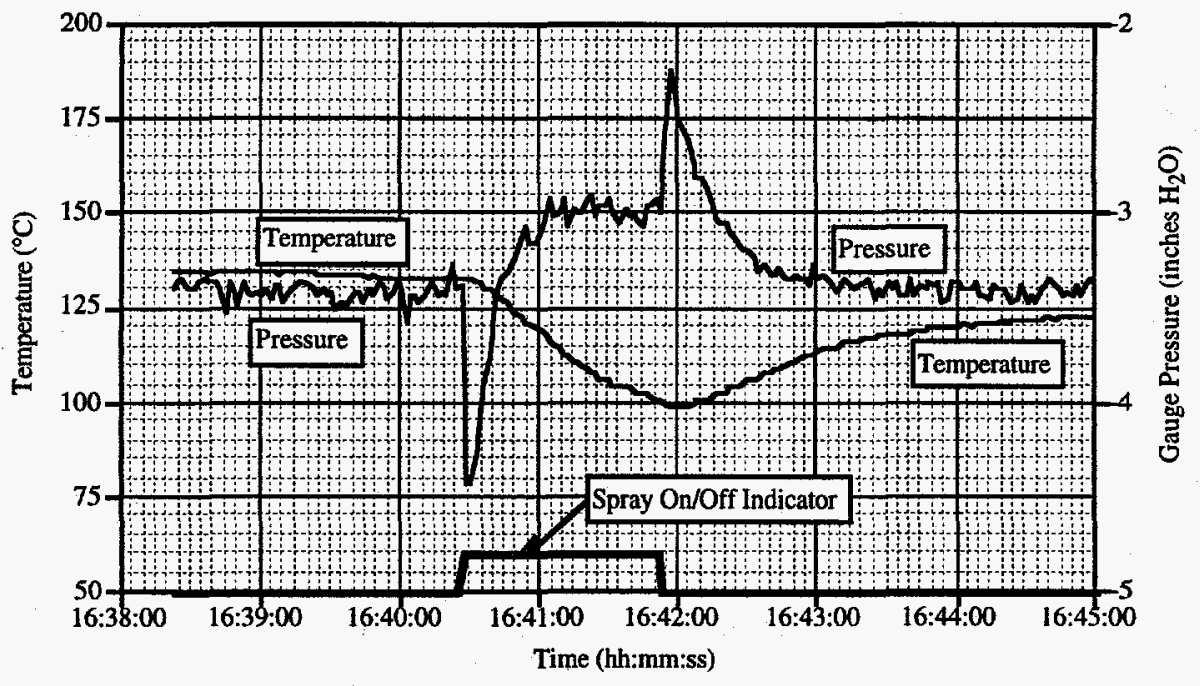

Figure 3.6.14. ORNL-ESBW-2a Plenum Pressure/Temperature Transients Following the Second Application of the Water Spray System. 


\subsubsection{ISV Block Statistics}

This test consumed $178 \mathrm{kWh}$ and produced a $209 \mathrm{~kg}$ block. These results are virtually identical to that reported fore the blocks generated in tests ORNL-ESBW-1c and ORNL-ESBW-2. The specific energy consumption was again $0.85 \mathrm{kWh} / \mathrm{kg}$.

\subsubsection{Test Retrospective}

The conditions of the preceding ORNL-ESBW-2 test were replicated in this test. However, for this test, the dynamically-compacted cans were recovered prior to final staging in the target vitrification zone, so that their condition could be recorded. This allowed better correlation of the plenum pressure/temperature transients that were experienced during the test with the condition of the can(s) generating the event.

Of the six cans pretreated with $\mathrm{DC}$, two were completely ruptured during the pretreatment process. These two were replaced with new cans. The two new cans were staged at the bottom layer in the target vitrification zone. The remaining four cans were affected by the $\mathrm{DC}$ process, but their integrity was still intact. In fact, one can (can 1A, staged on the uppermost layer of cans) was relatively unscathed by the DC process -- as if hit by a glancing blow during compaction.

Two events were realized during this test -- one while processing the top layer of cans, and another while processing the bottom layer of cans. The event experienced while processing the top layer of cans was attributed to processing can $1 \mathrm{~A}$. The success processing the other three compacted cans indicates that a breach of the can is not necessary to preclude its catastrophic rupture during ISV processing. However, as the experience with processing can $1 \mathrm{~A}$ indicates, the can must be more than slightly affected by the DC pretreatment. 


\subsection{ORNL-ESBW-3 TEST}

In the preceding tests ORNL-ESBW--1c, ORNL-ESBW-2, and ORNL-ESBW-2a, the benefit of pretreating the waste site with DC was demonstrated. These tests involved the "standard" top-down approach to ISV processing. In this approach, the melt is initiated at the soil surface and propagated down through the waste zone by the action of gravity. Without pretreatment of the target vitrification zone to effectively compromise the integrity of any sealed canisters containing volatile materials, the potential for a sudden catastrophic release of pressure built-up in these containers during their processing can introduce dramatic consequences of the safe and effective operation of the ISV remediation process. Tests ORNL-ESBW-2 and ORNLESBW-2a demonstrated that, if pretreatment by DC can effectively weaken the integrity of any sealed containers present in the target vitrification zone, the top-down ISV process can be applied to safely and effectively remediate the waste zone. These tests also demonstrated that a complete breach of the sealed canisters present in the waste is a sufficient but not necessary condition for this.

Another potential approach for obviating pressure buildup in sealed containers involves ISV processing that is initiated beneath the waste zone. Once established, the wastes are then fed into the pool of molten soil by the natural or induced collapse of the waste zone located above the molten soil pool. In theory, any sealed canisters that suddenly rupture as they are introduced into the melt, would displace only soil and possibly other unprocessed wastes, not molten soil. This result is thought to produce less severe consequences to the plenum and to help promote the safe and effective operation of the ISV systems. This test was designed to investigate this hypothesis. In addition, to facilitate comparison with those results obtained in the previous suite of tests, to the extent possible, the conditions set for those tests were reproduced for this test.

\subsubsection{Test Configuration}

As was done in the preceding tests, six factory-sealed steel canisters of hydrous, organic matter were staged in the target vitrification zone. For this ORNL-ESBW-3 test, the canisters were not pretreated with DC prior to their placement in the ISV container. Schematics illustrating the plan and elevation views of the setup are presented in Figure 3.7.1 and Figure 3.7.2.

The canisters were staged at the same elevations with respect to grade as in the previous tests. Since the melt must be initiated at depth for this test, the starter path was placed some distance beneath the "waste" zone. In practice, this starter path may be placed using directional drilling to 
auger-out a pathway in which to insert the starter path material. If this technique is used, it is likely that only an $\mathrm{X}$ pattern will be drilled, with each leg of the $\mathrm{X}$ connecting the two diagonallyopposed electrodes forming an electrode pair. Moreover, due to inaccuracies in directing a horizontally-oriented subsurface bore hole, the legs of the X may not intersect. While directional drilling was not employed to set the starter path for this test, this condition was mimicked for the test. Consequently, two tubes of starter material were laid at depth. This arrangement is depicted in Figure 3.7.2. Each tube was approximately $2.5 \mathrm{~cm}$ in diameter. Therefore, as Figure 3.7.2 indicates, there was approximately $2.5 \mathrm{~cm}$ of soil separating the two starter paths for this test. Also, to give the system adequate time to establish a melt before it begins to process sealed containers, the uppermost starter path was placed approximately $10 \mathrm{~cm}$ below the bottom layer of cans. As Figure 3.7.2 illustrates, one pair of electrodes was placed at an initial depth of $55 \mathrm{~cm}$ below grade, the other pair was placed at an initial depth of $60 \mathrm{~cm}$.

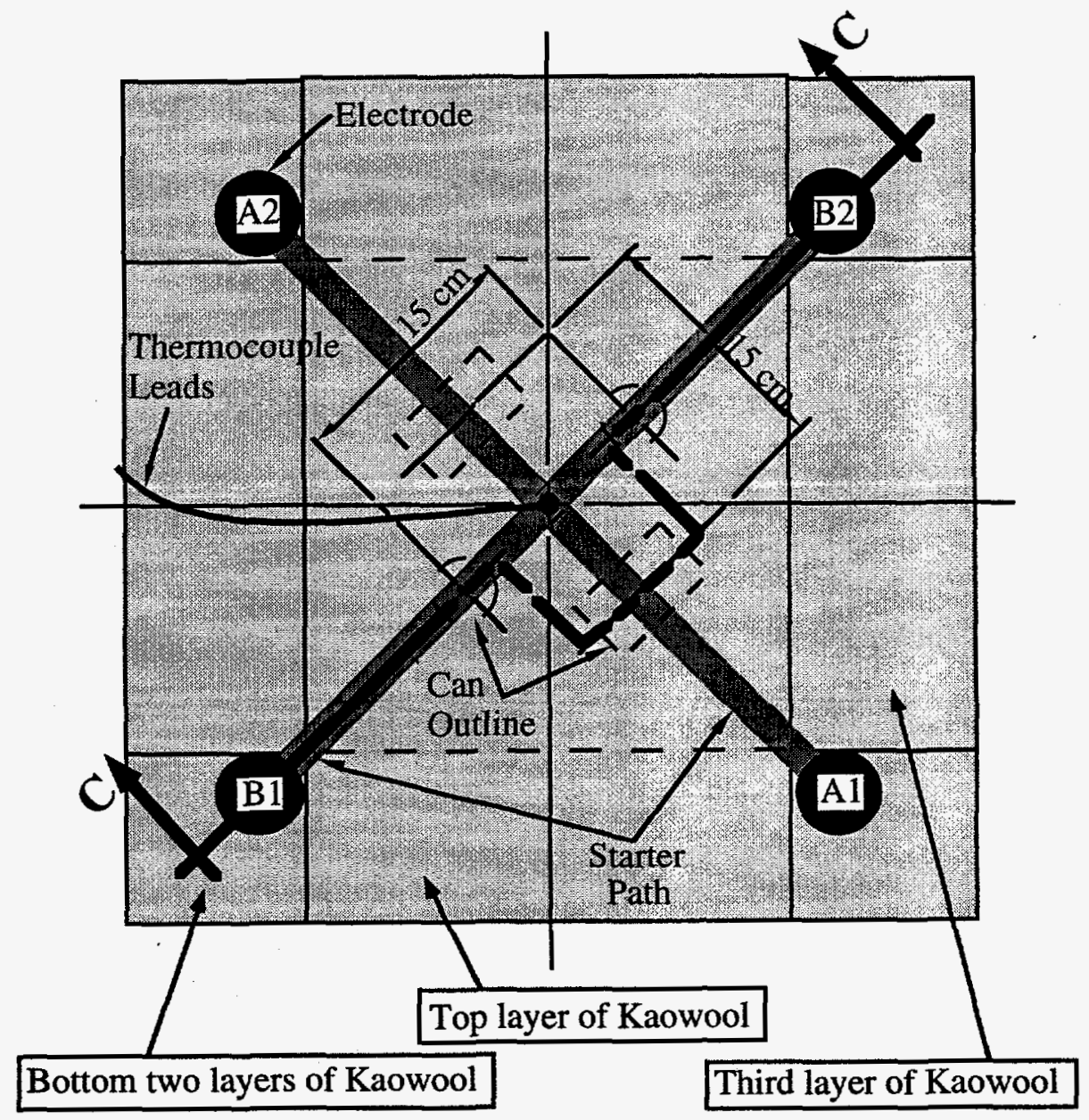

Figure 3.7.1. ORNL-ESBW-3 Test Configuration - Plan View. 


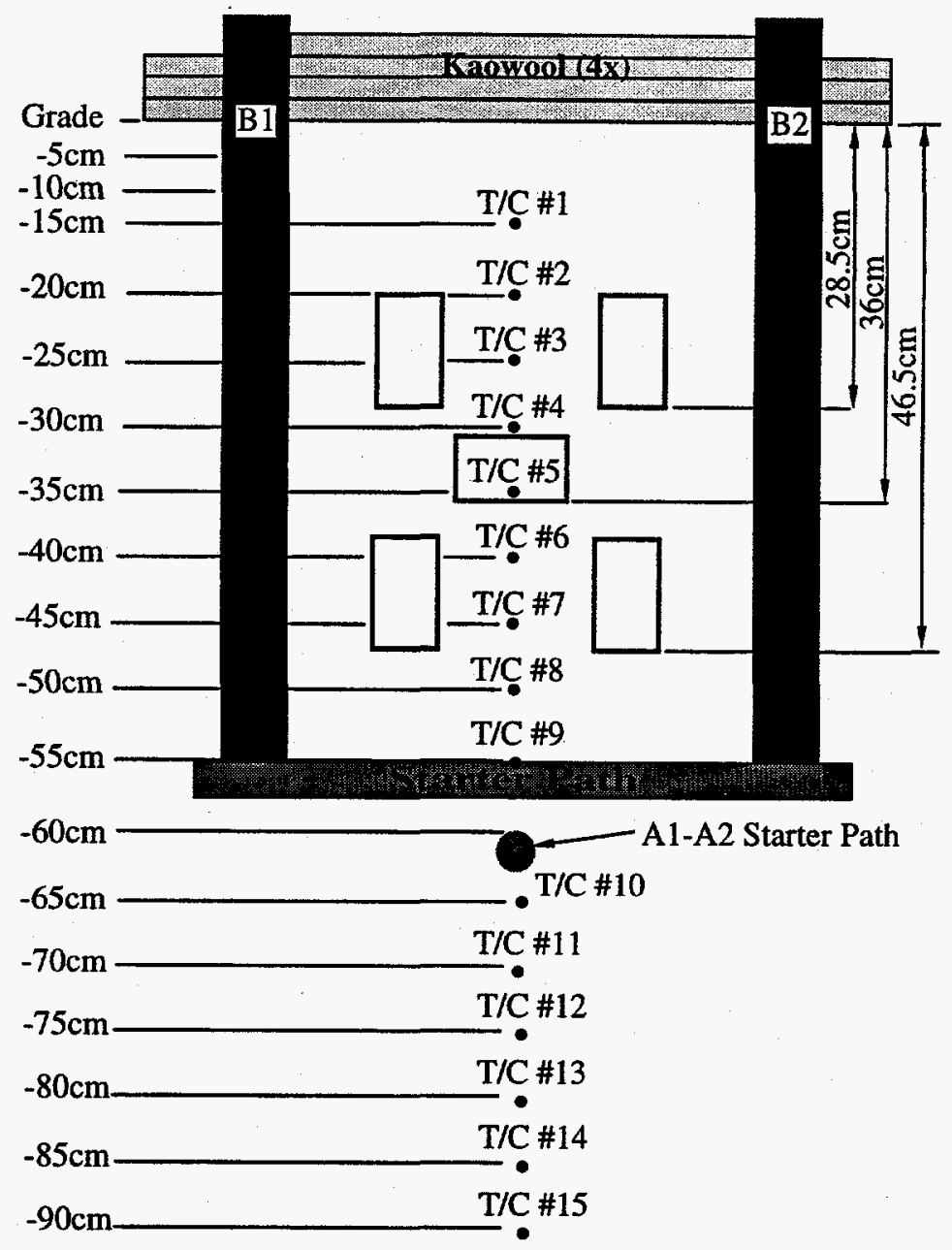

Figure 3.7.2. ORNL-ESBW-3 Test Configuration - Elevation View (Section C-C).

\subsubsection{Test Instrumentation}

Due to the inexorable pull of gravity, and to the increase in density as the soil changes from solid to liquid phase, the melt will likely propagate down. To somewhat counter this effect, the electrodes were withdrawn during processing to help induce upward development of the melt into the staged "waste" zone. To better understand and control this process, temperature measurements were taken in the zone below the initial starter path location, as well as up through the "waste" zone. As the schematic in Figure 3.7.2 indicates, 9 additional type " $K$ " thermocouples were placed below the "waste" zone. As was done in the previous tests, 8 type " $\mathrm{K}$ " thermocouples were placed 
up through the "waste" zone. This array of thermocouples was set along the vertical centerline of the configuration.

With the exception of the 9 additional centerline thermocouples, all other pressure, temperature, heat flux, and electrical system measurements were configured as per the previous suite of tests.

\subsubsection{Test Start-Up and Operation}

The usual two hour linear ramp-up in power was performed in this test to bring the system from $0 \mathrm{~kW}$ to the steady-state $25 \mathrm{~kW}$ level. Once attained, the $25 \mathrm{~kW}$ total power level was maintained for the duration of the test.

The electrical system was energized at 09:44 PDT on June 28, 1995. Full power was attained two hours later, at 11:44. This $25 \mathrm{~kW}$ power level was maintained thereafter.

Five separate pressurization events were realized in this test. These events occurred at four distinct times. With one exception, these events coincided with soil subsidence events. The first event occurred 5 hours into the test, at approximately 14:45. The second and third events occurred close together, at around 16:16 to 16:25, approximately 6.5 hours into the test. The fourth event occurred around 18:39, roughly 9 hours into the test. The fifth and final event occurred at approximately $20: 16,10.5$ hours into the test.

Electrode movement was frequently hindered during this test. Consequently, numerous attempts were made to raise and lower the electrodes in an effort to free them and better control the progression of the melt. Moreover, with the wastes dropping into the melt, it was difficult to determine precisely where you were in the process. This required close monitoring of the thermocouple response (looking for evidence of subsidence events), experiencing a pressurization event, or observing the state of the soil surface with the video. The electrode depths gave little indication as to the progress of the treatment process in this test.

The test was concluded in approximately 12.25 hours, at 21:56 PDT on June 28, 1995. A total of $274 \mathrm{kWh}$ were consumed during this test.

\subsubsection{Phase Voltage, Current, and Resistance Results}

Figure 3.7.3 presents plots of the phase voltage, current and resistance transients experienced during this test. As indicated in this figure, the balance between phases was not nearly as good as in the previous top-down tests. This was partly due to the initial relative displacement between 
electrodes pairs required for the starter path placement. It was primarily due however, to the difficulties encountered throughout the test in freeing-up the electrodes. The more erratic behavior of the voltage, current and resistance traces presented in Figure 3.7.3 is another manifestation of the difficulty encountered with balancing the electrical system in this test.

Figure 3.7.3 also indicates the considerably higher phase resistance encountered during this test. Typically for these engineering-scale melts, the phase resistance levels-out at around 1 to 2 $\Omega$. In this test, the resistance was closer to 5 to $10 \Omega$. This was a consequence of raising the electrodes to promote subsidence events and introduce the "waste" into the melt pool. As the electrodes were withdrawn from the melt pool, a smaller effective cross-sectional conduction resulted. Since the phase resistance is inversely proportional to this conduction area, the effect was to raise the phase resistance.

The phase voltages required to dissipate $25 \mathrm{~kW}$ in the melt were considerably higher for this test than for the previous tests -300 to $400 \mathrm{~V}$ for this test vs. 100 to $200 \mathrm{~V}$ for test ORNL-ESBW2. This was again a consequence of the higher phase resistance of the melt. Of course, to accommodate the $25 \mathrm{~kW}$ power level, the current demand was commensurately lower for this test than for the previous tests $-\approx 40$ A vs. 80 A for ORNL-ESBW-2.

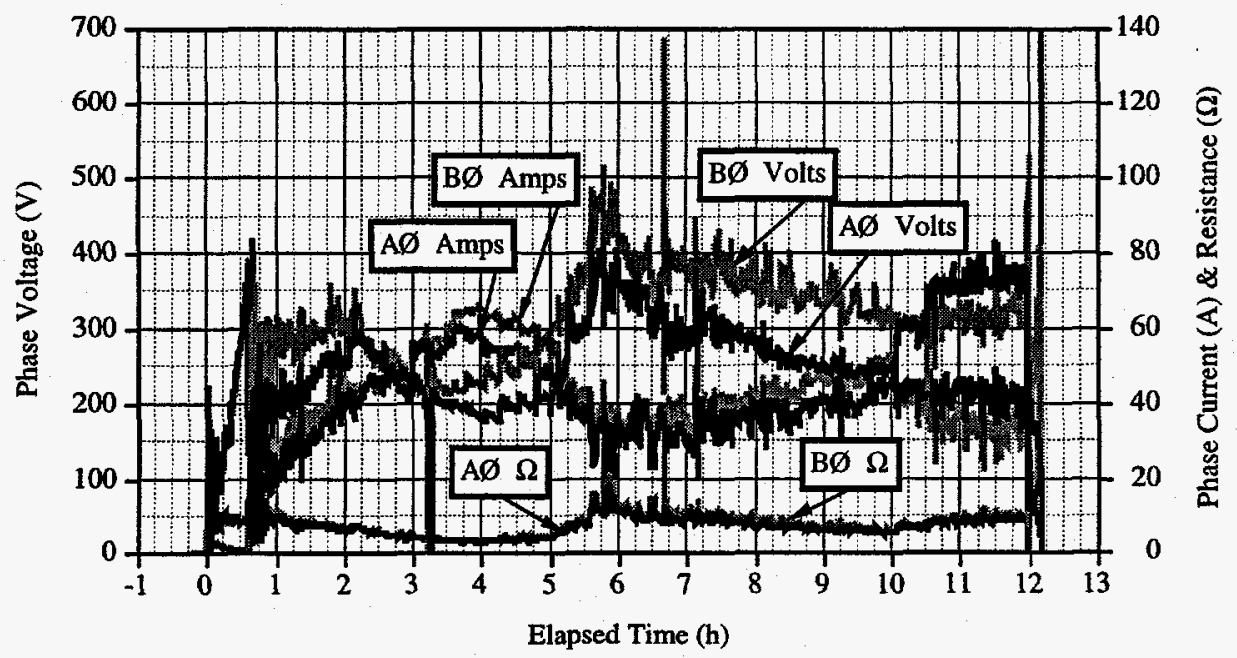

Figure 3.7.3. ORNL-ESBW-3 Phase Voltage, Current, and Resistance Transients.

Figure 3.7.4 provides a plot of the phase power, total power, and energy consumption transients realized in this test. Again, the difficulty maintaining a balance between the A and B phases is evident. The target $25 \mathrm{~kW}$ total power level was effectively maintained, though the erratic behavior indicated in these traces is again a manifestation of the difficulty in effecting this 
result. As this figure indicates, a total of $274 \mathrm{kWh}$ were consumed to process the "waste" zone in this test.

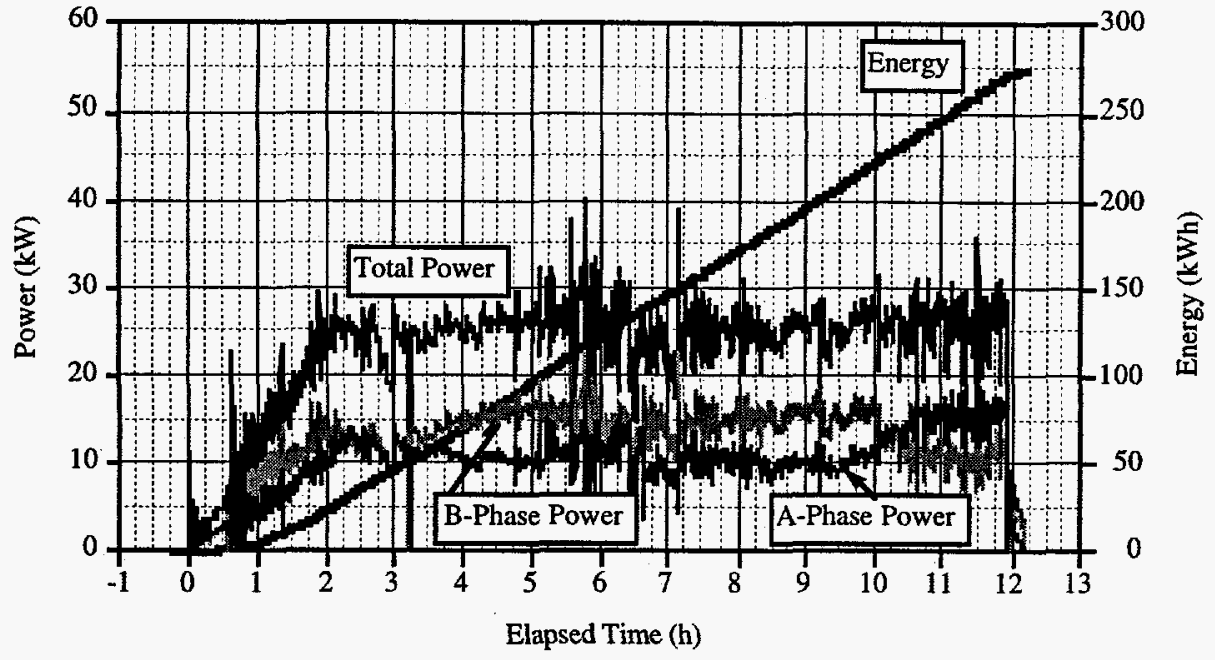

Figure 3.7.4. ORNL-ESBW-3 Phase Power, and Total Power \& Energy Transients.

\subsubsection{Electrode Depth and Soil Temperature Results}

Figures 3.7.5 and 3.7.6 present plots of the average electrode depth and centerline temperature transients produced in this test. Figure 3.7.5 provides the response realized for the uppermost 9 thermocouples at depths ranging from $-15 \mathrm{~cm}$ to $-55 \mathrm{~cm}$. The response of therrnocouples 8 through 15 (corresponding to depths of $-50 \mathrm{~cm}$ to $-90 \mathrm{~cm}$ ) is illustrated in Figure 3.7.6. The timing of each of the five events encountered in this test is also indicated in these figures. As previously mentioned, these events seemed to be closely correlated with the subsidence events that were experienced during this test. One means of detecting subsidence events is when a rapid drop in temperature is indicated in a thermocouple response. This drop reflects the collapse of the relatively hot soil initially present around the measurement location. When the measurement location remains in the soil subsurface, the original soil is replaced by cooler soil from above -- hence the drop in temperature.

The electrode depth transients plotted in these figures indicate that, as expected, the electrodes initially fed into the melt as it propagated downward under the action of gravity and soil densification during phase change. This natural downward progression was arrested by operator intervention at approximately 13:00 $(\Delta t \approx 3.25 \mathrm{~h})$. From that point on in the test, the electrodes were manually raised at frequent intervals to induce subsidence and process the "waste" zone located above the melt pool. At their deepest, the electrodes had propagated roughly $12 \mathrm{~cm}$ farther 
into the soil below their initial placement depth. At the conclusion of the test, the electrodes were raised roughly $14 \mathrm{~cm}$ above their initial insertion depth.

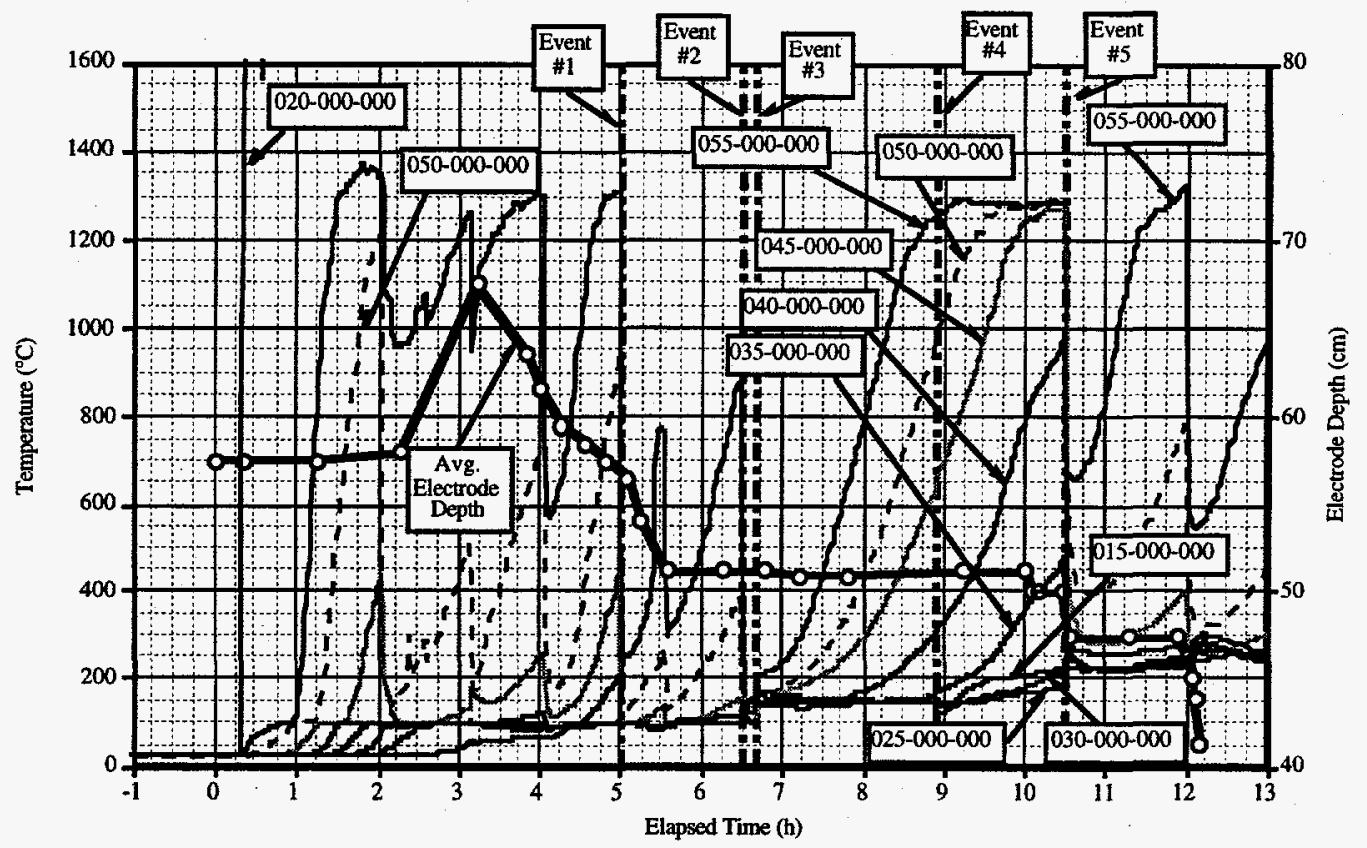

Figure 3.7.5. ORNL-ESBW-3 Electrode Depth and Upper Centerline Temperature Transients.

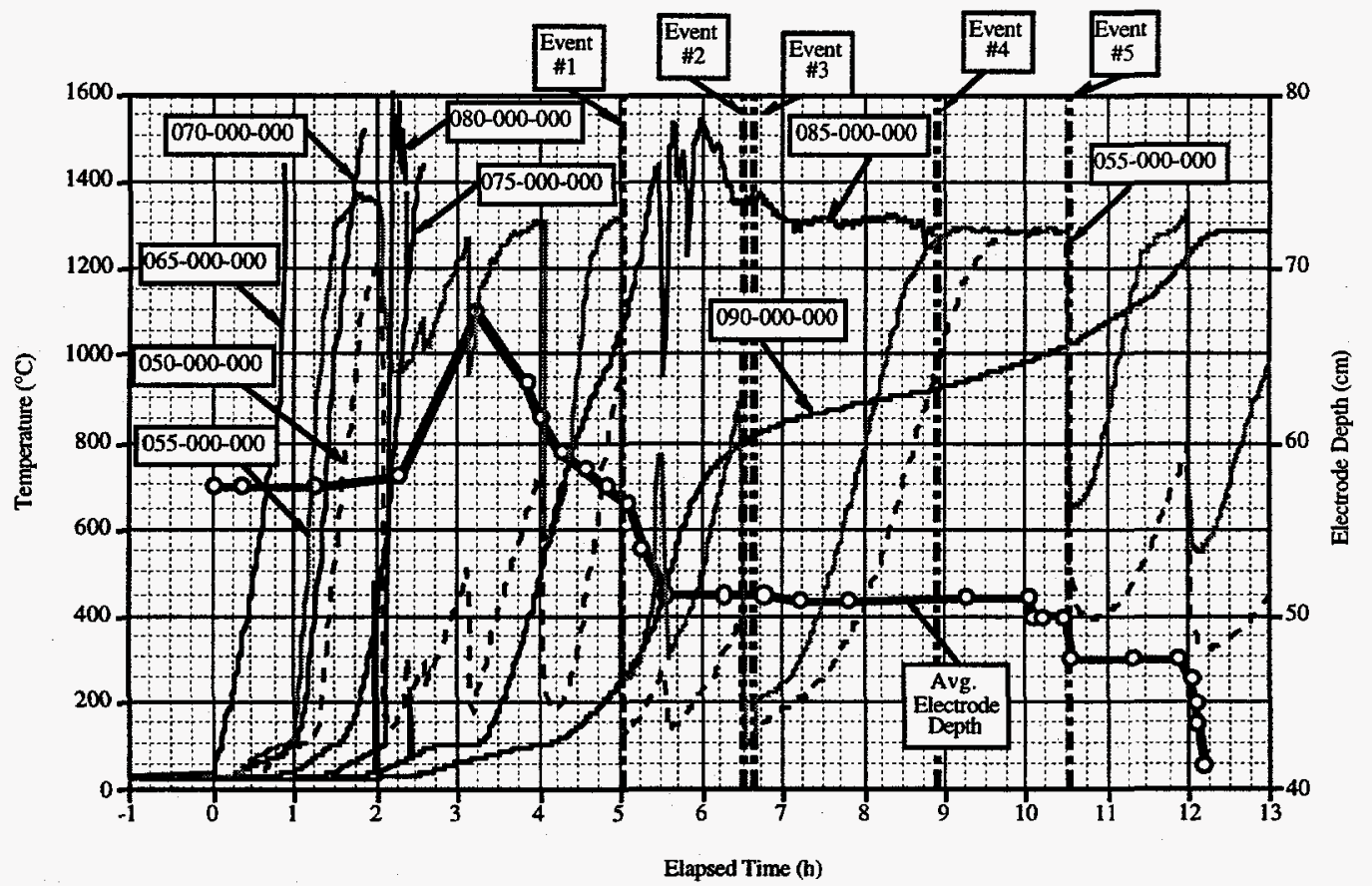

Figure 3.7.6. ORNL-ESBW-3 Electrode Depth and Lower Centerline Temperature Transients. 


\subsubsection{Plenum Pressure and Temperature Results}

Plots of the plenum pressure and temperature transients produced by the five events of this test are presented in Figures 3.7.7 through 3.7.11. For the more severe events \#2 and \#3, the water spray system self-actuated. The time and duration of its operation are indicated in the associated figure.

As the figures indicate, there was a wide range in the level of severity for these events. The first and final events produced modest plenum pressurization transients. These were likely associated with gas releases produced by subsidence events that did not introduce cans to the melt zone. At the other extreme, events \#2,\#3, and \#4 produced transients comparable to those experienced previously in test ORNL-ESBW-1c. Peak plenum pressure rises of up to 17 inches w.c. were realized during these events. As usual, the pressure spikes were of rather short duration, lasting only a few seconds. The temperature response was considerably longer-lived, however.

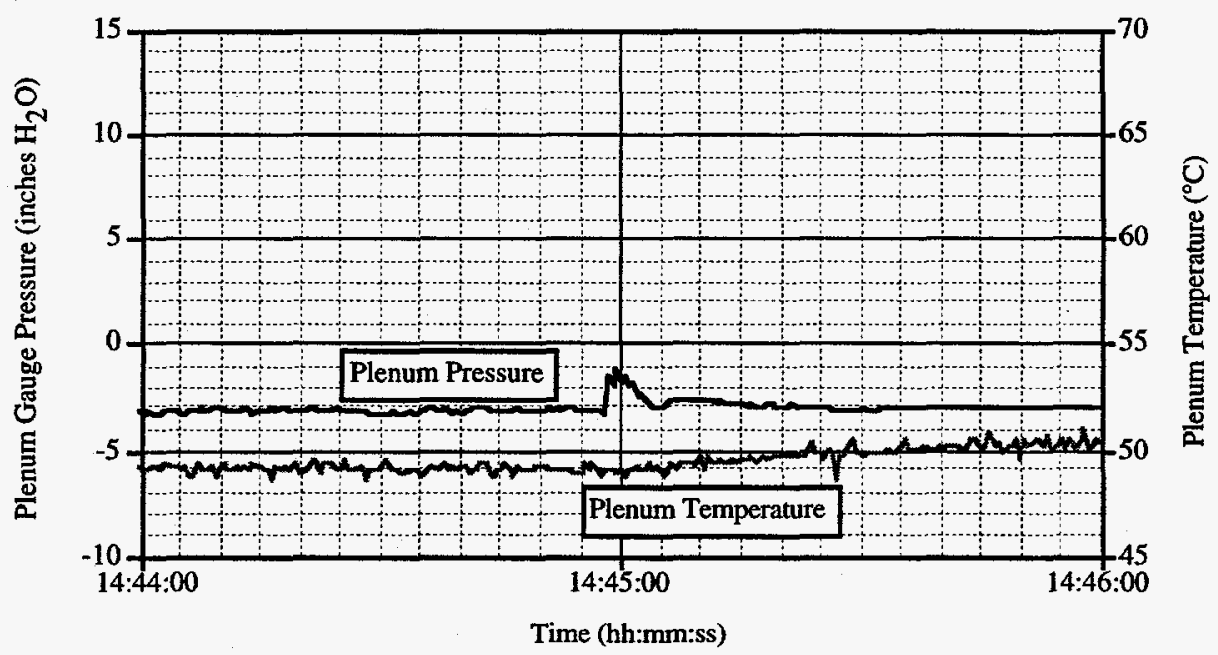

Figure 3.7.7. ORNL-ESBW-3 Plenum Pressure and Temperature Transients for Event \#1. 


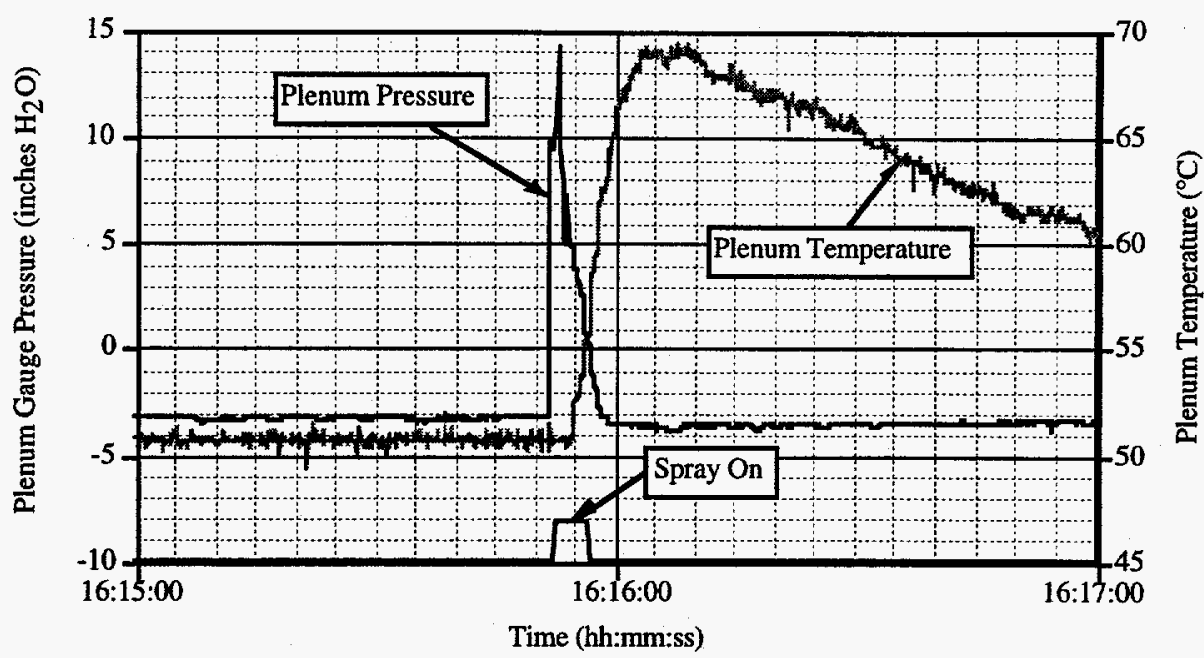

Figure 3.7.8. ORNL-ESBW-3 Plenum Pressure and Temperature Transients for Event \#2.

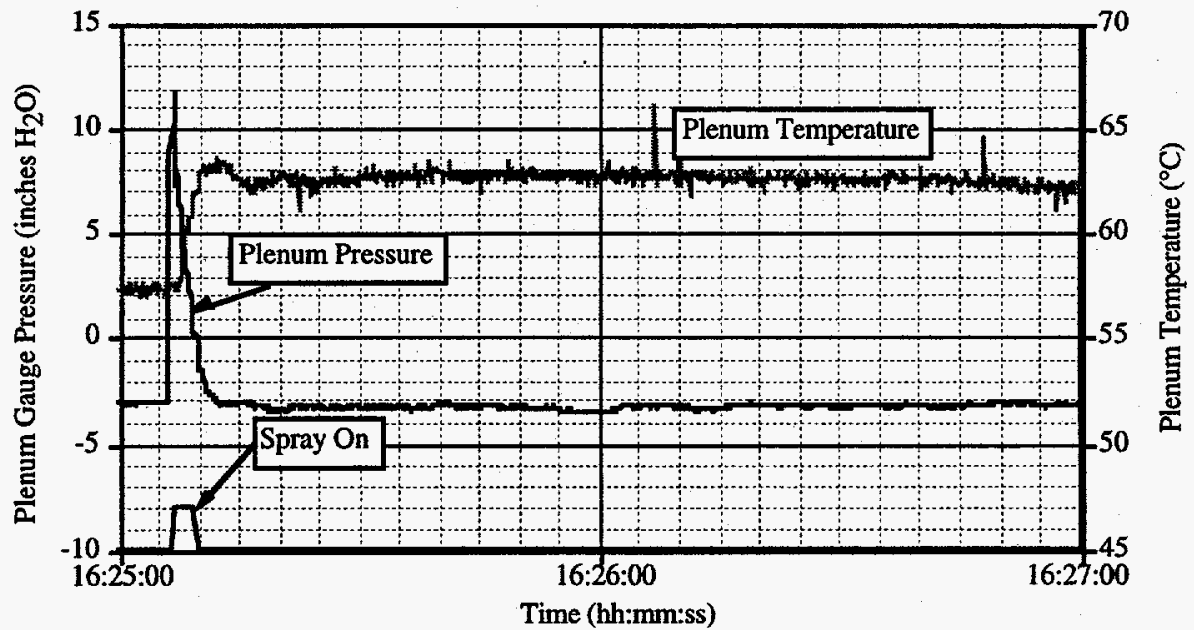

Figure 3.7.9. ORNL-ESBW-3 Plenum Pressure and Temperature Transients for Event \#3. 


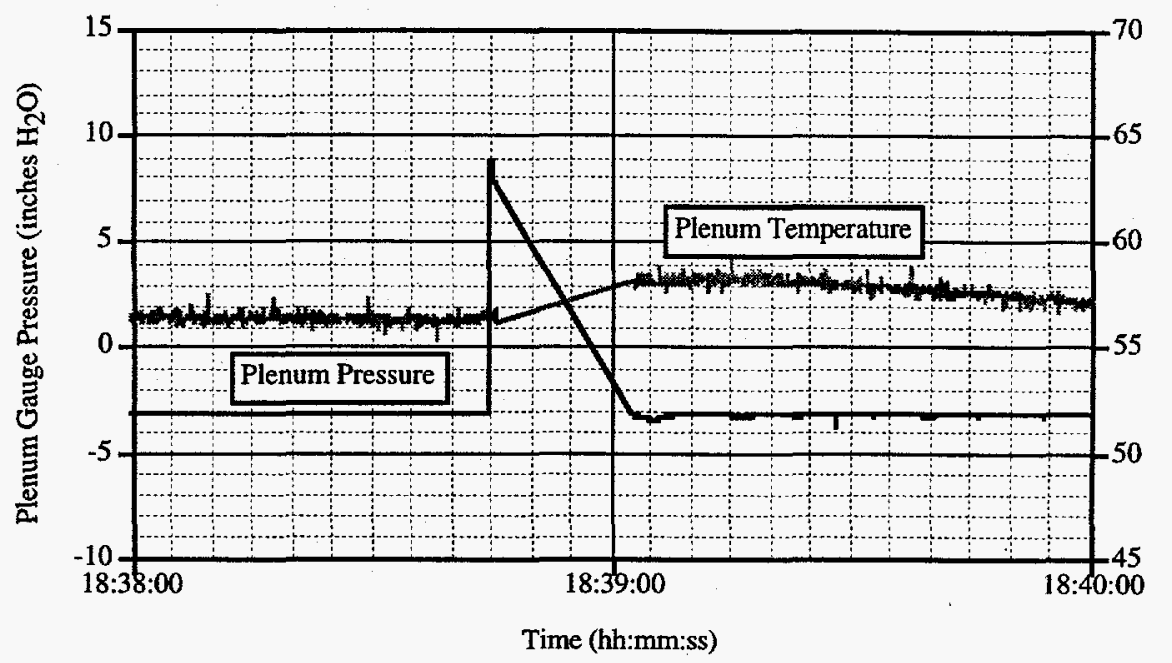

Figure 3.7.10. ORNL-ESBW-3 Plenum Pressure and Temperature Transients for Event \#4.

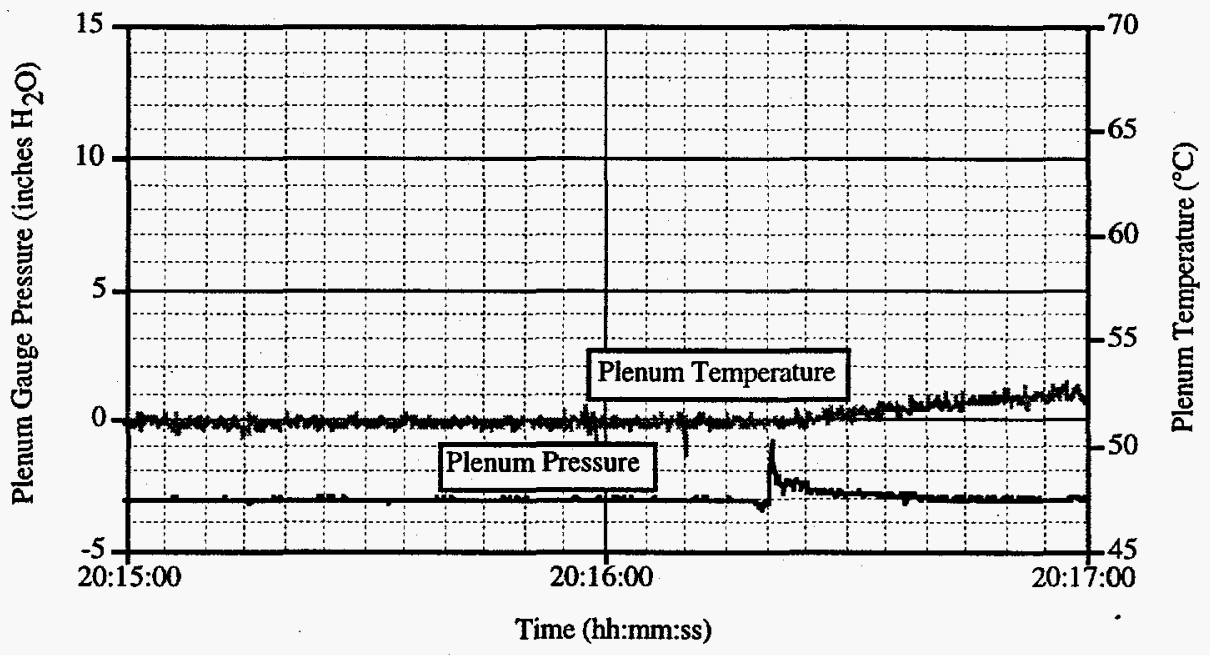

Figure 3.7.11. ORNL-ESBW-3 Plenum Pressure and Temperature Transients for Event \#5.

The off-gas hood and ring foundation surface temperatures and heat fluxes realized in this test are presented in Figure 3.7.12. The plenum and off-gas inlet temperature transients are also plotted in this figure. Note that the skin temperatures for the hood and ring foundation are nearly the same for most of this test. This is a consequence of the subsurface nature of this melt. The plenum region was insulated from the hot upper surface of the melt by a layer of soil. Also as a consequence of this, the plenum temperature was considerably lower than was realized in previous tests $--\approx 40^{\circ} \mathrm{C}$ vs. $\approx 100^{\circ} \mathrm{C}$ in test ORNL-ESBW-2. The heat flux distribution realized in this test 
was consistent with that obtained in previous tests, however. The ring foundation, due of the vertical orientation of its heat transfer surface and the consequent preferential convective flow patterns that result, exhibits a higher heat flux than does the inclined surface of the off-gas hood $\approx 250 \mathrm{~W} / \mathrm{m}^{2}$ vs. $\approx 200 \mathrm{~W} / \mathrm{m}^{2}$.

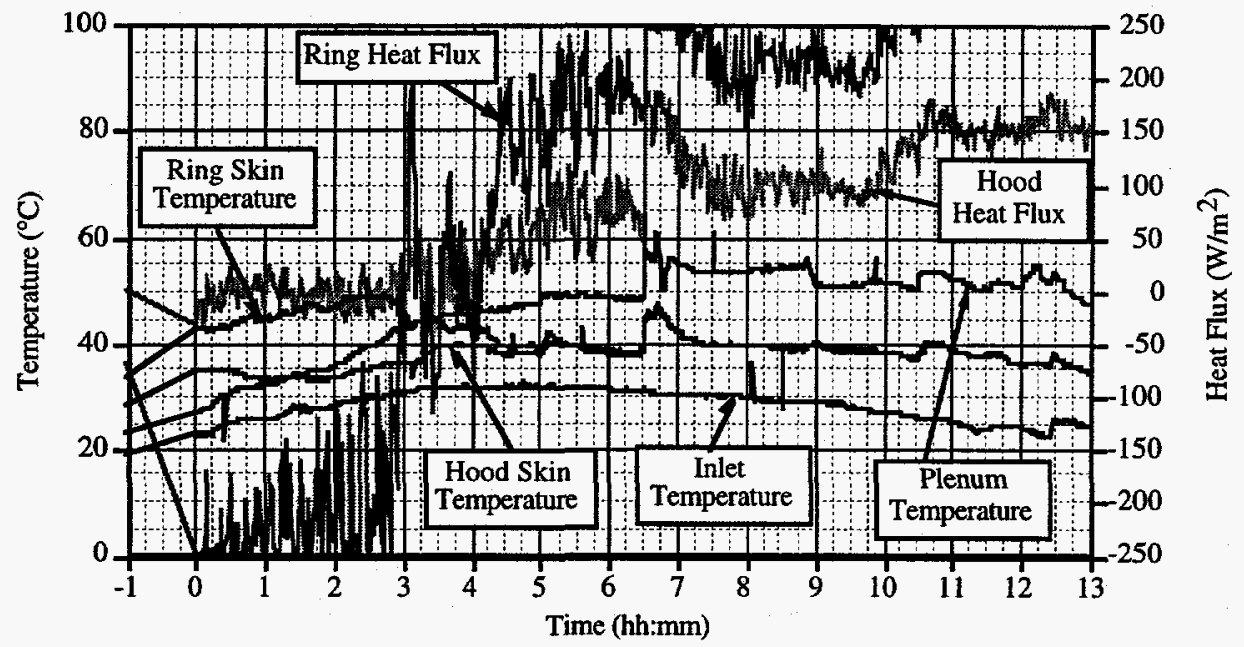

Figure 3.7.12. ORNL-ESBW-3 Off-Gas Hood Skin Temperatures and Heat Transfer.

\subsubsection{ISV Block Statistics}

This test produced a $370 \mathrm{~kg}$ block. The greater mass of this block relative to those that had been generated in previous tests was a direct consequence of the longer run time for this test (viz., 12.25 hours vs. $\approx 8$ hours for the ORNL-ESBW-2a test). As mentioned above, $274 \mathrm{kWh}$ were consumed in the production of this block. Therefore, the specific energy consumption realized in this test was $0.74 \mathrm{kWh} / \mathrm{kg}$. This was considerably below the values realized in the previous tests, and was also significantly lower than the nominal $1 \mathrm{kWh} / \mathrm{kg}$ required for the typical engineeringscale ISV melt. This was a consequence of the improved energy distribution and heat transfer associated with subsurface melts. The layer of soil above the melt zone provided an effective thermal barrier to reduce heat loss to the plenum air space. 


\subsubsection{Test Retrospective}

This test involved the bottom-up processing of six $6 \mathrm{oz}$ factory-sealed steel canisters of hydrous, organic material. The six cans were staged as per the preceding ORNL-ESBW-1c test. They were not pretreated with DC prior to processing with ISV.

Processing from the bottom up introduced considerably more complications to the operation of the ISV system than when processing from the top down. Specifically, the electrodes had to be attended-to frequently during the course of the test to help arrest the preferential downward progression of the melt and facilitate processing the "wastes" located above the melt pool. Moreover, on several occasions during the test, the electrodes had to be driven up and down significantly in order to free them. This action also helped induce subsidence which was the apparent mechanism for "feeding" the simulated waste into the melt, however.

Several plenum excursions were realized during this test. The plenum pressures generated during these excursions were comparable to those generated while processing from the top down. On the other hand, the corresponding plenum temperature transients were considerably less severe. Thus, while bottom-up processing does not, in and of itself, obviate the need for pretreatment in order to compromise the integrity of any sealed canisters present in the site, it does help to moderate the thermal transients that result. 


\subsection{ORNL-ESBW-4 TEST}

This test represented a combination of the ORNL-ESBW-2a and ORNL-ESBW-3 test conditions. That is, the canisters staged in this test were pretreated with DC (as was done for the ORNL-ESBW-2a test) and processed with a bottom-up approach (as per the ORNL-ESBW-3 test). This configuration and procedure should offer the best of both worlds -- the benefits of pretreatment using DC, combined with the insulative and dampening effects associated with bottom-up processing.

\subsubsection{Test Configuration}

The usual array of six $6 \mathrm{oz}$ factory-sealed, steel canisters of hydrous, organic material were subjected to a DC process. The pretreatment process was performed in the same manner as was done for the ORNL-ESBW-2a test. Following pretreatment, the cans were recovered and their condition recorded. The cans were then staged in the target vitrification zone with the ORNLESBW-3 configuration. Schematic diagrams illustrating the plan and elevation views of this setup have been provided as Figures 3.7.1 and 3.7.2 in the preceding Section 3.7. Figures 3.8.1 through 3.8.3 illustrate the condition and placement of each can used in this test as they were staged in the target vitrification zone. The arrangement of starter paths and initial electrode insertion depths employed was the same for this test as was staged in the ORNL-ESBW-3 test.

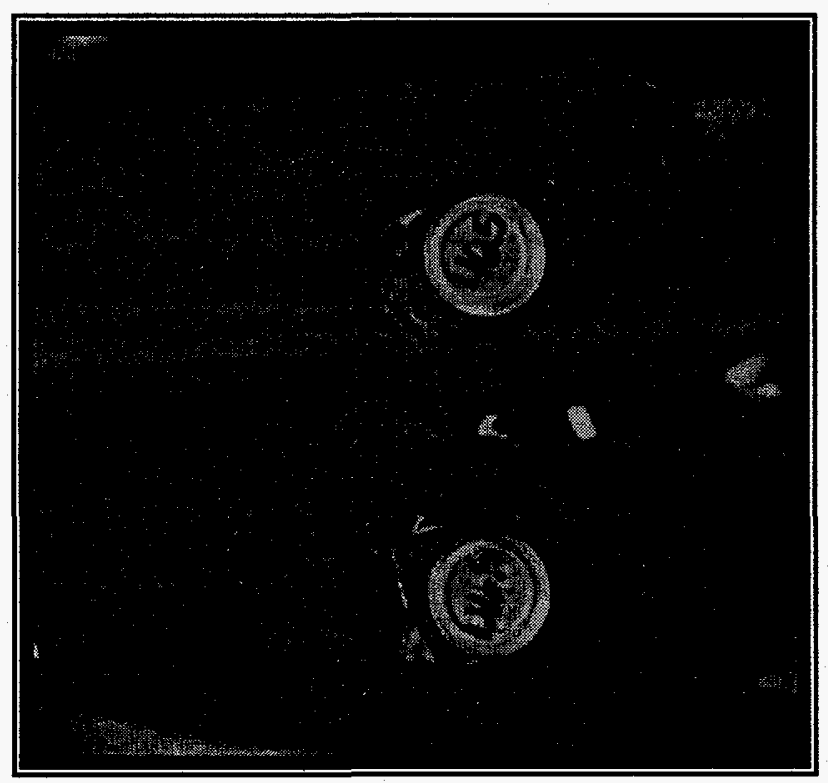

Figure 3.8.1. ORNL-ESBW-4 Bottom Layer Can Condition \& Placement. 


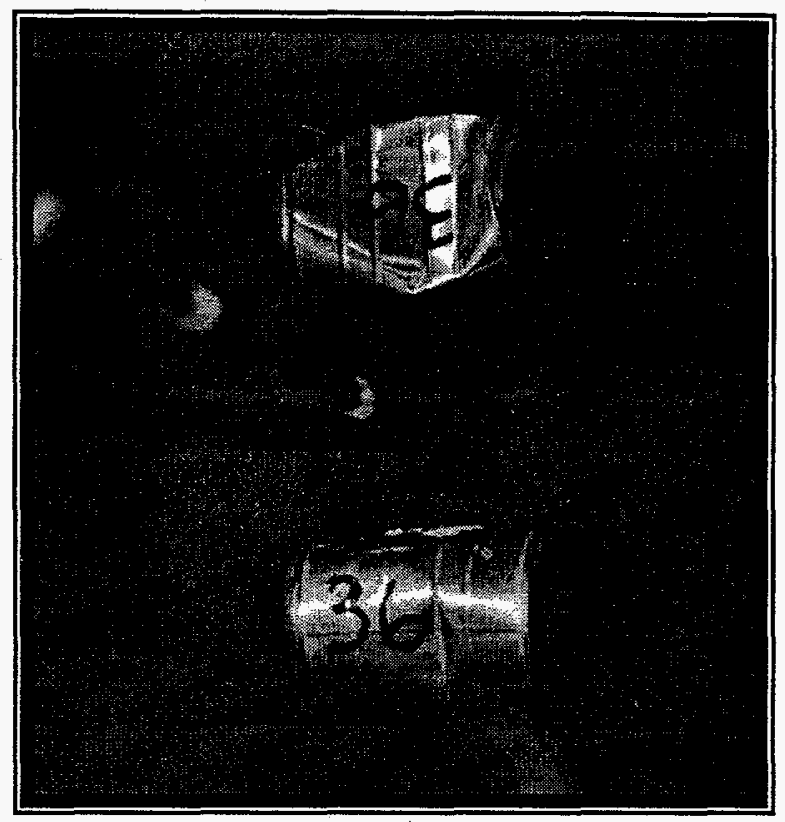

Figure 3.8.2. ORNL-ESBW-4 Middle Layer Can Condition \& Placement.

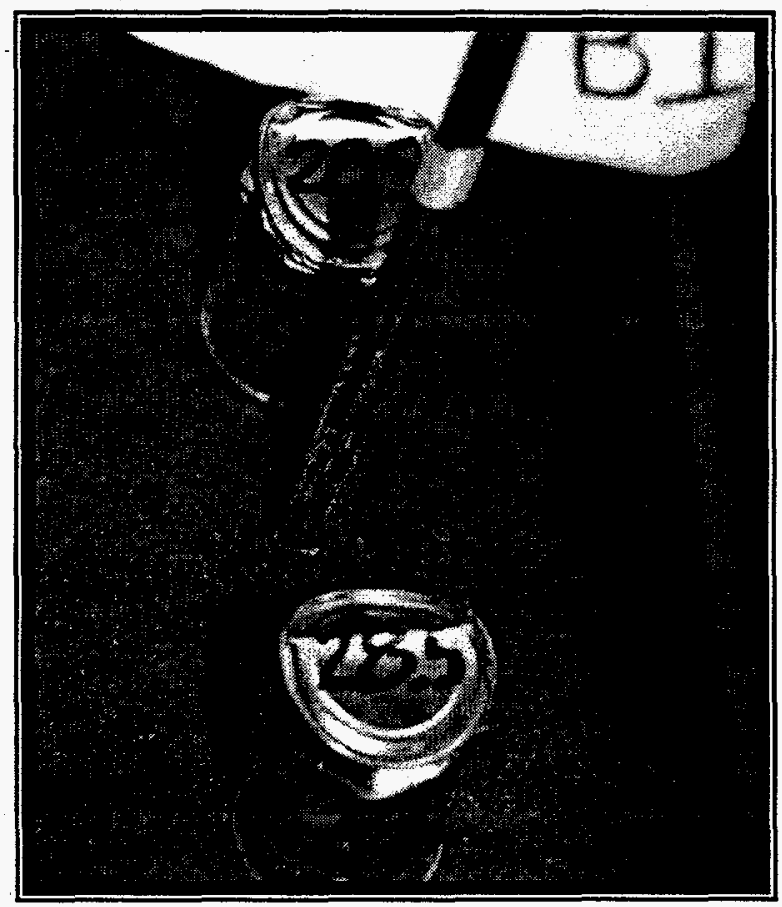

Figure 3.8.3. ORNL-ESBW-4 Top Layer Can Condition \& Placement. 


\subsubsection{Test Instrumentation}

To facilitate comparison of the results obtained from this test with the preceding suite of tests (and particularly with the ORNL-ESBW-3 test), the setup was instrumented as described in Section 3.7.2 for the ORNL-ESBW-3 test.

\subsubsection{Test Start-Up and Operation}

The ISV power supply system was energized at 09:45 PDT on August 10, 1995. The usual two hour linear ramp-up in power was followed until the target $25 \mathrm{~kW}$ steady-state total power level was attained. This was accomplished at 11:45.

There were no significant pressure events experienced during this test. All cans were processed without incident. There were the usual problems associated with bottom-up processing, however. As was experienced in the ORNL-ESBW-3 test, the electrodes were frequently difficult to raise during processing. In addition, they were often resting at differing insertion depths. This led to imbalances between phases of the power supply system. These difficulties were more of an annoyance, however, and did not dramatically affect the progression of melt process.

To the extent possible, the system was maintained at the $25 \mathrm{~kW}$ power level for the duration of the steady-state portion of this test. The test was concluded at 23:00 on August 10, 1995, for a total run time of approximately 13.25 hours. A total of $300 \mathrm{kWh}$ were consumed during this test.

\subsubsection{Phase Voltage, Current, and Resistance Results}

Figure 3.8.4 presents the phase voltage, current, and resistance transients experienced during this test. The erratic nature of the electrical system experienced during this test is clearly evident in these plots. In addition, the phase imbalance is also evident. As was the case for the ORNLESBW-3 test, the phase resistance was considerably higher than was realized in the previous topdown melts - again, $\approx 10 \Omega$ vs. 1 to $2 \Omega$ for the top-down melts. The phase voltage required to provide the $12.5 \mathrm{~kW}$ per phase was higher and the phase current lower as a result of this increased system resistance. 


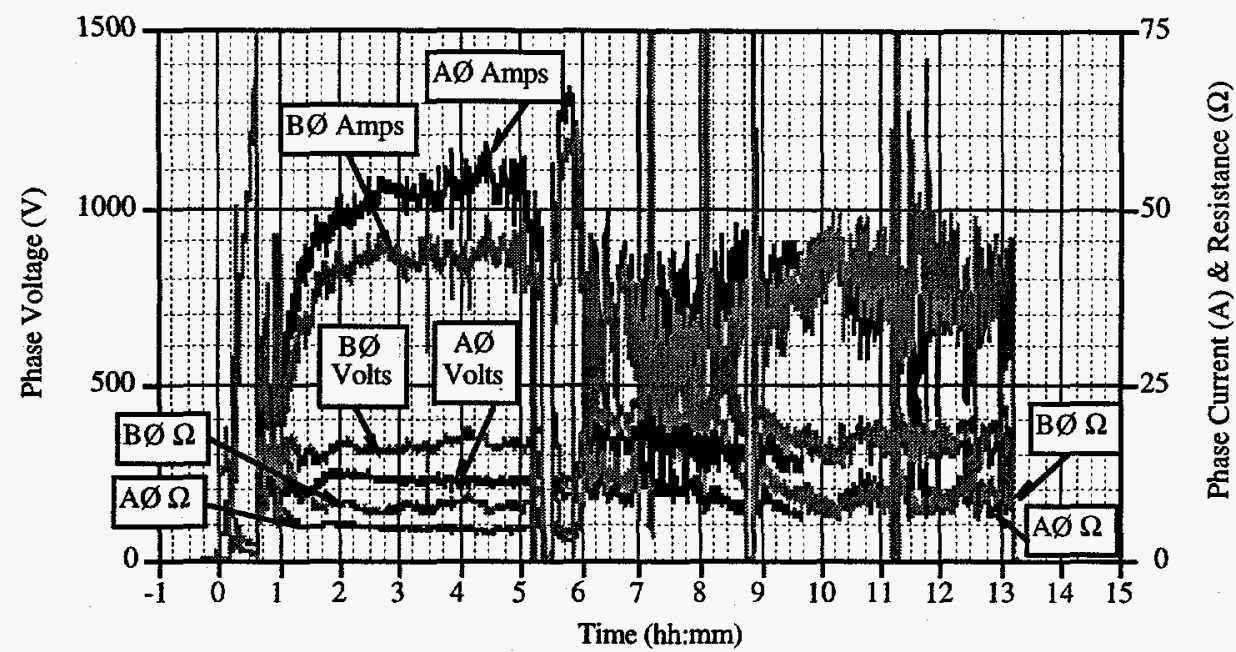

Figure 3.8.4. ORNL-ESBW-4 Phase Voltage, Current, and Resistance Transients.

Figure 3.8.5 illustrates the phase power, total power, and energy consumption transients experienced in this test. Again, the erratic nature of these plots indicates the difficulties associated with bottom-up processing. Despite this behavior however, the system was effectively maintained at a $25 \mathrm{~kW}$ total power level (on average) for the test. The plot of energy consumption vs. time presented in this figure indicates that $300 \mathrm{kWh}$ were consumed during this test.

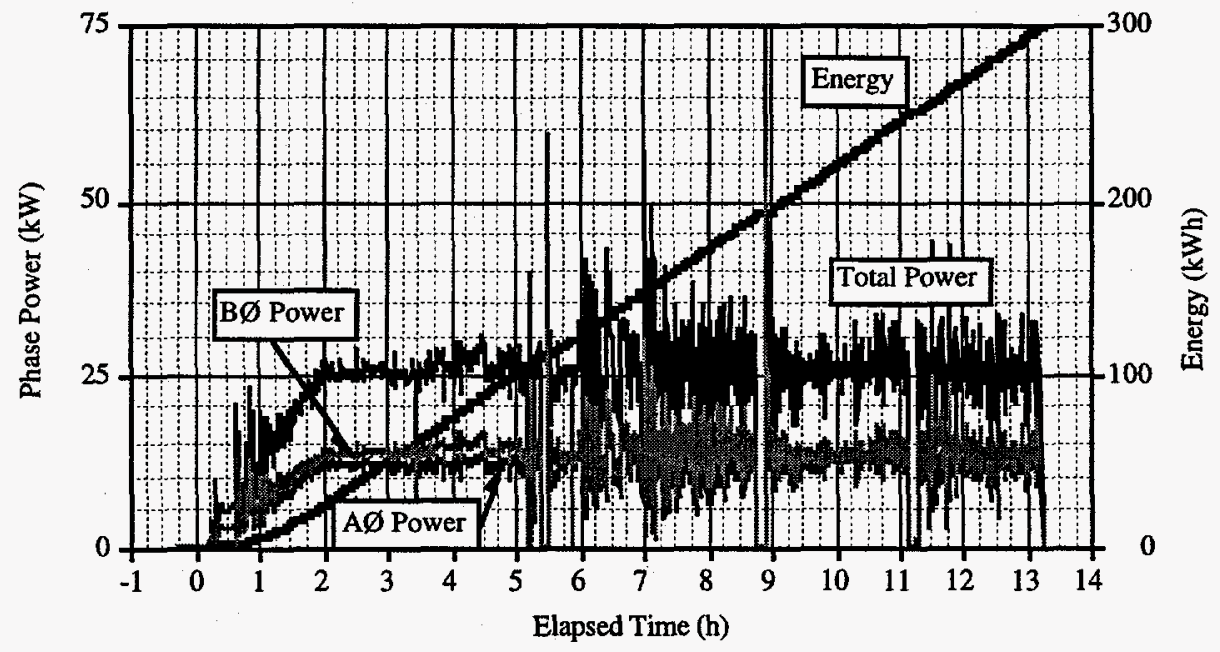

Figure 3.8.5. ORNL-ESBW-4 Phase Power, and Total Power \& Energy Transients. 


\subsubsection{Electrode Depth and Soil Temperature Results}

Figures 3.8.6 and 3.8.7 present plots of the average electrode depth and centerline temperature transients realized in this test. Traces for the upper 9 thermocouples are presented in Figure 3.8.6, along with a plot of the average electrode depth. Responses for the lower 6 thermocouples are plotted in Figure 3.8.7, again along with a plot of the associated average electrode depth.

As these results indicate, the electrodes were stuck in their initial position for a considerable period in the test. They weren't worked loose and withdrawn until about 15:00, roughly 5.25 hours after the start of the test. This is considerably longer than was realized in the preceding ORNL-ESBW-3 test. The difference may be attributed to differences in the initial soil moisture and degree of compaction imposed during the staging of the target vitrification zone, though these differences weren't quantified during staging. Once free to fall though, they gravity-fed into the melt to a maximum depth of approximately $65 \mathrm{~cm}$. The electrodes were retracted by the operator after this point to induce subsidence and promote processing of the "waste" zone. At the conclusion of the test, the electrodes had been withdrawn to an average depth of $35 \mathrm{~cm}$, some $20+$ $\mathrm{cm}$ above their initial insertion depth.

The temperature transients plotted in Figure 3.8.6 indicate a major subsidence event occurred at approximately 17:45 $(\Delta t \approx 8 \mathrm{~h})$. Another subsidence event is indicated at approximately 20:00 $(\Delta t \approx 10.25 \mathrm{~h})$. The final subsidence event was experienced at 22:15 $(\Delta t \approx 12.5 \mathrm{~h})$. None of these events were correlated with any major motion of the electrodes -- either naturally-occurring or induced. 


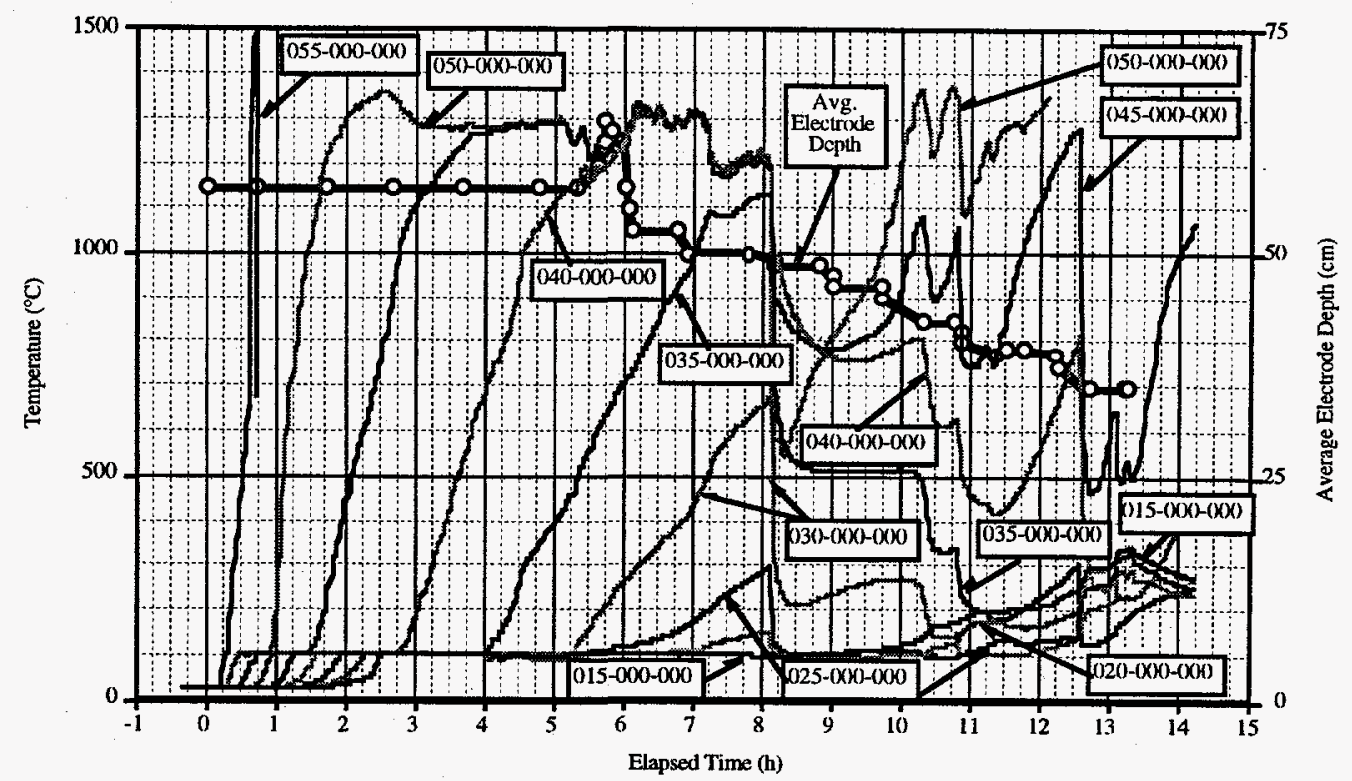

Figure 3.8.6. ORNL-ESBW-4 Electrode Depth and Upper Centerline Temperature Transients.

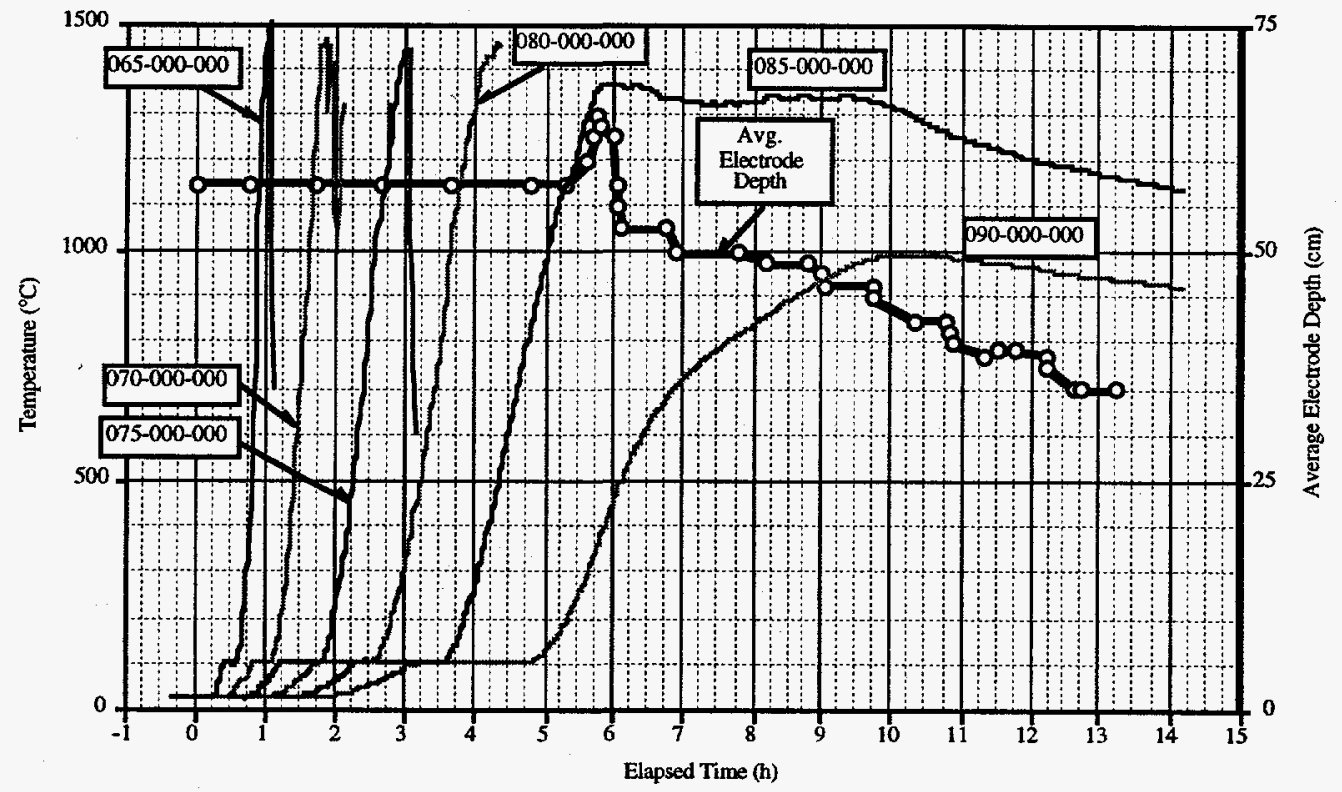

Figure 3.8.7. ORNL-ESBW-4 Electrode Depth and Lower Centerline Temperature Transients.

\subsubsection{Plenum Pressure and Temperature Results}

Plots of the plenum pressure, temperature, and off-gas inlet temperature transients experienced during this test are presented in Figure 3.8.8. As these results indicate, there were no 
appreciable pressurization events experienced during this test. There was one hint of the existence of an event indicated in the plot of the plenum temperature, however. There was a sharp increase in the plenum temperature indicated at approximately 17:54 $(\Delta \mathrm{t} \approx 8.2 \mathrm{~h})$. Figure 3.8.9 presents a plot of the plenum pressure and temperature transient experienced around this interval in time. Apparently there was a slight pressure pulse and associated temperature rise generated during this time. The plenum pressure rose a bit over 0.5 inches w.c. during this transient. This may have been the result of a mild canister rupture. It may also have resulted from gases released during reconfiguration of the soil and melt matrix as a consequence of the subsidence event that occurred at this time. In either case, the pulse was of little consequence to the overall operation of the test.

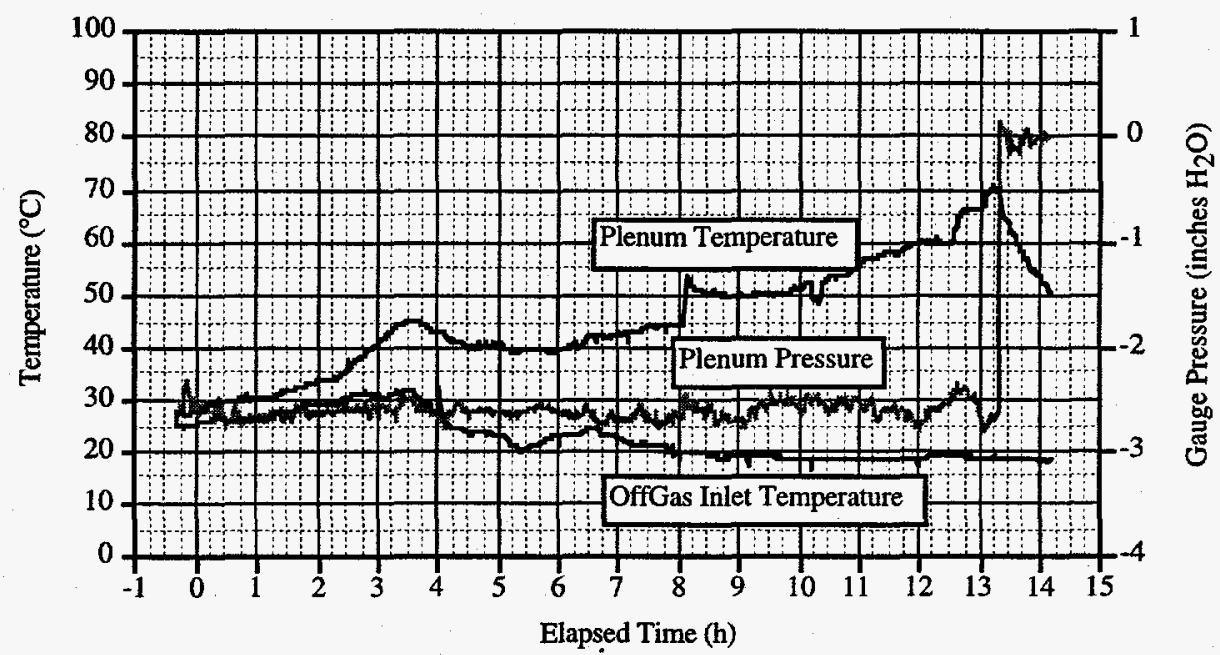

Figure 3.8.8. ORNL-ESBW-4 Plenum Pressure and Temperature Transients.

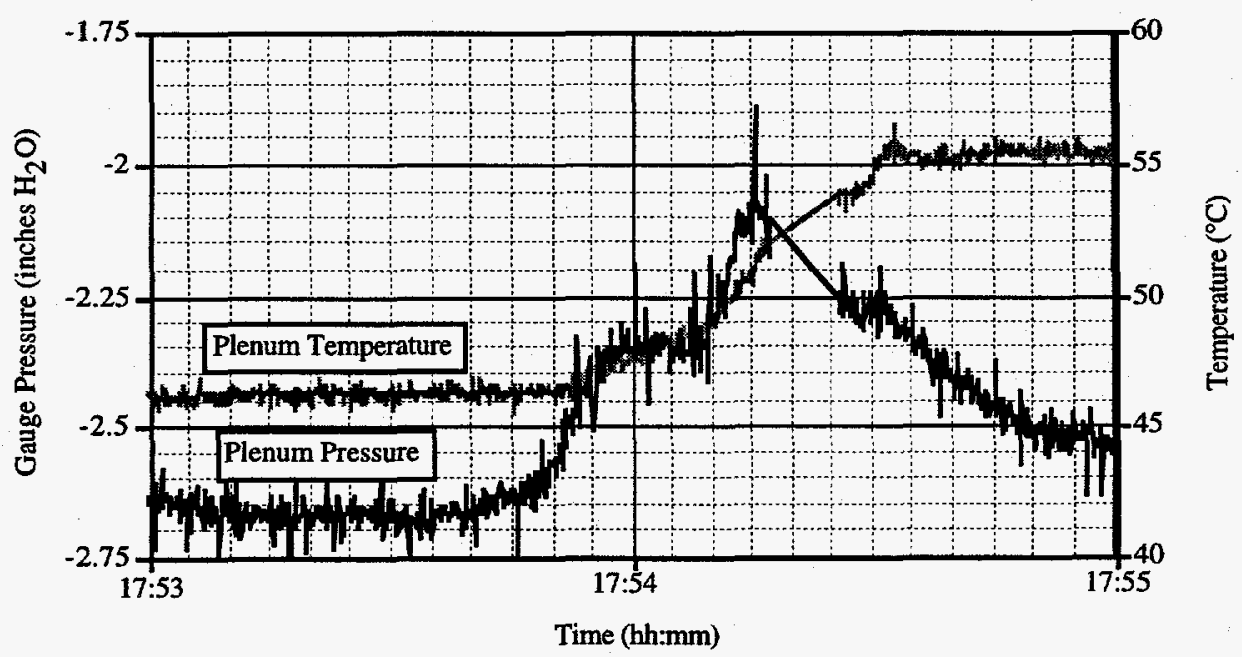

Figure 3.8.9. ORNL-ESBW-4 Plenum Pressure and Temperature Transients During a Major Subsidence Event. 


\subsubsection{ISV Block Statistics}

A $356 \mathrm{~kg}$ block was produced in this test. This, combined with the $300 \mathrm{kWh}$ consumed during the test, indicates a specific energy consumption value of $0.84 \mathrm{kWh} / \mathrm{kg}$. This is still below the nominal value of $1 \mathrm{kWh} / \mathrm{kg}$, but is higher than the value produced for the ORNL-ESBW-3 test. This is likely due to the greater time at the early phase of the test during which the electrodes were stuck in their initial positions.

\subsubsection{Test Retrospective}

This test involved the bottom-up processing of the six $6 \mathrm{oz}$ factory-sealed steel canisters of hydrous, organic material. The cans had been pretreated with DC prior to processing with ISV.

There were no plenum pressure/temperature excursions realized during this test. The combination of pretreatment with DC and bottom-up processing was apparently effective at precluding the conditions necessary for a GDE during ISV processing. The problems associated with bottom-up processing noted in the previous test (e.g., phase imbalance, higher melt resistance, electrode sticking, and the need for frequent monitoring and control of the electrodes during the test) were again experienced, however. 


\subsection{ENGINEERING-SCALE ISV TESTS INVOLVING SIMULATED WASTES}

The preceding series of tests served to define the conditions for staging and operation of these two final engineering-scale tests. In these tests, the interaction between ISV processing of dynamically-compacted canisters and simulated radioactive and chemical wastes was investigated.

The success of the ORNL-ESBW-2 series of tests led to choosing top-down processing of dynamically-compacted canisters as the method of approach in both tests performed in this phase. The chemical compounds included in these tests were chosen to represent the types of waste material disposed-of in the actual ORNL SWSA- 6 buried wastes trenches.

In the first of these tests (ORNL-ESBW-5), the chemicals were chosen to represent the spectrum of non-volatile, but radioactive, materials found in the SWSA- 6 trenches. The simulants incorporated in this test were non-radioactive, however. The follow-on ORNL-ESBW-6 test involved processing the more volatile solvent-type wastes buried in the SWSA-6 trenches.

The identifier and a brief synopsis of the conditions for each of the tests are as follows:

- ORNL-ESBW-5 -- Replicate of ORNL-ESBW-2a test with non-radioactive simulants representing the non-volatile and semi-volatile radioactive waste present in the typical ORNL buried waste trench staged. (Section 4.1)

- ORNL-ESBW-6 -- Replicate of ORNL-ESBW-2a test with non-radioactive simulants representing the volatile and semi-volatile chemical wastes present in the typical ORNL buried waste trench staged. (Section 4.2) 


\subsection{ORNL-ESBW-5 TEST}

Characterization studies performed on a number of the actual ORNL SWSA-6 buried waste trenches indicate that they contain significant quantities of ${ }^{60} \mathrm{Co},{ }^{3} \mathrm{H},{ }^{90} \mathrm{Sr},{ }^{152} \mathrm{Eu},{ }^{154} \mathrm{Eu},{ }^{155} \mathrm{Eu}$, ${ }^{235} \mathrm{U}$, various transuranic isotopes, and $\mathrm{Pb}$. In addition, the trenches and surrounding soil matrix also contain significant quantities of volatile and semi-volatile organic compounds. These include xylene, toluene, chloroehtane, methylene chloride, 1,1-dichloroethane, chloroform, 1,2dichloroethane, 1,1,2,2-tetrachloroethane, trichloroethane, 1,1,2-trichloroethane, benzene, cis1,3-dichloropropene, tetrachloroethene, ethylbenzene, styrene, phenol, 2,4-dimethylphenol, napthalene, bis-(2-ethylhexyl)-phthalate, o-cresol, and p-cresol.

This test represents an extension of the ORNL-ESBW-2a test to include an assortment of materials as simulants for the spectrum of inorganic wastes found in the ORNL SWSA-6 trenches. Non-radioactive forms of a number of the inorganic contaminants were included to assess ISV's capability to process these simulants simultaneously with containerized "wastes." Therefore, the various layers of the target vitrification zone staged in this test were loaded with quantities of nonradioactive $\mathrm{CeO}_{2}, \mathrm{CsCl}, \mathrm{Eu}_{2} \mathrm{O}_{3}$, and $\mathrm{SrCl}_{2}$. The $\mathrm{CeO}_{2}$ compound was used to provide a reasonable representation of the physicochemical behavior of uranium over the temperature range of interest (McAtee 1991).

\subsubsection{Test Configuration}

As indicated above, this test represented a repeat of the ORNL-ESBW-2a test with the inclusion of additional inorganic materials to act-as simulants of those contained in the actual ORNL SWSA-6 buried wastes. As such, the test configuration is identical with that employed for the ORNLESBW-2a test. The six $6 \mathrm{oz}$ factory-sealed steel canisters of hydrous, organic material were pretreated with DC as per the ORNL-ESBW-2a test. Following pretreatment, the cans were recovered from the DC drop zone and their condition recorded to facilitate correlation of their state with any pressurization events that may result from their subsequent processing with ISV. The cans were then transferred to the ISV test container where they were staged on three levels in the "waste" zone, two cans to a level. The simulants were staged on each of the three layers along with the cans. The powder simulants were poured loosely inside a square cardboard dam surrounding the cans on each layer. The dam measured approximately $25.4 \mathrm{~cm}$ on a side and was sufficiently tall to contain all the simulant staged on a layer. 728.59 grams of $\mathrm{SrCl}_{2} \bullet 6\left(\mathrm{H}_{2} \mathrm{O}\right)$ were staged along with the two cans at the bottom layer of the "waste" zone. 126.40 grams of $\mathrm{Eu}_{2} \mathrm{O}_{3}$ 
and 1492.31 grams of $\mathrm{CeO}_{2}$ were staged with the two cans on the middle layer of the "waste" zone. Finally, 712.90 grams of $\mathrm{CsCl}$ were staged with two cans on the top layer of the "waste" zone. Figure 4.1.1 provides a schematic elevation view of this setup. Elemental cesium, and

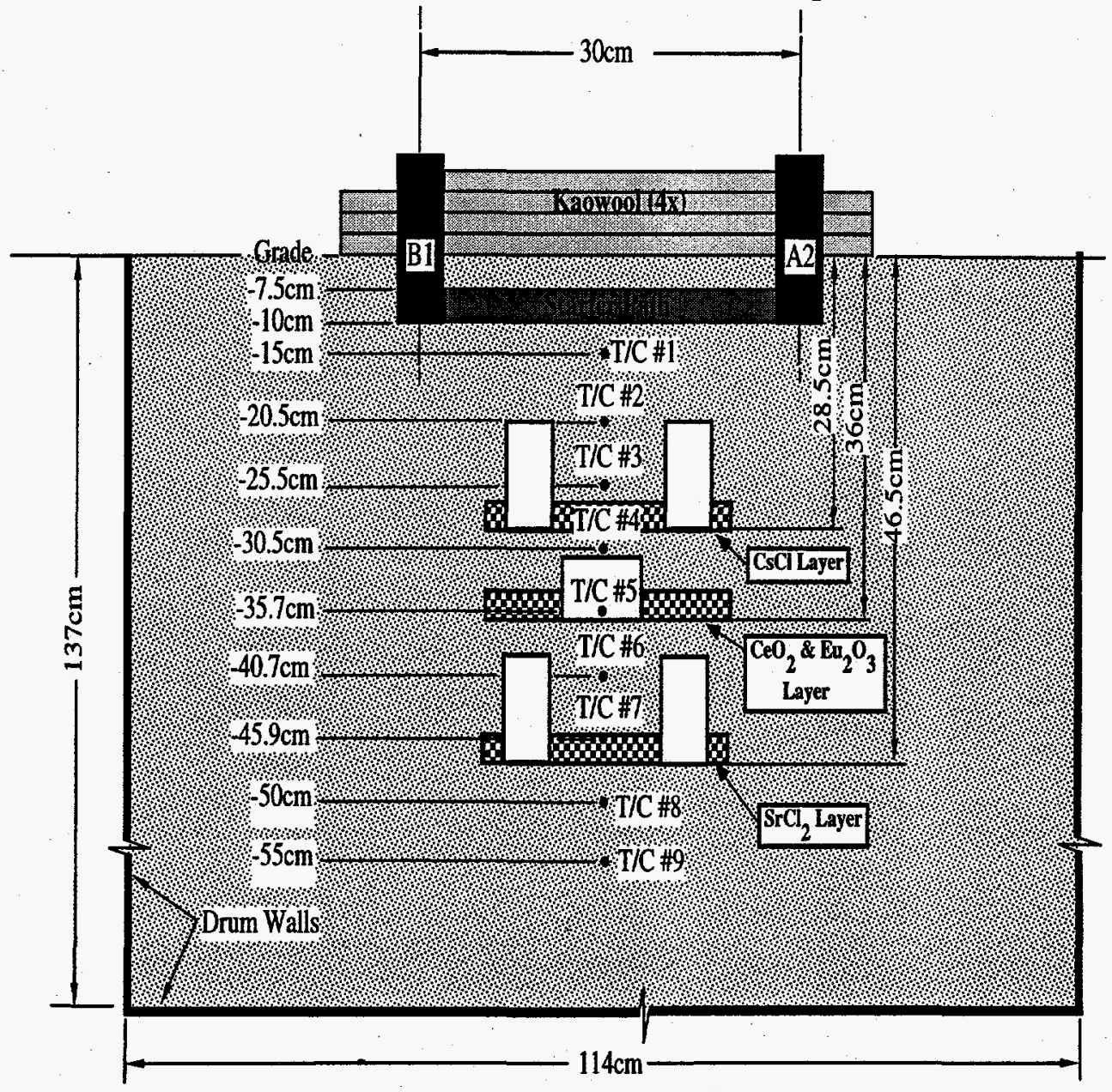

Figure 4.1.1. ORNL-ESBW-5 Test Configuration - Elevation View.

strontium have boiling-point temperatures comparable or below that attained in an ISV melt (viz., $670^{\circ} \mathrm{C}$ and $1375^{\circ} \mathrm{C}$, respectively vs. $1600^{\circ} \mathrm{C}$ for an ISV melt). Therefore, it is expected that some of this material may come-off in the off-gas during processing. To facilitate the post-test performance assessment for processing these materials, these releases must be captured to allow measurements to be made of simulant transport and distribution. Consequently, a HEPA filter was plumbed into the off-gas outlet line between the ISV hood exit port and the off-gas blower. To further facilitate the post-test analysis effort, a manifold was incorporated into the off-gas outlet line to allow three flow paths to be invoked at the operator's discretion. HEPA filters were plumbed into two of the three branch lines on this manifold. The third line consisted of straight 
pipe to allow bypass of the HEPA filters altogether. Ball valves were strategically placed in these lines to allow each branch to be valved in or out of service as desired. This configuration is illustrated in Figure 4.1.2. Three HEPA filters were employed for this test. Off-gas flow was directed through separate HEPA filters as each of the three layers was being processed.

Consequently, one branch of the off-gas outlet line was used to service two of the three HEPA filters.

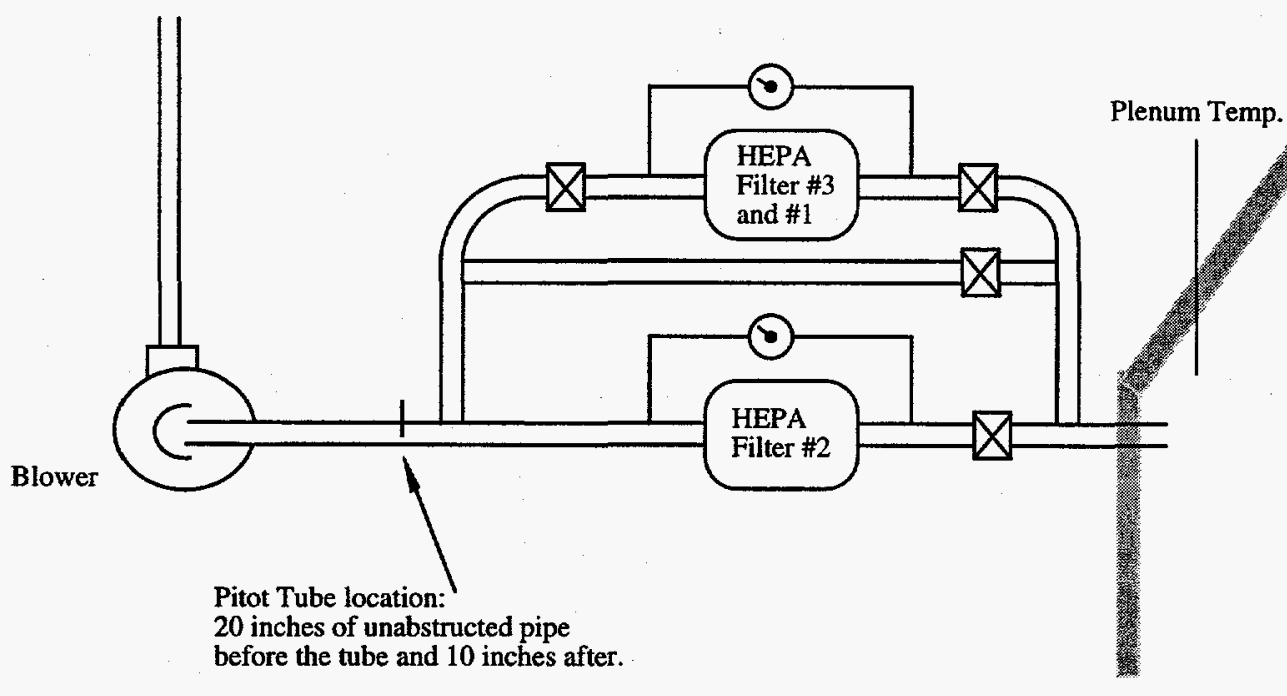

Container Wall

Figure 4.1.2. ORNL-ESBW-5 Test Off-Gas Outlet Line and HEPA Filter Connections.

\subsubsection{Test Instrumentation}

With the exception of the added simulants and HEPA filters, this test was a replication of the previlous top-down ISV tests (e.g., ORNL-ESBW-2a). Therefore, the type, number, and placement of the instruments used to monitor and record the transients encountered while performing this tests were identical with those employed in the preceding top-down tests. There was no automated data collection system associated with the operation of the HEPA filters. Differential pressures were monitored and recorded manually on an hourly basis or as conditions warranted. None of the HEPA filters became significantly loaded however, so this data was mainly for information only. 


\subsubsection{Test Start-Up and Operation}

The test was initiated at 11:16 PDT on September 29, 1995. Full power (25 kW) was attained via a linear ramp-up in power during the first two hours of the test. This $25 \mathrm{~kW}$ power level was maintained for the remainder of the test.

At 15:00 ( $\Delta \mathrm{t} \approx 3.75 \mathrm{~h})$, the melt had progressed to the point where it was apparent that the upper layer of cans and $\mathrm{CsCl}$ simulant had been processed. Therefore, the first HEPA filter was valved-out and the second HEPA filter valved-in. At $16: 44(\Delta t \approx 5.5 \mathrm{~h})$, it was apparent that the melt had progressed beyond the middle layer of cans and simulants (viz., $\mathrm{CeO}_{2}$ and $\mathrm{Eu}_{2} \mathrm{O}_{3}$ ). Consequently, the second HEPA filter was valved-out of service, ant the third HEPA filter valvedin. Flow was directed through the final HEPA filter for the remainder of the test.

At 20:12 $(\Delta t \approx 8.9 \mathrm{~h})$, all three layers of cans and simulants were processed without incident. There were no significant plenum pressure/temperature excursions experienced during this test. Therefore, power to the melt was terminated and the system shutdown. A total of $198 \mathrm{kWh}$ was consumed in this test.

\subsubsection{Phase Voltage, Current, and Resistance Results}

Figure 4.1.3 presents the phase voltage, current, and resistance transients experienced during this test. As with the previous top-down tests, the balance between phases is quite evident in these results. The phase power, and total power and energy consumption transients are presented in Figure 4.1.4. Again, the balance between phases is quite evident. The target $25 \mathrm{~kW}$ was also maintained relatively well during this test. As these data indicate, the total electrical energy consumed during this test was $198 \mathrm{kWh}$.

\subsubsection{Electrode Depth and Soil Temperature Results}

Figure 4.1.5 presents the average electrode depth and centerline temperature transients realized during this test. The depth portion of some of the thermocouple tags listed in this figure differ slightly from the depths indicated in the schematic elevation view of the configuration (Figure 4.1.1). For example, the second thermocouple from the top indicates its placement depth was $20.5 \mathrm{~cm}$ below grade while Figure 4.1 .1 indicates this thermocouple was placed at $-20 \mathrm{~cm}$ below grade. The locations indicated in Figure 4.1.5 are accurate and reflect the as-built layout of 


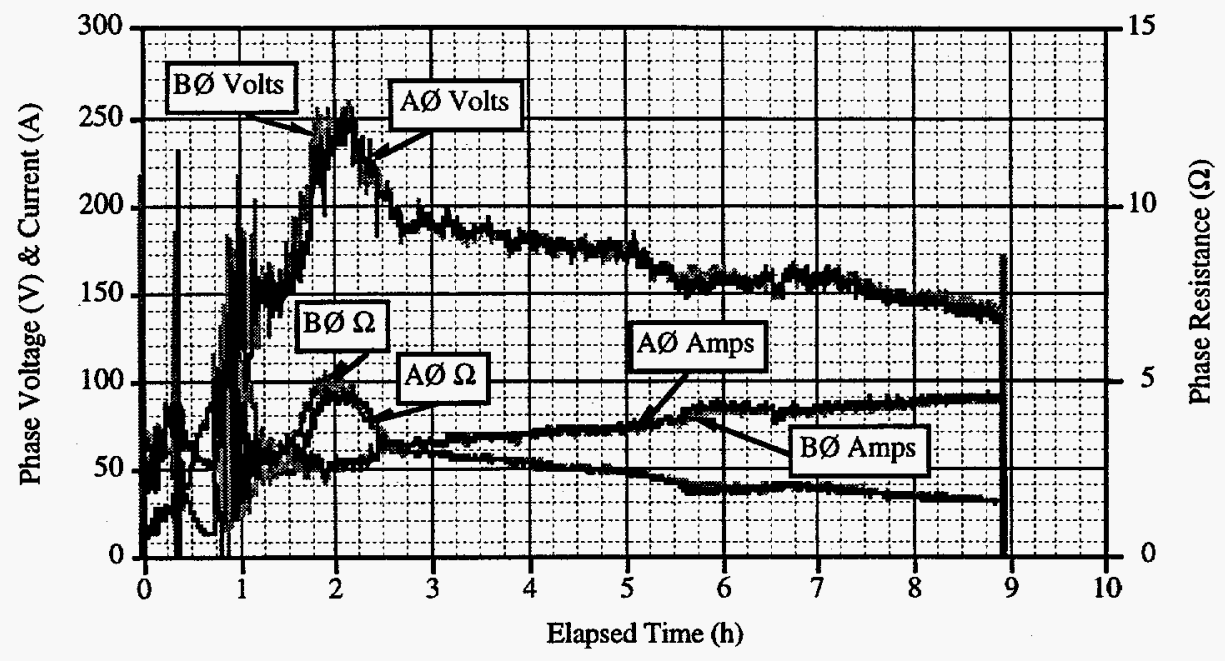

Figure 4.1.3. ORNL-ESBW-5 Phase Voltage, Current, and Resistance Transients.

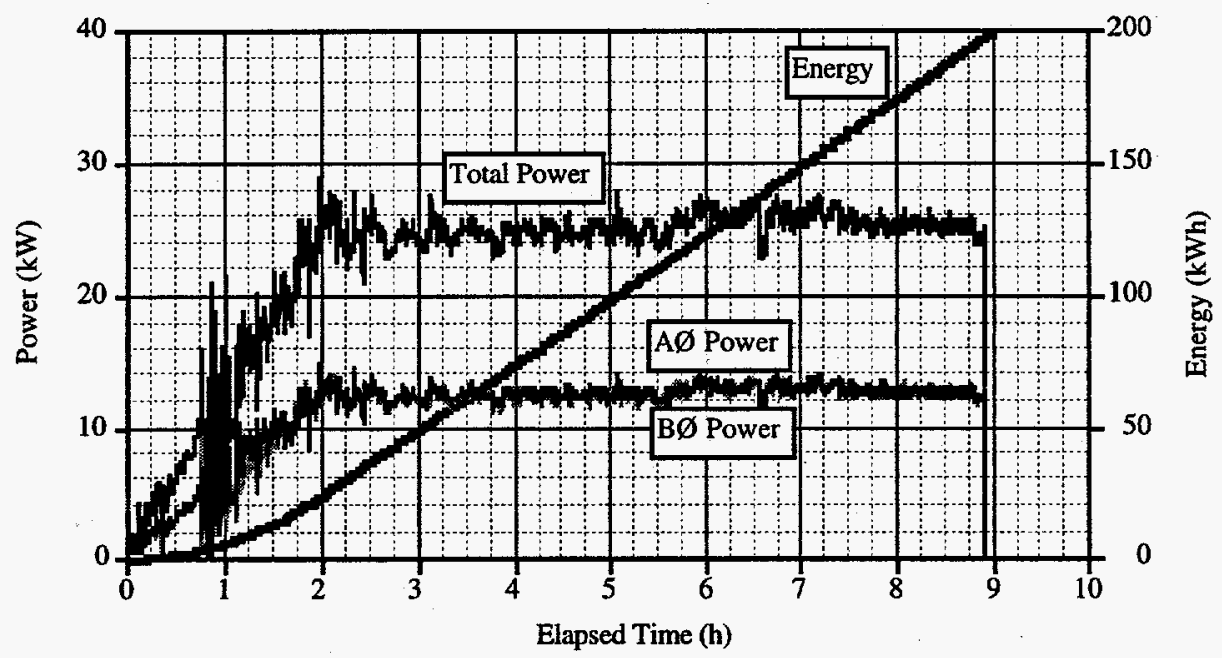

Figure 4.1.4. ORNL-ESBW-5 Phase Power, and Total Power \& Energy Transients.

the thermocouple bundle. This is a one-time occurrence and reflects some re-positioning that occurred during the staging of this test.

As these data indicate, the test proceeded very smoothly through the full depth of the "waste" zone. The temperature traces are very smooth with no sign of the sawtooth behavior indicative of the occurrence of a can rupture event. 


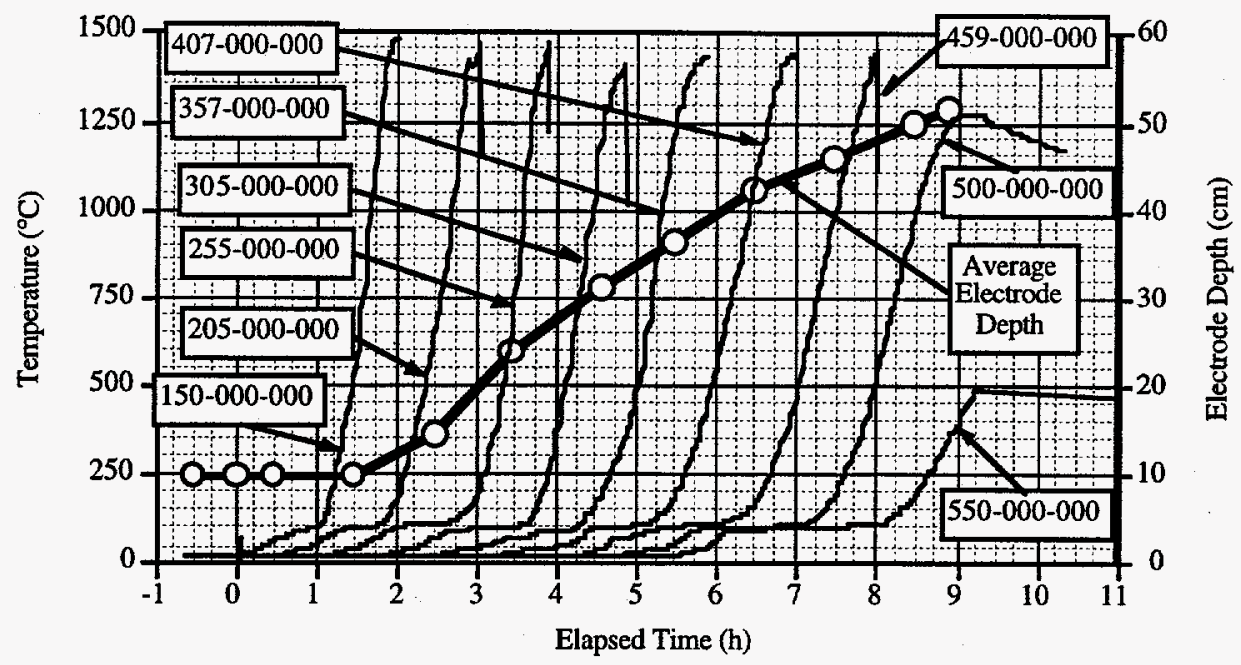

Figure 4.1.5. ORNL-ESBW-5 Electrode Depth and Centerline Temperature Transients.

\subsubsection{Plenum Pressure and Temperature Results}

Figure 4.1.6 illustrates the plenum pressure and temperature, as well as the off-gas inlet temperature transients realized during this test. There are several spikes indicated in the pressure trace provided in this figure. These spikes do not represent the result of a can rupture. Rather, they reflect operator-induced perturbations to the off-gas system. The spike at approximately 13:30 ( $\Delta \mathrm{t} \approx 2.25 \mathrm{~h}$ ) was the result of the operator closing-down the off-gas inlet valve in an attempt to maintain the plenum pressure at the target -3 inch w.c. level. This operation was done again at 14:17 $(\Delta t \approx 3 \mathrm{~h})$ - hence the variation in the plenum pressure trace at this time. At 15:00 $(\Delta \mathrm{t} \approx 3.75$ $h$ ), the first HEPA filter was valved-out and the second valved-in. Finally, at 16:44 ( $\Delta \mathrm{t} \approx 5.5 \mathrm{~h})$ the third HEPA filter was valved-in and the second valved-out. Thus, each of the pressure spikes evident in this figure were associated with some external system adjustment performed by the operator.

\subsubsection{ISV Block Statistics}

A $270 \mathrm{~kg}$ block was produced in 9 hours of operation in this test. As previously mentioned, a total of $198 \mathrm{kWh}$ were consumed in the process. Therefore, the specific energy consumption for this test was $0.73 \mathrm{kWh} / \mathrm{kg}$. This value rivals that realized in the ORNL-ESBW-3 bottom-up test. 
The increased efficiency is likely the result of reduced moisture content for the soil used to stage this test -- though quantitative data on the soil moisture content was not obtained in this test.

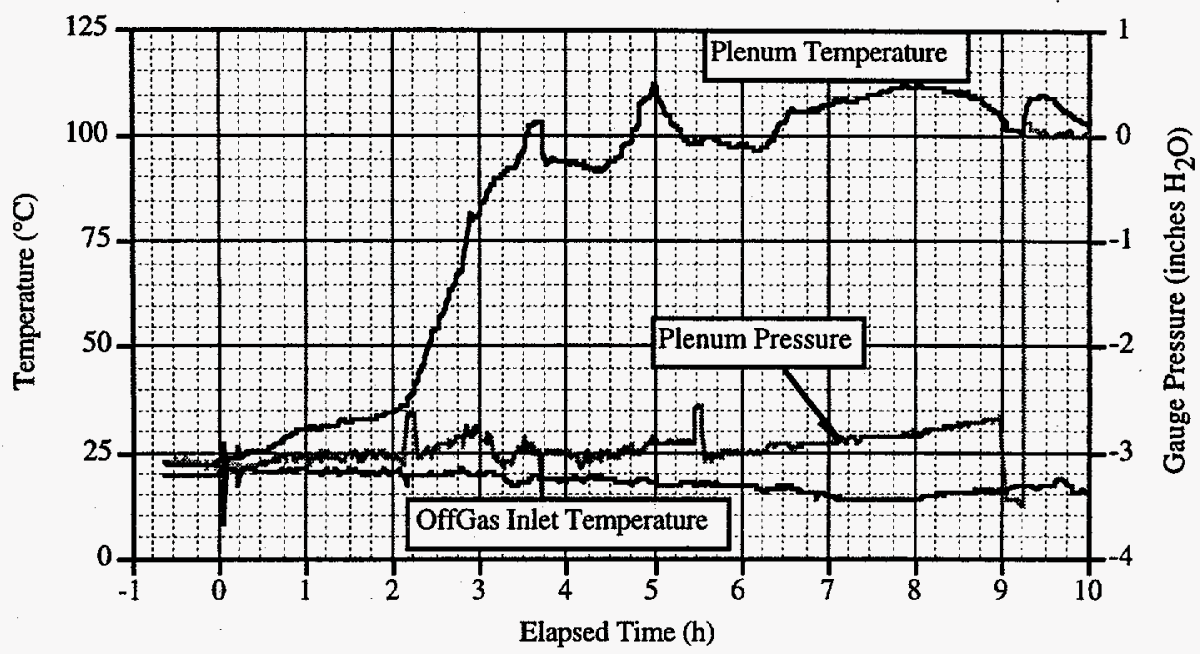

Figure 4.1.6. ORNL-ESBW-5 Plenum Pressure and Temperature Transients.

\subsubsection{Post-Test Chemical Sampling Analysis Plan \& Results}

To assess the effectiveness of the ISV process for remediating sites containing the sorts of inorganic chemicals staged in this test, an extensive post-test sampling and analysis program was undertaken. Twenty-four soil and glass samples were taken in and around the ISV block after this test. In addition, swipe samples were taken over several $10^{\prime \prime} \times 10^{\prime \prime}$ areas on the interior surfaces of the ISV hood and ring foundation. Each leg of the off-gas piping upstream of the inlet ports to the HEPA filters was swabbed separately to remove all simulant particulates that may have condensed on the sidewalls of this piping during the test. These three swab samples were then submitted for chemical analysis. The filter material from each of the three HEPA filters was also removed from its housing and a representative portion of it submitted for chemical analysis. Clean samples of both the reinforced paper toweling used to obtain the swipe samples and the HEPA filter material were also analyzed to determine the background concentration of cerium, cesium, europium, and strontium present in these substrates.

In addition to being analyzed for their composition, the glass samples obtained from the ISV block were also subjected to the Toxicity Characteristic Leaching Procedure (TCLP) test. The 
leachate generated by this process was analyzed to determine the extent to which the staged simulant material bound in the glass matrix could be leached-out.

The 24 soil/glass sample locations are indicated schematically in Figure 4.1.7. Results of the chemical analysis of the soil, glass, swipe, and Kaowool samples, as well as a brief description of the sample location are presented in Table 4.1.1. Soil sample elevations listed in this table are with respect to grade. The block subsided approximately $10 \mathrm{~cm}$ in this test.

In addition to the post-test samples taken, two samples of the native soil used in this test were analyzed to determine the baseline concentrations of the simulants present. These baseline concentrations are also indicated in the first row of data presented in Table 4.1.1. Note that two

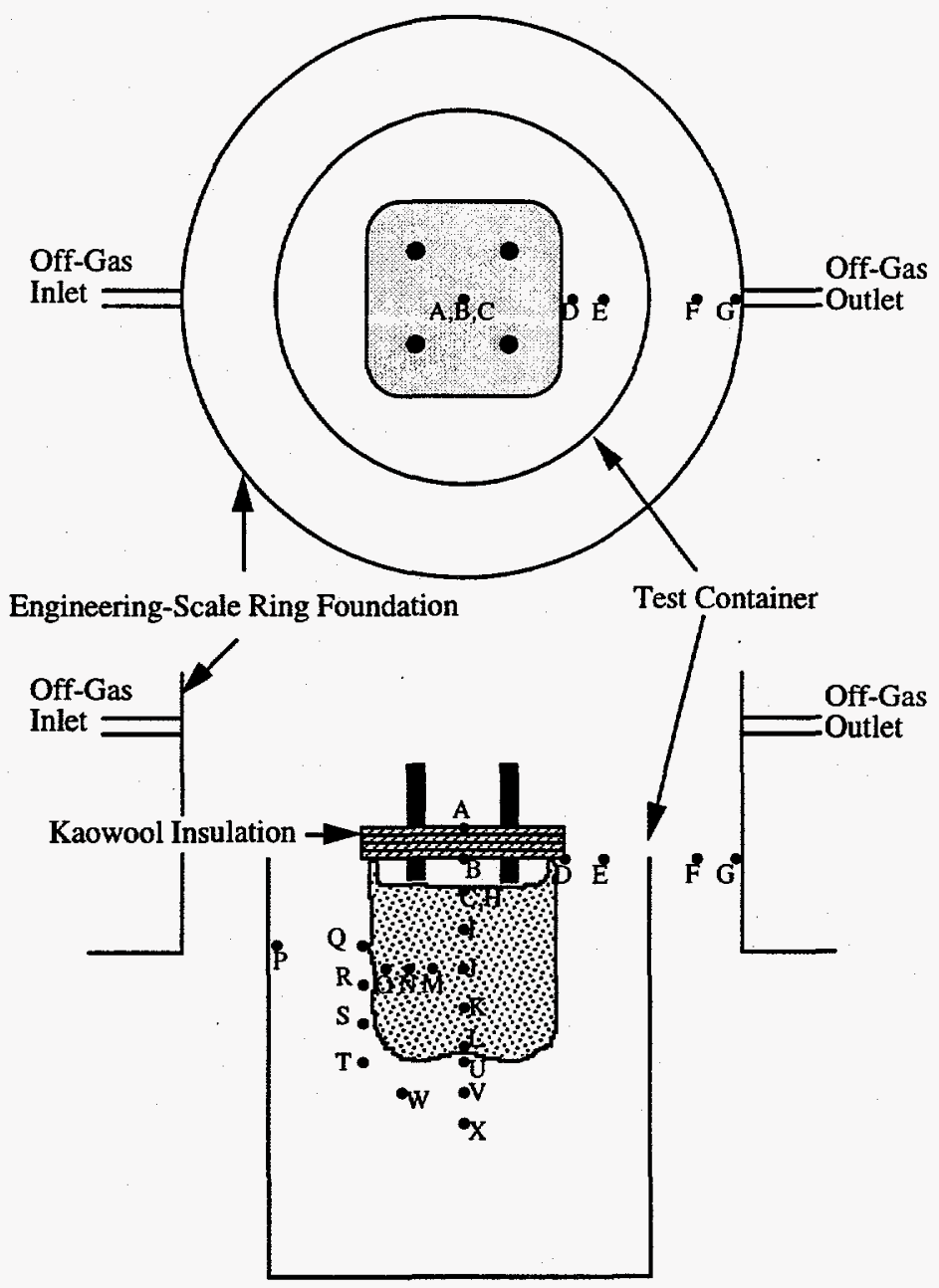

Figure 4.1.7. ORNL-ESBW-5 Soil and Glass Sample Locations. 
Table 4.1.1. ORNL-ESBW-5 Soil/Block Sample Chemical Analysis Results.

\begin{tabular}{|c|c|c|c|c|c|}
\hline $\begin{array}{c}\text { Sample } \\
\text { ID. }\end{array}$ & Sample Description & $\underset{(\mathrm{mg} / \mathrm{g})}{\mathrm{Cs}}$ & $\begin{array}{c}\mathrm{CeO}_{2} \\
\text { (wt.\%) }\end{array}$ & $\begin{array}{l}\mathrm{Eu}_{2} \mathrm{O}_{3} \\
\text { (wt.\%) }\end{array}$ & $\begin{array}{c}\mathrm{SrO} \\
(\mathrm{wt.} \%)\end{array}$ \\
\hline PRE & Hanford soil before testing & $\mathrm{dl}^{*}$ & $\begin{array}{c}\mathrm{dl} \\
-0.077\end{array}$ & dl & $0.048-0.053$ \\
\hline A & 1 in $^{2}$ of Kaowool surface & 0.105 & 0.089 & $\mathrm{dl}$ & 0.018 \\
\hline B & $1 \mathrm{in}^{2}$ of Kaowool underside & 0.739 & 0.057 & $\mathrm{dl}$ & 0.028 \\
\hline C & $\begin{array}{l}\text { Glass surface at center of block, } \\
\text { depth of }-10 \mathrm{~cm}\end{array}$ & 0.269 & 0.785 & 0.066 & 0.171 \\
\hline D & Soil surface below Kaowool & $\mathrm{dl}$ & 0.077 & $\mathrm{dl}$ & 0.055 \\
\hline $\mathrm{E}$ & Soil surface between test container and block & $\mathrm{dl}$ & 0.090 & $\mathrm{dl}$ & 0.051 \\
\hline $\mathrm{F}$ & $\begin{array}{l}\text { Soil surface between test container and ring } \\
\text { foundation }\end{array}$ & dl & 0.061 & dl & 0.054 \\
\hline G & Soil surface next to ring foundation & dl & 0.053 & $\mathrm{dl}$ & 0.053 \\
\hline $\mathrm{H}$ & $\begin{array}{l}\text { Glass surface at center of block, } \\
\text { depth of }-10 \mathrm{~cm}\end{array}$ & 0.277 & 0.899 & 0.076 & 0.202 \\
\hline I & Glass at center of block, depth of $-20 \mathrm{~cm}$ & 0.267 & 0.804 & 0.067 & 0.190 \\
\hline $\mathbf{J}$ & Glass at center of block, depth of $-30 \mathrm{~cm}$ & 0.292 & 0.844 & 0.072 & 0.192 \\
\hline K & Glass at center of block, depth of $-40 \mathrm{~cm}$ & 0.265 & 0.892 & 0.073 & 0.224 \\
\hline L & Glass at center of block, depth of $-50 \mathrm{~cm}$ & 0.247 & 0.719 & 0.061 & 0.325 \\
\hline M & Glass $7.5 \mathrm{~cm}$ from center, depth of $-30 \mathrm{~cm}$ & 2.714 & 0.771 & 0.066 & 0.195 \\
\hline $\mathbf{N}$ & Glass $15 \mathrm{~cm}$ from center, depth of $-30 \mathrm{~cm}$ & 2.922 & 0.917 & 0.077 & 0.211 \\
\hline $\mathrm{O}$ & Glass $22.5 \mathrm{~cm}$ from center, depth of $-30 \mathrm{~cm}$ & 2.442 & 0.873 & 0.074 & 0.213 \\
\hline $\mathbf{P}$ & Soil next to test container, depth of $-25 \mathrm{~cm}$ & $\mathrm{dl}$ & 0.053 & $\mathrm{dl}$ & 0.052 \\
\hline Q & Soil $32 \mathrm{~cm}$ from center, depth of $-25 \mathrm{~cm}$ & $\mathrm{dl}$ & 0.068 & dl & 0.053 \\
\hline $\mathbf{R}$ & Soil $32 \mathrm{~cm}$ from center, depth of $-35 \mathrm{~cm}$ & dl & 0.074 & dl & 0.060 \\
\hline $\mathrm{s}$ & Soil $32 \mathrm{~cm}$ from center, depth of $-44.5 \mathrm{~cm}$ & $\mathrm{dl}$ & dl & dl & 0.052 \\
\hline $\mathrm{T}$ & Soil $32 \mathrm{~cm}$ from center, depth of $-52 \mathrm{~cm}$ & $\mathrm{dl}$ & 0.086 & dl & 0.052 \\
\hline $\mathrm{U}$ & Soil at center, depth of $-52 \mathrm{~cm}$ & $\mathrm{dl}$ & 0.053 & dl & 0.058 \\
\hline $\mathrm{V}$ & Soil at center, depth of $-63 \mathrm{~cm}$ & $\mathrm{dl}$ & $\mathrm{dl}$ & $\mathrm{dl}$ & 0.055 \\
\hline W & Soil $20 \mathrm{~cm}$ from center, depth of $-63 \mathrm{~cm}$ & $\mathrm{dl}$ & $\mathrm{dl}$ & dl & 0.053 \\
\hline $\mathrm{X}$ & Soil at center, depth of $-73 \mathrm{~cm}$ & dl & 0.115 & dl & 0.052 \\
\hline
\end{tabular}

${ }^{*} \mathrm{dl}=$ concentration below detection limit 
different values were obtained for the background $\mathrm{CeO}_{2}$ and $\mathrm{SrO}$ concentrations. These reference values were used to help assess the distribution and concentration after the test. ICP and/or AA analyses were performed on the fused samples to determine the concentration of elements present in each.

The results indicate, in part, that no net quantity of cerium or europium had condensed on the Kaowool. This is consistent with the nonvolatile nature of these chemical compounds. However, $912 \mathrm{mg}$ of cesium and $227 \mathrm{mg}$ strontium had collected on these surfaces.

The results obtained for the swipes taken in the off-gas line indicate a total of $54 \mu \mathrm{g}$ cerium, $336 \mu \mathrm{g}$ cesium, $27 \mu \mathrm{g}$ europium, and $55 \mu \mathrm{g}$ strontium had condensed on the walls of the off-gas piping.

Table 4.1.2 indicates the results of the chemical analyses performed on the HEPA filter material. HEPA filter \#1 was in service for the first 3.75 hours of the test. HEPA filter \# 2 was in service for the next 1.75 hours of the test. HEPA filter \#3 was in service for the final 3.5 hours of the test. Based upon the electrode depth results (Figure 4.1.5), the melt had progressed to the 30 $\mathrm{cm}$ depth in approximately 4.5 hours. By the time the third HEPA filter was put into service, the melt had progressed to a depth of about $38 \mathrm{~cm}$. It is interesting to note that, while the cesium was placed on the uppermost of the three staged layers in this test, the highest concentrations of this material condensed on HEPA filters employed during the later stages of the test. Based upon its

Table 4.1.2. ORNL-ESBW-5 HEPA Filter Chemical Analysis Results.

\begin{tabular}{|c|c|c|c|c|}
\hline HEPA Filter \# & Ce $(\mathrm{mg})$ & Cs $(\mathrm{mg})$ & Eu (mg) & Sr (mg) \\
\hline \hline 1 & 66 & 8 & 4 & $\mathrm{dl}$ \\
\hline 2 & $\mathrm{dl}^{*}$ & 249 & $\mathrm{dl}$ & $\mathrm{dl}$ \\
\hline 3 & 72 & 1196 & 7 & $\mathrm{dl}$ \\
\hline
\end{tabular}

${ }^{*} \mathrm{dl}=$ concentration below detection limit

initial placement, one would expect that the bulk of the volatilized cesium would have been captured on the first and second HEPA filters. As the results of Table 4.1.2 indicate however, the majority of the cesium was captured in the last two HEPA filters employed in this test. Therefore, there must be a substantial hold-up time associated with reaction kinetics and decomposition of the $\mathrm{CsCl}$ compound. In addition, there will be some time lag associated with incorporating the products of reaction into the melt, volatilizing them into the off-gas system, and finally condensing the particulates on the surfaces of the Kaowool and off-gas piping and filtration systems. As 
previously indicated, over $900 \mathrm{mg}$ of cesium was captured by the Kaowool blanket material placed over the top surface of the melt. This is comparable to the amount captured by the HEPA filters. Together they represent approximately $4 \mathrm{wt} \%$ of the cesium inventory staged in this test.

Swipe sample of the interior surfaces of the ISV hood and ring foundation indicated that no cerium or europium condensed on these surfaces. These same samples indicated that $8 \mathrm{mg}$ cesium had condensed on the hood and ring foundation surfaces (with nearly all of this coming from the hood sample). Further, these results indicated that $617 \mu \mathrm{g}$ of strontium condensed on the interior surfaces of the hood and ring foundation (with roughly $80 \%$ of this coming from condensate on the hood).

The inventory of simulants found on the HEPA filters, off-gas piping, hood surfaces and Kaowool represent the quantity of these materials that were removed from their staged locations in the soil to the off-gas stream. These results, together with the quantity of simulant material staged, are summarized in Table 4.1.3. If one considers that these data reflect the quantity of staged

Table 4.1.3. ORNL-ESBW-5 Simulant Inventory \& Post-Test Distribution.

\begin{tabular}{||c|c|c|c|c|}
\hline Inventory I Material & Ce & Cs & Eu & Sr \\
\hline Staged & $1117.5 \mathrm{~g}$ & $54.9 \mathrm{~g}$ & $108.0 \mathrm{~g}$ & $239.5 \mathrm{~g}$ \\
\hline HEPA Filters & $138 \mathrm{mg}$ & $1453 \mathrm{mg}$ & $11 \mathrm{mg}$ & - \\
\hline Off-Gas Piping & $54 \mu \mathrm{g}$ & $336 \mu \mathrm{g}$ & $27 \mu \mathrm{g}$ & $55 \mu \mathrm{g}$ \\
\hline Hood Surfaces & - & $8 \mathrm{mg}$ & - & $617 \mu \mathrm{g}$ \\
\hline Kaowool & - & $912 \mathrm{mg}$ & - & $227 \mathrm{mg}$ \\
\hline Surrounding Soil & - & - & - & - \\
\hline
\end{tabular}

material that had been "volatilzed" or otherwise transported to subsequently condense on the ISV system surfaces during processing, approximately $0.01 \mathrm{wt} \%$ of the cerium and europium, 0.10 $w t \%$ of the strontium, and $4.3 \mathrm{wt} \%$ of the cesium staged in the test was transferred to subsequently condense on these surfaces.

The quantity of these materials present in the soil surrounding the vitrified mass can be estimated using the results from samples $D$ through $G$ and $P$ through $X$. All of these data indicate that, relative to the baseline soil concentrations of these materials, virtually none of the simulant material had migrated to the surrounding soil. Moreover, the data from samples $\mathrm{C}$ and $\mathrm{H}$ suggest 
that the migration path for these simulants was up through the melt, exiting in the region directly below the Kaowool layer placed over the top surface of the melt.

The results presented in Table 4.1.1 can also be used to estimate the average concentration of the staged materials contained in the block. Samples I through L indicate an average cesium concentration of $0.268 \mathrm{mg} \mathrm{Cs} / \mathrm{g}$ glass in the block. The standard deviation associated with this population is $0.016 \mathrm{mg} \mathrm{Cs} / \mathrm{g}$ glass. Samples $\mathrm{M}, \mathrm{N}$, and $\mathrm{O}$ were discarded from this statistic. They deviated from the other values by nearly a clean factor of ten. Concentration values obtained for the cerium, europium, and strontium consituents at these locations were more consistent with those taken along the block centerline. This suggests an error in the chemical analysis results reported for the cesium concentration in samples $\mathrm{M}, \mathrm{N}$, and $\mathrm{O}$. Therefore, the authors chose to discard these data from the cesium statistic calculations. This average value of $0.268 \mathrm{mg} \mathrm{Cs} / \mathrm{g}$ glass is a bit higher than the average concentration obtained by divided the staged quantity of cesium by the block mass, $0.226 \mathrm{mg} \mathrm{Cs} / \mathrm{g}$ glass (= $54.9 \mathrm{~g} / 243 \mathrm{~kg}$ ). Thus, there appears to be some stratification and/or inhomogeneity in the distribution of cesium contained in the block.

The average of the cerium concentration data for samples I through $\mathrm{O}$ is $6.46 \mathrm{mg} \mathrm{Ce} / \mathrm{g}$ glass, with an associated standard deviation of $0.53 \mathrm{mg} \mathrm{Ce} / \mathrm{g}$ glass. By comparison, the average concentration based upon the quantity staged and the mass of the block is $4.60 \mathrm{mg}$ Ce/g glass $(=1117.59 \mathrm{~g} \mathrm{Ce} / 243 \mathrm{~kg})$. Again, the sample statistics indicate an inhomogeneous distribution of this simulant material within the block.

For the europium, the data for samples I through $\mathrm{O}$ indicate an average concentration of $0.605 \mathrm{mg} \mathrm{Eu} / \mathrm{g}$ glass. The standard deviation associated with this sample population is $0.044 \mathrm{mg}$ $\mathrm{Eu} / \mathrm{g}$ glass. An average europium concentration of $0.444 \mathrm{mg} \mathrm{Eu} / \mathrm{g}$ glass is obtained when using the staged quantities and block mass $(=108.0 \mathrm{~g} \mathrm{Eu} / 243 \mathrm{~kg})$. Again, these results indicate inhomogeneities in the distribution of simulants contained in the block.

Finally, samples I through $O$ indicate an average strontium concentration of $1.45 \mathrm{mg} \mathrm{Sr} / \mathrm{g}$ glass in the block, with a standard deviation of $0.371 \mathrm{mg} \mathrm{Sr} / \mathrm{g}$ glass. Using the staged quantities and final block mass, the average strontium concentration was $0.986 \mathrm{mg} \mathrm{Sr} / \mathrm{g}$ glass $(=239.5 \mathrm{~g} \mathrm{Sr} / 243 \mathrm{~kg})$. An inhomogeneous simulant distribution with the block is again indicated by these results.

Simulant material captured on the HEPA filters and Kaowool blankets can be routinely processed in subsequent melts. Therefore, only those simulant inventories found on the off-gas piping and hood surfaces or in the surrounding soil represent the extent to which the ISV process was ineffective at remediating these materials. Under these conditions, the data indicate that essentially all the cerium, europium, and strontium materials were remediated by the ISV process. 
As anticipated, cesium, being the most volatile of these simulant materials, was the least retained in the ISV block. Still however, these data indicate that $99.985 \mathrm{wt} \%$ of the cesium material staged in this test was either retained in the block, or removed by filter material which could be routinely processed in subsequent ISV processes.

The ICP and AA results for the concentration of simulants found in the leachate obtained from the TCLP tests performed on the ISV glass samples are presented in Table 4.1.4. These concentrations are very low relative to those found in the corresponding glass samples from which the leachates were obtained (viz., samples H, J, and L). The fact that the cerium concentrations found in the TCLP leachate were below those found in the blank casts doubt about the veracity of the cerium numbers reported, however. The strontium results indicate that $0.0223 \mathrm{wt} \%$ of the simulant material originally present in the glass sample was leached-out in the TCLP test preformed on glass sample H. Similarly, $0.0231 \mathrm{wt} \%$ and $0.0136 \mathrm{wt} \%$ of the strontium originally present in the glass samples was leached-out by the TCLP test performed on samples J and L, respectively. Factoring-in the characteristic diameter associated with the ground glass used in these tests $(\approx 0.25$ $\mathrm{cm})$ and the corresponding glass density $\left(\approx 2.439 \mathrm{~g} / \mathrm{cm}^{3}\right)$, these strontium TCLP results translate to normalized releases of $0.226 \mathrm{~g} / \mathrm{m}^{2}, 0.234 \mathrm{~g} / \mathrm{m}^{2}$, and $0.139 \mathrm{~g} / \mathrm{m}^{2}$ respectively for samples $\mathrm{H}, \mathrm{J}$, and L. These TCLP results are comparable with those obtained from previous ISV tests involving these or similar non-volatile materials.

Table 4.1.4. ORNL-ESBW-5 TCLP Test Leachate Concentrations.

\begin{tabular}{|c|c|c|c|c|}
\hline Sample ID. & $\begin{array}{c}\text { Leachate Ce } \\
\text { Concentration } \\
(\mathrm{ppb})\end{array}$ & $\begin{array}{c}\text { Leachate Cs } \\
\text { Concentration } \\
(\mathrm{ppb})\end{array}$ & $\begin{array}{c}\text { Leachate Eu } \\
\text { Concentration } \\
(\mathrm{ppb})\end{array}$ & $\begin{array}{c}\text { Leachate Sr } \\
\text { Concentration } \\
(\mathrm{ppb})\end{array}$ \\
\hline \hline Blank & 240 & $\mathrm{dl}^{*}$ & $\mathrm{dl}$ & $\mathrm{dl}$ \\
\hline $\mathrm{H}$ & 220 & $\mathrm{dl}$ & $\mathrm{dl}$ & 20 \\
\hline $\mathrm{J}$ & 200 & $\mathrm{dl}$ & $\mathrm{dl}$ & 20 \\
\hline $\mathrm{L}$ & 190 & $\mathrm{dl}$ & $\mathrm{dl}$ & 20 \\
\hline
\end{tabular}

${ }^{*} \mathrm{dl}=$ concentration below detection limit

\subsubsection{Test Retrospecive}

All staged materials were processed in this test without experiencing any plenum pressure/temperature excursions. Therefore, the DC process again proved effective at 
compromising the canisters sufficiently to preclude these excursions. As before, the cans staged in this test were deformed by the DC process, but not breached.

The post-test soil samples taken in and around the block, as well as the samples taken of the hood and piping surfaces and filter material, indicate that the ISV process was successful at retaining the staged simulant materials in either the block, or on filter materials (e.g., the HEPA filter paper and the Kaowool insulative blanket) that could be routinely processed in subsequent ISV treatments. Virtually all the staged simulant material that was volatilized during the test condensed on either the Kaowool or the HEPA filter material.

For the cerium, only 0.0106 wt\% of the quantity staged evolved to the surfaces of the off-gas and ISV hood systems, with essentially all of this condensing on the HEPA filter material. The remainder of the cerium material was retained in the vitrifed block.

Cesium was the most volatile of the simulants staged in this test. Approximately $4.3 \mathrm{wt} \%$ of the elemental cesium staged in the target vitrification zone volatilized and was subsequently condensed on the ISV hood, off-gas system, and their appurtenances. Approximately $61 \%$ of this volatilized cesium was captured on the HEPA filter material. $38 \%$ was trapped on the Kaowool blanket placed over the top surface of the melt. The remaining $1 \%$ had condensed on the surfaces of the ISV hood and off-gas piping.

Based upon the cesium concentrations found on the three HEPA filters employed in this test, there was a significant time delay between the time at which the $\mathrm{CsCl}$ layer was processed and the time the volatilized portion migrated to the HEPA filters. HEPA filter \#1 was in service during the first 3.75 hours of the test. HEPA filter \#2 was valved into service at 3.75 hours into the test and remained in service until $t \approx 5.5 \mathrm{~h}$. HEPA filter $\# 3$ was valved into service for the final 3.5 hours of the test, at $\mathrm{t} \approx 5.5 \mathrm{~h}$. This filter captured the greatest quantity of cesium. Based upon the average electrode depth, the $\mathrm{CsCl}$ layer was processed at $\mathrm{t} \approx 4.25$ hours in the test. Thus, HEPA filter \#2 was in service for approximately 1.3 hours after the $\mathrm{CsCl}$ layer had been processed. However, as these data indicates, aproximately $82 \%$ of the volatilized cesium captured by the HEPA filters was captured on HEPA filter \#3. This indicates a time lag of at least 1.25 hours for this material to migrate to the HEPA filters.

A similar response was realized in a 1983 pilot-scale radioactive test (PSRT) (Timmerman \& Oma 1984). In this test, approximately $25650 \mathrm{~g}$ of radioactive material was staged in Hanford soil. Of the $25650 \mathrm{~g}$, approximately $2.7 \%$ (by activity) was ${ }^{137} \mathrm{Cs}$. The material was staged in a 5 liter vessel, $74 \mathrm{~cm}$ below grade. The top surface of this vessel was contacted by the melt at $\mathrm{t} \approx 3.3$ $h$ in the test. The bottom surface of the vessel was processed some 5.5 hours later, at $t \approx 8.8 \mathrm{~h}$. The majority of the cesium released to the off-gas system during this test appears to have occured 
during the interval between roughly 6 and 13 hours into the test. A total of $0.77 \mathrm{wt} \%$ of the cesium staged was volatilized to the off-gas system in this 1983 test. This is considerably less than was volatilized in this test. The differences are attributed to the greater placement depth in the 1983 test $(74 \mathrm{~cm}$ vs. $28 \mathrm{~cm}$ ), and the fact that the cesium staged in the 1983 test was containerized rather than placed loosely in the soil as in this test. In addition, the 1983 test was a pilot-scale test. Therefore, the scale of the melt was considerably larger than was produced in this test $(\approx 8600 \mathrm{~kg}$ vs. $270 \mathrm{~kg}$ for this ORNL-ESBW-5 block). As a consequence, the volatilized cesium had to traverse a much longer, more tortuous path to escape to the off-gas stream in the 1983 test than for the ORNL-ESBW-5 test. This increase in scale translates to an increased exposure time for incorporation of the cesium into the block and, as such, would have the effect of inhibiting the release of volatilized cesium to the off-gas system.

A 1987 pilot-scale test performed at ORNL also included some cesium material (Carter et al. 1988). In this test approximately $0.12 \mathrm{wt} \%$ of the staged cesium was volatilized and captured by the off-gas system. The 1987 test involved processing $73274 \mathrm{~g}$ of $\mathrm{Cs}$ (staged as $\mathrm{Cs}_{2} \mathrm{CO}_{3}$ ). This material was staged loosely, along with a limestone filler material. The "waste" zone occupied the region between 1.5 and $2 \mathrm{~m}$ below grade. The greater placement depth, combined with the larger scale of the melt would account for much of the differences in the percent of volatilized cesium ultimately released to the off-gas stream between this 1987 pilot-scale test and the ORNL-ESBW-5 test. In addition, Spalding (1994) has identified that cesium volatility is quite sensitive to the presence of chlorides. Moreover, cesium exhibits a greater affinity for sorption on the illite-rich ORNL soils than for Hanford soils. These effects would also contribute to resolving the discrepancy in cesium release to the off-gas stream in the two tests.

In 1990, an engineering-scale ISV test involving cesium (and other) materials was performed in ORNL soil (Peterson et al. 1992). In this test, $1220 \mathrm{~g} \mathrm{Cs}_{2} \mathrm{CO}_{3}$, together with $25.9 \mathrm{~kg}$ ORNL limestone and $7.0 \mathrm{~kg} \mathrm{Na} \mathrm{CO}_{3}$ were staged in a $10 \mathrm{~cm}$ thick layer, at an average depth of $41 \mathrm{~cm}$. In this test, $0.37 \mathrm{wt} \%$ of the cesium was volatilized and captured by the off-gas filtration system. Again, this volatile fraction was significantly less than was experienced in this ORNL-ESBW-5 test. However, the deeper placement of the cesium, combined with the fact that the cesium was staged as a carbonate rather than a chlorinated compound, likely accounts for the difference.

Finally, in 1991 a pilot-scale ISV test was performed at ORNL (Spalding 1992). This test involved the processing of $490 \mathrm{~g}$ of radioactive sludge. This sludge was inserted into the target vitrification zone through a $7.5 \mathrm{~cm}$ diameter PVC riser which extended from the bottom of the "waste" zone (approximately $2 \mathrm{~m}$ below grade) to the surface. The sludge was contained in a series of plastic bottles to facilitate their placement in the target vitrification zone. The PVC riser 
was processed along with the sludge and soil staged in the target vitrification zone. Spalding (1994) estimated the mass of this PVC pipe to be $4.8 \mathrm{~kg}$, and that it was composed of $56.76 \mathrm{wt} \%$ chlorine. In this test $2.4 \%$ (by activity) of the cesium staged was volatilized during processing for subsequent capture by the ISV off-gas filtration system. This volatilized fraction is approaching the level realized in the ORNL-ESBW-5 test, but is still significantly less. The chlorine loading was much higher in the 1991 test than in this ORNL-ESBW-5 test $(2724 \mathrm{~g}$ vs. $\approx 150 \mathrm{~g}$ for this test). This would tend to accentuate the cesium volatilization in the 1991 relative to the ORNLESBW-5 test. In addition, the presence of the relatively loosely packed soil placed over the sample bottles in the PVC riser would also promote more direct release of volatilized cesium to the off-gas system. The importance of this effect is supported by the fact that, in the 1991 test, there was apparently not the significant delay in the arrival of volatilized cesium at the off-gas filtration components whereas, in the ORNL-ESBW-5 test, there was a substantial time lag. Each of these factors would serve to promote the transport of volatilized cesium to the off-gas stream. Why then was the volatile fraction greater in the 1991 test than for this ORNL-ESBW-5 test? These factors must have been outweighed by the influence of the relative scale of the two melts, and the greater affinity for cesium to bond with ORNL soils.

Results for the release of strontium to the off-gas stream were available for the 1983 PSRT, and the 1987 and 1991 ORNL pilot-scale tests. The two ORNL tests produced strontium releases to the off-gas comparable to those realized in this ORNL-ESBW-5 test. In the 1987 ORNL test, $0.00062 \mathrm{wt} \%$ of the strontium staged was found in the off-gas stream. Similarly, for the 1991 ORNL test, $0.000088 \mathrm{wt} \%$ strontium was collected-from the off-gas stream. In this ORNLESBW-5 test, $0.00028 \mathrm{wt} \%$ strontium was collected from the off-gas piping and hood surfaces. The 1983 PSRT results indicated that approximately $0.032 \mathrm{wt} \%$ strontium was collected in the offgas stream. This is significantly greater than the quantities indicated in the ORNL tests and the ORNL-ESBW-5 test, but is still a relatively small quantity. Similar data for the fraction collected on any Kaowool material placed over the melt was unavailable, however. In the pilot-scale tests, there is likely no Kaowool left at the conclusion of the test. However, this data was not indicated in the 1983 PSRT report.

Finally, the average simulant concentration data obtained from the block samples suggested that the distribution of these materials in the glass block was inhomogeneous. Previous experience with ISV tests indicates that this is quite common for melts performed at the engineering scale as the scale of the melt itself inhibits the development of convective currents sufficient to homogenize the melt materals. Therefore, it is not surprising that the pilot-scale block concentration data 
exhibits a much more uniform distribution of the non-volatile simulant materials throughout the block than was obtained in this ORNL-ESBW-5 test. 


\subsection{ORNL-ESBW-6 TEST}

This test represents an extension of the ORNL-ESBW-5 test discussed in the preceding section. In this ORNL-ESBW-6 test, a representative sample of the volatile and semi-volatile organic contaminants found in the actual ORNL SWSA-6 buried waste trenches was used. As indicated in Section 4.1, the trenches and surrounding soil matrix also contain significant quantities of volatile and semi-volatile organic compounds. These include xylene, toluene, chloroethane, methylene chloride, 1,1-dichloroethane, chloroform, 1,2-dichloroethane, 1,1,2,2tetrachloroethane, trichloroethane, 1,1,2-trichloroethane, benzene, cis-1,3-dichloropropene, tetrachloroethene, ethylbenzene, styrene, phenol, 2,4-dimethylphenol, napthalene, bis-(2ethylhexyl)-phthalate, $o$-cresol, and p-cresol. These compounds span a considerable range of volatility and density -- viz., boiling points ranging from $12^{\circ} \mathrm{C}$ to $384^{\circ} \mathrm{C}$, and specific gravities of less than 0.8 to 1.6. In addition, many of these compounds are quite toxic. Consequently, a subset of four compounds were chosen from this list to be included in this test. They were xylene, toluene, 1,1,2-tricloroethane, and o-cresol. The xylene and toluene have specific gravities less than 1 ( $\approx 0.86$ for both), while the o-cresol and 1,1,2-trichloroethane have specific gravities greater than 1-viz., 1.047 and 1.4416 , respectively. Of these, toluene is the most volatile with a boiling point of $110.6^{\circ} \mathrm{C}$. Next, in order of decreasing volatility, are 1,1,2-trichloroethane (@ $\approx 114^{\circ} \mathrm{C}$ ), xylene $\left(@ \approx 140^{\circ} \mathrm{C}\right.$ ), and o-cresol (@ $\approx 192^{\circ} \mathrm{C}$ ). As was done in the ORNL-ESBW-5 test, these chemicals were placed together with the cans on each of the three layers of the target vitrification zone.

\subsubsection{Test Configuration}

As indicated above, this test represented a repeat of the ORNL-ESBW-2a test with the inclusion of additional organic materials to act as simulants of those contained in the actual ORNL SWSA-6 buried wastes. As such, the test configuration is identical with that employed for the ORNL-ESBW-2a test. The six $6 \mathrm{oz}$ factory-sealed canisters of hydrous organic material were pretreated with DC as per the ORNL-ESBW-2a test. Following pretreatment, the cans were recovered from the DC drop zone and their condition recorded to facilitate correlation of their state with any pressurization events that may have resulted from their subsequent processing with ISV. The cans were then transferred to the ISV container where they were staged on three levels in the "waste" zone, two cans to a level. The chemicals were staged on each of the three layers along with the cans. With the exception of the o-cresol, these chemicals are liquid at ambient conditions. 
Therefore, the xylene, toluene, and 1,1,2-trichloroethane chemicals were poured into $11 \mathrm{ml}$ glass sample vials and sealed with teflon press-on caps prior to their staging in the target vitrification zone. The o-cresol was contained in a large amber glass jar. The head space in this jar was filled with soil and the screw cap threaded onto the jar prior to staging.

A schematic illustrating an elevation view of the test setup is presented in Figure 4.2.1. As indicated in this figure, 216.11 grams of xylene were staged along with two dynamicallycompacted cans on the top layer of the "waste" zone. 403 grams of 1,1,2-trichloroethane and 312 grams of toluene were placed on the middle layer along with two of the dynamically-compacted cans. Finally, 310 grams of o-cresol were staged along with two dynamically-compacted cans at the bottom layer of this configuration. Figures 4.2.2 through 4.2.4 illustrate the placement of the cans and chemicals at each of the three layers of the target vitrification zone.

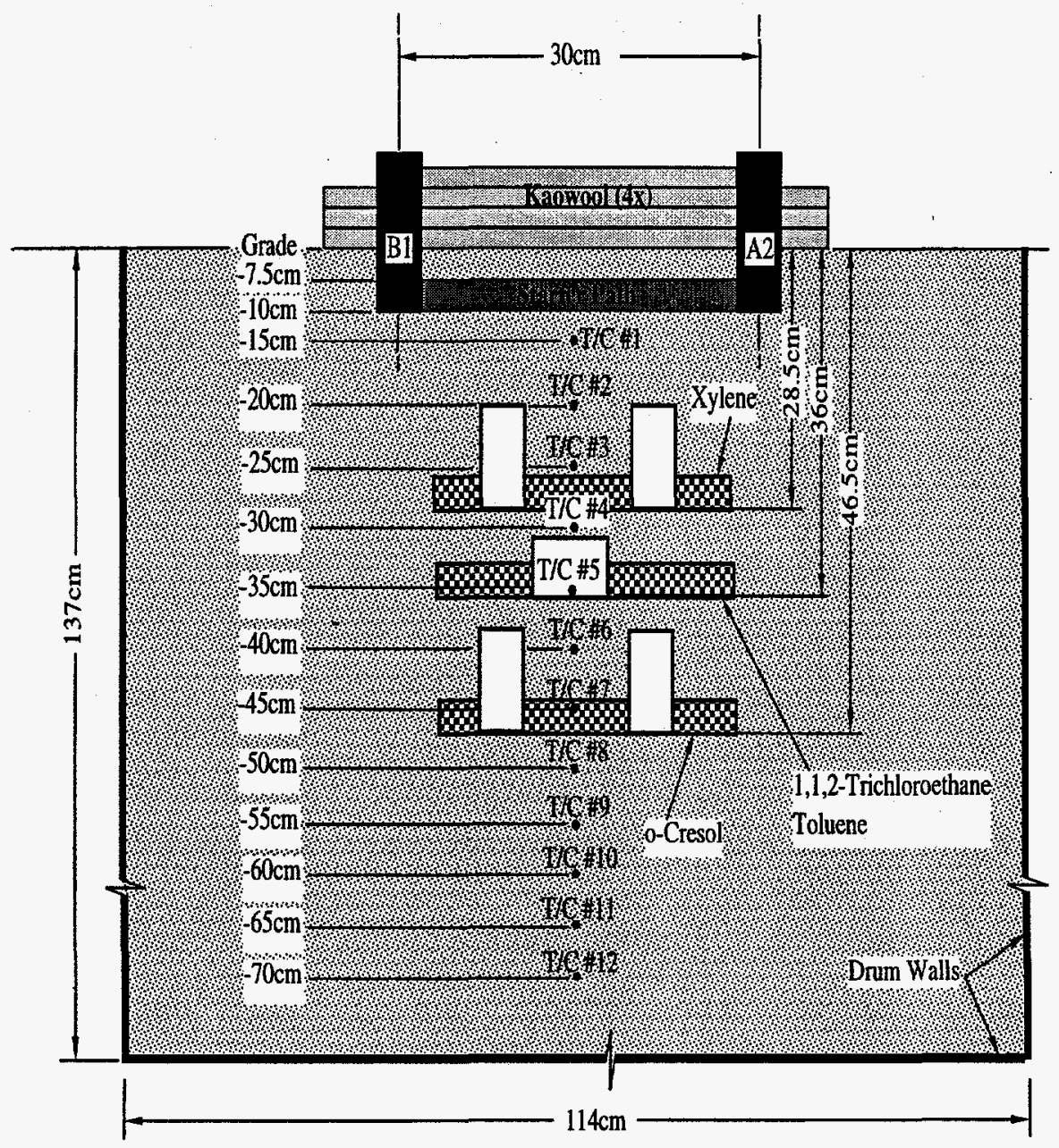

Figure 4.2.1. ORNL-ESBW-6 Test Configuration - Elevation View. 


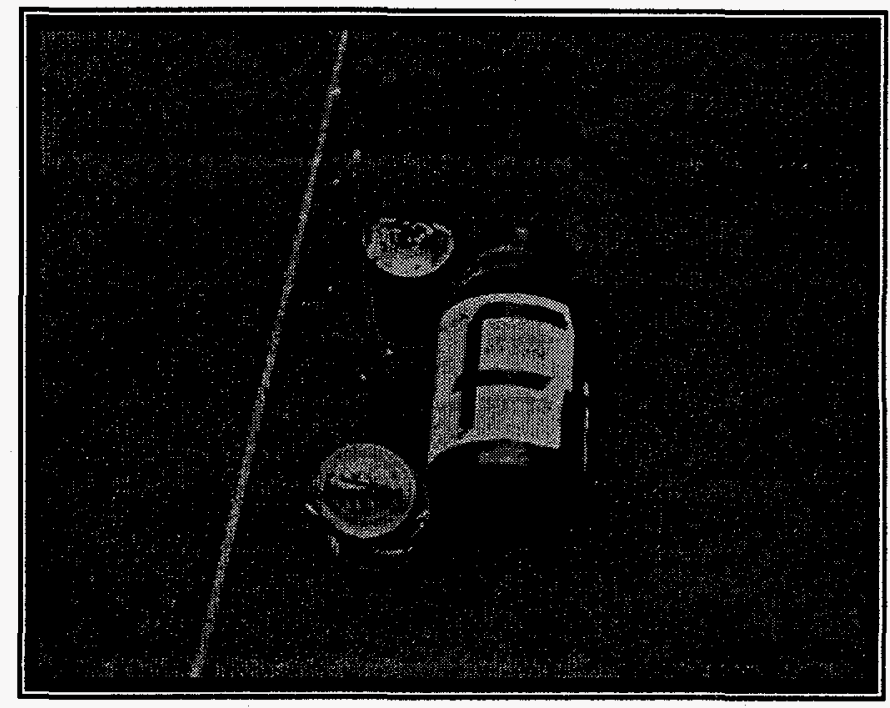

Figure 4.2.2. ORNL-ESBW-6 Can \& Chemical Placement - Bottom Layer.

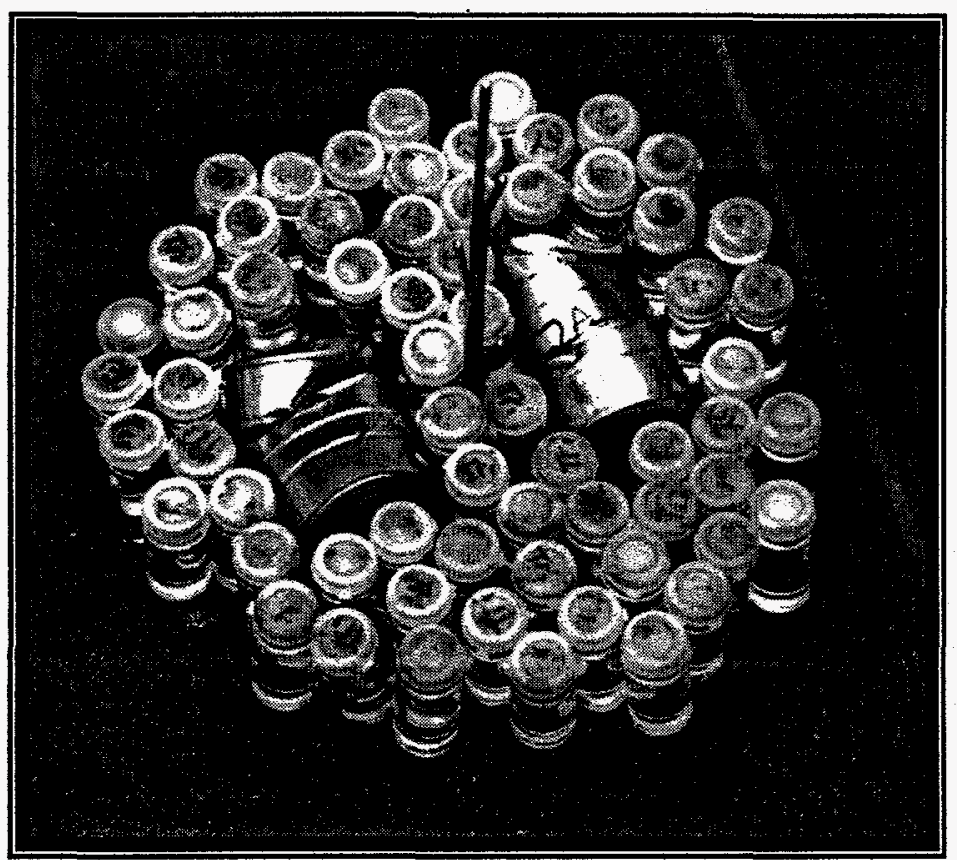

Figure 4.2.3. ORNL-ESBW-6 Can \& Chemical Placement - Middle Layer. 


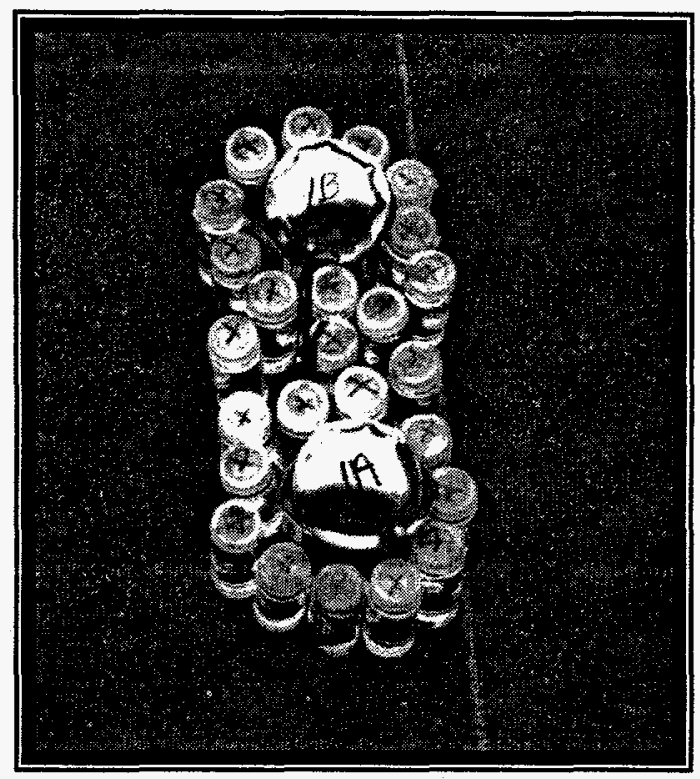

Figure 4.2.4. ORNL-ESBW-6 Can \& Chemical Placement - Top Layer.

\subsubsection{Test Instrumentation}

With the exception of the added chemicals, this test was a replicate of the test performed for the previous top-down ISV tests (e.g., ORNL-ESBW-2a). Therefore, the type, number, and placement of the instruments used to monitor and record the transients encountered while performing this test were identical with those employed in the preceding top-down tests.

Off-gas samples were collected on an hourly basis (or more frequently as conditions warranted) throughout the test. These were obtained by drawing a portion of the off-gas flow through a $125 \mathrm{ml}$ glass sample bottle. The sample was taken from a sampling port in the off-gas outlet flow line. The sampling port was located just outboard of the ISV container. A sample was drawn at $5 \mathrm{scfh}$ for a period of 90 seconds (time to purge the sample bottle about 20 times before collecting the sample). After 90 seconds, the teflon stoppers on both the inlet and outlet ports of the sample bottle were closed. The bottle was given a unique label and prepared for rapid delivery to the lab following the test. Dräger-tube samples were also drawn from this sample port periodically both during and after the test. These results provided an quick-turnaround assessment of off-gas emissions. These Dräger tubes sampled for xylene/toluene, 1,1,2- trichloroethane, ocresol, and $\mathrm{CO}_{2}$ (to indicate extent of reaction). 
Obtaining reliable post-test soil samples for these volatile materials than was considerably more involved than for the inorganics utilized in the preceding test. This was done by removing the soil to within a few centimeters of the sampling location. The remaining soil was then quickly removed and a sample extracted into a glass jar. Every attempt was made to minimize the time required to obtain a sample during this process. In addition, every effort was made to reduce the head space in the sample jars to near zero.

Both the off-gas gas samples and the soil samples were analyzed by Analytical Resources Incorporated (ARI) of Seattle, Washington. The gas samples were transported by air courier from the ISV site in Richland, Washington to ARI. The soil sample vials were packed in a sealed, insulated container along with sufficient "chemical ice" to maintain the container at or below $4^{\circ} \mathrm{C}$ for the duration of the transport process. The analytes were then processed by ARI in accordance with the guidelines set forth in EPA Test Method 8260 or 8270, as appropriate

\subsubsection{Test Start-Up and Operation}

This test was initiated at 10:01 PST on November 8, 1995. The usual two hour linear rampup in power was followed to bring the system to the $25 \mathrm{~kW}$ steady state power level at 12:01. This $25 \mathrm{~kW}$ power level was maintained from this point for the duration of the test.

$125 \mathrm{ml}$ samples of the off-gas effluent were taken at 11:20 $(\Delta \mathrm{t} \approx 1.3 \mathrm{~h}), 12: 17(\Delta \mathrm{t} \approx 2.25 \mathrm{~h})$, 13:25 $(\Delta \mathrm{t} \approx 3.4 \mathrm{~h}), 14: 20(\Delta \mathrm{t} \approx 4.3 \mathrm{~h}), 15: 20(\Delta \mathrm{t} \approx 5.3 \mathrm{~h}), 16: 14(\Delta \mathrm{t} \approx 6.2 \mathrm{~h}), 17: 20(\Delta \mathrm{t} \approx 7.3 \mathrm{~h})$, 18:20 $(\Delta \mathrm{t} \approx 8.3 \mathrm{~h})$, and 19:20 $(\Delta \mathrm{t} \approx 9.3 \mathrm{~h})$ during the test. An additional post-test gas sample was extracted at 10:20 $(\Delta t \approx 24.3 \mathrm{~h})$ the following day (November 9, 1995). Dräger tube readings of the xylene/toluene, cresol, and 1,1,2-trichloroethane concentrations present in the off-gas were also taken at these times to provide a quick-check of the concentration levels of these chemicals.

The full depth of the target vitrification zone was processed at approximately 20:20 $(\Delta \mathrm{t} \approx$ $10.3 \mathrm{~h}$ ) on November 8,1995 . There were no plenum pressurization events realized during this test. To test the sensitivity of melt growth to power level, the power level was increased to $30 \mathrm{~kW}$ at this point and the test continued another 3 hours 41 minutes until 00:01 $(\Delta t \approx 14 \mathrm{~h})$ the next day, November 9,1995 . A total of $347 \mathrm{kWh}$ was consumed during this test.

\subsubsection{Phase Voltage. Current, and Resistance Results}

Figure 4.2.5 presents the phase voltage, current, and resistance transients realized in this test. These data are consistent with those obtained in the previous top-down tests. Again, the good 
balance between phases is evident. Figure 4.2.6 presents plots of the phase power,total power, and energy consumption transients produced during this test. The jump in power from $25 \mathrm{~kW}$ to $30 \mathrm{~kW}$ at approximately $20: 20(\Delta \mathrm{t} \approx 10.3 \mathrm{~h})$ is evident in this figure.

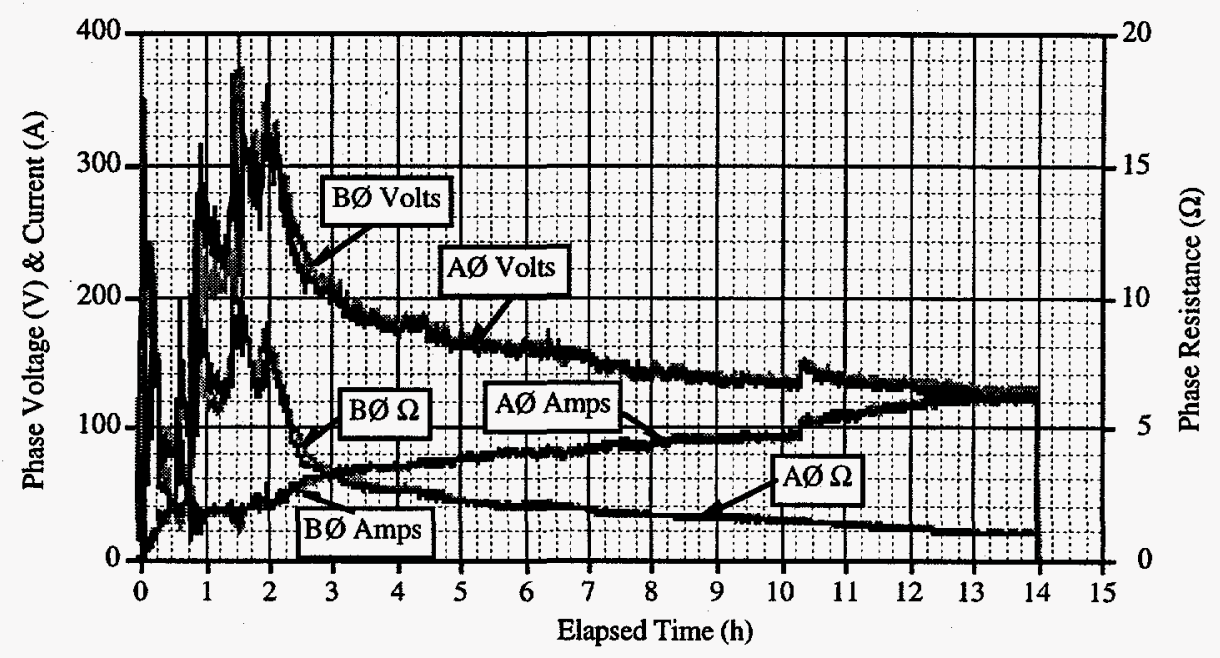

Figure 4.2.5. ORNL-ESBW-6 Phase Voltage, Current, and Resistance Transients.

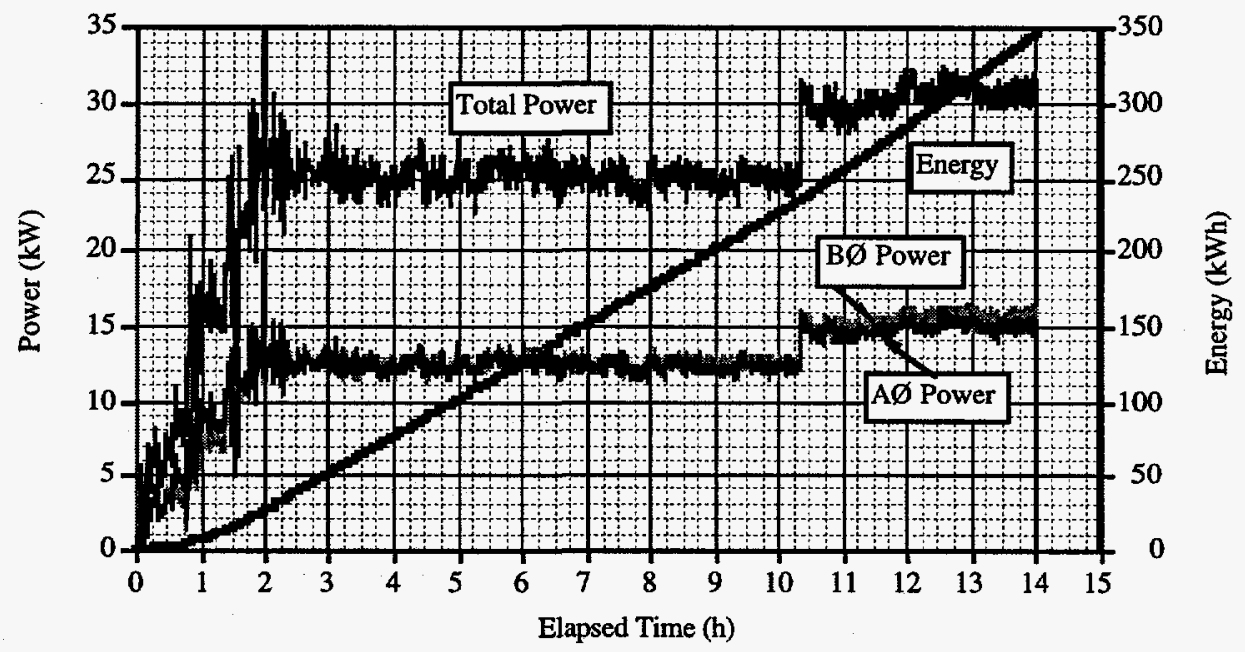

Figure 4.2.6. ORNL-ESBW-6 Phase Power, and Total Power \& Energy Transients. 


\subsubsection{Electrode Depth and Soil Temperature Results}

Figure 4.2.7 illustrates the average electrode depth and centerline temperature transients realized in this test. No evidence of catastrophic can failure is evident in the temperature traces presented in this figure. The average electrode depth trace also exhibits the usual behavior for a top-down melt.

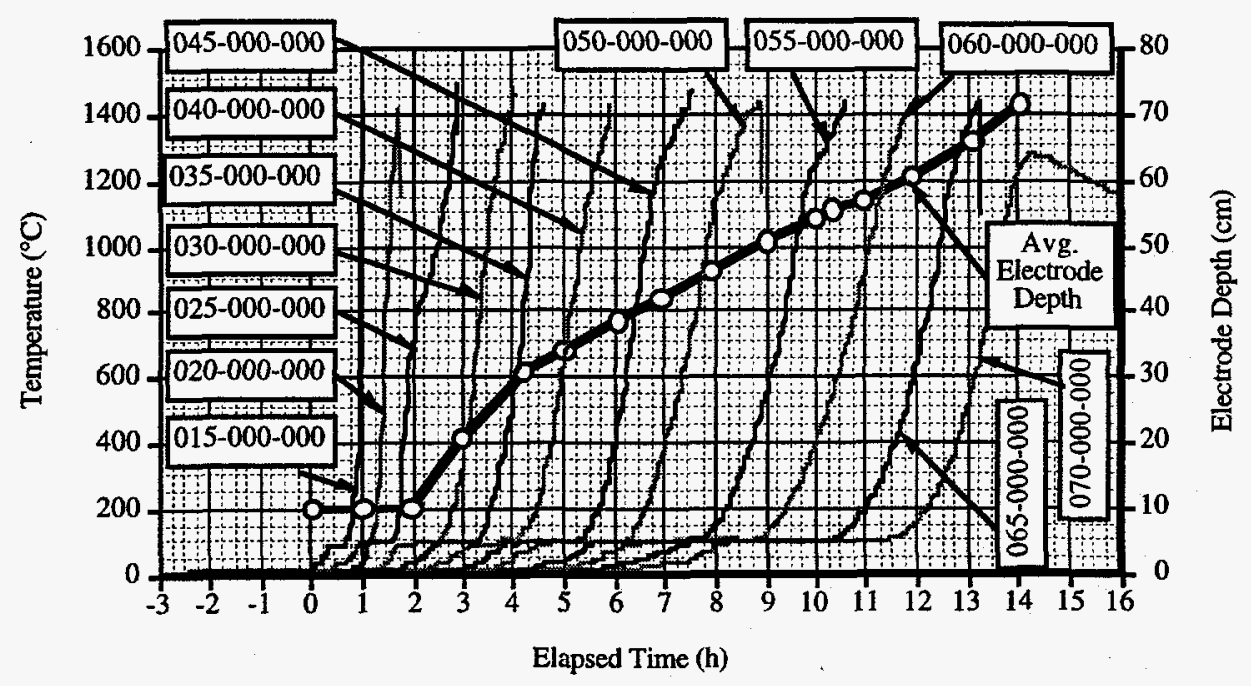

Figure 4.2.7. ORNL-ESBW-6 Electrode Depth and Centerline Temperature Transients.

\subsubsection{Plenum Pressure and Temperature Results}

The plenum pressure and temperature response, together with the off-gas inlet temperature transient is plotted in Figure 4.2.8. Again, no evidence of a pressurization event is indicated in these results. The small, but sharp spikes in the plenum pressure trace coincide with times when off-gas samples were being drawn. 


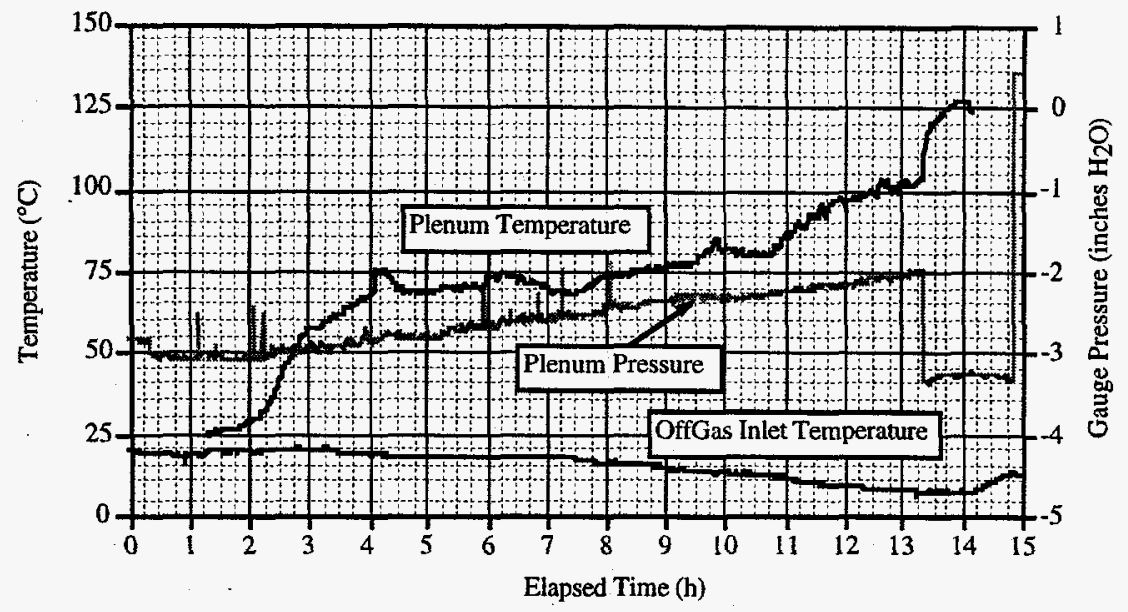

Figure 4.2.8. ORNL-ESBW-6 Plenum Pressure and Temperature Transients.

In addition to the usual plenum pressure and temperature instruments, a high temperature heat flux pad was placed between the top two layers of Kaowool insulation to measure the temperature in and heat flux across this surface. The temperature and heat flux data obtained from this device, together with the plenum and off-gas inlet temperatures, are presented in Figure 4.2.9. As indicated here, the heat flux through the Kaowool was approximately $300 \mathrm{~W} / \mathrm{m}^{2}$ for much of the test. The corresponding temperature was approximately $1200^{\circ} \mathrm{C}$. The cross sectional area of the top surface of the melt zone was roughly $900 \mathrm{~cm}^{2}$. Thus, the heat loss out the top surface of the Kaowool in this area is approximately $27 \mathrm{~W}$ - a small fraction of the electrical power input to the system. Of course, typically in large scale melts, the Kaowool is effectively incorporated into the melt after a period of time. Thus, the heat loss out the top surface to the plenum region for these cases would be considerably higher.

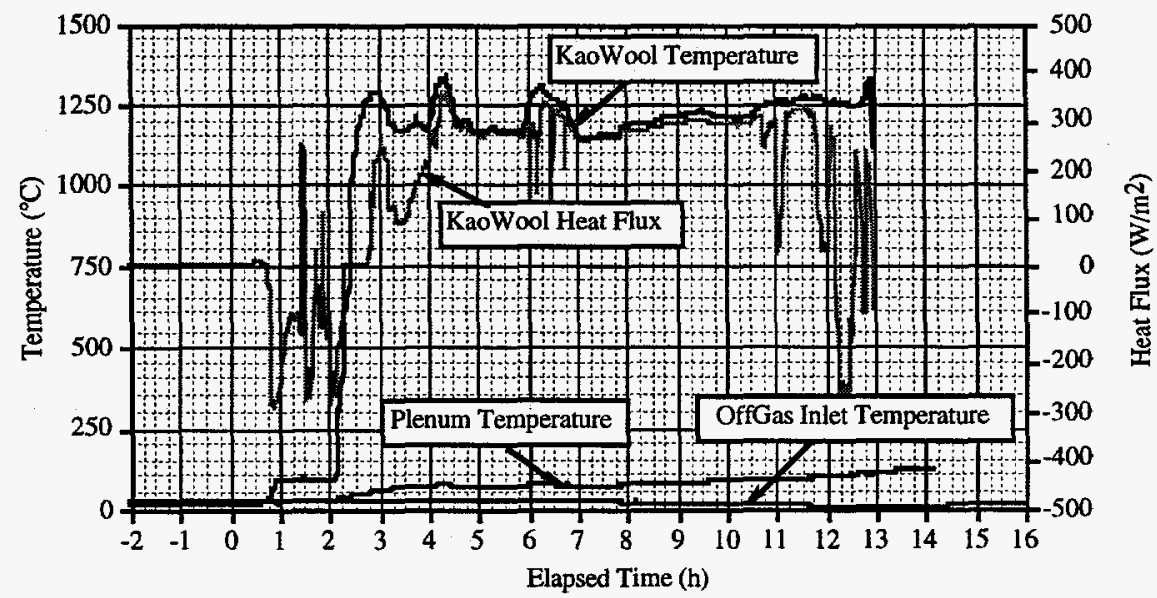

Figure 4.2.9. ORNL-ESBW-6 Kaowool Heat Flux \& Temperature Transients. 


\subsubsection{ISV Block Statistics}

A $430 \mathrm{~kg}$ block was produced in this test. $347 \mathrm{kWh}$ were consumed in the process. Therefore, the specific energy consumption for this case was $0.81 \mathrm{kWh} / \mathrm{kg}$. This specific energy consumption is comparable to the values obtained in the previous tests.

\subsubsection{Post-Test Chemical Sampling Analysis Plan \& Results}

As previously indicated, four chemical compounds were staged in this test to help assess the efficacy of ISV for remediating the spectrum of volatile organic compounds present in the ORNL SWSA- 6 buried waste trenches. These were xylene, toluene, 1,1,2-trichloroethane, and o-cresol. To determine the distribution and fate of these compounds both during and after this test, an extensive sampling program was invoked as part of the operating procedure of this test. This included hourly off-gas samples taken during the test, an additional gas sample taken the day following shutdown of the test, and a series of soil samples taken during the block recovery process several days after the test.

As indicated in Section 4.2.3, off-gas samples were taken at approximately 1.3, 2.25, 3.4, $4.3,5.3,6.2,7.3,8.3$, and 9.3 hours into the test. An additional gas sample was drawn the next day, approximately 24.3 hours after the test was initiated. Table 4.2.1 presents the results of the chemical analysis performed on these samples. Quantities listed in bold in this table represent offscale readings for the test performed. When this occurred, the maximum measurable concentration for the device has been indicated in this table. Unfortunately, the tests performed on these samples required that the entire gas sample be analyzed at once. Therefore, the analyses were

performed in one pass only. This table also presents the Dräger tube results for the carbon dioxide concentrations found in the off-gas during the test.

These results indicate that no cresol was detected in the off-gas during or after the test. Combining these off-gas concentrations with the off-gas flow rate imposed on the system during the test (nominally $155000 \mathrm{~L} / \mathrm{h}$ ) results in an estimate of the fraction of simulant material volatilized. For the 1,1,2-trichloroethane, this calculation indicates that slightly over 2 grams (or approximately $0.5 \mathrm{wt} \%$ of that staged) were transferred from the waste zone to the off-gas. Similarly, slightly under 2 grams of the xylene staged in the test (or approximately $0.9 \mathrm{wt} \%$ ) was volatilized to the off-gas system during the test. The toluene concentrations indicate that a more significant quantity of this material was volatilized during the test. Unfortunately however, the 
Table 4.2.1. ORNL-ESBW-6 Off-Gas Sample Chemical Analysis Results.

\begin{tabular}{||c|c|c||c|c|c|c||c||}
\hline Date & $\begin{array}{c}\text { Clock } \\
\text { Time } \\
(\mathbf{h h : m m})\end{array}$ & $\begin{array}{c}\text { Elapsed } \\
\text { Time } \\
(\mathbf{h})\end{array}$ & $\begin{array}{c}\text { Cresol } \\
\text { Conc. } \\
(\mu \mathbf{g} / \mathbf{L})\end{array}$ & $\begin{array}{c}\mathbf{1 , 1 , 2 - t r i} \\
\text { Conc. } \\
(\mu \mathbf{g} / \mathbf{L})\end{array}$ & $\begin{array}{c}\text { Toluene } \\
\text { Conc. } \\
(\mu \mathbf{g} / \mathbf{L})\end{array}$ & $\begin{array}{c}\text { Xylene } \\
\text { Conc. } \\
(\mu \mathbf{g} / \mathbf{L})\end{array}$ & $\begin{array}{c}\mathbf{C O}_{\mathbf{2}} \\
\mathbf{C o n c} . \\
(\mathbf{p p m})\end{array}$ \\
\hline \hline $11 / 8 / 95$ & $10: 01$ & 0 & 0 & 0 & 0 & 0 & $\approx 450$ \\
\hline & $11: 20$ & 1.32 & 0 & 0.05 & 0.75 & 0.05 & $\approx 1100$ \\
\hline & $12: 17$ & 2.27 & 0 & 0.05 & 1.4 & 0.63 & $\approx 2500$ \\
\hline & $13: 25$ & 3.40 & 0 & 0.13 & 3 & 1.39 & $\approx 3000$ \\
\hline & $14: 20$ & 4.32 & 0 & 3.6 & $\mathbf{9 . 8}$ & 3.55 & $>\mathbf{3 0 0 0}$ \\
\hline & $15: 20$ & 5.32 & 0 & 1.2 & $\mathbf{6 . 5}$ & 1.32 & $>\mathbf{3 0 0 0}$ \\
\hline & $16: 14$ & 6.22 & 0 & 2.3 & $\mathbf{7 . 7}$ & 1.67 & \\
\hline & $17: 20$ & 7.32 & 0 & 2.5 & 7.4 & 1.34 & \\
\hline & $18: 20$ & 8.32 & 0 & 2.4 & $\mathbf{7 . 5}$ & 2.33 & \\
\hline & $19: 20$ & 9.32 & 0 & 3.6 & $\mathbf{7 . 7}$ & 1.47 & $>\mathbf{3 0 0 0}$ \\
\hline $11 / 9 / 95$ & $10: 20$ & 24.32 & 0 & $\mathbf{5 1}$ & $\mathbf{3 2}$ & $\mathbf{3 1}$ & $\mathbf{3 0 0 0}$ \\
\hline
\end{tabular}

concentrations measured in the chemical analysis were off-scale. As before, when this occurred, the maximum measurable concentration for the analysis setup has been indicated. Therefore, there is greater uncertainty associated with the calculated quantity volatilized. Using the number as listed indicates that more than 7 grams (or $2.3 \mathrm{wt} \%$ ) of the staged toluene was passed to the off-gas system. If it's assumed that the off-scale concentrations are low by a factor of ten, the "corrected" results indicate that roughly 64.5 grams (or approximately $20.7 \mathrm{wt} \%$ ) of the toluene staged in the target vitrification zone was volatilized to the off-gas plenum and removed by the off-gas flow. The off-gas system employed in actual ISV site remediation efforts typically employs a thermal oxidizer unit to completely destroy any residual volatile materials present in the off-gas. Therefore, these numbers provide an indication of the relative importance of the destruction mode and location for processing these types of materials using ISV. The $\mathrm{CO}_{2}$ concentrations listed in this table provide a measure of the extent of reaction occuring during processing. Normal dry air has a $\mathrm{CO}_{2}$ concentration of approximately $450 \mathrm{ppm}$. The elevated levels measured in this tests suggest that substantial reaction of the combustible materials present in the soil was taking place. As a point of reference, $\mathrm{CO}_{2}$ concentrations of $5 \mathrm{wt} \%$ (or $50000 \mathrm{ppm}$ ) are commonly measured in the stack effluent of the off-gas thermal oxidizer during large-scale ISV treatments.

In addition to the gas samples identified in Table 4.2.1, a number of Dräger tube gas samples were drawn to determine the concentration of the staged chemicals present in the off-gas plenum 
during the cooldown phase of the test. The cresol and 1,1,2-trichloroethane Dräger tube readings indicated essentially no detectable levels of these compounds were present in the plenum vapor space during this phase. However, the toluene/xylene readings were considerably higher. Table 4.2.2 presents the results of these samples. There is some interference in the Dräger tube readings for toluene. The presence of xylene affects the toluene reading and visa versa. Consequently, only the toluene readings are presented in Table 4.2.2. The values listed should be interpreted as representing the combination of toluene and/or xylene present in the plenum vapor space. The initial reading was taken with a Dräger tube which had a 300 ppm upper limit in its operable range. Subsequent to this reading, higher-range Dräger tubes were obtained and used for the remaining samples taken. All but the final reading presented were taken with the off-gas blower system shutdown. Therefore, any flows were due to leakage only. However, the final reading reflects the off-gas plenum concentration following operation of the off-gas blower for approximately one hour. This was done to purge the system and bring the concentrations down to levels acceptable for removal of the off-gas hood and subsequent block excavation and soil sampling operations. The off-gas plenum vapor space volume is approximately $2.5 \mathrm{~m}^{3}$. Therefore, at $1800 \mathrm{ppm}$, approximately 5.5 grams of toluene and/or xylene were contained in the off-gas hood in the test. As with the calculated quantities volatilized during the test, in the application of ISV to remediation of an actual site, the off-gas system would be run for an acceptable period during the cooldown phase of the process. Therefore, these materials would also be processed by the off-gas thermal oxidizer system .

Table 4.2.2. ORNL-ESBW-6 Post-Test Dräger Tube Readings.

\begin{tabular}{|c|c|c|}
\hline Date & Time (hh:mm) & $\begin{array}{c}\text { Toluene/Xylene } \\
\frac{\text { Concentration }}{\text { (ppm) }}\end{array}$ \\
\hline $11 / 9 / 95$ & $10: 40$ & $>300$ \\
\hline $11 / 10 / 95$ & $12: 00$ & 1800 \\
\hline & $13: 00$ & 1500 \\
\hline $11 / 11 / 95$ & $14: 00$ & 1600 \\
\hline $11 / 12 / 95$ & $09: 00$ & 1200 \\
\hline $11 / 13 / 95$ & $10: 00$ & 1000 \\
\hline & $09: 30$ & 600 \\
\hline & $12: 30$ & $<100$ \\
\hline
\end{tabular}


As previously indicated, an extensive soil sample program was undertaken to determine the distribution of the staged materials in the soil surrounding the ISV block. Figure 4.2.10 illustrates the locations of the soil samples taken in this effort. A total of 14 soil samples were obtained and submitted for chemical analysis. The results of these analyses, together with a brief description defining the sample location, are presented in Table 4.2.3. As with the ORNL-ESBW-5 test results, the top surface of the ISV block subsided approximately $10 \mathrm{~cm}$ below grade during this test. The sample location depths listed in Table 4.2.3 are with respect to grade.

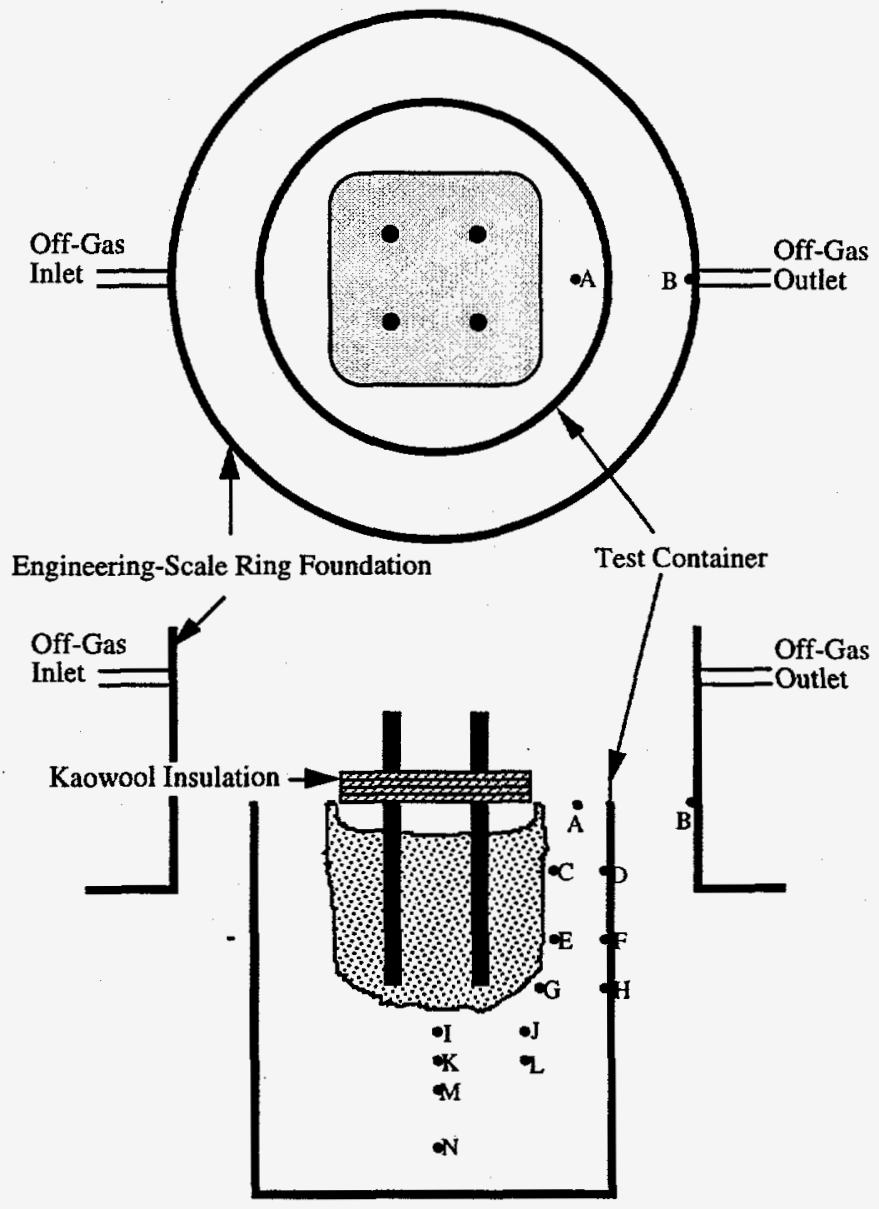

Figure 4.2.10. ORNL-ESBW-6 Soil Sample Locations.

The results presented in Table 4.2.3 indicate that, with the exception of the cresol, the concentrations present in the soil surrounding the ISV block are very low. They further indicate that, for all the volatile materials staged, there was a tendency for that portion which was not destroyed directly by the ISV melt to migrate away from the melt in both the downward and lateral 
directions. Unfortunately, there were no lateral thermocouples placed in this test. Therefore, this trend could not be directly correlated with the lateral location of a particular isotherm.

Some sense of this information was obtained from the observed state of the soil during excavation, however. At about midway along the depth of the ISV block, the soil was dry outside the block to within about $15 \mathrm{~cm}$ from the inner radius of the test container. There was a relatively wet band of soil extending.from this location to the test container wall. Figure 4.2.11 provides an indication of this result. Outboard of the test container, the soil was again relatively dry to within

Table 4.2.3. ORNL-ESBW-6 Soil Sample Chemical Analysis Results.

\begin{tabular}{|c|c||c|c|c|c||}
\hline $\begin{array}{c}\text { Sample } \\
\text { ID. }\end{array}$ & Sample Description & $\begin{array}{c}\text { Cresol } \\
(\mu \mathbf{g} / \mathbf{k g})\end{array}$ & $\begin{array}{c}\text { Trichloroethane } \\
(\mu \mathbf{g} / \mathbf{k g})\end{array}$ & $\begin{array}{c}\text { Toluene } \\
(\mu \mathbf{g} / \mathbf{k g})\end{array}$ & $\begin{array}{c}\text { Xylene } \\
(\mu \mathbf{g} / \mathbf{k g})\end{array}$ \\
\hline \hline PRE & Hanford soil before testing & 0 & 0 & 0 & 0 \\
\hline A & Soil Surface between test container and \\
block & $\mathrm{dl}^{*}$ & 230 & 160 & 310 \\
\hline B & Soil Surface at ring foundation wall & $\mathrm{dl}$ & 1.8 & $\mathrm{dl}$ & $\mathrm{dl}$ \\
\hline C & $2.5 \mathrm{~cm}$ from block, depth of $-23 \mathrm{~cm}$ & $\mathrm{dl}$ & 62 & 80 & 431 \\
\hline D & Test container wall, depth of $-23 \mathrm{~cm}$ & $\mathrm{dl}$ & 1.5 & $\mathrm{dl}$ & 1.3 \\
\hline E & 2.5 cm from block, depth of $-46 \mathrm{~cm}$ & $\mathrm{dl}$ & 150 & 230 & 2140 \\
\hline F & Test container wall, depth of $-46 \mathrm{~cm}$ & $\mathrm{dl}$ & 1300 & 580 & 2730 \\
\hline $\mathrm{G}$ & $2.5 \mathrm{~cm}$ from block, depth of $-65 \mathrm{~cm}$ & 13000 & 180 & 160 & 1050 \\
\hline H & Test container wall, depth of $-65 \mathrm{~cm}$ & 12000 & 2.7 & $\mathrm{dl}$ & $\mathrm{dl}$ \\
\hline $\mathrm{I}$ & Soil at center, depth of $-80 \mathrm{~cm}$ & 60000 & 3.4 & 1.7 & 2.1 \\
\hline $\mathrm{J}$ & $30 \mathrm{~cm}$ from center, depth of $-80 \mathrm{~cm}$ & 130000 & 7.5 & 1.6 & 1.7 \\
\hline K & Soil at center, depth of $-90 \mathrm{~cm}$ & 130000 & 14 & 1.8 & 2.0 \\
\hline L & $30 \mathrm{~cm}$ from center, depth of $-90 \mathrm{~cm}$ & 220000 & 9.6 & 1.5 & 2.3 \\
\hline M & Soil at center, depth of $-100 \mathrm{~cm}$ & 180000 & 300 & 11 & 14 \\
\hline $\mathrm{N}$ & Soil at center, depth of $-120 \mathrm{~cm}$ & 1600 & 120 & 100 & 33.8 \\
\hline
\end{tabular}

${ }^{*} \mathrm{dl}=$ concentration below detection limit 


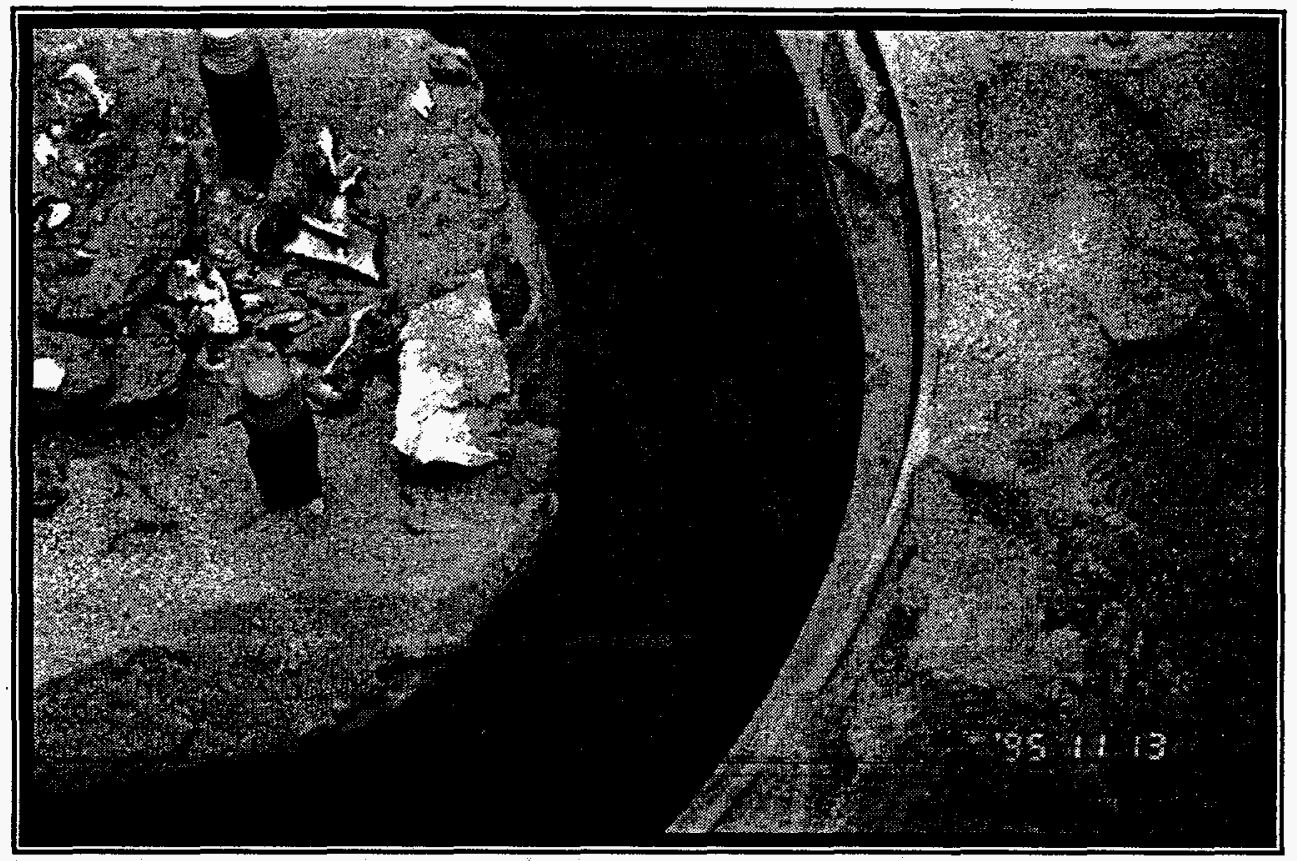

Figure 4.2.11. ORNL-ESBW-6 Lateral Soil Moisture Pattern .

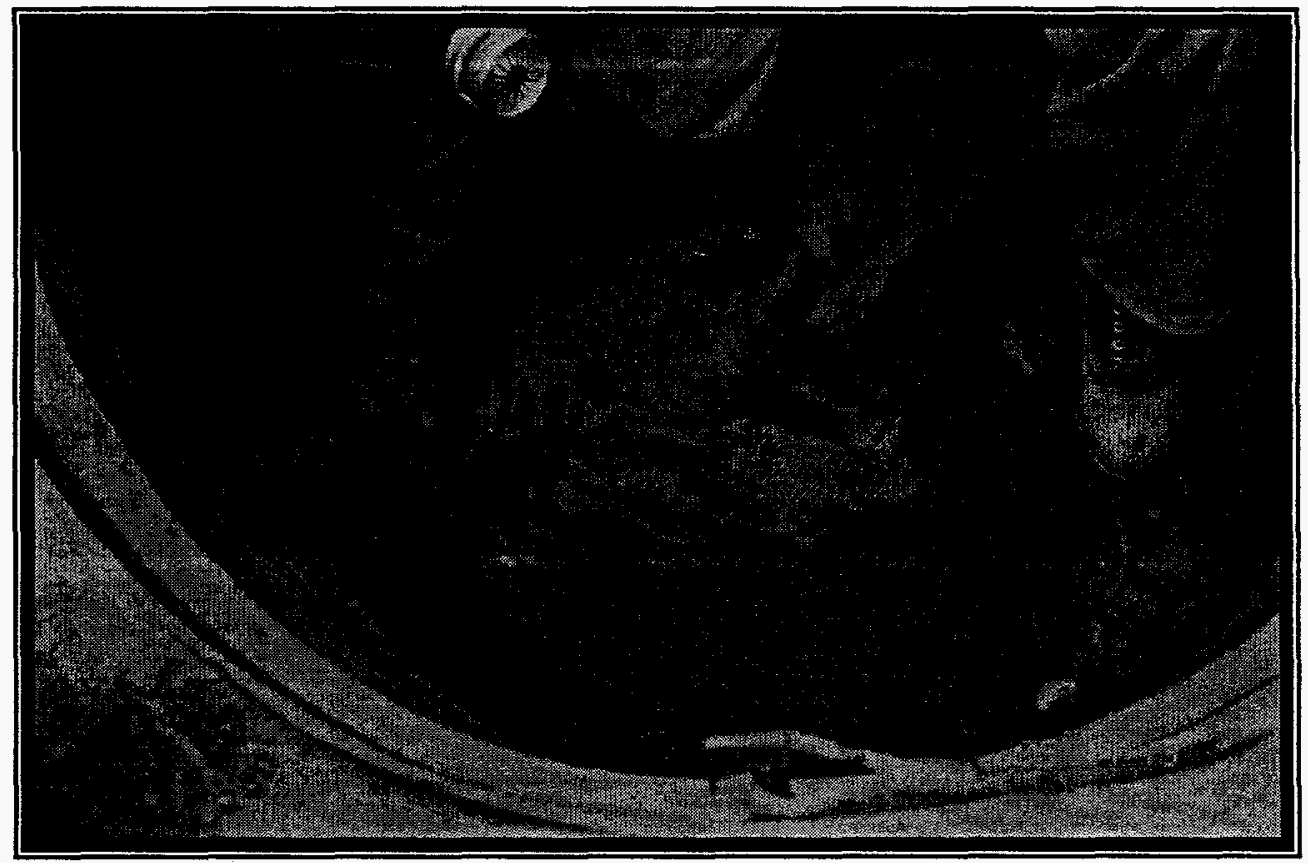

Figure 4.2.12. ORNL-ESBW-6 Soil Moisture Pattern Beneath the ISV Block. 
about $15 \mathrm{~cm}$ of the ISV hood ring foundation wall. Of course, the staged materials could not penetrate the walls of the test container. Instead, as the results of Table 4.2 .3 suggest, at the depths corresponding to the highest soil concentrations, there was a tendency for these migratory simulants to collect along the wall of the test container.

The unprocessed simulants also migrated a significant distance below the ISV block. This was especially true for the cresol staged in this test. Figure 4.2.12 illustrates the soil moisture pattern present beneath the ISV block during excavation. The soil moisture found at these depths during excavation increased substantially with increasing depth. In fact, at a depth of approximately $120 \mathrm{~cm}$ there was standing water in the soil. Thus, the bottom $17 \mathrm{~cm}$ of the container had soil that was saturated with water.

These soil concentrations can be used to estimate the quantity of material resident in the soil surrounding the ISV block and therefore left unprocessed. For the calculation, the test container was subdivided into 8 levels along its $137 \mathrm{~cm}$ height. The horizontal planes separating levels was chosen to bisect the distance between vertical sample locations. For those levels on which more than one sample was taken, the lateral variation in constituent concentration was assumed to vary linearly with the two lateral sample point concentrations defining the slope and intercept of the linear curve fit. Finally, for the estimates at the levels involving samples C \& D, E \& F, and G \& $\mathrm{H}$, the inner radius of the toroidal volume occupied by the soil was set to the local ISV block radius. For all levels, the outer radius used was that of the test container $(57 \mathrm{~cm})$, and a soil density of $1.65 \mathrm{~g} / \mathrm{cm}^{3}$ was assumed. Also, for the lone non-zero concentration registered at sample location $\mathrm{B}$, this concentration was assumed to be representative of a toroidal disk with inner radius $57 \mathrm{~cm}$, outer radius $91 \mathrm{~cm}$ (corresponding to the inner radius of the off-gas ring foundation), and thickness of $3 \mathrm{~cm}$. With these assumptions, and the concentrations listed in Table 4.2.3, approximately 122 grams of cresol (or $39 \mathrm{wt} \%$ of that staged), 0.3 grams $1,1,2-$ trichloroethane (or $0.1 \mathrm{wt} \%$ of that staged), 0.2 grams toluene (or $0.1 \mathrm{wt} \%$ of that staged), and 0.8 grams xylene (or $0.4 \mathrm{wt} \%$ of that staged) were left unprocessed in the soil. As discussed earlier, the volatilized portion of these materials is routinely processed by the off-gas system. Therefore, only these soil-bound portions contribute to reducing the effectiveness of the ISV process. As such,

$61 \mathrm{wt} \%$ of the cresol,

$99.9 \mathrm{wt} \%$ of the 1,1,2-trichloroethane,

$99.9 \mathrm{wt} \%$ of the toluene, and

$99.6 \mathrm{wt} \%$ of the xylene

was effectively processed by ISV in this test. 


\subsubsection{Test Retrospective}

As with the previous ORNL-ESBW-5 test, this test successfully processed the dynamicallycompacted canisters without experiencing any measurable pressure or temperature excursions in the off-gas plenum. Thus, the DC process again proved effective for rendering the canisters in a condition sufficient to preclude these events.

With the exception of the cresol, the volatile simulants staged in the test were effectively processed by the ISV treatment. The results obtained for the 1,1,2-trichloroethane, toluene, and xylene are quite consistent with those obtained in previous engineering-scale tests with these, or similar, volatile materials (e.g., Geosafe 1993; Shade et al. 1991; and Timmerman 1986). It is interesting to note however, that the concentrations for these three simulants exhibit a peak at a depth about half-way down the treated zone (i.e., $\approx 46 \mathrm{~cm}$ ). These concentrations are very small (in the parts per billion), and therefore do not detract from the efficacy of the ISV treatment process. The concentrations also increase at depths well below the $70 \mathrm{~cm}$ melt depth for this test. Again however, the concentration levels are in the ppb range.

These distributions may have been influenced by the presence of the drum walls in which this melt was performed. Recall that post-test activities performed during excavation of the block indicated that there was a significant quantity of water in the soil in the region below the block. The presence of this water would serve to quench the migrating materials. Since each of these chemical compounds has a boiling point above that of water, this would have served to change its phase from gaseous to liquid, making further transport up through the soil to the off-gas stream considerably more difficult.

The post-test distribution of cresol in the soil surrounding the block was signficantly higher than for the other simulants staged in this test. These concentrations were somewhat surprising. One previous test involving materials with similar or higher boiling-point temperatures was more successful. The 1992 ES-INEL-6 test (Geosafe 1992a) involved processing a series of volatile organics that had been staged in steel canisters and arranged in random fashion throught the target vitrification zone. Two of the chemcals staged in this test were dichlorobenzene $\left(\mathrm{T}_{\mathrm{bp}} \approx 173^{\circ} \mathrm{C}\right.$ $\left.180^{\circ} \mathrm{C}\right)$ and pentachlorophenol $\left(\mathrm{T}_{\mathrm{bp}} \approx 310^{\circ} \mathrm{C}\right)$. The post-test soil samples taken around the block indicated concentrations below the detection limit for each of these chemicals. On the other hand, another test in the ES-INEL series, ES-INEL-4 (Shade et al. 1991), achieved success-rates comparable to those obtained in this ORNL-ESBW-6 test. The ES-INEL-4 test simulants were contained in a glass bottle to facilitate their placement in the target vitrificaiton zone, similar to what was done for the cresol staged in the ORNL-ESBW-6 test. In the ES-INEL-4 test, post-test soil 
samples indicated that the soil surrounding the ISV block contained approximately $0.04 \mathrm{wt} \%$ (or $400 \mathrm{ppm}$ ) of the trichloroacetic acid (TCA, $\mathrm{T}_{\mathrm{bp}} \approx 196^{\circ} \mathrm{C}$ ) staged. This concentration is higher than was found for the cresol $\left(\mathrm{T}_{\mathrm{bp}} \approx 191^{\circ} \mathrm{C}\right)$ in this ORNL-ESBW-6 test.

Many factors can influence the efficacy of a treatment process. Solubility in water is one very influential consideration in determining the processability of a volatile chemical using ISV. Cresol is $2 \%$ soluble in water at STP (U.S. Dept. of H\&HS 1994). Recall that the bottom $17 \mathrm{~cm}$ of soil inside the test containerr and below the ISV block was found to be essentially saturated with water. This depth corresponds to a soil volume of $173500 \mathrm{~cm}^{3}$. At a nominal soil porosity of $30 \%$ and saturated conditions, water would occupy approximately $52000 \mathrm{ml}$ of this volume. Finally, at $2 \%$ solubility (i.e., $2 \mathrm{~g}$ cresol can be dissolved in $100 \mathrm{ml}$ water) a total of $1040 \mathrm{~g}$ cresol could be dissolved in this water. This is considerably more than was found from the sampling results. Moreover, solubility commonly increases with increasing temperature. Therefore, it seems quite likely that the cresol found in the bottom region of the test container arrived there via transport with the water that moved-down away from the melt.

In the ES-INEL-6 test referenced earlier, the dichlorobenzene and pentachlorophenol materials staged had solubilities of $\approx 0.01 \%$ and $0.001 \%$, respectively (U.S. Dept. of H\&HS 1994). Therefore, the relatively low solubilities would mean that little of these chemicals would be dissolved and transported with any migrating water. On the other hand, the TCA staged in the ESINEL-4 test is miscible in water (U.S. Dept. of H\&HS 1994). Therefore, this compound would easily mix with any migrating water and, as a consequence, could be expected to be found in the soil surrounding an ISV melt. This may be one reason for the disparity in process effectiveness between these two tests and the ORNL-ESBW-6 test performed in this work.

Other considerations can also influence the processability of a chemical using ISV. For example, the nature in which the chemicals have been staged in the target vitrification zone (viz., loose vs. staged in steel or glass containers) can affect their ability to move-out ahead of the melt. One would expect that chemicals housed in steel containers would be retained in-place in the face of the advancing melt front longer than those staged in glass bottles or loosely mixed with the surrounding soil. This may be one factor why the ES-INEL-6 test was so much more effective at remediating the high boiling-point chemicals than were the ES-INEL-4 and ORNL-ESBW-6 tests.

The interaction at the soil granule-chemical interface can also dramatically affect the dynamics of transport for these chemicals. A chemical which is very volatile may still be effectively remediated by ISV if the surface chemistry at the interface results in a strong bond between the chemical and its neighboring granules of soil. Such a bond would serve to retard the chemicals migration sufficiently to allow the ISV melt temperatures to pyrolize the compound. Complicating 
matters further, the physical and chemical composition of the soil, as well as the "soak" time for the chemical in the soil matrix, can also have a profound effect on the affinity of the chemical for the surrounding soil.

It would be convenient if these effects could be charactreized by a (relatively few) simple metrics like the solubility and boiling-point temperature of the chemical. However, the aforementioned results indicate varying levels of success for chemicals with boiling-point temperatures and solubilities both above and below that of cresol. Therefore, these alone are insufficient to predict the level of success for remediation of a particular contaminant using ISV. Apparently, much more is involved. Investigating these more basic considerations was, however, well beyond the scope of work for this effort. 


\subsection{CONCLUSIONS}

A series of 10 engineering-scale ISV tests have been performed in this work. These tests were designed primarily to help assess the efficacy of dynamic compaction as a pretreatment process to compromise any sealed containers resident in a waste zone targeted for remediation using ISV. In addition, these tests were used to help assess the capability of ISV to process regions with relatively high loadings of metals and combustibles. Several of these tests also investigated the efficacy of bottom-up processing for remediating regions with sealed containers. To the extent possible, these tests were performed in pairs - one each with and without pretreating the simulated "waste" containers using dynamic compaction (DC). This was done to facilitate evaluation of the benefits of pretreatment using DC. As such, a number of these tests generated significant plenum pressure and temperature excursions as the sealed canisters of volatile material were processed. In every instance however, these excursions were readily accommodated by the PNNL engineering-scale ISV system and its associated pressure and temperature relief systems.

The first test in this series, ORNL-ESBW-1, involved scaled-down replicas of containerized volatile materials, together with significant quantities of metal, plastic, cloth, and cellulose materials. This test did not produce the desired plenum pressure and temperature events. However, it did serve to identify that a region containing relatively high loadings of metal and combustible materials could be processed without consequence to the effectiveness of the ISV process. Based upon the soil mass of the simulated trench, this test successfully processed a region containing $3.5 \mathrm{wt} \%$ plastic materials, $0.3 \mathrm{wt} \%$ paper and cloth, and $0.4 \mathrm{wt} \%$ aluminum and steel.

Several tests in this series demonstrated that pretreatment of sealed containers can effectively render them safe for remediation using ISV. As mentioned above, these tests were performed in pairs. Significant attention was directed toward staging and operating these paired tests so that, with the exception of the DC pretreatment process, they would be replicates of one another. In the tests performed without pretreatment using DC, plenum pressure and temperature excursions were routinely encountered. Peak plenum pressure increases in the range of 15 inches w.c. were generated, again without consequence to the safe operation and conduct of the test. Pretreatment of a duplicate set of containers with DC, followed by processing with ISV, typically encountered no such plenum pressure and temperature events, however.

Several of these DC/ISV tests recovered the dynamically-compacted containers prior to their being processed with ISV so that their condition could be recorded. This information was useful ' in helping to correlate any plenum pressure and temperature transients experienced with the 
processing of these canisters. It was identified that the canisters need not be breached to preclude their catastrophic rupture during processing with ISV. It was apparently sufficient to significantly deform the sidewall and/or lid of the canister. If the canister was only slightly affected by the DC. process however (as if hit with a glancing blow), a catastrophic rupture would likely result when the can was finally processed with ISV. Therefore, it appears important to thoroughly "cover" the target vitrification zone to help ensure that the entire contents of the region have been affected by the DC pretreatment process.

Two of the tests performed in this series employed a bottom-up approach to processing the simulated waste zone - one with and one without the benefit of pretreatment using DC. Plenum pressure excursions comparable to those obtained when processing using the "standard" top-down approach were obtained in the test which did not pretreat the sealed canisters. The corresponding temperature excursions were slightly less severe in the bottom-up test, due to the insulative effect of the soil layer over the melt pool. While no significant quantity of glass was displaced from the melt zone during the events encountered in the test performed without pretreatment using DC, there was evidence that, during this bottom-up processing, some canister contents had been ejected from the yet-to-be-processed region above the melt pool to the soil surface surrounding the target vitrification zone.

Processing the melt from beneath the waste did have the added benefit of increasing the thermal efficiency of the melting process. Specific energy consumptions significantly below those obtained with the "standard" top-down approach to melting were obtained. This difference was attributed to the insulative effect of the soil layer over the melt pool.

From an operational perspective, bottom-up processing was found to be considerably more difficult to control. Electrode sticking was a relatively common occurrence during these tests. In addition, it was more difficult to determine the extent to which the target vitrification zone had been processed during the test. This was because the mechanism for processing appeared to be one in which the canisters and neighboring soil materials fell into the melt pool during treatment. Consequently, one had to rely on subsidence events (either natural or induced by operator control of the electrode depth) to "feed" the melt. As might be expected, these conditions led to significantly greater imbalances in the electrical aspects of the melt process. As evidenced by the successful conclusion of these bottom-up tests however, none of these conditions were insurmountable. The benefits relative to reduced severity of any catastrophic canister ruptures experienced while processing from the bottom up may well outweigh these minor processing annoyances. Additional insurance may be obtained by the combination of pretreatment of the target vitrification zone using DC, followed by bottom-up ISV processing. 
The final two tests in this series included an number of non-volatile, semi-volatile, and volatile chemical compounds to simulate the presence of radioactive and chemically hazardous materials typically found in the ORNL SWSA- 6 buried waste trenches. The first of these tests included four chemical compounds to simulate the non-volatile and semi-volatile radioactive materials found in the actual buried waste trenches. The non-volatile materials included oxides of cerium and europium, together with a strontium chloride compound. Cerium was used as a simulant for the uranium and plutonium materials present in the actual ORNL buried waste trenches. None of the simulant materials staged in this test were radioactive. These materials were staged loosely in the soil adjacent to the dynamically-compacted canisters. The simulated trench was then processed using the "standard" top-down ISV approach. The simulants were effectively retained in the glass block that was produced in this test. Cesium was volatilized to the off-gas system during this test, however. The volatilized fraction was significantly higher than had been realized in previous ISV tests - by a factor of approximately $1.8 \times$. This was attributed to several factors, of which the most significant were the relatively small scale of this test and the fact that cesium chloride was used as the simulant material. Previous work at ORNL has indicated that the presence of chlorides can dramatically increase the volatility of cesium during ISV processing.

A final test involved the top-down processing of a region containing both dynamicallycompacted canisters and volatile organic chemical compounds. This test successfully treated the target vitrification zone without encountering any plenum pressure and temperature excursions. With one exception, the volatile materials were effectively remediated by the ISV process. Processing efficiencies comparable to those obtained in previous ISV tests involving the same or similar materials were realized in this test. The exceptional material was cresol, which was staged near the bottom of the target vitrification zone. Roughly two-thirds of this material was destroyed by the ISV process. The remaining third was displaced to a region well below the ultimate melt depth. This result was somewhat surprising as previous ISV tests had successfully treated regions containing materials of comparable volatility. Several factors are proposed as contributing to this effect. These include the solubility of cresol in water, the nature in which the cresol material was staged in this test, and the possibility that the surface chemistry at the soil-cresol interface results in a weaker affinity between the two materials. A consequence of this later consideration is that migration of the cresol is more difficult to restrain in the face of the advancing melt front. The results obtained in this test suggest that further testing involving cresol in soil at elevated temperatures is warranted relative to the ISV environment. 
On the whole, the tests performed in this work indicate that dynamic compaction can be an effective tool for compromising sealed canisters sufficiently to preclude their catastrophic rupture during follow-on processing with ISV. 


\section{REFERENCES}

Bechtel National, Inc. 1988. "Closure Plan for Solid Waste Storage Area 6, Volume 1: Closure Plan.” ORNL/RAP/Sub-87/99053/9\&V1/R1. Oak Ridge National Laboratory, Oak Ridge, TN.

Bergsman, T.M., Shade, J.W., and Farnsworth, R.K. 1992. Fifth In Situ Vitrification Engineering-Scale Test of Simulated INEL Buried Waste Sites. PNL-8152, Pacific Northwest Laboratory, Richland, WA.

Brouns, R.A., Buelt, J.L., and Bonner, W.F. 1983. "In Situ Vitrification of Soil." U.S. Patent \#4,376,598.

Buelt, J.L., C.L. Timmerman, K.H. Oma, V.F. Fitzpatrick, and J.G. Carter. 1987. In Situ Vitrification of Transuranic Waste: An Updated Systems Evaluation and Applications Assessment. PNL-4800, Supplement 1, Pacific Northwest Laboratory, Richland, WA.

Carter, J.G., S.S. Koegler, and S.O. Bates. 1988. Process Performance of the Pilot-Scale In Situ Vitrification of a Simulated Waste Disposal Site at the Oak Ridge National Laboratory. PNL-6530. Pacific Northwest Laboratory, Richland, WA.

Davis, E.C., D.S. Marshall, R.G. Stansfield, and R.B. Dreier. 1986. ORNL Solid Waste Storage Area 6 Trench Photos and Geologic Descriptions: July 1984 through September 1985. ORNL/TM-9874. Oak Ridge National Laboratory, Oak Ridge, TN.

Geosafe Corporation. 1992a. ES-INEL-6: In SItu Vitrification of a Simulated Randomn Burial Site at the Idaho National Engineering Laboratory Subsurface DIsposal Area. Geosafe Corporation, RIchland, WA.

Geosafe Corporation. 1992b. ES-INEL-7 In SItu Vitrification of a Simulated Randomn Burial Site at the Idaho National Engineering Laboratory Subsurface DIsposal Area. Geosafe Corporation, RIchland, WA.

Geosafe Corporation. 1993. Investigations into the Causes and Application Significance of the Melt Displacement Event Occurring During Geosafe Operational Acceptance Test \#2 (OAT-2). GSC 2301, Geosafe Corporation, Richland, WA.

Hasegawa, H.K., K.J. Staggs, and S.M.Doughty. 1993. Fire Testing of 55 Gallon Metal Waste Drums for Dry Waste Storage. UCRL-CR-115037, Lawrence Livermore National Laboratory, Livermore, CA.

Luey, J.K., T.D. Powell, W.O. Heat, and R.L. Richardson. 1992. Evaluation of New Concepts for In SItu Vitrification: Power System, Melt Insulation, and Off-Gas Containment. PNL8213, Pacific Northwest Laboratory, Richland, WA.

Mayne, P.W., Jones, J.S., and Dumas, J.C. 1984. "Ground Response to Dynamic Compaction.” J. Geotechnical Engr. 110:757-775. 


\section{REFERENCES}

McAtee, R.E. and M. Beal. 1991. Comparison of the High Temperature Chemistry of Plutonium and Rare Earths, A Review Study. EGG-WTD-9801, Idaho National Engineering Laboratory, EG\&G Idaho Inc., Idaho Falls, ID.

Peterson, M.E., T.D. Powell, and C.L. Timmerman. 1992. Engineering-Scale In Situ Vitrification of Simulated Oak Ridge National Laboratory Liquid Waste Seepage Trenches. PNL-7988, Pacific Northwest Laboratory, Richland, WA.

Phillips, S.J., T.W. GIlbert, H.E: McGuire, and M.R. Adams. 1984. "Dynamic Consolidation Alternatives Tests for Low-Level Waste Disposal Site Corrective Measures: An Overview." In Proceedings of the Sixth Annual Participants' Information Meeting DOE Low-Level Waste Management Program CONF-8409115, EG\&G Idaho Inc., Idaho Falls, ID. pp. 322-331.

Shade, J.W., R.K. Farnsworth, J.S. Tixier, and B.L. Charboneau. 1991. Engineering-Scale Test 4: In SItu Vitrification of Toxic Metals and Volatile Organics Buried in INEL Soils. PNL7611, Pacific Northwest Laboratory, Richland, WA.

Sliger, W.A. 1994. "Starter Tube for use in Vitrification Processes." U.S. Patent \#08/363,259.

Spalding, B.P. 1985. "Burial Trench Dynamic Compaction Demonstration at a Humid Site." In Proceedings of the Seventh Annual Participants' Information Meeting DOE Low-Level Waste Management Program. CONF-8509121, EG\&G Idaho, Inc., Idaho Falls, ID. pp. 676-693.

Spalding, B.P. 1994. "Volatilization of Cesium-137 from Soil with Chloride Amendments during Heating and Vitrification." Environ. Sci. Technol. 28(6):1116-1123.

Spalding, B.P., G.K. Jacobs, N.W. Dunbar, M.T. Naney, J.S. Tixier, and T.D. Powell. 1992. Tracer-Level Radioactive Pilot-Scale Test of In SItu Vitrification for the Stabalizatoin of Contaminated Soil Sites at ORNL. ORNL/TM-12201. Oak Ridge National Laboratory, Oak Ridge, TN.

Thompson, L.E., Owczarski, P.C., Miller, M.C., Powell, T.D., and Tixier, J.S. 1993. Underground Tank Vitrification: A Pilot-Scale In Situ Vitrification Test of a Tank Containing a Simulated Mixed Waste Sludge. PNL-8846, Pacific Northwest Laboratory, Richland, WA.

Timmerman, C.L. and K.H. Oma. 1984. An In Situ Vitrification Pilot-Scale Radioactive Test. PNL-5240, Pacific Northwest Laboratory, Richland, WA.

Timmerman, C.L. 1986. In Situ Vitrification of PCB-Contaminated Soil. EPRI CS-4839. Prepared for Electric Power Research Institute by Battelle, Pacific Northwest Laboratory, Richland, WA.

U.S. Department of Health \& Human Services. 1994. NIOSH Pocket Guide to Chemical Hazards. U.S. Government Printing Office, Washington, D.C. 20402.

U.S. Environmental Protection Agency. 1995. Geosafe Corporation In Situ Vitrification: Innovative Technology Evaluation Report. EPA/540/R-94/520. Risk Reduction Engineering Laboratory, Office of Research and Development, Cincinnati, OH. 


\section{DISTRIBUTION}

1. W. D. Brickeen

2. K. W. Cook

3. D. G. Cope

4. E. R. Cox, DOE/OS, Room 700N, 1301 Clay Street, Oakland, CA 94612-5208

5. B. Creighton, WETO, P. O. Box 3767, Butte, MT 59702

6. D. G. Garrett

7. G. Huffman, RFS, Building T1 16, P. O. Box 928, Golden, CO 80402-0928

8. G. K. Jacobs

9. C. M. Kendrick

10. B. L. Kimmel

11. J. W. Kubarewicz, Jacobs Engineering, 125 Broadway Avenue, Oak Ridge, TN 37830

12. A. J. Kuhaida

13. W. LaVeille, SRS, Building 703-A, P. O. Box A, Aiken, SC 29802

14. K. Lowe, RFS/ORNL, Building T124A, P. O. Box 928, Golden, CO 80402-0928

15. P. S. Lowery, Pacific Northwest National Laboratory, P. O. Box 999, Richland, VA 99352

16-18. D. M. Matteo

19. S. McMullin, DOE/SRS, P. O. Box A, Building 703-A, Aiken, SC 29802

20. J. O. Moore, DOE/TD

21. P. Moskowitz, Brookhaven National Lab, Building 830, Upton, NY 11973

22. D. Nickelson, INEL LITCO, P. O. Box 1625, Idaho Falls, ID 83415-3710

23. C. O'Laughlin, NTS, P. O. Box 93518, Las Vegas, NV 39193-3518

24. E. Phillips, DOE/TD

25. D. Pflug, Chicago Site, EAD/900, 9700 South Cass Avenue, Argonne, IL 60439-4832

26. M. Serrato, SRTC

27. R. Shank, SRS/WSRC, Building 730-2B, Room 1035, P. O. Box 616, Aiken, SC 29808

28. R. C. Sleeman, DOE/ORO

29. B. P. Spalding

30. J. Trabalka

31. V. L. Turner

32. Central Research Laboratory

33. ER Document Management Center-RC 